\title{
MOTOR PHONETICS
}

R. H. STETSON, PH. D.

第 Springer 


\section{Archives Internationales de Pharmacodynamie et de Thérapie.}

Ces Archives paraissent par fascicules, avec planches et figures intercalées dans le texte, au fur et à mesure que les travaux parvenus à la rédaction le permettent.

Les auteurs reçoivent 50 tirés à part.

Six fascicules forment un volume d'environ 500 pages.

Prix du volume XXXII: 100 francs.

Secrétariat de la rédaction: Institut de Pharmacodyna mie, 3, Quai Baertsoen, Gand (Belgique).

On s’abonne à la rédaction ou chez les éditeurs: O. Dorn, Place de l’Odéon, Paris, et H. Lamertin, rue Coudenberg, Bruxelles.

\section{Bibliographia Physiologica.}

Cette bibliographie est publiée par le Concilium bibliographicum de Zurich, fondé en 1895 par le Dr. H. H. Field, sous le protectorat des Congrès internationaux de Zoologie et de Physiologie. En 1921 il a été réorganisé sous les auspices de la Société Helvétique des Sciences Naturelles et de l'American National Research Council. Trois séries de la Bibliographia Physiologica avaient paru précédemment. Depuis 1923 a commencé à paraître une $4^{e}$ série en quatre fascicules annuels, qui réunissent toute la littérature de la physiologie, exposée dans le système décimal adopté par les Congrès internationaux.

On s'abonne au Concilium bibliographique, Hofstrasse, 49, à Zurich, ou chez son libraire. Prix du premier volume: 40 francs suisses.

\section{Scientia.}

Revue internationale de synthèse scientifique, paraissant mensuellement (en fascicules de 100 à 120 pages chacun). Directeur Eugenio Rignano.

Cette revue traite des questions de toutes les sciences: histoire des sciences, mathématiques, astronomie, géologie, physique, chimie, biologie, psychologie et sociologie. Elle conduit des enquêtes: sur les principes philosophiques des diverses sciences; sur des questions d'astronomie et de physique et en particulier sur la relativité; sur la contribution que les divers pays ont apportée au développement des diverses branches du savoir; sur les plus importantes questions de biologie, et en particulier sur le vitalisme; sur la question sociale; sur les grandes questions internationales soulevées par la guerre mondiale. On peut demander un numéro spécimen gratuit au Secrétaire Général de „Scientia”, Milan, en joignant à la demande, pour simple remboursement des frais d'envoi, la somme de quatre francs en timbres-poste de son pays. Abonnement: Lit. 150 .

Bureaux de la Revue: Via A. de Togni, 12, Milano (1]6). Secrétaire Général Dr. Paolo Bonetiti.

Editeurs: Félix Alcan, Paris - David Nutt, Londres - Nicola Zanichelli, Bologne - G. E. Stechert \& Co., New York - Ruiz Hermanos, Madrid - Renascenza Portuguesa, Porto - The Maruzen Company, Tokyo. 
MOTOR PHONETICS

A STUDY OF SPEECH MOVEMENTS IN ACTION

R. H. STETSON, PH. D.

Professor of Psychology, Oberlin College. 
ISBN 978-94-015-2147-5

ISBN 978-94-015-3356-0 (eBook)

DOI 10.1007/978-94-015-3356-0 
TO THE MEMORY OF ABBE ROUSSELOT 
HOTOR PIIONETICS

A Study of Speech Movements in Action.

R. H. STETSON Ph. D.

PROFESSOR OF PSYCHOLOGY, OBERLIN COLLEGE.

P R E F A C E.

The analysis of skilled movements has been employed in the explanation of making and perceiving rhythms. It has been applied also to the activities of writing and of piano playing. The present study has grown out of the application of this analysis of skilled movements to the processes of speech.

A phonetics based on movements is primarily concerned with the nature of the syllable. If the consonants delimit the syllable movement but have no independent existence, the relation of the consonant movement to that of the syllable is a vital matter. For this reason tracings of the air-pressure in the mouth, and in some cases of air-pressure in the chest, have been taken parallel to all tracings of consonants. The variation of air-pressure is the one available indication of the chest movement which forms the syllable.

The normal person controls the movements of speech by the sounds produced and he perceives speech by the ear. It is probable however that the movements are the primary thing, and that what we hear is not a mere acoustic pattern but a series of movements which the sounds make audible. One may or may not subscribe to this position to which many psychologists are inclined, but in any case the movements of speech are subject to the same conditions as those of any muscular process working at high speed.

WuNDT's statement is still true that "among all the factors which condition sound changes, the rate of enunciation is one of the most significant, although to date the phoneticians have 
given it little consideration." (Völkerpsychologie, 3d ed. I, p. 497.) Not only sound changes but also the fundamental coordinations of speech are conditioned by the maximum rate of the movements involved.

Full use has been made of the well determined limits of skilled movements at high speed. Varying the speed of utterance progressively in a uniform series has proved a fruitful method of study. It may be considered the fundamental method in this investigation.

Fields like metrics and phonetics invite statistical treatment because measurements are possible but the quantities measured are constantly varying within limits. The large number of cases necessary is a disadvantage; but on the other hand it is impossible to get quantitative data of value in phonetics with a mere handful of cases. The statistical methods used in this study are simple, and every effort has been made to secure accuracy. The measurements have been carefully checked, and two persons have gone over all the computations.

Objections are often made to the use of artificial combinations. But the fact is that the processes of ordinary speech are far too elaborate for unaided analysis. For the past twenty years much study has been devoted to detailed records of actual speech, but little has resulted for phonetic theory. In other sciences it is necessary to simplify material, to delimit problems, to work under artificial conditions; so in phonetics experiments must be made with simple combinations under carefully controlled conditions before we can hope to attack the extremely complicated phenomena of ordinary speech.

The larger obligations of the author, especially to the great pioneer and leader in experimental phonetics, are apparent in the text. It is a pleasant duty to mention the care and precision of Mme M. Guth's demonstrations, and to thank M. Henri Dupres for his interest andh elpful suggestions. Mr. L. E. Cole and Mr. H. E. Weaver of the Oberlin laboratory have been of valuable assistance in securing the tracings studied.

R. H. S.

August, 1927 .

Oberlin, Ohio, U.S.A. 


\section{TABLE OF CONTENTS.}

\section{INTRODUGTION.}

Speech a highly elaborate set of skilled movements like the musical technics. . . . . . . . . . . . . . . I84.

Study of movements rather than of acoustic records; the tones, noises, and silences of speech merely make the movements audible. - 185 .

I. GURRENT FORMULATIONS OF THE UNITARY MOVEMENTS OF SPEECH.

Word and Syllable often counted fictitious. . . . . I85.

Definitions of the syllable; pressure- and "sonority-" syllables. . . . . . . . . . . . . . . . . . . I86.

Rousselot's unitary movement: tension-tenue- détente. . Igo. Speech as a continuous flow of "sounds." . . . . . . I92.

Opposed by Paget who treats vowel and consonant as gestures. . . . . . . . . . . . . . . . . I93.

II. MOVEMENT OF THE SYLLABLE AS THE FUNDAMENTAL UNIT OF PHONETIC ANALYSIS.

The "sound" cannot be fundamental since it can be defined only in terms of function in the syllable. . . . . . . I94.

Breath pulse $=$ pulse of the chest muscles. . . . . . . I95.

Discuss then: apparatus and experimental methods, syllable movement, vowel articulation, consonant movement, and function of consonants in syllable linkage. . . . . . . . I95.

Apparatus and experimental methods. . . . . . I95.

Three types of movement; syllable as a balistic movement $20 \mathrm{I}$.

Demarcation of the syllable. . . . . . . . . . 207. Same problem as the demarcation of musical notes . . 207 .

III. VOWEL AND SYLLABLE . . . . . . . 212. Function of the vocal cords. . . . . . . . . 2I5.

\section{MOVEMENT OF THE CONSONANT.}

Consonant differs from the vowel in having a function in the syllable movement . . . . . . . . . . . . . 216.

This function is that of either arresting or releasing the syllable movement 
The arresting consonant. . . . . . . . 217 .

The releasing consonant. . . . . . . . . $22 \mathrm{I}$.

Releasing and Arresting Consonants as two functions of one movement

Types of syllables due to different functions of consonants. 230 .

Certain differences in syllables due to function of consonants . 237 .

\section{FUNGTION OF CONSONANTS IN LINKING SYL- LABLES.}

The double consonant and other forms of abutting consonants involve two distinct consonant movements, one stopping and the other starting the twolinked syllables; they are inter-syllabic. 239 .

Tracings of double consonants (abutting consonants with like doublets) in actual words. . . . . . . . . . 24I .

Influence of speed on this doubling of consonants . . 259 .

Tracings of double consonants obtained by increasing the speed . . . . . . . . . . . . . . . . . . 260.

Restoration of the original form when the speed decreases. 273 .

Tracings of abutting pairs (doubles with unlike doublets) produced by one member (lips or tongue) obtained by increasing the speed.

Tracings of abutting pairs produced by two members (lips and tongue) obtained by increasing the speed . . . . . . 277 .

Tracings of "constructive doubles," showing that in any series an arresting consonant requires the time of a double consonant . . . . . . . . . . . . . . . . . . 288.

Compound and multiple consonants are intra-syllabic; the abutting pair is inter-syllabic . . . . . . . . 293 .

Tracings of the inflected air-pressure curve of certain single consonants

VI. WORD AGGENT IN RELATION TO THE SYLLABLE, THE UNIT-GROUP, AND THE BREATH GROUP.

Definition of word accent . . . . . . . . . . 3I4.

Accent is a matter of increase of force of the syllable movement; intensity and duration characterize all movements, but pitch is not a property of movement . . . . . . . . . 315.

Measurement of intensity difficult; artificial material necessary, whether intensity of sound, or of chest movement is to be measured. . . . . . . . . . . . . . 316. 
Accent and dynamic form in two-syllable, three-syllable, and four-syllable groups . . . . . . . . . . . . . 318.

Separation and linkage of syllables as result of rate. 330.

Functions of singling and of doubling of consonants in grouping syllables . . . . . . . . . . . . . . . . . 330.

Function of word accent in grouping syllables . . . 332 .

Experimental study of groups of syllables . . . . . 34 .

Groups of two syllables. 34I. Iambs, 34I ; trochees, 342 . Reduction and elimination of the median trochaic consonant. 346 .

Groups of three syllables. 350. Elision of both trochaic and iambic syllables. . . . . . . . . . . . . . 353.

Groups of four syllables. 354. Elision of syllables. . . 355 .

Comparison of the processes of abutting and of singling of consonants in I) series obtained by increasing speed, 2) accented groups of syllable. . . . . . . . . . . . . . 363 .

The processes prove to be the same . . . . . . 371.

Reversion to the prescribed form when the rhythm permits. $37 \mathrm{I}$.

Groups of more than four syllables. . . . . . . 372 .

Influence of the word accent and the syllable movement in the modification of "sounds" . . . . . . . . 376 .

VII. RHYTHM AND THE CHARACTERISTIC PRONUNGIATION OF A LANGUAGE.

Rhythm is fundamental to the pronunciation . . . 379 .

Differences between the Teutonic and Romance Languages in matters of rhythm . . . . . . . . . . . . 380.

Changes of rhythm as a possible influence on the history of a .language. . . . . . . . . . . . . . . 382.

Appendix.

$A$ Syllables developed into series with doubles by increasing the speed of utterance. . . . . . . . . . 382 .

$B$ Syllables developed into series with one-member abutting pairs by increasing the speed . . . . . . . $3^{8} 3$.

$C$ Syllables developed into series with two-member abutting pairs by increasing the speed . . . . . . . 383 .

$D$ Abutting pairs, and arresting consonants = "constructive doubles" . . . . . . . . . . . . . . . 384 . 
$E$ Accented groups of two syllables . . . . . . 385 .

$F$ Accented groups of three syllables . . . . . . . 386 .

$G$ Accented groups of four syllables . . . . . . . 386 .

Index of the words, phrases, and syllables discussed. 387 .

\section{INTRODUGTION .}

The "sounds" of speech are produced by an elaborate series of rapid, highly skilled and somewhat complex movements. In this regard the problem of phonetics is like the problem of the coordination of the movements of piano-playing, of typing, or of other activities at high speed.

Like speech, a musical technic is also an organized system of movements for the production of a series of sounds. In the playing of wind instruments we have a close analogy to speech; the breathing apparatus of the player furnishes the series of air puffs, the lips and fingers of the player modify these puffs so as to produce the requisite pitches. The reed (or the player's lips) corresponds to the larynx and furnishes the tone for the notes. Each note is equivalent to a syllable in speech. The skilled movements of whistling are still nearer speech; the notes are the result of separate puffs of air, of chest pulses, while the tone is produced by the lips.

The note of the wind instument is equivalent to the syllable in speech, but usually to the syllable without consonants. It is only in movements like "triple-tonguing" that the tongue performs the function of the consonant and stops or starts the note of the wind instruments. The note in whistling is produced by the chest pulse alone; it is not stopped or started by the articulatory apparatus. The series of notes in whistling corresponds exactly to the series of syllables made by a singer vocalizing on a single vowel.

It is partly because the movements are hard to observe, and partly because recent forms of recording apparatus have favored the study of the sound alone, that phonetic analysis is concerned so largely with the tones and noises produced, rather than with the movements of speech. But there are excellent reasons for 
considering the movements the primary essentials of speech, and for assuming that the tones and noises and occasional silences figure merely as the means whereby the movements of speech are made audible.

\section{Gurrent Formulations of the Agtual Elements of SPEEGH.}

One unit has been admitted on every hand: the breath group. Sweet, Rousselot, E. W. Saripture, all assume that there is no justification for the subdivision of this phrase; they count words, syllables, "sounds" as fictitious divisions having no real existence.

"The only division actually made in speech is that into breath groups due to the organic necessity of taking breath."1)

"Strictly speaking the syllable has no physiological existence except in isolated monosyllables."

"The word like the syllable does not exist intact except when isolated ... The breath group has a genuine individuality." 2)

"I do not believe however, that a division of the flow of speech into separate blocks (termed syllables) has the slightest justification . . . . speech does not consist of any such blocks of sounds as the letters are supposed to indicate, or of any such large groups as syllables." 3)

The form of record employed has made many investigators feel that speech is a continuum and that subdivisions smaller than the phrase are arbitrary. The phrase has the obvious unity of a single breath; it is separated by pauses; but the words and syllables seem to be due to movements which flow into each

1) Sweet, History of English Sounds, Clarendon, Oxford, '88 p.i4.

2) Rousselot, Principes de Phonétique Expérimentale, Welter, Paris, 'oi-'o8 p. 969, 972.

$\left.{ }^{3}\right)$ Scripture, E. W., Experimental Phonetics, Scribners, N.Y. 'O2 p. 450. Die Verskunst und die experimentelle Phonetik, Wiener Med. Wschr. 72, '22, no. 33, p. 1378 . Impossible to divide the verse ,Somebody said it couldn't be done" into words, or syllables, or separate sounds. 
other. Vowels and consonants are known to overlap, and some of the analyses proposed have seemed to involve the overlapping of syllables.

In spite of the denial of the independent existence of the syllable, the nature of the syllable and its delimitation have been frequently discussed. The word is admittedly an arbitrary grouping of syllables, often obscured by the flow of speech; but the syllable is important as a unit because the fundamental classification of "sounds" as vowels and consonants hangs on their function in the syllable; it is therefore impossible to avoid a discussion of the syllable as an essential unit. ${ }^{\mathbf{1}}$ )

Although SwEET feels that the only real division is into breath groups, he provides for the unity of the syllable in the following words: "Every syllable must be uttered with a single impulse of the breath, as it would otherwise split in two." ${ }^{2}$ )

Rousselot gives no detailed consideration to the nature of the syllable, but the syllable is frequently assumed in the analysis; and he states that "we have the feeling of a movement corresponding to the syllable, since in one type of aphasia it is replaced by an expiratory effort." ${ }^{3}$ )

"Aphasia subcortical motor: only the ability to articulate is lost. It is an interesting fact that the patient retains the idea of the syllable, for when he tries to talk he makes as many expiratory efforts as there are syllables in the word." ${ }^{4}$ )

Sievers has an elaborate discussion of the demarcation of the syllable and defines two types. He recognizes the syllable due to an expiratory pulse as the "pressure syllable" (Drucksilbe.) An isolated vowel, however short, is a syllable. ${ }^{5}$ )

"A vowel lasting as long as a breath is still a single syllable. But if pulses enter into this continuum, then there are new syllables. The increase of expiration makes the new syllable, and the frontier of the syllable is the point where the expiration is weakest. Thus $a-i-a$ may be three syllables, or the division may

1) A. W. DE Groot, La Syllabe: Essai de Synthèse, Bul. de la Soc. Linguistique de Paris, 27 , ' 26 , p. $\mathrm{I}-42$, has a very interesting discussion of the nature of the syllable and develops a functional concept of the syllable as a rhythmic element.

2) Hist. Eng. Sounds, '88, p. 8.

3) Principes II, p. 969 .

4) Principes I, p. 307 .

5) Grundzüge der Phonetik, Breitkopf u. Härtel, '93, 4. ed. p. r82. 
give two, $a i-a$, or $a i-i a$. A syllable includes whatever is uttered with an independent, simple, expiratory pulse." 1)

This pressure syllable of Sievers is very like the type of syllable already suggested as a single, expiratory movement of the breathing apparatus. But SiEvers adds a second type of syllable. This is the "sonority syllable" (Schallsilbe.) The sonority syllable was added to explain cases in which the breath pressure seems not to change and yet a new syllable occurs. Thus in the utterance of $a-i$ with the mouth wide open and the , $i$ " much constricted, the breath pressure may not change, and yet there are two syllables. In $a-l-a$ the " $l$ " constricts the mouth slightly with its stroke, but need not change the breath pressure at all, and yet the " $l$ " marks the appearance of a second syllable. This is due to what Sievers conceives as a "discontinuity of sonority" (Discontinuität der Schallstärke.) He defines the „sonant" which makes the core of the syllable as the resultant of its pressure and of its sonority (Schallfülle) in relation to the neighboring elements ${ }^{2}$.

In the hands of later phoneticians, the doctrine of the syllable after Sievers has settled into a form very well phrased by PASSY:

„Sounds produced with the same force (breath pressure) may not strike the ear with the same intensity. If I pronounce a word like "passe' the vowel " $a$ " is heard much better than the consonants ' $p$ ' and ' $s$ '. It is not a result of the breath pressure for that has not varied. But the sound ' $a$ ' for which the voice proceeds from the throat almost without hindrance, is more sonorous than ' $p$ ' and ' $s$ ' which are merely noises.

"On comparing the sonority of different sounds, one can easily convince oneself that the vowels are heard farther than the consonants, the voiced consonants farther than the voiceless, the open vowels farther than the closed vowels; while the aspirate ' $h$ ' has very little sonority indeed.

"Along with this actual sonority, there is the apparent sonority procuded by the sudden, abrupt fashion in which certain sounds strike the ear, or by the clear-cut way in which they stand out in the complex of vague sounds almost always present to the ear; thus ' $i$ ' often appears more sonorous than ' $a$ ' The apparent sonority depends in part on individual peculiarities of the sound

1) Ibid. p. I83.

2) Ibid. p. $184 \mathrm{f}$. 
and in part on external causes; but it is noteworthy that ' $s$ ' is set off among the consonants by its great apparent sonority.

"Sonority together with the breath pressure (force du souffle) produces intensity which is the resultant of the two factors.

"The variations of intensity give rise to the groups of sounds which we call syllables. A syllable is simply a group of sounds separated from the others by a sudden diminution of intensity a diminution caused either by a decrease of the breath pressure, or by the presence of a sound of less sonority between two of greater sonority."1)

This is probably as clear a statement as can be made of an extremely vague theory. A purely subjective factor "sonority" is added to breath pressure, to provide for cases where there is no apparent variation of breath pressure. And a second variety of "sonority", called "apparent sonority" is added - due to "individual peculiarities" of sounds, and also to "external causes". A judicious mixture in varying quantities of "breath pressure", of "sonority", and of "apparent sonority" ought to fit any puzzling case of syllable division.

It is important to note that the concept of "sonority" (Schallfülle) was introduced to explain cases in which there is noapparent change in breath pressure. In the first place the occurence of such syllables without a distinct breath pulse should be objectively established. In the second place, whispering and breathless speech will have to be explained as cases in which habitual association makes it possible to sense the syllable, although the "sonority" factors have gone wrong. Why not assume that the breath pulse is replaced by some concomitant factor habitually associated with it? There is such a concomitant factor in cases like $a-i-a$ and $a-l-a$ in the rapid movement of the vocalic apparatus in $a-i-a$ and in the rapid movement of the tongue in $a-l-a$.

The case of voiceless speech deserves attention in this matter of the nature of the syllable. It is possible to articulate words without any breath whatever. If one draws a breath, closes the glottis and eliminates all breath pressure and then makes the movements of uttering a sentence, the syllables do not run together; instead the balistic movements of jaw and tongue replace the movements of the breathing apparatus and form clear-cut syllables in which the consonants play their part. If

1) Petite Phonétique Comparée, Teubner, Leipzig, '22, 3d ed. p. $4^{\mathrm{I}}$ f. 
"actual sonority" and "apparent sonority" really played an essential part in syllable division, breathless articulation would be without syllable demarcation. Perhaps the doctrine will undergo one more refinement and "silent sonority" will be added to "actual sonority," and "apparent sonority."

If factors dependent on acoustic qualities - the effect on the ear - were essential to the division of the syllables it is very difficult to see how mutes could be taught to speak properly. It seems far more reasonable to assume that the syllable demarcation is a matter of movements which the sounds make audible, and which can be taught the mute without involving "individual peculairities of sounds "and "external causes."

There have been strictures on this "sonority" concept. F. DE Saussure has a vigorous criticism of this analysis of Sievers. ${ }^{1}$ )

F. DE SAussure's own analysis of the syllable is better but fails to take account of the breath pulse of the syllable. The notion that an implosion-explosion juncture is a syllable frontier is good; but the fact is not recognized that implosion involves the ending of a syllable and explosion involves the beginning of a syllable. F. DE SAussure does not sense the fact that a syllable consisting of a single vowel, including his exception " $a$ ", must have both the beginning and ending phases. Isolated vowels as words are very common in the South Sea Island dialects, and occur in the " $a$ " and " $I$ " of the English, and the " $a$ ", $e u$ ", "un" and " $y$ " of the French. The very vowel " $a$ " (French) which F. DE SAUSSURe assumes has neither implosive- nor explosiveform must nevertheless have both the beginning and the ending phase of the syllable in the word " $a$. " And the overlapping of the explosive and implosive phases of "sounds" to which RousSELOT has called attention, makes a fundamental difficulty for a system in which the syllable division depends on the implosion-explosion juncture.

As has been said Rousselot does not discuss in detail the nature of the syllable. He was the first to make a systematic study of the actual movements of speech, and it is inevitable that he defines a unitary movement. This unitary movement of RousSELOT is not primarily a syllabic movement. It is rather the fundamental movement of any articulation whatever, and applied to a "sound" rather than to a syllable; it is obvious that the

1) Cours de Linguistique Générale, РАуот, Paris '22 p. $88 \mathrm{f}$. 
syllable is to be built up of a group of these elementary articulatory movements.

The most obvious thing about the functioning of the vocal apparatus is the opening and closing of the vocal canal. This leads Rousselot to distinguish three phases:

I. Taking position.

2. Holding position.

3. Quitting position. ${ }^{\mathbf{1}}$ )
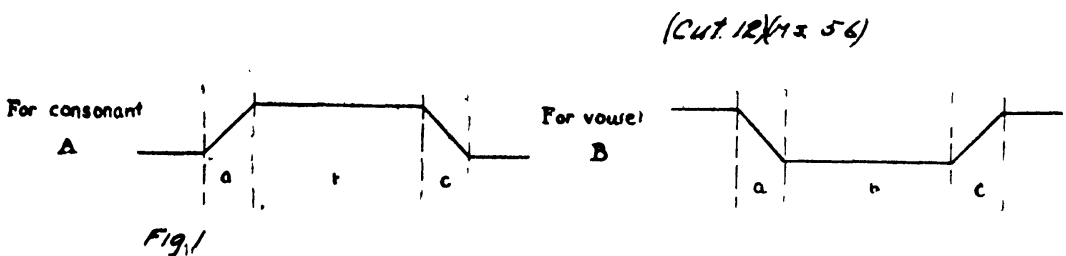

$A$, movement of consonant:

$a$ "tension", taking position; articulatory process closes vocal canal.

$b$ "tenue" holding position; articulatory I rocess maintains closure.

c "détente," quitting positon; articulatory process opens vocal canal.

$B$, movement of vowel:

a "tension," taking position; articulatory process opens canal.

$b$ "tenue," holding positon; articulatory process maintains opening.

"détente," quitting position; articulatory process closes canal.

The curves of Figure I represent the opening and closing of the vocal canal by the articulation. For a consonant like " $t$ " the rising phase of the curve, $a$, represents the movement of closing when the tongue rises for the stroke of the " $t$ " (tension;) the horizontal phase, $b$, represents the tongue holding position for the explosion of the consonant (tenue;) and the falling phase of the curve, $c$, represents the sudden release of the tongue qui $i_{-}^{-}$ ting position when the explosion occurs (détente.) For a vowel like " 2 ," the opening of the jaw and tongue constitutes the "tension" (taking position,) the maintenance of the vowel position the "tenue" (holding position,) and the return of the jaw and tongue to the neutral position the détente (quitting position.)

1) Principes I p. 334-5 Fig. I 6 , I 17.

Précis de Prononciation Française, Welter, Paris, '13, 2d éd. p. 25 Fig. 12. 
This analysis is in terms of the position of the vocal organs, and it can be applied to any articulatory movement, save possibly that of the "mute $e$ " which corresponds to the neutral position of the vocal apparatus, and would consist entirely of "tenue" as no "tension" or "détente" would be necessary. There are several indications however that the analysis is not fundamental.

In the first place this schematized movement does not correspond to the elementary "sound" involved; the "sound" may occur during a single one or during all these phases, and any one of these phases may be omitted. In a syllable like the "hub-" of "hubub" the "tension" of the " $b$ " marks the close of the vowel (the vowel position does not change as the vowel is repeated in the following syllable.) In fricatives like " $s$ " in "this," the end of the "tenue" marks the close of the "sound", but in the " $b$ " of "bubbling it is the beginning of the "tenue" which marks the close of the "sound." The "dark $e$ " of "detail" occurs during the "détente" of the " $d$ " and closes with that releasing stroke.

The analysis is based on the assumption that a "sound" either opens or closes the vocal canal; but in actual speech the particular opening or closing of the vocal canal necessary for a given "sound" may have occured before the sound is uttered. For the analysis of an articulatory movement, the movement itself is more important than the position in which it happens to start, or the position in which it happens to stop. Sometimes the movement will involve bringing the organs to position; sometimes the position has already been assumed in the preceding articulation. And quitting the position is not essential; in the case of a sentence closing with a " $p$ " or a " $b$ " or an " $m$ " the lips may remain closed indefinitely. If taking position and quitting position are made essential phases of the movement, it becomes necessary to provide for the extensive overlapping of these phases from articulation to articulation. In a consonant combination like " $t-l$ " in "atlas" the "tension" and "tenue" of the " $l$ " are unnecessary because the tongue is already in position.

In the second place the relation of this fundamental articulatory movement to the braath pulse is not discussed. The mechanism of speech may be separated into a breathing apparatus, the chest; a voice apparatus, the larynx; and an articulatory apparatus, the tongue, lips, jaw, soft palate, etc. which have to do with "sounds." It is obvious that the breath pulse is necessary to ordinary speech, voiced or unvoiced, and while the mo- 
vements of articulation have been most effectively studied by RoussELOT, it remains to coordinate the articulation with this movement of expiration.

The position of many phoneticians that speech is a continuous flow of sound - a position that seems well supported by the appearance of acoustic records - involves the assumption that speech is primarily a matter of acoustics and that it is a series of sounds. Explanatory concepts like "sonority" as handled by Sievers and PAssy (cf.above) and appeals to the "acoustic eflect" assume that there is something in the sound essential for the analysis of speech. Rousselot makes the distinction between the single and the double consonant hang on the "acoustic effect;" if spoken with unusual energy and if prolonged so that the ear perceives both the "tension" and the "détente," the consonant becomes double. ${ }^{1}$ ?

This assumption that speech is primarily a series of sounds is to be seriously questioned. In the first place, the sounds of speech are radically altered in whispering and are eliminated in voiceless speech. In the second place, the speech of the deaf and the "lip-reading" of the deaf show that sound is not essential to speech, that the process can occur without it.

The great improvement in acoustic records has turned attention to the acoustic problems. And the study of acoustic records has not seemed to justify the conventional division into syllables; no syllables are apparent in the tracings. There are gaps - silences - to be sure, but they may occur in the middle of a syllable, or of a "sound." The syllable has been counted a convenient distinction without foundation in fact. The detailed coordination of the movements has been ignored for it is assumed that they merely produce the sounds which really constitute speech.

But the detailed acoustic analysis of the vowels and consonants has recently led to some disconcerting conclusions on the part of the acousticians. R. A. S. PAGET concludes an experimental study of all the principal consonants:

"Comparing the terminal resonances of $\mathrm{k} / \mathrm{g}$ and $\mathrm{t} / \mathrm{d}$ respectively, there is no general principle of resonant change characterising these two types of consonant when used with different associated vowels, except the greater rapidity of closure for $t / d$

]) Principes. I p. 348 . 
than for $\mathrm{k} / \mathrm{g}$, and, to a less extent, the greater loudness of the upper and lower resonances of $t / d$ than those of $k / g$.

"This absence of any general characteristic resonant change seems to indicate that, in identifying these particular consonant sounds, and probably also in identifying all speech sounds, the ear is primarily concerned in recognizing where and how the closure (or release) is made in the vocal cavity, rather than in identifying the actual resonance changes themselves.

"This conclusion is confirmed by the observations of the writer and others on the vowel sounds, from which it appears that, in the case of voiced vowels sounded on a succession of different larynx notes, there is no particular components common to the same vowel when sounded with different frequencies of larynx note. What the ear hears, in each case, is the general effect on the larynx note of the resonant characteristics of the cavities through which that larynx note has passed, which characteristics are due (as already pointed out by the present writer) to the relative volume and areas of orifices produced by the different attitudes of the tongue and lips.

"In other words, human speech appears to be essentially a branch of human gesture, which the ear has learnt to identify -without the aid of sight - by means of its secondary effects in modifying the resonances produced by the passage of air by or through the gesticulating members of the vocal cavity." 1)

If the essence of a phonetic "sound" is, a movement of the speech apparatus, there is no reason to puzzle over degrees of "sonority". Apparent sonority merely expresses in misleading fashion the fact that a given speech movement is apparent in a given sound pattern. And the ease with which whispered speech, and speech for mutes can be handled is comprehensible if the movements are the essential things, produced and perceived now by one set of motor cues and now by another. It is possible to handle the same series of movements now by one set of sounds and now by another, now by visual and now by kinesthetic stimuli.

Indeed in ordinary speech, silences are quite as important

1) Vowels: Roy. Soc. Proc. 102, p. 752-765, Mar. I, '23.

Consonants: Roy. Soc. Proc. 106, p. 150-1 74, Aug. I, '24. Quotation, p. I73. Popular statement of the position, "Invention of Human Speech," Sci. Am. 83, '27, p. 204. Also „Human Speech and its Artificial Production,” Discovery, 8, '27, p. 7-9. 
in any phonetic pattern as are the neighboring sounds. Speech is not a series of sounds produced by certain movements. Rather speech is a series of movements made audible by certain sounds and silences which these movements produce. Much of the acoustic minutae presented by acoustic tracings has little phonetic significance. Details which succeed each other at too high a speed (faster than I $5^{-1} 8$ per sec.) cannot be grasped as separate items. Many "on-glides" and "off-glides," etc. may modify the sound complex as a whole, but they cannot be separate sounds to the ear. The operation of the general principle known as "WEBER's Law" accounts for an extensive simplification of the complex phonetic pattern as it is interpreted into movements.

It is safe to say that the progress to date in phonetic theory has been due to the intelligent study of the movement process. Even in the hands of men like Rousselot and Sievers, acoustic explanation has come to little. Siever's treatment of the "discontinuity of sonority" as the boundary of the syllable, and Rousselot's explanation of the double consonant in terms of the "acoustic effect," are not fortunate. The concept of the "centroid," a still more vague notion due to E. W. Saripture, is useless as an explanatory concept.

\section{The Movement of the Syllable as the Fundamental Unit of Phonetic Analysis.}

If movements are the essentials in speech why not consider the simple movement of the "sound" as the fundamental unit? The answer is that the "sounds" and their movements cannot be discussed without involving their function in the syllable. The nature of the "sound" depends on what it does in the syllable. The distinction between the vowel and the consonant, or between a "syllable-forming sonant" and a true consonant must depend on the part the "sound" plays in the syllable. The distinction between consonants implosive and explosive ("appuyantes et appuyées") and their different fate in the course of phonetic changes can be explained only by reference to their function in the syllable. The movements of the "sounds" often overlap and often fuse; they are not always separate. But by common consent a syllable is always a separate event in the speech series. And while it has not been easy to determine the 
principle of syllable division, no one has assumed that two syllables could in any sense coincide.

The fundamental unit for phonetic analysis is the movement of the syllable, a single breath pulse which is sometimes released by a consonant movement and sometimes arrested by a consonant movement. The division of the syllables is the division of these chest pulses one from another. The delimiting consonants are integral parts of this chest pulse; they either release or arrest the chest pulse; the vowel on the other hand is an articulatory movement accompanying the chest pulse. When abutting consonants appear between syllables, the first consonant of the pair arrests the chest pulse of the first syllable and the second consonant releases the chest pulse of the second syllable. A "double consonant" is a case in which the arresting consonant of the first chest pulse and the releasing consonant of the next chest pulse are the same consonant repeated. It should be possible to demonstrate these movements experimentally, and to deternime their coordinations. We shall discuss, then:

Apparatus and experimental methods.

The syllable movement $=$ the breath pulse $=$ the "chest pulse."

The vocalic articulatory movement which accompanies and colors the "chest pulse" = the vowel.

The consonant movement which releases and arrests the chest pulse.

The abutting pairs of consonants - various cases in which a releasing and an arresting consonant come together as abutting consonants at the syllable frontier.

This includes the "double consonant," in which the same consonant repeated functions as arresting consonant and releasing consonant.

\section{Apparatus and Experimental Methods.}

The records were made by the pneumatic method which Rousselot has made familiar. The recording parts of the Marey tambour were made of bamboo that they might be as light as possible; the writing lever was made very short, $6 \mathrm{~cm}$., tipped with a glass filament; mass and vibration were reduced to a minimum.

The tambours for recording the strokes of lips and tongue were of small diameter, I cm., and very loose; they were of goldbeat- 
er's skin or of thin rubber without tension, and distented until they hung loose. The tambours for recording the air pressure in the mouth, outside the mouth, and in the chest, were larger, $5 \mathrm{~cm}$., and stretched very taut. In the case of the lips and tongue, the capsule at the mouth was sufficiently resilient to provide for the return of the recording lever; in the case of the air pressures, the recording tambour had to provide for the resiliency.

The rubber tubes from the lip- and tongue- pieces, and from the air-pressure tips, were short and thick walled to avoid loss of pressure.

The apparatus was tested for possible lags between the tracings of the air pressure wave and the tracings of the pressures

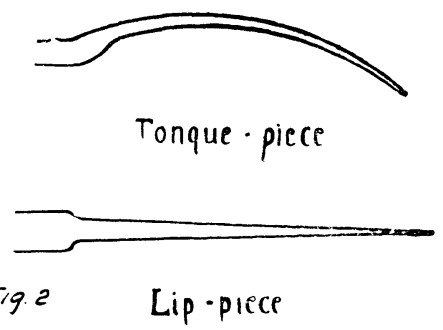

Diagrammatic cross-sections of capsules used for recording contacts of the lips and tongue.

The capsule with resilient walls and wedge-shaped cross section responds quickly to variations of pressure but will not collapse completely under heavy pressure.

Lip-pieces were of mica or collodion.

Tongue-pieces were of collodion hardened to resilient wall.

of lips and tongue; the records proved to be simultaneous within the limits of measurement used. The resonances of the apparatus were determined; frequencies of 20-40 per sec. were present, due mainly to the resilient lip- and tongue-pieces, and to the resilient tambours for the air-pressure tracings. Such frequencies occasionally show in the tracings; but they are easily noted and do not mask the details studied.

The lip- and tongue-pieces were made with a thin wedgeshaped cross-section. Cf. Fig. 2.

It is essential that they be very sensitive but that they do not entirely collapse whatever the pressure. Lip-pieces were constructed of thin mica bound at the thin edge with animal membrane fastened with rubber cement, and with sides of animal 
membrane. Another satisfactory form was made by stretching very thin rubber tightly over a flattened wire loop of the proper shape; the thick end of the wedge received the small tube to which the wire loop was attached. The thin wedge of taut rubber was coated repeatedly with collodion. The collodion dried to a wall more rigid than the rubber which was merely a temporary support for the layer of collodion.

The tongue pieces were also constructed with a collodion wall laid on over stretched rubber. The frame of flattened wire was shaped to a plaster cast of the subject's palate; thin rubber was stretched over the wire frame mounted so as to make a thin wedge. The wall next the palate was repeatedly coated with collodion until quite rigid; the side receiving the pressure of the tongue was given one or two coatings to make a firm but resilient wall. The tongue-pieces stand usage better if the edges at the wire are bound with narrow strips of animal membrane laid into the first moist coat of collodion.

It did not prove possible to get satisfactory tracings with lenticular rubber bulbs, or with capsules of thin, taut rubber; they do not respond to the rapid variations of pressure, and the form of the "double" or of the abutting consonants does not show two maxima; the tracings all resemble the consonant curve in Fig. 27 X. p. 256 .

The wedge-shaped capsules were thin enough so that they did not introduce a thickness of more than a millimeter between the lips or between the tongue and the palate. These capsules and their fittings had of course to be kept air-tight; a leak betrays itself very quickly in the tracing.

The tracing of the consonant can be called a record of the consonant movement only in so far as the movement of the consonant results in contact of lip or tongue with the opposing surface. In general the tracing is a record of the consonant contacts.

The curve of the air pressure in the mouth was taken simultaneously with the tracings from the strokes of lips and tongue. A small, curved metal tube was inserted at the corner of the mouth so that the tip was behind the articulating organ; the orifice of the tip was regulated so as to give pressures suited to the range of the recording tambour.

The technic of Rousselot was followed for the tracings of pressure just outside the mouth. A firm rubber mask was fitted 
about the mouth, an escape valve of some type was provided near the mask, and the pressure was led to a $5 \mathrm{~cm}$. tambour of very thin, taut rubber like the tambour used for the tracings of the pressure in the mouth. The pressures were regulated by changing the escape valve in the line from mask to tambour. The mask was pierced to provide for the lip- and tongue-pieces, and for the mouth-pressure tube at the corner of the mouth.

The tracings of pressure outside were meant to be comparable to tracings of pressure in the chest. The range of oscillation is larger than that of most records of outside pressure. The tracings were intended to show variations of pressure rather than sound vibrations. It happens however that the sound vibrations are usually apparent in one or more of the three tracings: of the consonant, of mouth pressure, or of outside pressure.

Tracings which record sub-glottal pressures were made of some 250 series ( I I kymograph sheets). These were taken from the speech of a single subject. After a tracheotomy, the subject had recovered voice and had been speaking for a year and a half, but found it necessary to breathe through the tracheotomy tube. The time relations, the consonant strokes, the mouth- and outside pressures were all normal, and there is no reason to believe that the tracings of chest pressures are not typical.

A tight connection, which could easily be opened for taking breath, led from the breathing tube to a taut tambour of some $5 \mathrm{~cm}$. diam. The membrane must resist pressures of $250-300 \mathrm{~mm}$. water; the most satisfactory membranes were built up of layers of thin rubber cemented together. It is difficult to have such membranes as responsive at high as at low pressures; and yet the fact that the oscillations of pressure in speech may take place at a high or at a low level of pressure makes it important that the membrane have a wide range of responsiveness. The tracings obtained are only fair; it is probable that the pulses occuring at a high pressure level could be made more marked by some form of compensating pressure recorder. Throughout, the changes are not as sharply defined as in the case of the mouth- and outside pressures.

A Jacquet time marker indicated fifths of sec.; in measuring the tracings these fifths were divided into tenths and the hundredths estimated, so that the unit of measurement was .02 sec. with fractions estimated. This is sufficiently minute for the purpose and as close as the limits of error of the method warrant. 
The measurements were made with a protractor in reference to the nearest fifth indicated on the time line.

While the tracings of chest pressure were taken from only one subject, extensive records were taken in all other cases from at least four subjects; seven subjects were used in all; there are no essential differences though some minor variations appear. Double consonants, only, of two other subjects were recorded for comparison. Each series consisted of 15-30 syllables; the word or phrase was repeated again and again; all the legible examples to be found in the series were studied and tabulated. Tracings were made of all the labial and front lingual consonants; it was difficult to secure air pressure tracings for the rear linguals; with the exception of a few records from a single subject, tracings were not made of " $r$ " or " $k / g . "$

The cuts are photographic reproductions of the kymograph tracings. It is now convenient, with reversible film negatives, to make photographic prints from smoked paper with black lines on white ground. These prints were produced by using the smoked paper itself as the negatieve. The ground was cleared in some cases with a reducing agent on the positive film, followed by an intensifier for the lines. More satisfactory results were obtained by making both positives and negatives of a very "hard," thin printing paper and clearing by managing exposure and development. In a few cases the time line has been retouched; but the tracings of the lip- and tongue- movements, and of the air-pressure outside, in the mouth, and in the chest, have not been retouched.

In some cases dots have been put under the maxima of the consonant-mouth-pressure- and chest-pressure- curves. Dots just above the tracing indicate the limits of vibration; a series of dots above a consonant contact indicates that it is vocalized throughout.

The lip- and tongue- movements, and the air-pressure curves, have been indicated at the left; the initials of the subject, the number of the record, and the letter of the series, at the right. Only those syllables were numbered which were measured.

The measurements of the single consonants, of the abutting pairs, and of the doubles, have been in terms of the actual contact as indicated in the consonant tracings. This gives no indication of the complete consonant movement, except in case of doubles and abutting pairs which include the entire consonant cycle. Cf. p. 255 . 
Syllables both open and closed, when in series, have been measured from the détente of the releasing consonant to the détente of the initial consonant of the next syllable. Isolated syllables have been measured, if closed, from the détente of the releasing consonant to the détente of the arresting consonant; if open from the détente of the releasing consonant to the end of the vowel. This method of measuring syllables accords best with other studies, and has the advantage of giving an accurate rate per sec., and of eliminating the erratic length of contact of the initial consonant of a group or series.

In the tracings the letters and combinations have their usual Eng. values. The vowels are the Eng. short vowels unless otherwise indicated. Occasionally digraphs are used for a single vowel; " $e e$ " or " $e a "=$ long " $e$;" " ay" = long " $a . "$

The interpretation of tracings so obtained will depend on an analysis of the movements involved. The function of the consonant stroke in delimiting the chest pulse is the fundamental thing for an understanding of the movements of speech. For that reason we must consider the types of movements in question and their relation to each other.

\section{The Three Types of Skilled Movement and Application to the Movement of the Syllable.}

In discussing any system of skilled movements, there are three fundamental types of movement to consider:

I. The movement of fixation: opposing groups of muscles hold the member in position. When a person is about to speak, the chest is partly inflated and is often held in that position for a short time before any syllable is uttered. The chest is fixated before speech begins in such a case.

2. The "controlled" movement: in this type at least two opposing groups of muscles work together in producing the movement. Both the antagonistic muscle-groups are contracted throughout the movement. The direction of the movement can be changed after it is under way; such a movement is relatively slow, and "controlled" throughout its course.

Any slow adjustment is of this type; when one traces a curve 
slowly the "controlled" movement is employed. Writing is a very different process. A forgery by tracing can always be detected by the minute changes of direction in a "controlled" movement, changes which are visible under the microscope. The slow expiration of air in a prolonged vowel constitutes a "controlled" movement. The large breathing movement of the entire phrase (the only natural division recognized by many phoneticians) is a slow, "controlled" movement during which the. rapid pulses of the syllables occur, like ripples on a wave.

3. The balistic movement: the entire movement consists of a single jerk. It is impossible to change the movement during its course. The member is indeed thrown from one limit to the other like a projectile, as the name implies.

A study of the action of the muscles in such balistic movements shows that the movement is started by a sudden contraction of the positive muscle-group which immediately relaxes. During at least half of the course of the movement neither of the antagonistic muscle-groups is contracted, so that the moving member flies free. At the end of its course the movement is usually arrested by the contraction of the negative muscle-group. The movement is a movement by momentum.

When a tennis stroke is made, a sudden contraction of the extensors of the arm starts the stroke; the extensors immediately relax, during the first quarter of the excursion, and the arm and racket are carried through the stroke by their momentum; at the close of the stroke the flexors of the arm come into play and arrest the arm. All rapid movements are of this type. In speech the rapid movements of articulation, and of the syllable pulse, are balistic. If one is unfamiliar with a language, one is always impressed by the high speed of its movements. ${ }^{1}$ )

\section{Analysis of the Balistic Movement with Special Reference to the Syllable.}

In the simplest possible case, the balistic movement is stopped by the muscles themselves, as is the movement of the con-

1) For details as to types of movements, Sterson, R. H., Psy. Mon.s, 32 , '23, No. 3. Stud. Oberlin Psy. Lab. Mechanism of the Different types of Movements, p. $18 \mathrm{f}$ : 
ductor's baton, of the violinist's bow, or of the writer's pen. The antagonistic muscles involved divide into two groups: the positive group which starts the movement, and the negative group which arrests the movement; in case the movement is repeated this negative group returns the member to the starting point.

When the arrest is almost instantaneous, and the member is returned at once to the starting point, as in the case of a rapid repeated movement, the action of the positive muscle-group results in a beat stroke, and the action of the negative musclegroup results in a back stroke which returns the member to the original position.

If the member when arrested is held in position at the lower limit of the movement, the time relations are the same; the negative muscle-group acts to stop the movement and take up the momentum of the moving member; then the relaxation of the negative muscle-group occurs before the next beat stroke. Such a movement is to be seen in beating three-four time so that the baton follows a triangular path. This interval during which the negative muscle-group contracts, arrests the movement and then relaxes, may be called "the relaxation phase." It is an interval equivalent to the duration of the back stroke, and is sometimes called a "condensed back stroke," or a "back stroke in contact with an obstacle." This back stroke or relaxation phase includes the preparation for the next beat stroke.

The beat stroke is always balistic; it occurs very rapidly and can hardly be longer than $.040^{-}-075 \mathrm{sec}$. On the other hand the interval involved in the back stroke varies greatly. In the slow beating of time, beats may occur at the rate of two in three seconds, i. e. with an interval of I.5 sec. per movement. Assuming that the interval of the beat stroke is .050 sec., the back stroke, or relaxation phase, would be at this maximum, I.45 sec. in duration. At maximum speed, a movement can be repeated c. Io per sec. At such high speed the back stroke as well as the beat stroke is balistic, and the back stroke has a duration of .050 sec. The back stroke, or relaxation phase (including preparation for the coming beat stroke) may vary then from I . 45 to $.05 \mathrm{sec}$.

The significant points in the application of the balistic movement to the syllable are: I) The nature of the movement constituting the syllable, and 2) The function of the consonants and of the vowels in this fundamental syllable movement.

The syllable is a sudden movement, a stroke, of the muscles 
of expiration. The syllable is not contituted by a vowel: it is admitted that a fricative like " $s h$ " or " s" may form a syllable.

As a rule, the stroke of the mutcles of expiration is accompanied by an articulatory movement for the ovwel; the expiration nearly always sets the vocal cords to vibrating.

The vowel apparatus makes movements which merely accompany the syllable movement. On the other hand the consonants are accessory movements which arrest and release the chest pulse, the syllable movement, they are functional parts of that movement.

The syllable then is constituted by a balistic movement of the expiratory muscles. Its delimitation is not due to a "point of minimum sonority," but to the conditions which define a movement as one movement. In the individuality of the syllable the sound is secondary; syllables are possible without sound. Speech is rather a set of movements made audible than a set of sounds produced by movements.

The consonants are not mere noises floating in the stream of sound. They are accessory movements, connected by the compressed air column with the chest muscles, and they have a function in releasing and arresting the chest pulse which constitutes the main movement of the syllable.

For the purposes of utterance, the breathing apparatus consists of two groups of muscles; the one group compresses the chest in exhalation, the other group dilates the chest in inhalation; they are the positive and negative muscle-groups of the breath pulse.

The syllable may consist of nothing but such an expiratory movement or chest pulse. This is the case with the single syllable consisting of a single vowel; " $a$," " $I$," " $O$," in English, " $a$," " $y$," "O," "ou," "eu," "an," "in," "un," "on," in French, and the first syllable of words like "opinion" and "aseptic." The articulatory position may be set beforehand and the syllable occur when the rapid chest pulse takes place.

Fig. 3 gives tracings of a syllable composed of a repeated vowel in comparison with a similar syllable with a releasing consonant. The variations in the chest pressure show the separate syllables when with and when without the consonant.

The articulatory conformation may not be that of a vowel; any continuitive will do; " $f, s, v, z, l, n, m$," will all form syllables provided there is an expiratory pulse. If the articulatory 
conformation is maintained, as many syllables are formed as there are new balistic chest pulses. Thus the series of " $n$ "s discussed by Sievers in "berittenen." 1 )

The " $n$ " can be developed into an indefinite series; one has only to fixate the vocal apparatus in position for " $n$," and give a series of chest pulses, expiration strokes, and a series of syllables is the result. In Fig. I 24 p. 373 "runnin" an' neighin" and Figs. 91, 92 p. 329. "Lil' 'll lie low," the tracing of the chest pressure shows that the pressure does not rise because of the consonant closure; on the contrary the minimum pressure occurs during the releasing consonant and the pulse is only partly under way when the releasing consonant opens. The maximum chest pressure occurs between the consonants. In forms like "runnin"

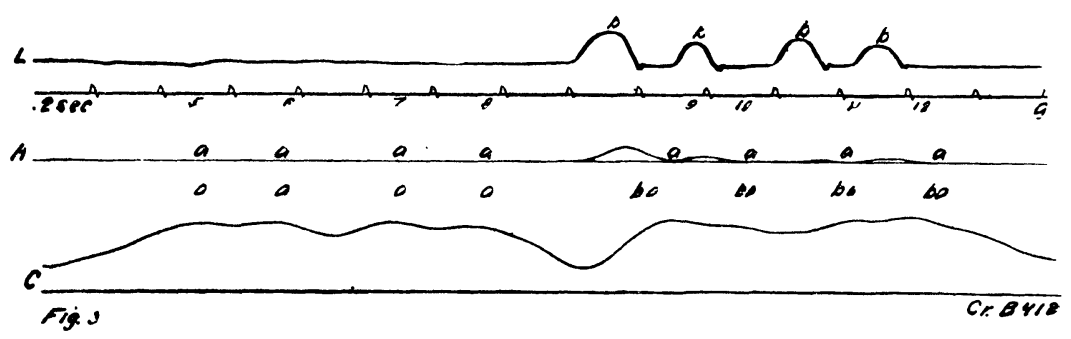

Orig. $2 \mathrm{I} \times 6 \mathrm{~cm}$. " $a, a, a, a$," as compared with " $b a, b a, b a, b a . "$

$L$, Lip movement; the usual forms for the syllable " $b a$."

$A$, Air-pressure in mouth: The tracing for the consonant " $b$ " is defective. $C$, Chest pressure: Shows a distinct pulse for each syllable.

' $n$ ' neighin" "it seldom happens, as Sievers assumes, that the " $n$ " position is retained; this does occasionally take place, but as a rule the tongue makes a definite stroke for each syllable. The same observations hold for the series of "l"s in "Lil" 'll lie low."

KLESTADT gives pneumographic tracings of speech in which each syllable is clearly indicated by a chest pulse. ${ }^{2}$ )

At the beginning of this rapid expiratory movement which produces a syllable, the positive muscle-group contracts suddenly, the air is compressed in the chest, and in a few hun-

') Grundzüge, p. 39; commented on by F. DE SAussure, Cours Ling. p. 94 .

$\left.{ }^{2}\right)$ Zur qualitative Analyse der Sprechatmung, Zschr. f. Hals-, Nase, u. Ohren-h. 12, '25, 257-277. 
dredths of a second a puff of air escapes; this is the chest pulse. Sometimes the vocal cords give a tone; sometimes the glottis is open as in whispering or in whistling. This movement is arrested by the contraction of the negative muscle-group (muscles which inflate the chest in inspiration) and the puff ceases as the pressure falls in the chest.

This is a balistic movement with self-release and self-arrest. If the movement were not self-arrested it would trail off in a
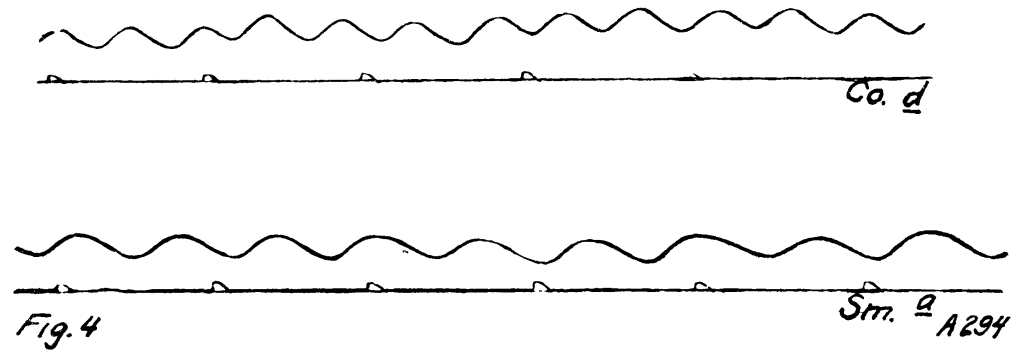

Rapid series of breath pulses taken from the nose. The articulatory organs were in positon for a whispered , $m$ " in $294 d$, and for a whispered , $n$ " in $294 a$. The vocal cords were relaxed so that there is no possibility of a glottal catch or other consonantal movement.

$d$ is at the rate of c. 10.5 per sec.

$a$ is at the rate of c. 8 per sec.

The series $a$ and $d$ are from different subjects.

The record shows that the muscles of chest used in speech, work quite as rapidly as any of the small muscles of the body.

sigh or a moan. If a consonant is incorporated, we may have the syllable " $t a$ " in which the chest pulse is released by the consonant; or the syllable "at" in wich the chest pulse is arrested by the consonant. All phoneticians are agreed that the releasing and arresting consonants are unlike. Compare Fig. 6 p. 2 I9 where "eat . . ." becomes "tea ...."

The speed of the syllable movement is very rapid and approximates that of the most rapid balistic movement. It is possible to repeat a single vowel like " $a, a, \ldots$. at the rate of $5^{-7}$ per sec. The highest speed is obtained when the syllable has an occlusive releasing consonant; " $t a, t a$. ." can be repeated at the rate of 7-10 per sec.; the speed depends slightly on the rhythmic grouping and is equivalent to the maximum repetition time ("tapping time") of the subject.

It is interesting that the chest muscles are capable of producing 
7-10 pulses per sec. This is the highest speed of small and wellcoordinated muscles like those of the hand. Tracings such as those shown in Fig. 4 prove that the muscles involved in the syllable movement can hardly be the larger muscles of diaphragm and abdomen.

"Long" vowels are distinctly slower, if the characteristic quality is preserved. "tea, too, tay" can be repeated at the rate of $4.8-5.2$ syllables per sec.

RousSELOT's reading of a selection from the Chanson de Roland shows an average rate of 4.9 per sec. for I io syllables; a reading of the same selection some five years later gives an average of 4.5 syllables per sec. ${ }^{1}$ )

The duration of the syllable depends somewhat on the force with which it is uttered. This force of utterance involves a greater contraction of the positive muscles of expiration 'and this requires a longer time for the process of arresting the movement. Sometimes this increase in length shows in the vowel, when the negative chest muscles which arrest the movement come into play during the latter part of the vowel. This is unusual in the Romance languages, but quite common in English in which most of the "long" vowels have a "vanish" during which begins the arrest of the syllable movement.

It is possible to prolong a syllable at will, if the syllable is "open" or if the syllable ends with a voiced continuitive like " $m, n, l, r$, etc." In beating time so that the baton describes a "figure-eight" the movement may be prolonged after the pulse of the beat; in the same way the beat stroke of the syllable may be arrested by a back-stroke process which continues the course of the movement in a slow, "controlled" form. Movements of this sort, which begin with a balistic pulse and are continued as a "controlled" movement are very common in all fields. In unusual cases a vocal movement of the "controlled" type begins, perhaps in the utterance of a fricative, and is finally merged into a balistic pulse; in such cases the preceding movement is counted part of the syllable generated by the balistic pulse. It is after this fashion that the preliminary slow movement of the orchestral conductor merges into the entering beat stroke of the selection.

1) Computed from Précis, p. 96 f., and from Principes II, p. I055 f. 
The Demarcation of the syllable.

The question of the syllable as an individual unit, and the question of the demarcation of the syllable, "the division of the syllables," are essentially the same problem. But they may be discussed separately for convenience.

If the syllable is made an individual unit, somehow it must be one indissoluble movement. It should be possible to define this one movement and to show that the "sounds" of which it is sometimes assumed that the syllable is composed, have no independent existence in speech.

In all languages it is possible to fit the syllables into a meter without doing violence to the nature of the syllable. Whatever the supposed character of the syllables so arranged, whether they are syllables by breath pressure or by "sonority," whether they are divided by "implosion-explosion" or by "discontinuity of intensity," they can all be represented by a rhythmic series composed of a single nonsense syllable. The metric scheme of any actual verse or prose group can be adequateley outwith "ta, ta, .."

If a "sonority syllable" is assumed it must be admitted that stressed or unstressed it is a rhythmic element, either an accented or unaccented beat. One must say then that a "subjective" rhythmic beat is present for each "sonority syllable." That is another way of saying that sounds having "sonority" occasion a subjective beat.

Instead of saying that "the syllabic sonant has sonority real, or apparent" which produces a subjective beat, it is simpler to say that the sounds of the syllable, whether prominent or not, naturally occasion in the hearer just that balistic pulse which made the syllable a syllable for the speaker.

The observation of Rousselot already cited that in subcortical aphasia the syllable is preserved, bears on the same point. There are as many expiratory pulses as there are syllables in the phrase that the patient attempts to say.

In singing the syllable corresponds to the note. It is worth notice that while it is possible to put two or more syllabic pulses into the same vowel and so make two or more notes of what was originally one syllable, it is never possible to sing two distinct syllables to the one note. ${ }^{1}$ )

1) Cf. Rousselot, Principes I 349; discussion of a continuous vowel into which new pulses are introduced. 
The problem of the unity of the syllable and the demarcation of the syllable is precisely the problem of the unity and demarcation of the beat in rhythm and of the note in music. The same questions may be raised in the field of music. The notes occur in series; they are different when isolated; they are grouped into elaborate figures; they are very short or indefinitely prolonged. Precisely where does a note begin and precisely where does a note end? Is the note an independent unit, or merely a division for convenience? There is no essential difference between syllables when spoken and syllables when sung; the notes in whistling are essentially syllables, and by extension so are all the notes of the wind instruments.

In singing, whistling, and the playing of wind instruments, there are always intermediary processes, "slides" and "glides" between the notes, momentary pauses during which a motor preparation is made for the next audible event. An elaborate analysis of an acoustic record of music would show all the phenomena of "continuous flow," of unexpected silences, of transitional processes, etc. which have been emphasized in the case of acoustic speech records. It is merely chance that the vexed question of the demarcation of the syllable has not been paralleled in music by the vexed question of the demarcation of the note. Where for example is the line between a series of repeated notes and a series of swells and diminuendoes in a single note? Where is the line between the tremolo and the repeated note? The division of notes in music gives quite as good an opportunity as the division of syllables in speech for the application of the "minimum of sonority," or of any of the other criteria proposed. ${ }^{1}$ )

The same question as to the individuality and demarcation of the movement may be raised in the case of any series of skilled movements. In telegraphy or typing it would be extremely hard to say where a given word ends or another begins, or to define the natural boundary for the movement of a given dash or a given letter - all the movements flow into each other; they seem a continuous series. In piano playing the movements of

1) A. W. DE GRoOT makes a critique of the various theories of the syllable and attempts a synthesis on the basis of the syllable as a rhythmic unity. „La Syllabe; Essai de Synthèse,” Bul. de la Soc. de Ling. de Paris, 27 fasc. I, '26. Reviewed by L. KaIser, Arch. Néerl. de Phon. Exp. I, 1927, p. I28. 
the next note are being prepared while the present note is being struck, and often the movement of leaving the last note continues during the present note. It is difficult to separate any movement from the context of preparatory and adjusting movements which are always going on and which always overlap in rapid action. Motion pictures taken at very high speed and exhibited at low speed so that the movements are slowed down are a striking illustration of the difficulty of setting limits to so definite a thing as a tennis stroke, or a base ball strike; the movements flow into each other; everything is continuous.

And yet we have no difficulty in pointing out definite blows or strokes which are individual. And an interesting thing happens when we attempt to slow down certain processes; writing can be reduced in speed and a type of movement we call tracing is the result. But it is impossible to slow down the movements of beating time in the same fashion; the conductor may beat time "very slowly," but the beat itself remains a rapid stroke. One may play the piano "very slowly," and all the movements may be slow indeed save only those of striking the key; the key must have a quick, definite stroke. Precisely the same thing is true of speech, which is also a rhythmic process; certain elements can be prolonged, but there are blows, strokes, in speech which must occur rapidly, and about which the other movements are grouped.

The problem of one movement as applied to the syllable may be generalized: it is the problem of defining one movement in any series of rapid skilled movements. How are we to define a single movement?

If the moving member starts from a position of rest, and comes again to a position of rest, the excursion would seem to constitute a definite, single movement. But in such a familiar process as beating time in the "figure-eight" form the flow of the movement may be continuous, and yet the process generates a peculiarly definite series of separate beats. The beat occurs in the lower segment of each loop; in that phase of the movement there is a definite pulse, the flowing movement takes on a sudden increase of speed and this constitutes the "beat stroke." Between the beat strokes the movement may be slowed down at will, it may retard or accelerate; but the beat stroke remains invariable, and in a peculiar sense it determines one movement. A slow, "controlled" movement with definite limits formed by positions 
of complete rest is also recognized as one movement; but if such a slow movement is continuous with a beat stroke it is felt to belong to the beat stroke.

The syllable is one in the sense that it consists essentially of a single chest pulse, usually made audible by a vowel, which may be started or stopped by a consonant movement. These accessory articulatory movements cannot be considered independent, for their essential function is to delimit the chest pulse, and their characteristics depend on that function.

This reduction of the movement of the syllable to a balistic chest movement (for which an associated balistic articulatory movement is perhaps rarely substituted) eliminates Sievers' distinction between "pressure syllables" (Drucksilben) and "sonority syllables" (Schallsilben). All syllables become pressure syllables, assuming that the "pressure" is due to a sudden breath pulse. The concept of the "variation of sonority" is most unsatisfactory. As W. Perret points out, it is possible to run through the whole gamut of vowels in a single syllable. ${ }^{1}$ )

And it may be added that the order of vowels may be varied, and consonant movements introduced; the one thing essential to a long, continuous syllable is simply that no second balistic movement occur; it is not a matter of variations in sonority or in any other quality. To make a new syllable, the change in the velocity of utterance must be rapid, but not too rapid. The $a-i$ of the English "long $i$ " shows a striking change both in sonority and in degree of closure, but no second syllable develops because the change occurs during the one balistic chest movement. If Sievers" " $a-i$ " and " $a$-la" can be pronounced as two syllables with no change of breath pressure, the associated balistic movement of iaw and tongue for the " $-i$," and the associated balistic movement of the tongue for the "-l-" determine the new syllable. However, such a pronunciation has still to be demonstrated experimentally. The same thing is to be said of the pronunciation of the first two syllables of the word "Aragón" suggested by Navarro Tomâs.

In this connection NAVARRo TomÁs makes an interesting suggestion as to the nature of the syllable; after speaking of it as separated acoustically by the diminution of sonority, he continues:

1) Some Questions of Phonetic Theory, Hefrer \& Sons, London, 'I9 p. 25 and 67 . 
"Considered from the physiological point of view, it is an articulatory nucleus contained between two successive diminutions of the muscular activity." ${ }^{1}$ )

Not the change in "sonority" but the new balistic movement makes the new syllable. Almost invariably this new pulse is a pulse of expiration, a chest pulse, and the "pressure syllable" was a good formulation. But the "sonority syllable" was an unfortunate addendum to explain certain cases in which the new pulse, the balistic movement which marks the new syllable, does not seem to occur in the breathing apparatus.

The division of the syllables, the determination of the syllabic frontier, is a phase of the problem of the unity of the syllable. If one balistic movement constitutes the syllable then the division between the two balistic movements constitutes the division of the syllables.

It often happens that the division between the two balistic chest pulses is made apparent by a reduction in the force of utterance at the syllable frontier. This is noted in the case of a continuous sound running across the syllabe division. The " $s$ " is continuous in the double sibilant of "this sigh" (Cf. "this eye,") although there is a reduction in intensity at the syllable frontier. Diminution of intensity is sometimes made the general principle of syllable division. ${ }^{2}$ )

But there are cases in which the new chest pulse occurs without "diminution of intensity." Instead a sudden rise in intensity marks the entrance of the new chest pulse. Rousselot has published records of a series " $\grave{a}, \grave{a}, \ldots$. in which the laryngeal tone is continuous from " $a$ " to " $a$ " but there is a sudden rise in the intensity as a result of a change in the breath regulation (régime du souffle,) i. e. a new chest pulse occurs for the new syllable. ${ }^{3}$ )

The division between the syllables may be made to depend on an implosion-explosion juxtaposition, providing it is translated into the arrest of the chest pulse followed by the release of the following chest pulse. And it is to be remembered that syllables without consonants on either side of the division pre-

1) T. Navarro Tomás, Manual de Pronunciacion Española, 4. ed., Madrid, '26, p. 28.

2) PAssy, Phon. Comp. p. 45: "The separation of the syllable is marked by the point where the intensity is at its minimum."

3) Principes I 349 . 
sent just this same arrest-release phenomenon. F. DE SAUSSURE's observation of the implosion-explosion as a sign of syllable demarcation is good; but to assign to a series of vowels and consonants a series of "explosions," as in "trya" (in which $t, r, y$, are all counted as explosions) is a mistake; there can be but one release of the syllabic movement. The same objection is to be made to a series of "implosions" like "arst" ( $a, r, s, t$ implosive); a syllabic movement can have but one arrest. It is also a mistake to assume that a given "sound" can have but one phase in a given syllable. In any syllable there is a release and an arrest of the movement, so that a single vowel like the English word " $a$ " or the French word " $y$ " has both the release and the arrest and would present in F. DE SAUSSURE's nomenclature "explosionimplosion."

The relation to the syllable division of the double consonant, and of the other forms of abutting consonants at the syllable frontier will be considered later.

\section{Relation of the Vowel to the Movement of THE Syllable.}

In popular phonetics the vowel is counted the core of the syllable and is often identified with the syllable. In general such a "sound" does constitute the bulk of the syllable in point of duration and is quite prominent as a matter of quality. So much so that Marage and Devaux-Gharbonnel, reasoning from the prominence of the vowel in acoustic records, have counted the vowel the important item. A. G. BELL was surprised to find however, in dealing with the speech of mutes, that the vowel is far less important than the consonants. He found that with a vague indeterminate vowel substituted for all the vowels a reading may still be quite comprehensible. The Semitic languages betray this feeling that the vowel is incidental by writing only the consonants on the line, and marking the vowels, ad libitum, as mere "points."

In singing on the contrary the vowel becomes primarily important, and the consonants often lose their function and are neglected.

Sievers and others have stressed the fact that a syllable may 
be composed of a consonant like " $m, n, l, r$ " counted in some sense as a vowel ("liquid.") But one can go farther; the action of the vocal cords is not essential to the syllable. A syllable may be composed of "sh" or of "pst." In whistling through the teeth we have a series of syllables composed of nothing but a long drawn "s."

The syllable however, involves a breath pulse and the vowel involves a more or less open conformation of the vocal canal for emitting this breath pulse. The vowel then is most convenient for emitting this chest puff which is made audible by the action of the vocal cords.

The coordination of the vowel with the balistic pulse of the breathing apparatus which produces the syllable is entirely different from the coordination of the consonant. The consonant has a function in the movement of the syllable; the vowel on the other hand is merely a movement which accompanies the chest pulse, but is not an integral part of it. The articulatory movement which produces the vowel conformation usually involves a movement of the jaw as well as of the lips and tongue. The coordination is very simple; just as in piano-playing the two hands strike together, or in violin-playing the fingers change the pitch of the tone produced by the bow, so the vocalic movement occurs side by side with the chest pulse. The vocalic movement merely determines the timbre of the tone, just as the fingering of the violinist determines the pitch of the tone.

Rousselot has shown that the vowel is heard not only when the position has been reached, but also while the organs are taking position, and also while the organs are quitting position and moving to a new vocalic formation. In speech at the ordinary speed of $4^{-7}$ syllables per sec. there is no holding of the position possible; there must be constant change and the vowel cannot be acoustically a pure tone. It is apparent that the diphthong is a complex vowel, in which the changing movement is vocalized during the syllable pulse. Many of the English vowels are really diphthongs, not only such recognized forms as the "long $i$ " and "oi" but also the "long" vowel with "vanish" which is so characteristic of the English pronunciation. The apparent simplicity of the vowel sounds of a language is due to the fact that minute differences cannot be recognized; this is the effect of WEBER's Law. It is also true that at a certain 
speed, separate elements cannot be heard as separate but must fuse to qualitative aspects of the whole mass of sound; this is the law of discrete succession. This type of fusion occurs at speeds of 12-18 per sec., which is well within the speed of the various elements of speech. It is not only the case that small changes cannot be noticed and that successive sounds at high speed fuse to the ear, but is is also true that what is actually heard is not the acoustic detail, but the simple, definite, articulatory movement; therefore the vowels seem fairly definite, simple sounds.

The quality of the vowels depends somewhat on the syllable movement. The "short" vowels of the English demand a certain syllable movement; they occur often in closed syllables, and they are very rapid; they cannot be prolonged. The "mute $e$ " of the French and the "dark $e$ " of the English are cases of a vowel reduced to its lowest terms; there is as little as possible vocalic movement from the neutral or "resting" position of the vocal apparatus and the vowel is as brief as possible. Since the "short" English vowels are also brief they seem to approach the "dark $e$ " in quality; like them the "mute $e$ " and the "dark $e$ " cannot be prolonged without changing the quality of the sound. The difficulty of singing words like "bit" and "heaven" is a familiar illustration of the change in vowel which must occur if the syllables are prolonged.

In French the vowels are all rather brief and there is little apparent change during the vowel; in the utterance of the "long" English vowel on the other hand the vocalic apparatus is shifted for the next sound while the vowel is still sounding and a secondary quality is always heard at the close; this is very marked in vowels having the heavy word stress common to the Teutonic languages. When English is pronounced very slowly, the resulting drawl produces two distinct syllables for each of the "long" vowels; "days" becomes "dai-uz"; this is a rather common vice in English enunciation in certain localities.

The contrast noted by PASSY ${ }^{1}$ ) between the "tense" vowel of the French "site" and the "relaxed" vowel of the English "sit" is due to the fact that the English "sit" has a complete consonant arrest, while the French "site" has an arrest which is partly from the chest - self-arrest - so that the - "te" tends to

1) Phon. Comp. sec 235, p. 96 . 
become a second separate syllable, unvocalized in the ordinary pronunciation, but vocalized and apparent in emphatic speech and in singing. In such cases, the complete "relaxation" is that of the chest muscles in the balistic stroke with consonant arrest; there is no contraction of the chest muscles at the end of the stroke. In the French "site" on the contrary, there is a contraction of the chest muscles at the close of the chest pulse along with the consonant movement.

\section{The Functions of the Vocal Cords.}

For various reasons, the action of the vocal cords has never been considered to be like that of the other organs of articulation. It is true that the glottis closes or opens the vocal canal, just as do the other organs of articulation. But in the main this closure is not absolute and there is a tendency to treat the action of the vocal cords as if they merely added a quality to the outgoing breath stream. The breath stream is said to be "voiced" or "unvoiced."

There are very real reasons for this usage. It is only rarely as in the "glottal catch" (coup de glotte) that the larynx acts as a true consonantal organ. In the production of the vowels and o fthe voiced consonants, the action of the cords is not consonantal; their movement has no part in the production of the syllabic movement, as has the movement of the consonant.

And there is a distinction to be made between the action of the vocal cords, and the movement of the jaw and lips and tongue which produce the vowel quality. Although the voice is ordinarily essential to the vowel, the action of the cords can never replace the syllable movement, as does the vowel articulation in breathless whispering. In fact the larynx does not initiate any syllabic or consonantal or vocalic movement. It is an open question if the larynx can be said to initiate a tone. While the pitch is due to the action of the larynx, the inception of the tone is due to the pulse of the breathing apparatus. And it is possible that this is the case, even with the voiced occlusives. At first sight it would seem that the difference between a voiced occlusive $(b, d, g)$ and an unvoiced occlusive $(p, t, k)$ must be due to the action of the larynx alone. And yet both Alexander G. BELL, and Rousselot report cases in which speech with an artificial larynx presented perfectly satisfactory voiced and unvoiced oc- 
clusives, when in these cases the difference between the voiced and unvoiced occlusives must have been due to the management of the pressures above and below the artificial larynx, and not to the larynx itself, the reed of which is not under control but is ready to sound at any and all times. There can be no question as to the accurary of these two observers - though oddly enough the importance of the cases for the theory of the voiced occlusives occured to neither of them at the time of observation. BELL might have found important evidence against his theory of continuous breath-pressure during speech. Rousselot was concerned solely with the question of the vowels. ${ }^{1}$ )

\section{The Movement of the Consonant.}

Although the same "sound" has sometimes been counted both a vowel and a consonant, in one form or another a distinction has always been drawn between the vowels and the consonants. It is the custom to recognize a vowel " $i$ " and a consonant " $i$ "; (the consonant " $i$ " in English is often spelled " $y$ " as in "yes"; in French it is often unchanged, as in "rien, dieu"); a vowel "ou" and a consonant "ou" (written "w" in English but unchanged in the French as in "oui".) The difficulty of making a distinction has given rise to the term semi-vowel sometimes applied to the liquids " $l$ " and " $r$ " and to the nasal " $m$ " and " $n$ ".SIEvers has been at pains to point out that the same "sound" may function in rapid alternation as a consonant and as a vowel; "berittenen" has already been cited. But aside from the practice of dividing "sounds" into the "sonant" which is supposed to be the core of the syllable and the "con-sonant" which is merely added to the syllable, there has been little attempt to define the function of the consonants. Often the consonant has been considered quite secondary to the vowel. Marage defines the consonant as a supralaryngeal noise preceding or following the aero-laryngeal vibration of the vowel; he feels that the consonant occupies but a small place in the syllable and therefore should be subordinated to the vowel. ${ }^{2}$ )

1) Rousselot, La Parole avec un Larynx Artificiel, La Parole, I2, 'o2, p. 65. Bell, A. G., The Mechanism of Speech, Funk \& Wagnalls, N.Y.' 'o6, p. 80.

2) Contribution a l'Etude des Consonnes, C. r. sci. I52, 'i I, p. 1265. Gf. Devaux-Charbonnel, Ia Photographie de la Parole, C.r. sci. I46, 'o8, p. 1258 . 
RousseLot applies his general analysis of the tension-tenuedétente to the consonant; this describes the position of the organs and, can be made to explain the important difference between the implosive (arresting) and the explosive (releasing) functions of the consonant. The study of historic phonetics has shown that there is an important distinction between the consonant which closes a syllable and the consonant which opens a syllable. The explosive consonant which opens a syllable is called appuyée, while the implosive consonant which closes the syllable is called appuyante when it abuts the explosive consonant of the next syllable. The different fate of these consonants in the evolution of the Romance languages led to this distinction. The terms imply that the explosive consonant of the abutting pair is somehow supported and so buttressed against change, while the implosive is supporting and may disappear. Rousselot defines the explosive consonant as consisting primarily of taking-position and holding-position, while the implosive consists primarily of holding-position and quitting-position. F. DE SAUSSURE counts the implosive-explosive junction important for the division of the syllables. But these analyses do not touch the fundamental question of of the relation of the movement of the consonant to the movement of the syllable.

The consonants are to be divided into releasing consonants which start the syllable movement and arresting consonants which stop the syllable movement. "Explosive" and "appuyée" are other names for the releasing consonant; "implosive" and "appuyante" are other names for the arresting consonant.

\section{The Arresting Consonant.}

In a series of syllables like "up, up.." the syllable pulse is started by the chest muscles; is it "self-releasing." But the syllable pulse is stopped, arrested, by the consonant stroke. The consonant closes the vocal canal, and the rise of air pressure in the pharynx and chest brings the movement to a stop. Figs. 5, 6, and 7 show that the highest chest pressure of the pulse occurs when the consonant stroke closes the vocal canal. The lowest chest pressure between the syllable pulses occurs well after the consonant. The next syllable pulse does not begin until after the back stroke of the consonant. There is a hiatus 


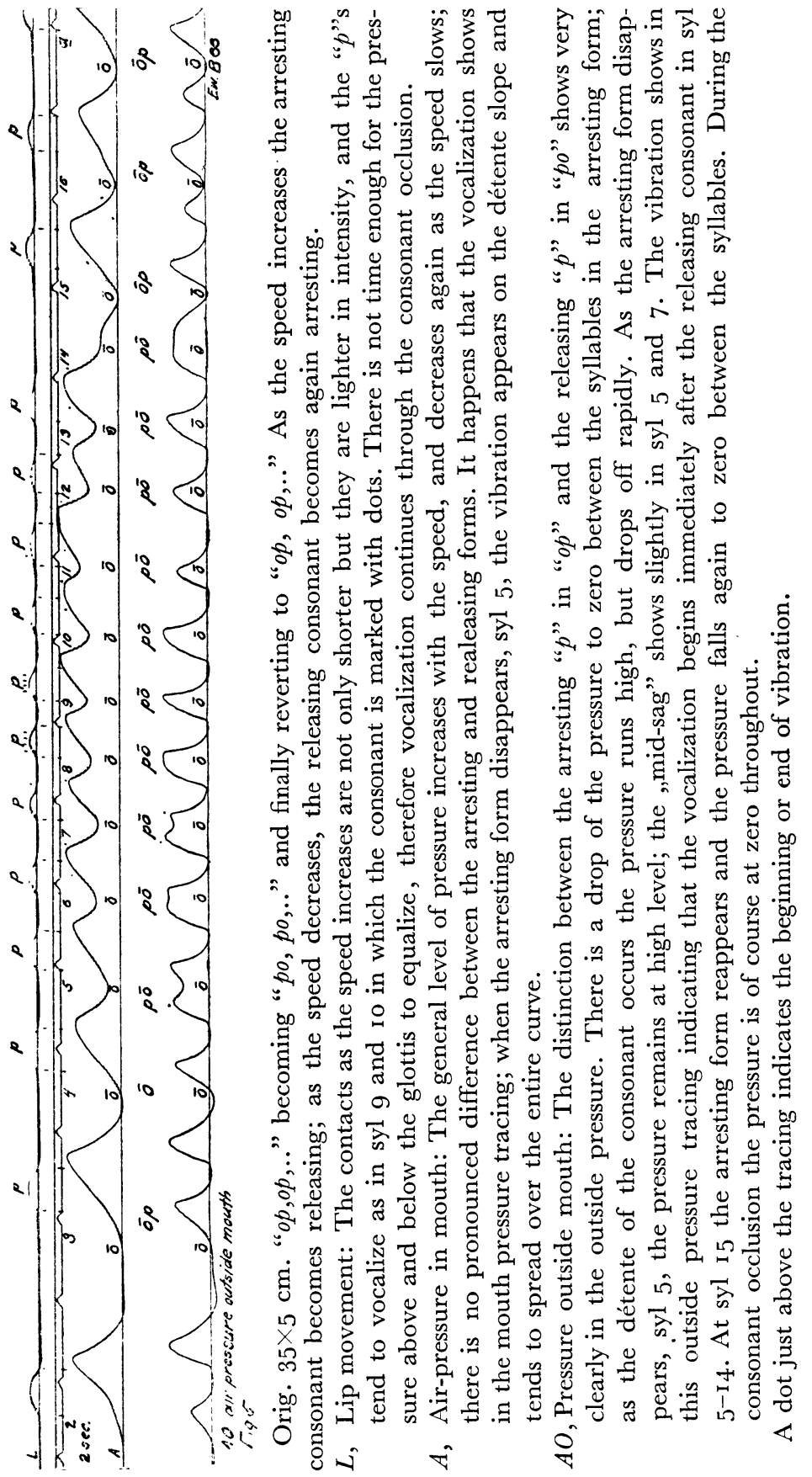




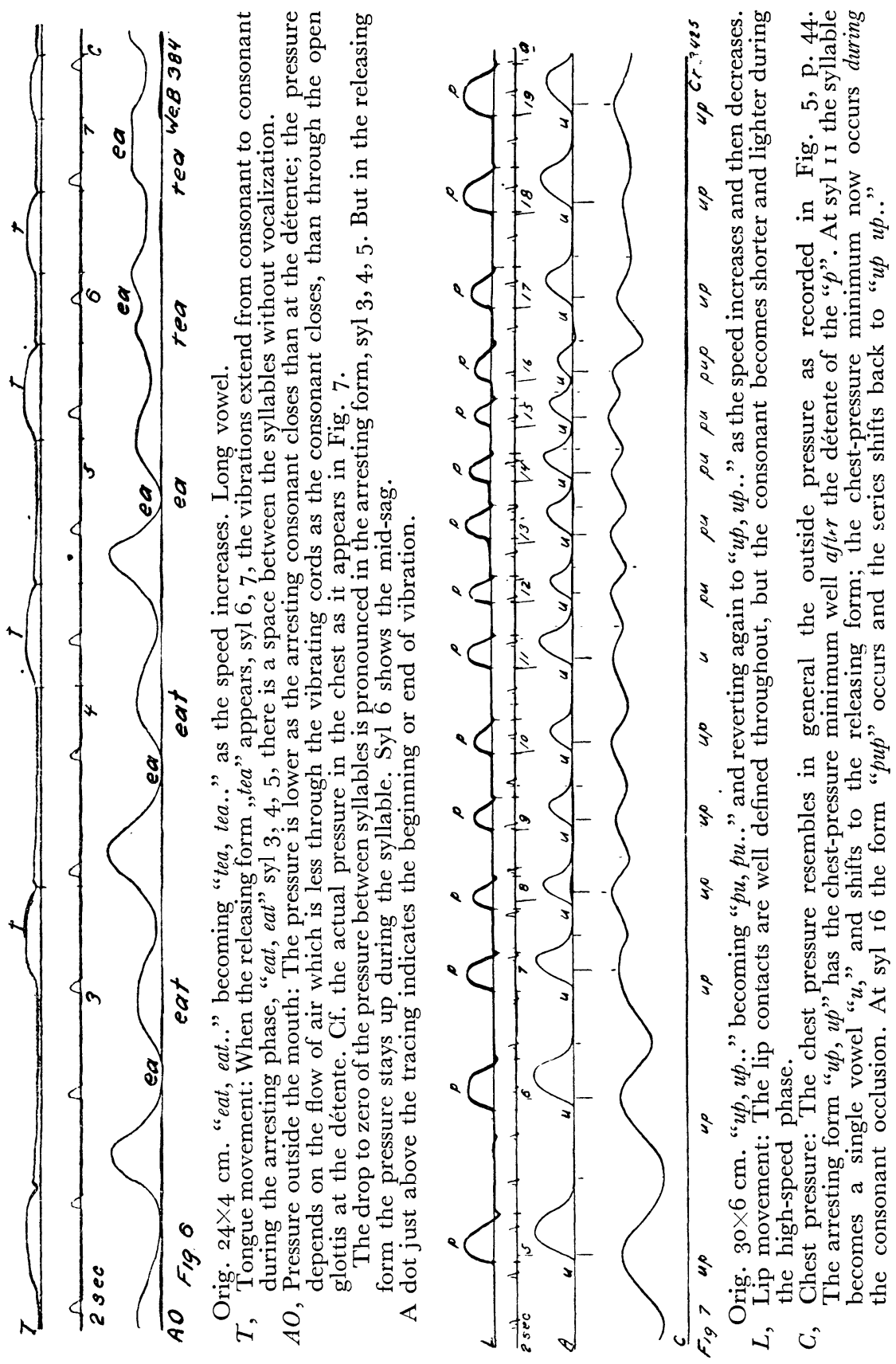


in the sound, for vocalization of the vowel of the next syllable does not occur until the delayed rise in chest pressure.

The pressure in the mouth has the typical arresting form; the closure of the lips brings the rise in mouth pressure which accompanies an arresting consonant. The curve has the rounded form due to the gradual subsidence of pressure; the chest pressure sinks as the chest muscles prepare the next pulse.

When the pressure just outside the mouth is recorded with the ordinary form of RousseLOT's apparatus, the tracing shows something of the variations in the chest pressure, interrupted of course during the closure of the consonants. The mid-sag in the pressure outside is not due however to any change in the chest pressure, but to the enlargement of the mouth cavity as the mouth opens which affects the pressure in the mask before the mouth. There is a corresponding rise in pressure in the mask when the mouth cavity is rapidly diminished as the mouth closes. The point of minimum chest pressure is well marked in the tracing of pressure outside, and the rapid rise for the next vowel is clearly indicated; the vocalization usually appears in this tracing if the membrane is delicate. Tracings of whispered syllables do not often show the mid-sag; the glottis is open enough to sustain the mouth pressure in spite of changes in volume and the curve of pressure outside merely shows a steady decrease in pressure during the syllable. Fig. 5 may be compared with Fig.s 8 and 9.

PAssy notes that the English can differentiate "an aim" and "a name," i.e. an arresting consonant may persist in English where it would shift to the releasing position and transfer to the next syllable in French. ${ }^{1}$ )

This is true, but only at a moderate speed. If "an aim" is said faster and faster it soon becomes "a name." The " $n$ " has shifted from the arresting function in " $a n$ " to the releasing function in "name". The arresting consonant is virtually added to the syllable and as the speed increases tends to shift to the releasing position in the next syllable where it does not require extra time. Binet and Henri found that at maximum speed the syllables of the digits with consonant arrest required more time than those with open syllables. ${ }^{2}$ )

1) Phon. Comp. sec. 126, p. 46 .

2) Les Actions d'Arrêt, l'Année psy., 37, '94, p. 6I I. 
This change can easily be studied in experimental series. Fig. 5 shows "op, op.." becoming "po, po.." and as the speed slows reverting to "op, op.." Fig. 6 shows "eat, eat.." becoming
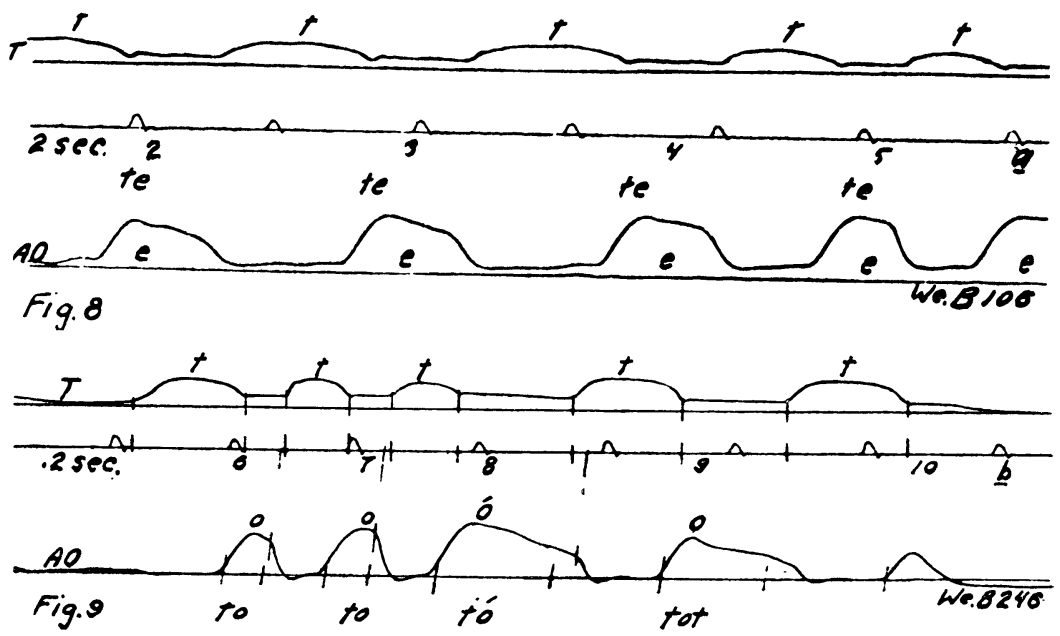

Outside-pressure forms without mid-sag in whispered utterance; long and short vowels.

Figure 8. Orig. $\mathrm{I}_{5} \times 4 \mathrm{~cm}$. "te, te,.." normal rate; short vowel.

Figure 9. $16 \times 5 \mathrm{~cm}$. "to, to to' tot," accented group; long vowel; dynamic form due to the accent.

$T$, Tongue movement: Usual forms for " $t . "$

$A O$, Air-pressure outside mouth: A slow descent of pressure in each syllable without the mid-sag.

Fig. 9 shows the culmination at the accent of the dynamic form of the entire group.

"tea, tea.." Fig. 7 shows "up, up.." becoming "pu, pu.." and reverting to "up, up.." The reversion to the original form, and the increase in chest pressure and decrease in the consonant stroke at high speed will be considered later.

\section{The Releasing Consonant.}

This consonant releases the syllable pulse. The stroke of the expiratory chest muscles and the beat stroke of the consonant occur at the same time. The consonant stroke closes the vocal canal so that the action of the chest muscles compresses the air, 
then the rapid back stroke of the consonant releases the air. The beat stroke and often the back stroke of the consonant occur during the beat stroke of the chest. At high speed the back strokes of consonant and chest muscles, as well as the beat strokes, tend to coincide. The releasing consonant never adds to the length of the syllable and it actually accelerates the syllable movement. The coordination is much faster than that of the arrested syllable. The rate may be as high as 9-10 per sec. which is the maximum speed of a skilled movement.

Tracings show that the pressure in the chest continues to fall when the consonant closure occurs, while the pressure in the mouth rises because of the pressure difference of the two cavities. Although the consonant muscles and the chest muscles contract at the same time, the chest pressure does not begin to rise until the middle of the consonant contact. For the actual relations cf. Fig. 40 syl 10-12, Fig. 4I syl 4-5, p. 260, etc. This lag of .03-.05 sec. is due to the size of the cavities involved. In speech the consonant muscles quickly close a cavity of 200 c.c. at most, while the chest muscles act on a limited area of the walls of a cavity of 2500 c.c. at least. The pressure conditions permit vocalization to continue up to the releasing consonant and to begin immediately after. This has led some to assume that the median releasing consonant belongs to both syllables. ${ }^{1}$ ) But the consonant belongs to the syllable in which it functions.

\section{The Releasing and Arresting Consonants as Two Functions of One Movement.}

The consonant stroke seems now to open and now to close the vocal canal; how can it be be counted the same thing in these different cases? When the tongue moves from the neutral position and makes a quick stroke to the palate as in " $a$-la" or "hut" there seems little question that the stroke is made to the palate. In the word "hut" the stroke must occur in that fashion; but in the case of "la" or "to" it is possible that the tongue is in contact with the palate before the essential stroke occurs. While the same spot is involved there seems at first sight a radical difference between the essential stroke of the releasing consonant in " $t a$ " and "la" which seems to be from the hard

1) ViëroR, El. d. Phonetik, 7. ed., Reisland, Leipzig, '23, p. 357. 
palate and the essential stroke of the arresting consonant in " $a t$ " and "al" which is to the palate. Apparently the arresting and releasing strokes are in opposite directions although they move over precisely the same path. But the movement shifts from arresting to releasing and back again, and at fairly high speed; it is improbable that the entire coordination of the movement changes with this change of function.

The consonant movement involves an obstacle, an opposing surface to which and from which the stroke of the consonant plays. The detail of such movements to an opposing surface will help in understanding the arresting and releasing functions of the consonants. It is sometimes said that a rapid movement is apt to be followed by a "rebound"; in reality the return movement, the back stroke, is not due to elasticity, but to the accurately timed contraction of the negative muscle-group which arrests the member and returns it to the starting point; it is this rapid back stroke which is sometimes called the "rebound". In case the movement is arrested by an obstacle, the opposing surface, precisely the same sequence may occur; the momentum of the movement is taken up by the obstacle, the negative musclegroup acts at the proper time and returns the moving member; the time consumed proves to be precisely the same as if the opposing surface had not intervened; plotted against time, the movement would have presented a u-shaped or v-shaped path at the end of the stroke; the opposing surface truncates this $\mathrm{u}$-shaped or $\mathrm{v}$-shaped curve and gives a flattened form, Fig. Io $A$, but the time relations are the same as if the movement had been completed with self-arrest and normal return, Fig. Io $B$. When the movement barely reaches the obstacle, barely flicks the opposing surface, the curve of the complete movement is practically normal, and the truncation is eliminated; the member does not remain in contact with the surface, Fig. IoC.

This means that although the movement is to a surface, the holding in position is eliminated. Many of Rousselot's records show such forms. ${ }^{1}$ )

This normal movement may be modified by eliminating either the excursion to the opposing surface, or the excursion from the

1) Principes I, p. 597, Fig. 387, 390 and others; II, p. 949, Fig. 63I ; p. 952, Fig. 635,636 . For details as to termination of skilled movements, Psy. Mon. 32, '23, No. 3; Stud. Oberlin Psy. Lab., p. 29. 
opposing surface. A blow can be delivered to an opposing surface when the member is in actual contact with that surface. The essence of the blow, of the beat stroke, is the sudden contraction of the positive muscle-group which exerts pressure on the opposing surface. Such blows delivered to a surface with which the member is in contact are very common. In pianoplaying and in typing the finger is often in contact with the key struck; precisely the same movement can be executed with the finger resting on the surface of a table. In the case of the stroke to the piano- or typewriter-key the back stroke may be of large amplitude, and may be the most obvious thing in the movement; this is true of "staccato" playing.

Translated into terms of phonetics this would mean in the

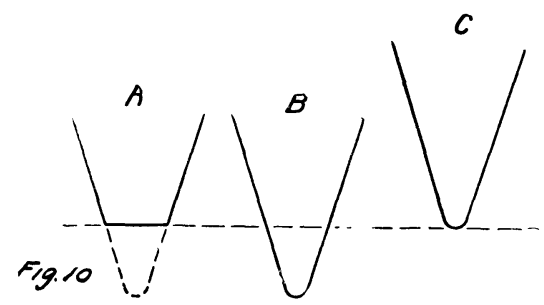

$A$ Blow delivered to an opposing surface; the member remains in contact with the surface during part of the relaxation phase (back stroke).

$B$ Similar blow as it would appear if the surface were withdrawn and the beat stroke were self-arrested.

$C$ Blow at high speed which barely touches the opposing surface.

case of the explosive " $t$ " that the tip of the tongue may be in actual contact with the palate when the blow is delivered to the palate; the beat stroke actually occurs although the tongue tip is in contact with the opposing surface at the time of the sudden contraction of the positive muscle-group. The methods of recording employed to date have not been very satisfactory for showing this sudden pressure against the opposing surface, nevertheless it does appear in some records published. ${ }^{1}$ )

In the word "pap-pa" the lips are still in contact when the " $p$ " of the second syllable occurs, but the sudden pressure which is the beat stroke of the releasing " $p$ " shows clearly. The beat stroke is not eliminated although the excursion of the lips does

1) Rousselot, Précis, p. 77, Fig. 68, p-p in "pappa." 
not appear. The essence of a movement lies in the contraction of the positive muscle-group, and a pressure is a stroke.

The "condensation of the back stroke," the elimination of the excursion from the opposing surface is as often observed. When the blow is struck to the opposing surface there may be no "rebound"; the momentum may be taken up by the obstacle and the negative muscle-group does not return the member to the original position; the relaxation of the positive muscles and the preparation of the next movement may occur while the member remains in contact with the surface to which the blow is struck. In the pronunciation of the word "hut" the tongue may deliver the stroke of the " $t$ " to the palate and remain in contact during the relaxation process. This is the "condensation of the back stroke." The tongue may or may not leave the palate at once; in any case the excursion from the palate has nothing to do with the consonant.

This analysis of the consonant stroke makes the arresting consonant and the releasing consonant modifications of the one movement. The essential thing is a stroke to the opposing surface, which may be given in contact, and which may or may not be followed by a back stroke from the surface. When the beat stroke occurs in contact the only apparent movement may be from the palate in the releasing consonant; when the back stroke occurs in contact the only apparent movement may be to the palate in the arresting consonant.

The study of the tracings proves that all consonants, whether continuitives or occlusives, have essentially the same function of releasing or arresting the syllable movement. Cf. later material on the double consonant and on other abutting pairs.

The time relations of the consonants show that they are essentially the same process. Rousselot says that "attributing to each consonant the interval necessary for its production, the consonants are all of about the same length; there are but slight differences:

Strong continuitives require c..I8o sec.

\begin{tabular}{|c|c|c|c|}
\hline & & , & \#I50-.i6o sec. \\
\hline Strong & occlusives & & $\# .140 \mathrm{sec}$. \\
\hline Weak & , & , & \#.120 sec. $\left.{ }^{1}\right)$ \\
\hline
\end{tabular}

1) Précis, p. 88. Principes II, 993, 998. 
E. W. Scripture quotes similar values from Gregoire. ${ }^{1}$ )

These values compare very well with the intervals of rapid movements in other fields. The interval .180 sec. is equivalent to a rate of 6.6. per sec.; .I 20 sec. is equivalent to a rate of 8.3 per sec. 6.6-8 per sec. is well within the limits of the "tapping time," or "repetition time" as measured for rapid movements of the hand; such repeated movements involve of course the beat stroke and the back stroke. The ordinary method of taking "tapping time" involves a stroke to an opposing surface; the records however are like those taken of a free movement with self-arrest. The balistic stroke (contraction phase) of most of the consonants can be executed with great rapidity, in .020-.040 sec. a fact which has important bearings on the functions of the consonant in the syllable movement.

The lingual occlusives " $t / d$ " and " $k / g$ " show the stroke and the opposing surface very clearly but these are not so apparent in the case of the other linguals.

The lingual continuitives " $s / z, s h / j$ (French $c h / j), t h / t h, c h$ French $t c h)$, German $c h$ ", etc. all contract the vocal canal but do not close it. The organs however spring into position with a balistic stroke and quit the position with precisely the same type of back stroke as occurs in the case of the occlusives. The fundamental distinction lies in the fact that they do not completely close the canal; in other respects their action and their time relations are much the same. The fact that the breath is escaping gives them a continuous sound during the movement while the corresponding closure of the occlusive is silent; but this does not affect the function of the continuitives in the least. Cf. Fig.s 36 p. 262, 66 p. 297. Fig.s I I, I2, I3, I4, I 5 show forms in which the pressure in mouth rises for the continuitives just as for the occlusives, and there is often little difference in the consonant contact.

The labials include the occlusives " $p / b$ " and the continuitives " $f / v$." The movements of the lips are fairly obvious; in reality the lower lip is primarily the moving member. Cf. Fig.s I I and I3. The tongue may be substituted for the lower lip; with a little practice all the labials can be made successfully with the tongue striking the upper lip (or the lip and teeth.)

The soft palate plays against the base of the tongue in producing

1) La Durée de la Syllabe Française, La Parole, '99, I, p. I6 I, 263, 418. 


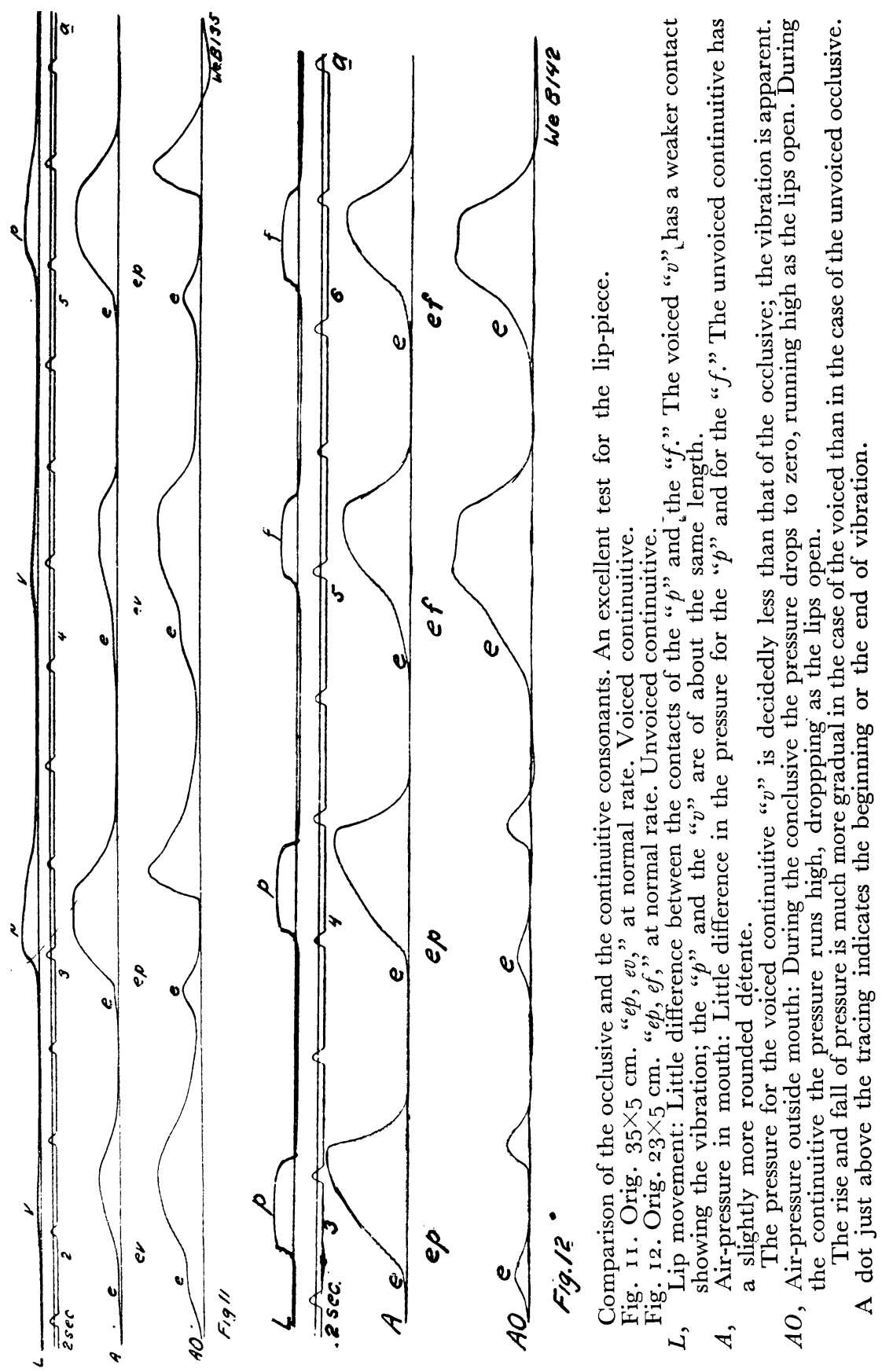


R. H. STETSON.

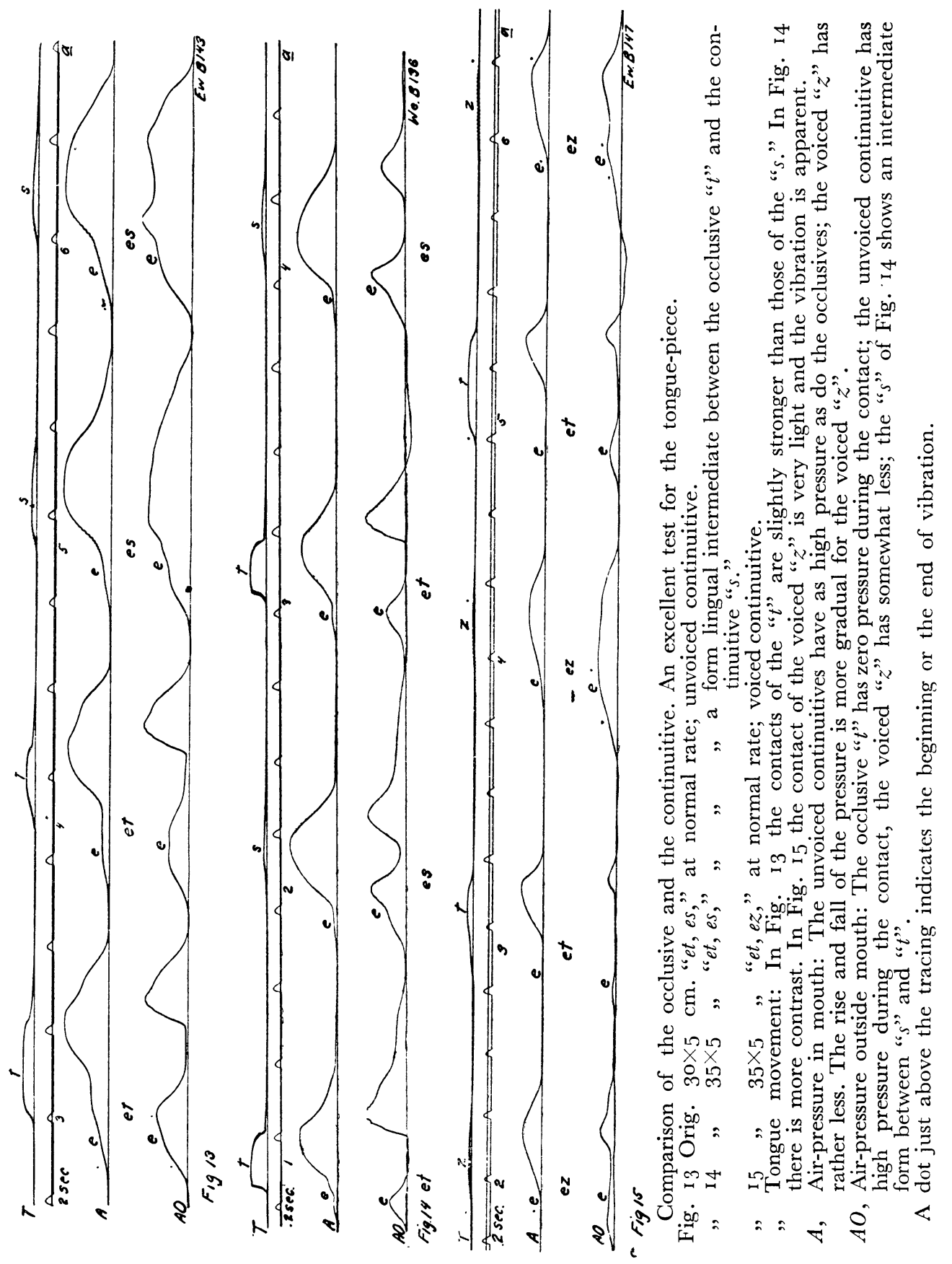


thegutturals " $k / g$ ", German " $c h$ " (hard), Greekgamma, and French " $r$ grasseyée," but the tongue is primarily the moving member. The glottis figures in two sounds. The aspirate " $h$ " common in English and occuring on occasion in French, ${ }^{1}$ ) is strictly speaking not a consonant. It is really a modification of the vowel and cannot occur in the arresting position. The rarer glottal catch (coup de glotte) figures as a consonant. In this glottal consonant the back stroke is uncertain; it is possible that it does not exist, and that there is merely a relaxation of the positive musclegroup.

In addition to the consonants considered there are two other classes. The first class contains the vowels which narrow the canal to such an extent that when they are very abrupt they may function as consonants; "ou" = consonant " $w$," and " $i$ " consonant " $y$." These have no peculiarities save that they are often associated with the vowels and may arise in vowel combinations. Although these consonantified vowels are sometimes called "semi-vowels," a second class has a better claim on the term because they leave the vocal canal so open that they may easily figure as vowels: the liquids " $l$ " and " $r$ " and the nasals " $m, n, n g . "$ Since these "sounds" are all vocalized and allow the breath to escape freely they may figure as vowels. On the other hand they constrict the vocal canal sufficiently to function in the arrest and release of the syllable movement.

As a whole the consonants are divided into two parallel series, the "voiced" and "unvoiced" (sonant and surd.) It is evident that the quality is due to the action of the vocal cords which are often supposed to act independently, like the other organs of articulation. But the vocal cords do not come into play as a separate factor, instead they are activated by the pulse of air from the chest. And there are reasons for thinking that the difference between the voiced and unvoiced consonants is no due to the direct action of the vocal cords, but rather to the coordination of the articulatory apparatus and the chest. When the pressure in the buccal cavity is practically that of the chest there is no air to activate the vocal cords; when the pressure in the buccal cavity is reduced by the consonantal release of air, or when the expiratory muscles increase the chest pressure

1) Passy \& Michaelis, Dictionnaire Phonétique, Soudier, Paris, 'I4, 2d ed. p. XXIII. Statements like Clédat's are merely traditional, Manuel de Phonétique et de Morphologie, Hachette, Paris, 'I 7, p. 73. 
the vocal cords are activated. The experience of subjects with an artificial larynx has already been cited.

The movement of most of the consonants is more complex than ordinarily assumed. Either by direct action of the vocal cords or by their indirect control, all the consonants are either voiced or unvoiced. In addition to this complication it has long been recognized that the soft palate must be closed for all the consonants except " $m$ " and " $n$." An accurate analysis adds to " $m$ " and " $n$," " $b, d, g$," for each of which the soft palate is momentarily lowered. " $b, d, g$ " are occlusive sonants for which some release of mouth pressure is necessary for flow of air through the vocal cords. ${ }^{1}$ ) The remainder of the consonants are not nasalized. The relation of these movements which change the quality of the consonants is somewhat the relation of the movements of the vowel to the syllable movement. The movements occur together but they do not condition each other though they cooperate in producing the given consonant.

\section{Types of Syllables as Determined by the Consonants.}

In dealing with the function of the accessory consonant stroke in the syllable movement there are four types to consider:

I) A syllable movement arrested by its own negative musclegroup (the inspiratory muscles) may be called the syllable movement with self-arrest. This is the case in uttering " $a, a, .$. " or " $t a, t a, . . "$

2) The syllable movement is arrested by the consonant stroke; this is the syllable with consonant arrest. Thus, "at, at," "tat, tat." Cf. Fig. 2 I p. 245 "up" and "pup".

Many movements are arrested by an obstacle. When the finger of the typist hits the key, the momentum of the movement is taken up by the obstacle, not by the counter action of the negative muscle-group. This very common form may be called balistic movement with arrest by obstacle. Sometimes the obstacle is another member the movement of which puts it in the path of the balistic movement. Thus one claps one's hands; an orator arrests the blow of the right hand in the palm of the left. This is the movement with accessory arrest; it is the type

1) Musenold, A., Akustik und Mechanik des menschlichen Stimmorgane, Springer, Berlin, 'I 3 , p. 5 I 
of syllable movement with consonant arrest. The consonant stroke is the obstacle arresting the chest pulse.

3) The beginning of the balistic movement may be initiated in different ways. Often the chest muscles start the syllable movement themselves; this is the movement with self-release. Thus " $a, a, . . "$ and "at, at.." Cf. Fig. 2 I, p. 245, "up".

4) An accessory consonant stroke may release the chest pulse, Thus, „ta, ta," "tat, tat." In snapping the fingers the movement of one finger releases the movement of the other. When one puffs out a candle, the closed lips suddenly release the air compressed by the muscles of expiration. This is the chest pulse with consonant release. Cf. Fig. 2 I p. 245, "pup".

Elaborate combinations of movements are frequent in complex habits. In the playing of wind instruments accessory movements sometimes release the chest pulse as in the case of "tripletonguing"; the movement is very seldom arrested by an accessory movement; a whistled note is sometimes brought to a close by a consonant stroke resembling the " $t$ " stroke.

In flicking a coin or shooting a marble the finger holds the thumb (or the thumb holds the finger) during a growing tension which is finally released by the accessory movement. In coughing the pressure of the chest compression is finally released in the throat.

The physician's movement of shaking down the mercury in a clinical thermometer involves an arrest produced by the movement of the other hand which intercepts the beat stroke of the hand holding the thermometer; the movement of the left hand is actually substituted for a self-arrest by the muscles of the right hand. It is possible to produce somewhat the same shaking movement with the right hand alone, with self-arrest. A refractory fountain pen is often subjected to the same treatment. In movements of plucking and picking, the thumb and fingers arrest each other's movements in closing on the object.

The negative pressure syllable of puffing a pipe illustrates both accessory arrest and accessory release. The consonant is " $p$. ." The negative pressure produced by closing the lips against the muscles of inspiration is released by the opening of the lips; the movement is arrested by again closing the lips. The negative syllable so formed is not "puff" but pup." It is also possible to terminate this negative pressure syllable with the lips apart, a case of a negative breathing pulse with self-arrest. 
In the ordinary forms of movement with self-arrest, the muscles of the breathing apparatus are connected with each other by an intervening system of bones, cartilages and joints. This is the rule with antagonistic muscle-groups. At first sight it seems difficult to think of the muscles of the tongue or of the lips functioning as the negative muscle-group for the breathing apparatus; the muscles of the tongue and lips are not attached to the chest. How can the lips and tongue act as antagonists to the chest muscles? An examination of the entire speech mechanism shows that the column of compressed air in the chest and vocal canal becomes the intermediary between the expiratory muscles of the chest acting as the positive group and the muscles of the consonant apparatus acting as the negative group. At the end of the syllable, the sudden closure (or constriction) of the vocal canal by the consonant movement stops the escape of air, raises the air-pressure, and thereby arrests the beat stroke and takes up the momentum of the movement. The movement of the consonant apparatus is harnessed to the movement of the breathing apparatus as effectively as the organist's finger is connected with the valve at the pipe in an organ with pneumatic action.

Fig. I6 represents schematically the possibilities of coordination of the articulatory apparatus with the chest movement.

In very rare cases it may be that the chest movement is a continuous, slow, "controlled" movement of expiration, and that the syllable is due to the balistic stroke of the consonant (accompanied on occasion by the movement of the jaw); it is possible that " $a-l a$ " may be so uttered. There is no experimental evidence of such a correlation, and the series of syllables in "Lil' 'll lie low," Fig. 91 , 92 p. 329 and "runnin' ' $n$ ' neir. " $n$ "" Fig. I 24 p. 373 do not show any tendency to maintain continuous chest pressure while the syllable is initiated by the " $n$ " or the " $l$. "If such a coordination occurs, it is to be figured by Fig. I6, $A$.

In some cases the articulatory apparatus is fixated as in Fig. I $6 B$ II, and the syllable is due entirely to the breathing apparatus. This is the case with a series of vowels; cf. Fig. 3 (p. 204).

But in most cases, the chest pulse is released or arrested or both by the movement of the consonant. The scheme $C$ I, II represents a series like "tat, tat tat." For details of such movements compare Fig. I 7 . 
$A$

$$
\begin{aligned}
& \text { Breatting } \\
& \text { movement }
\end{aligned}
$$

Consonantal
movement

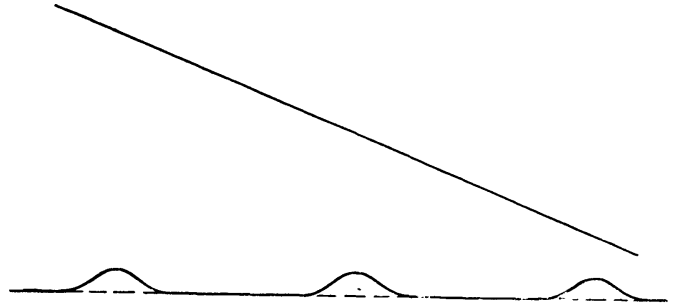

B
J Breathing

$$
\text { movement }
$$

\section{Consonantal} movement

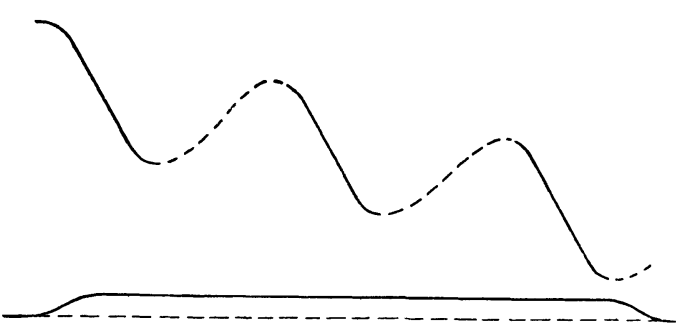

$c$

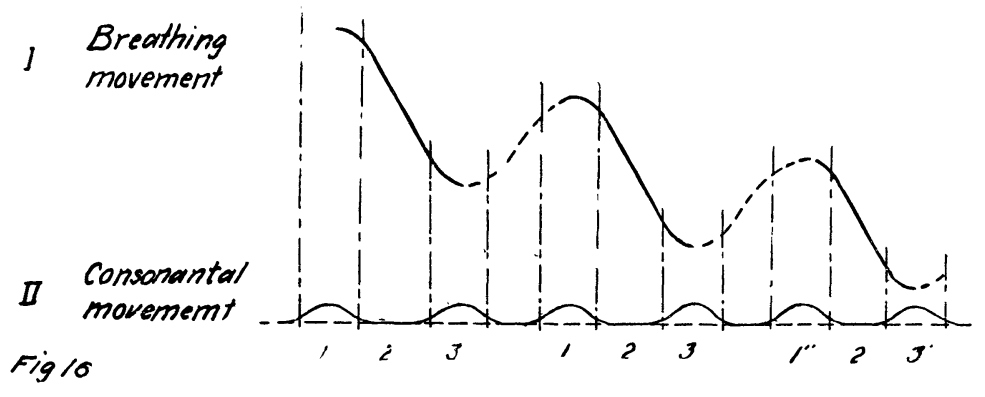

A. I Breathing movement showing a continuous expiratory movement without syllable pulses;

II Consonantal movement showing a series of balistic movements in the articulatory apparatus, " $a-i-a$ " of vowels or " $l$ " stroke of tongue, producing syllables. Very rare, if it occurs.

B. I Breathing movement showing pulses for each syllable.

II Consonantal movement is fixated, as for " $n, n$, $n$ " or for vowel " $a, a, a$ ". Syllable is due entirely to the breathing apparatus.

C. I Breathing movement showing pulses for each syllable.

II Consonantal movement releasing and arresting each chest pulse; "tat, tat, tat." The more common form; any syllable may be selfreleased or self-arrested, e.g. " $a t$ " or " $t a$ ". 


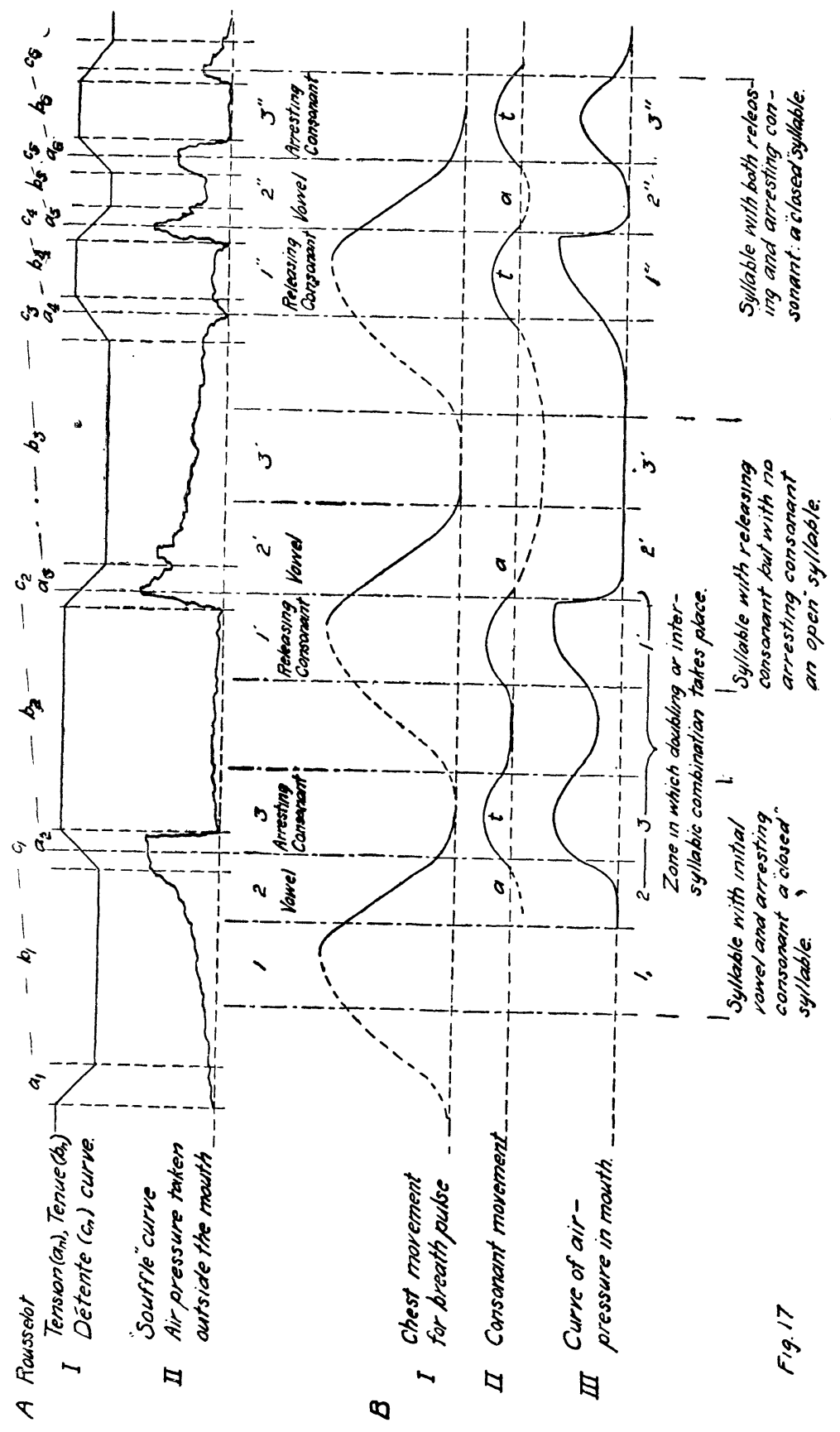




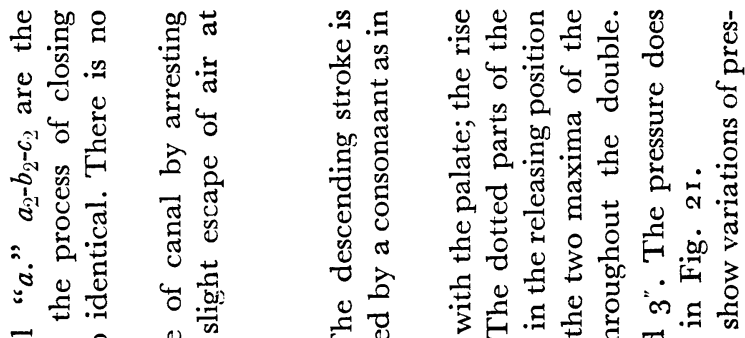

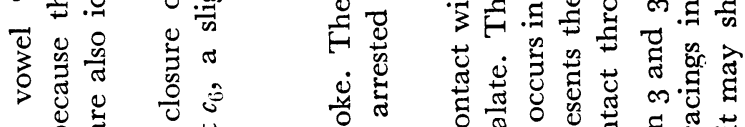

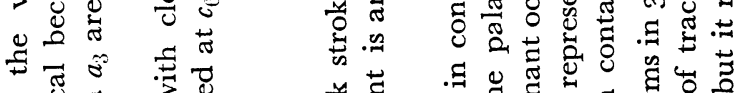

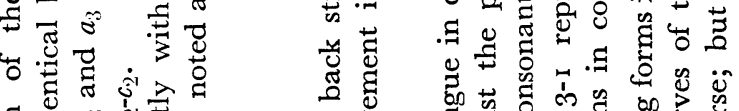

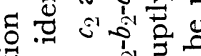

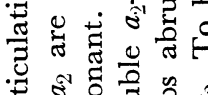

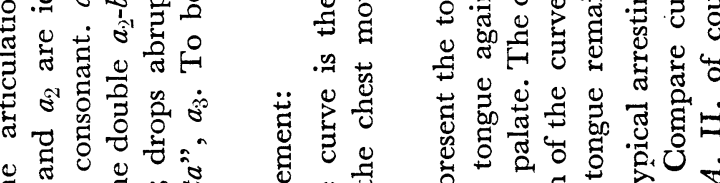

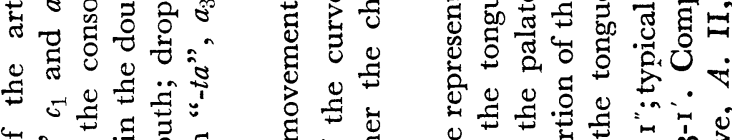

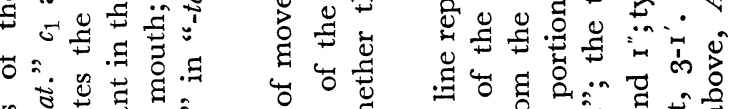

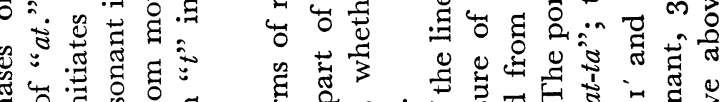

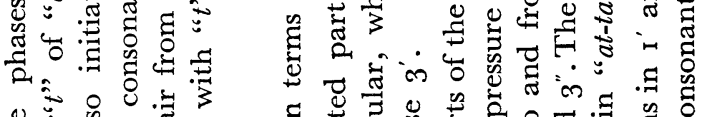

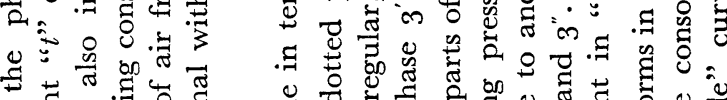

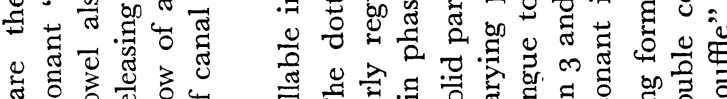

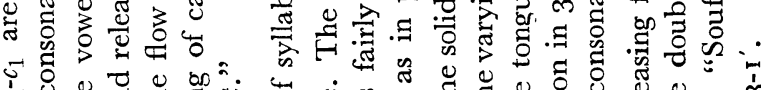

广ठ

它五 bo

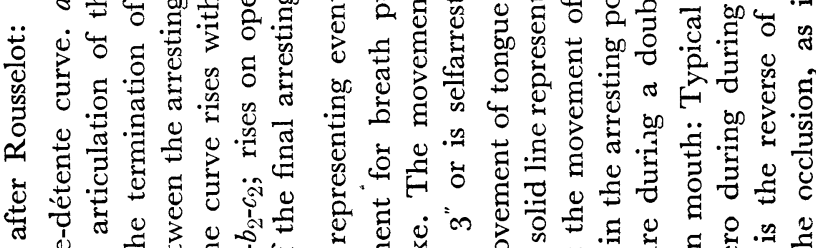

y

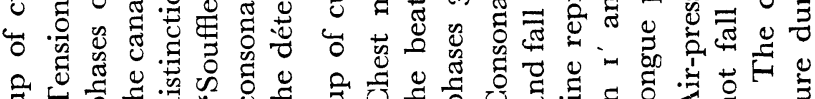

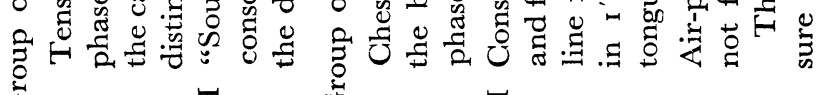

『ं 
Figure I 7 shows the events in a series of syllables "at-ta tat" according to the system. of Rousselot, with a parallel scheme for the analysis of the movements.

In the first curve of Rousselot, Fig. I $7 A$ I, it will be noted that the "détente" phase of one articulation is identical with the "tension" phase of the next $\left(c_{1}\right.$ and $a_{2} ; c_{2}$ and $a_{3}$ etc.) If the syllables "at-ta" had been represented as separated there would have been a complete cycle for the articulation of each " $t$," and the series would have been $a_{1} b_{1} c_{1}$, and $a_{2} b_{2} c_{2}$. If however the syllables had been "at-la" the overlapping of phases would have been more extensive than in the preceding figure, for the "tenue" of the " $t$ " would be identical with that of the " $l$ " and the "tension" of the " $t$ " would serve for the " $l$," and the "détente" of the "l" would serve for the " $t$."

In the second curve of Rousselot, Fig. I7, $A$ II there is shown diagramatically the air pressure just outside the mouth; it falls to zero of course during an occlusion, and rises the moment the vocal canal is opened. The curve is nearly the reverse of the curve of the air pressure in the mouth, given in $B$ III below. It is to be noted that any variations of pressure during an occlusion cannot of course appear in the "Souffle" curve. Cf. Fig. I 25 p. 374 .

Fig. I $7, B$ gives a group of curves representing the events of the syllable in terms of movements. Only the outline of the coordination is given here; the system of movements will be treated more fully later.

In the first syllable "at," there is no releasing consonant; the chest pulse, curve B I is self-released. The descending stroke, B I, I-3 represents the rapid movement of the pulse; in I the sudden contraction of the chest muscles occurs, compressing the chest; during phase 2 the momentum of the chest continues the compression and a stream of air flows freely through the vocal canal; in phase 3 the movement of the consonant (B II 3) closes the canal and blocks the flow of air; the rapid rise in air pressure arrests the chest movement. In this case the consonant movement replaces the contraction of the negative musclegroup of the chest. The actual connection between the chest and the accessory movement of the consonant is effected through the columm of compressed air in the vocal canal.

Between the syllables "at-" and "-ta" (between 3 and I') the chest muscles readjust for a new compression (the back stroke 
represented by the dotted ascending part of the curve I.) The tongue remains in contact but the muscles of the tongue relax in preparation for the releasing stroke of the " $t$ " in "-ta" ( $\mathrm{I}$ " of the next syllable.)

In this second syllable "-ta" the rapid contraction of the chest muscles recurs in $I^{\prime}$, the pressure suddenly rises because of the consonant closure (shown in III I',) but is suddenlyr eleased by the back stroke of the tongue from the palate (II I') and the air flows freely through the canal in $2^{\prime}$ as before. In the phase $3^{\prime}$ the inspiratory muscles of the chest itself contract to stop the momentum of the chest, forming an open syllable "-ta." The syllable movement is self-arrested and the air pressure remains at zero III $3^{\prime}$ because there is no consonant closure.

Between the syllables "-ta" and "tat" (between 3 ' and I") the chest muscles readjust for the new compression (back stroke, dotted line I $3^{\prime}-\mathrm{r}^{\prime \prime}$.)

In the third syllable "tat" the consonant and the syllable movements are coordinated in phase $I^{\prime \prime}$ as in $\mathrm{I}$. Phase 2 " shows the free flow of air with zero pressure in mouth (III 2".) The coordination in phase $3^{\prime \prime}$ is precisely that of 3 , the arresting consonant in "at."

In III 3 and $3^{\prime \prime}$ the maxima of the air pressure are of rounded form when the arresting movement closes the canal; in III I and $\mathrm{I}$ the fall in pressure is abrupt when the releasing consonant opens the canal. Cf. Fig. 34 p. 26 i syl $5^{-7}$.

An actual tracing which will give something of these relations will be found Fig. 125 p. 374 .

Certain Differences in the Syllable as Modified by the Accessory Movements of Release and Arrest.

When the syllable has a consonant release, the length of the syllable movement is not affected; the consonant movement fuses with the syllable movement. The syllable may be very short, a rapid balistic movement with self-arrest, or it may be indefinitely prolonged, changing into a controlled movement. The accessory release does not limit the duration of the syllable.

On the other hand, when the syllable movement has a consonant arrest, the length of the syllable is conditioned; the balistic stroke is arrested by the consonant movement and the 
syllable movement cannot be indefinitely prolonged into a controlled movement; its maximum length therefore is that of a balistic movement, .I3 sec. at the most. ${ }^{1}$ ) The arresting consonant may be prolonged, or a pause may occur after the syllable, but the syllable beat stroke is of necessity brief. This means that the vowel of the syllable with arresting consonant will always be a brief vowel.

Thus the records of "closed" syllables (syllables with arresting consonants) show a short duration of the vowel: patte, .I 6 sec. (including the " $p$ "); patelin, . Iо sec. ("pa-"). $\left.{ }^{2}\right)$ Beat, . I4, bid, .I4, bin, .1 0, bit, .o6 sec. $\left.{ }^{3}\right)$ These may be compared with pa, .24, pâte, .28 (pâ-), bee, .50, bonjour, .68 sec, (bon-), in all of which the syllable is "open". E. W. Saripture quotes GRÉGOIRE's observation that for some reason in pâte sucrèe the " $t-s$ " shortens the vowel and lengthens the occlusion. ${ }^{4}$ ) The " $t$ " has become an arresting consonant, and the syllable "pât" is now closed, therefore the vowel shortens; the position of the tongue against the palate is maintained from " $t$ " to " $s$ " and the back-stroke phase of the first syllable occurs during that interval, therefore the occlusion is lengthened.

The German and especially the English have a large number of syllables which are closed with consonant arrest. The whole series of "short" English vowels belong in this category. Although the term is used to indicate their quality, they are actually short in duration, and it is a matter of common knowledge that such syllables cannot be prolonged without destroying the quality of the vowel; they are essentially brief syllables.

In the Semitic languages the closing of the syllable is especially important, and its influence on the length of syllable and therefore on the nature of the vowel is well recognized. The doubling of the consonant is important and is carefully provided for in the pointing of the Hebrew because of its influence on the syllable.

As can be inferred from Sievers' discussion, not all syllables

1) A group of 40 cases studied, 3 subjects, gives a maximum of .1 3 and a minimum of $.05 \mathrm{sec}$.

2) Rousselot, Précis, p. 86.

3) D. Jones, Analysis of the Mechanisms of Speech, Nature, 99, 'I 7 , p. $285^{-287}$.

4) Exptal Phon. p. 496 . 
which end in a consonant are actually closed syllables. If the vowel is long in duration, the arrest of the syllable movement and possibly the change to a controlled movement will be well under way before the consonant is uttered. In such cases the consonant occurs with the latter part of the syllable movement but is not an integral part of it. Such consonants are often noticeable in singing where the prolongation of the vowel leaves the consonant dangling; often the consonant is given as an explosive and really constitutes an inconspicuous added syllable. Cf. Fig. 74 p. 306 syl 2.

The tradition in English orthography which makes a spelling like "mate" and "hate" indicate a "long $a$ " while "mat" and "hat" indicate a "short $a$ " harks back to the days when the " $e$ " was the sign of a second syllable, and the first syllable was therefore open: ma-te, ha-te, while "mat" and "hat" were closed syllables.

V. Abutting Consonants, Including Double Consonants. Function of Consonants in the Linkage of Syllables.

The tension-tenue-détente analysis of Rousselot led him to group the arresting (terminal) consonant of one syllable with the releasing (initial) consonant of the next syllable; these were made to constitute a single "group." On occasion the distinction between the two constituents was noted:

"If $\mathrm{t}$ e two consonants are attached (s'appuyer) to a single vowel, as in 'psaume, p'tit, apt,' their union is closer than it is if they are attached (s'appuyer) to two different vowels, as in 'ap-titude."' 1 )

If the group confined to a single syllable is called a "compound" or "multiple" consonant, the abutting consonants of two syllables may be called an intersyllabic pair. In case of abutting consonants it often happens that the arresting consonant of the first syllable and the releasing consonant of the next syllable are the same consonant repeated; this is the familiar "double consonant." It is of especial interest because the syllable division must take place during this double consonant. The

1) Précis, p. $8 \mathrm{r}$.

ARGHIVES DE PHYSIOLOGIE, TOME XIII. 
process. which divides the syllable also makes the consonant "double."

Sievers notes that the double consonant is different from a single consonant prolonged; he points out that when implosionexplosion occurs within such a double consonant, there is a "discontinuity of expiration" and that the syllable division takes place between the doublets. ${ }^{1}$ )

F. Josselyn, using Rousselot's methods for the study of Italian phonetics, discusses the peculiarities of the Italian double consonant, showing the increased length of the occlusion and the compensatory shortening of the preceding vowel; it is evident that the double consonant is very unlike the single consonant in duration and in function. ${ }^{2}$ )

But Rousselot's analysis failed to differentiate the double from the single consonant. He states:

"The initial and final consonants can produce only a single impression. That is the case also with a consonant between vowels pronounced without effort. But if the utterance of the consonant in this position has a certain force and an unusual duration, two consonants are heard, that of taking position (tension) and that of quitting position (détente.) The length of the silence which separates the 'tension' from the 'détente' allows the ear to recognize the characteristic sounds which accompany first the closing, and second the opening of the vocal canal." 3 )

This is Rousselot's conslusion in spite of the work of PoIrot which he cites. Porrot showed that both the pressure of the lips, and the pressure of the air behind the lips have two definite maxima in the case of the double labials " $a p-p a$ " and " $a b-b a$. ." $)$.

RousSELOT publishes a tracing of the Swedish " $p a p-p a$ " with a distinct depression in the middle of the $p-p$, and points out the " $p$ implosive" and the " $p$ explosive." 5 )

1) Grundzüge, p. I91.

2) Etudes expérimentales de la Phonétique italienne, La Parole, I I, 'or, p. $227 \mathrm{f}$.

Cf. Rousselot, Précis, p. 78 as to the shortening of the first vowel in $a b-b a$.

3) Principes I, 349; II, p. 993 "A consonant! prolonged becomes double." Précis p. 50 .

4) Cited by Rousselot, Principes II, p. I087: „Quantité et Accent Dynamique," Mémoirs de le société néo-philologique à Helsingfors, IV, p. 365-396; Contributions a l'étude de l'e muet, ibid. III, p. $540 \mathrm{f}$.

5) Précis Fig. 68, p. 77. 
He also publishes such tracings for the labial " $v$ " but is certain that the other double consonants show no such maxima. ${ }^{1}$ )

RousSELOT's statement that a consonant between vowels if prolonged becomes double is not adequate. The doubling depends on the ocurrence of a second consonant stroke with a new chest pulse. In the phrase "I'm Ike," the " $m$ " may be indefinitely prolonged without becoming double; in the case of "I' $m$ Mike" the second consonant stroke and the entrance of the new chest pulse with this second " $m$ " can be perceived. Neither Sievers nor Rousselot explain the greatly increased length of the double consonant or its influence on the preceding vowel.

Only a few English and French words contain true double consonants, but in many phrases the consonant is doubled. In English, "up puppy; lob Bobby; topic and top pick; top egg and top peg; Otto ought to; hit him, hit Tim; I do, I'd do; this eye and this sigh; Z is Z; unknown; un-own; I owe none, I own none; I'm Ike, I'm Mike; I lie, I'll lie" are phrases in which the contrast between the double and single consonant is marked. In most cases the meaning depends on making the distinction. A careful English enunciation can distinguish between "whole ode, hoe load," and "whole load"; between "thus E, the C, Thus C."

If records give proper details, one should expect to find two distinct consonant strokes which arrest and release the separate chest pulses of the two syllables; and there will be two distinct maxima of the air pressure in the mouth, as the first chest pulse is arrested and as the second chest pulse is released. This should be the form of the typical tracings of doubling consonants. Cf Fig. I 7, (p. 234).

\section{Tracings of double Consonants [special form of abutting pairs.]}

The tracings of the various words and phrases containing doubled labials and doubled linguals show without question that the "double" consonant is actually two consonants; there are two distinct maxima in the curve indicating the movements of the lips or of the tongue.

And the curve of the air pressure in the mouth also shows the ending of the one chest pulse and the beginning of the

1) Principes, I, 351, av-va, Fig. I50-I 54 inclusive; II, I087. 
R. H. STETSON.

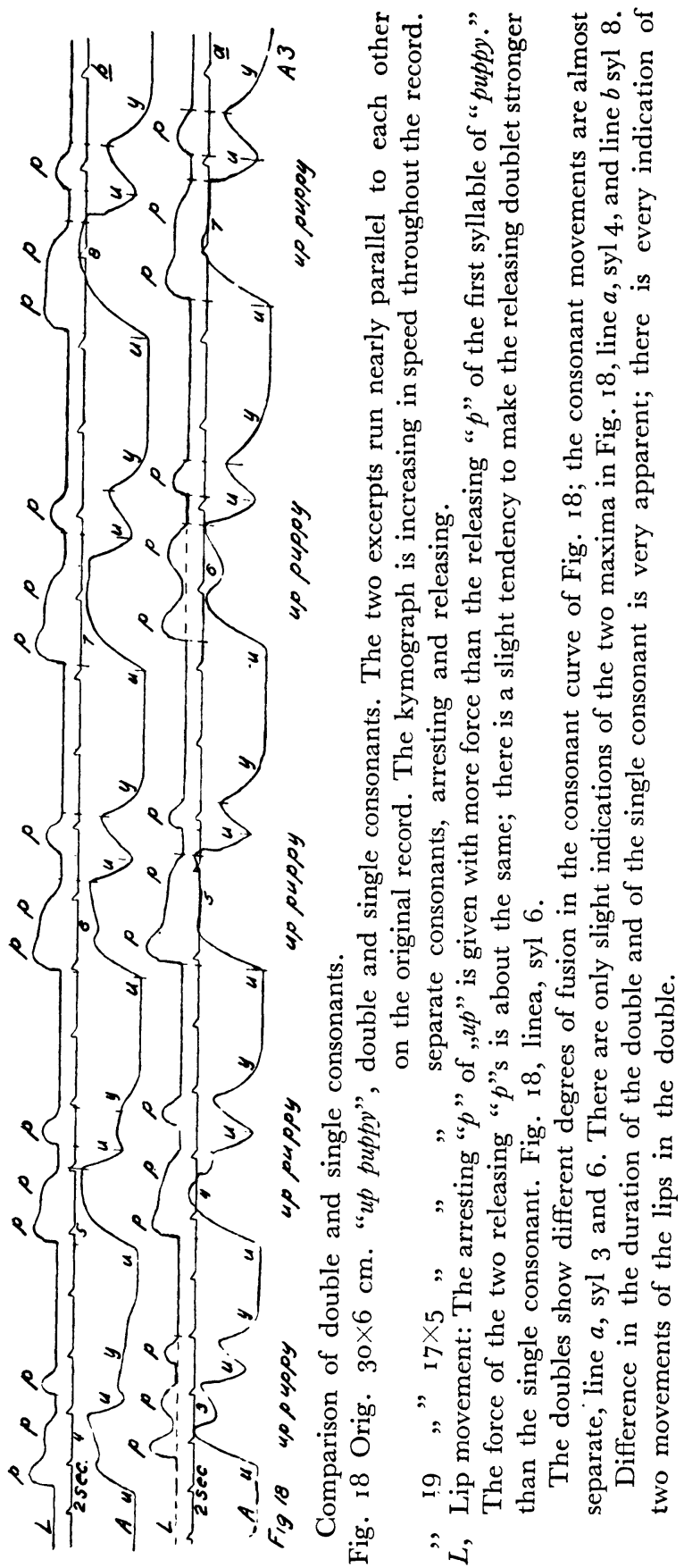


MOTOR PHONETICS.

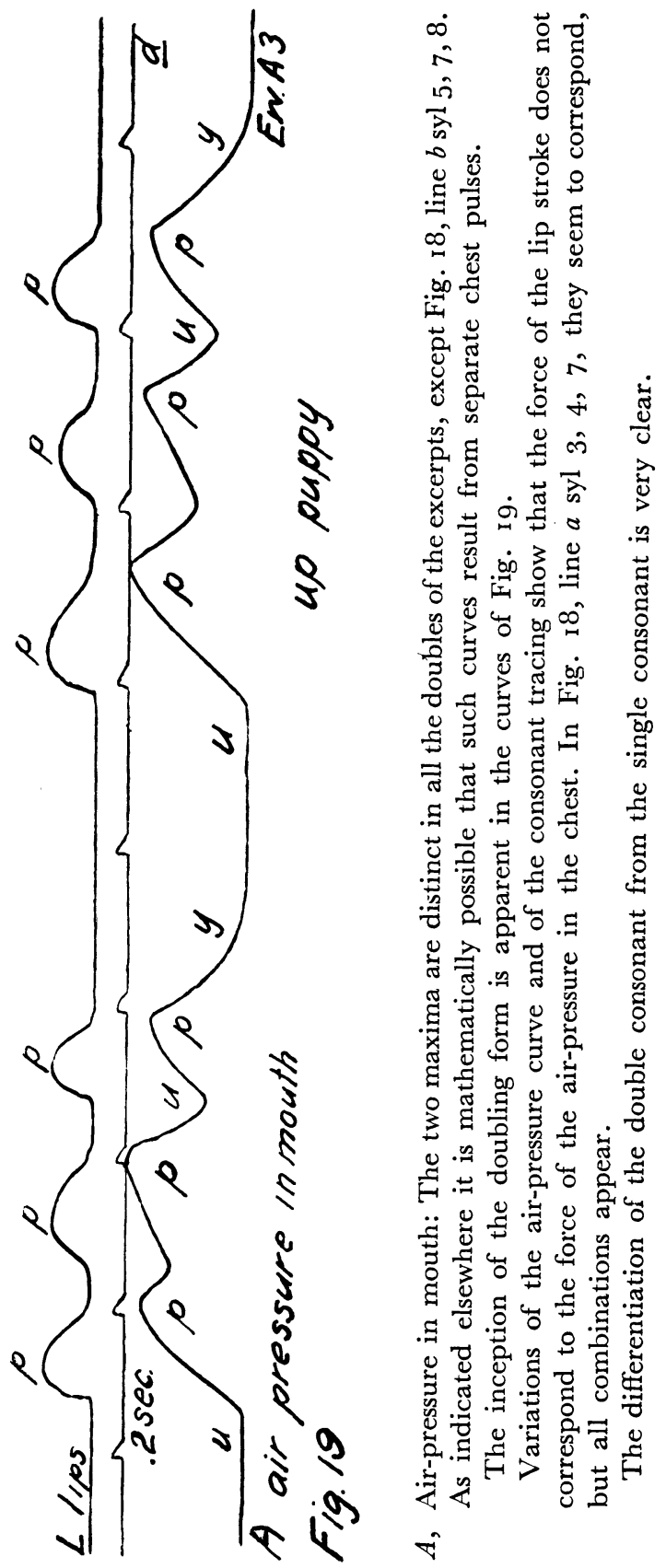




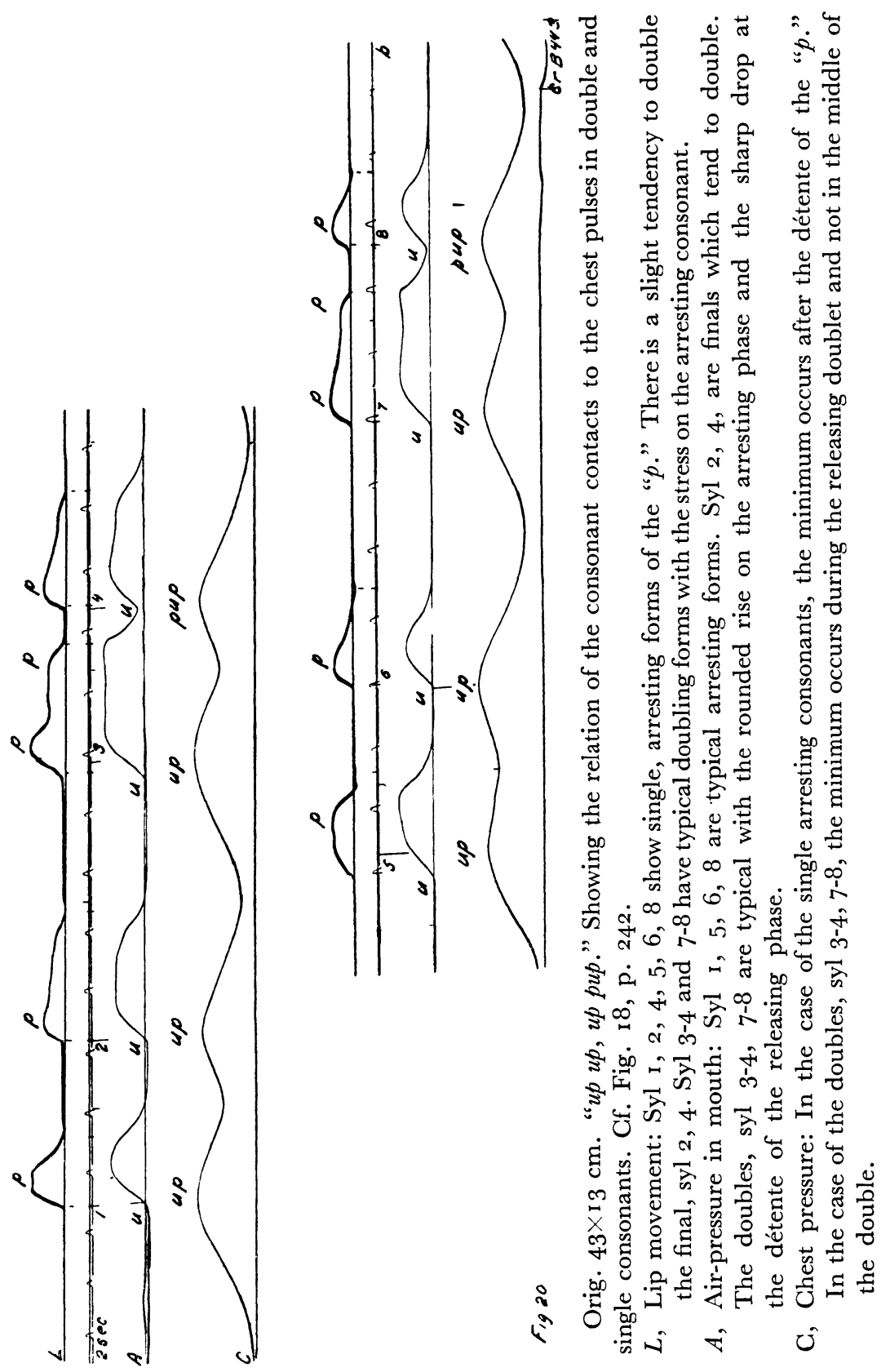




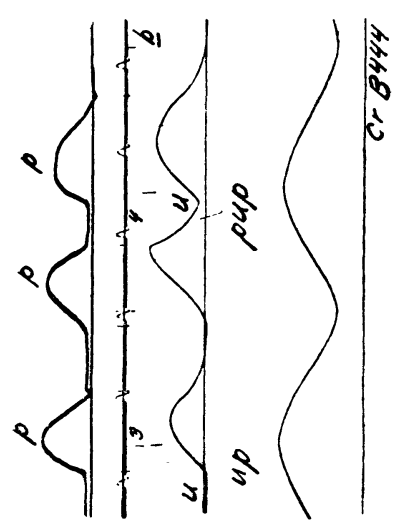

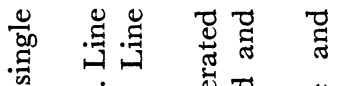

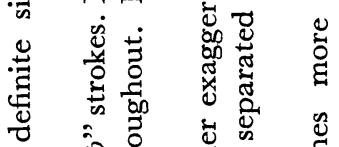

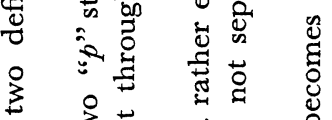

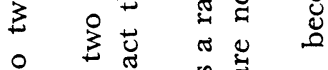

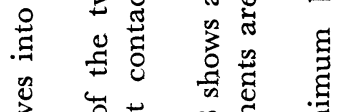

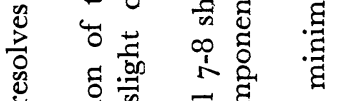

党

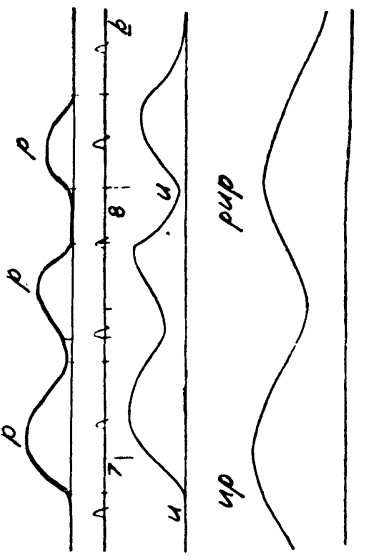

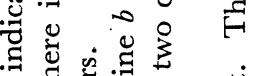

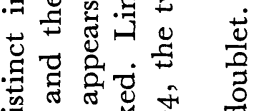

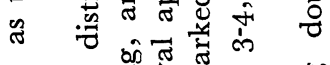

总

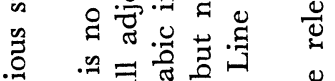

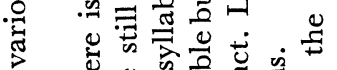

‡ ङ

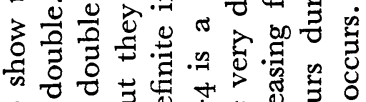

의

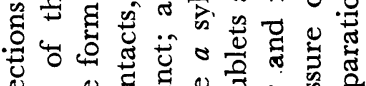

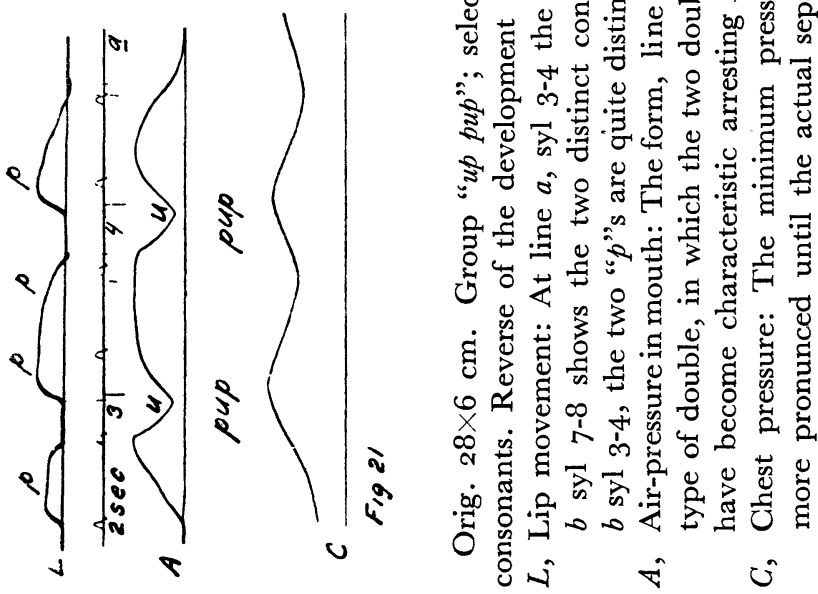


second; the pressure curve at the "double" consonant is a bimaximal curve, showing the arrest of the one pulse and the back stroke of the chest, before the increasing pressure for the release of the second pulse.

The division of the syllable is to be seen in the two maxima of the double articulation, also in the two maxima of the pressure curve in the mouth, which mark the arrest of the one chest pulse and the release of the second chest pulse and of the definite maxima and minima of the chest pressure in the records which show it.

Fig. I 8 shows the tracings of the phrase "up puppy" in which

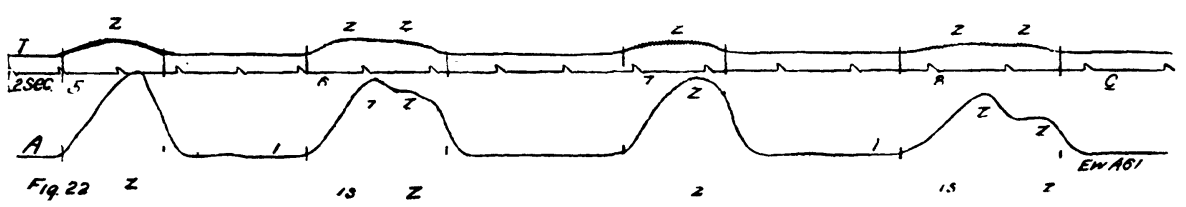

Orig. $23 \times 4 \mathrm{~cm}$. Phrase " $Z$ is $Z$ " showing single " $z$ " and double " $z-z$."

$A$, air pressure in mouth: Forms are rather rounded in contrast with the sharper releasing curves of the occlusives. In Syllables 6 and 8 the arresting consonant is stronger than the releasing. This is true throughout the series of records of which this is an excerpt.

$T$, tongue movement: The two maxima are apparent though not as clearly defined as in the case of occlusives. The vibration of the voiced consonant is clearly seen in the original; if the tongue- piece is sensitive enough to respond to the varying pressures of the tongue it is apt to pick up the stronger vibrations.

A continuitive is much harder to record than an occlusive; the consonant contact is never complete, of course, and the two strokes of the tongue are not so apparent, and the air-pressure curve lacks the definition of the occlusive curve.

the first " $p$ " is doubled, but the second " $p$ " in spite of its orthography is not doubled. In Fig. I9 the words are spoken slowly and distinctly so that the doubling does not show in the consonant curves, for the consonants are separate; the doubling does show however in the air-pressure curve. In Fig. I 8 the pronunciation is fluent enough to produce the complete double consonant; both the consonant curve and the air-pressure curve show the two maxima; it is apparent that the pressure of the lips is greater for the arresting consonant.

Fig. 22 gives the tracing of a continuitive, double and single, " $Z$ is $Z$." The two maxima of the consonant curve are not so well defined as in an occlusive but they are evident. The air- 
MOTOR PHONETICS.

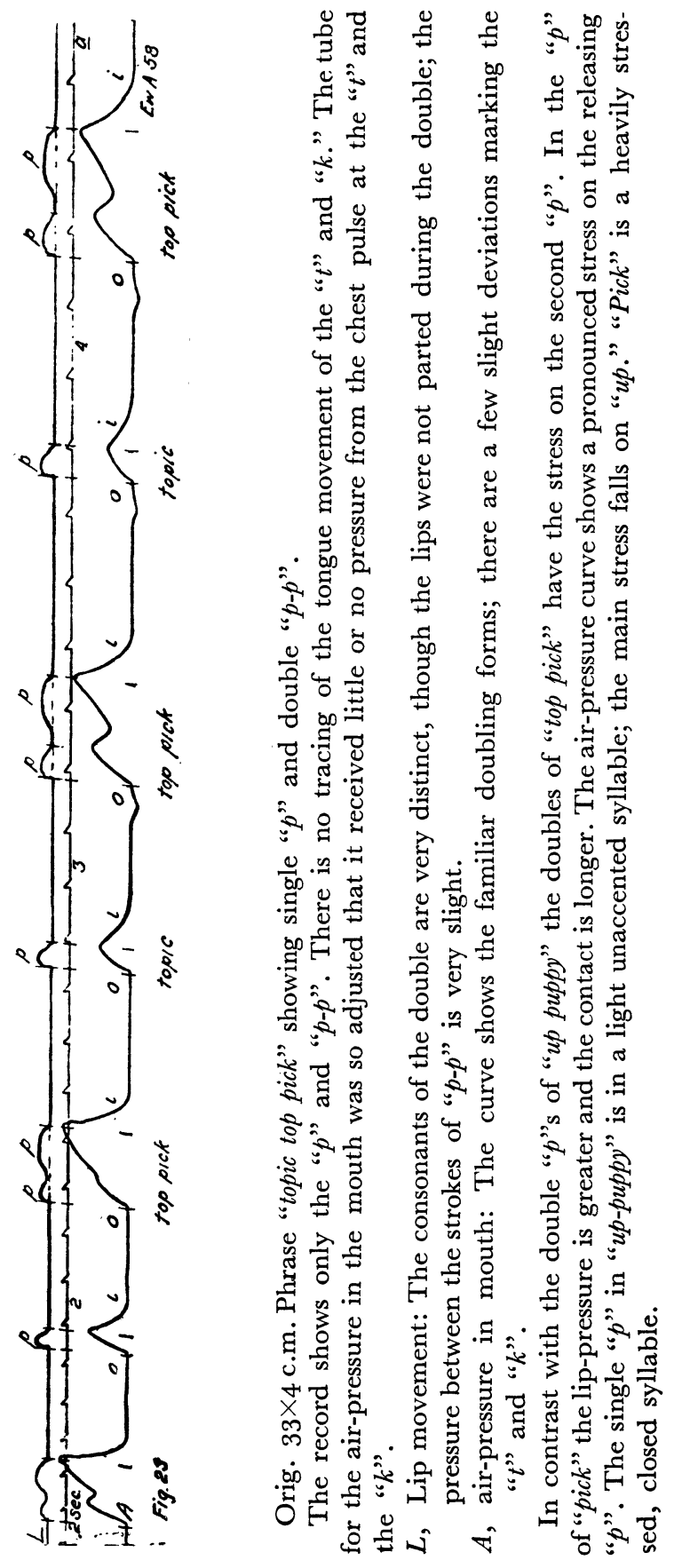




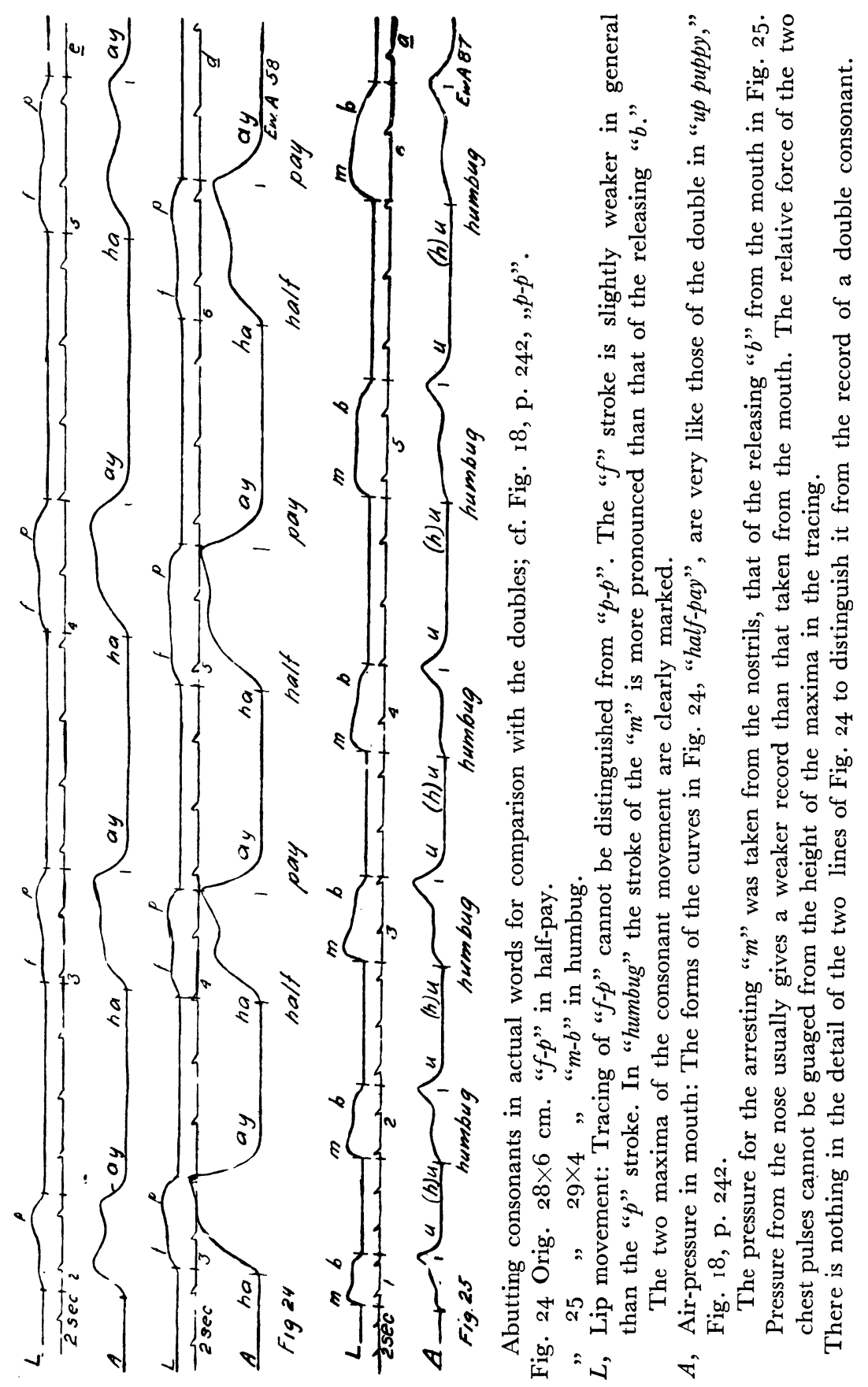


pressure curve for the double shows the stress on the arresting consonant of the double.

Fig. 23, "topic "and" top pick," shows a sharp contrast between the single consonant and the double. The air-pressure curve has the ordinary doubling form, but the maxima of the " $p$ "s in the double are separated although the lips do not part.

Fig. 24, "half pay", shows a form precisely like the doubles preceding; the abutting consonants in this case are two different labials. Fig. 25, "humbug", has curves of similar form; the abutting consonants are a nasal and an occlusive. When Fig. 18 and 23 are compared with Fig. 24 and 25, it is plain that the two consonants of the "double" function precisely as do the two abutting consonants.

Table I gives summaries of the actual measurements of tracings of the various phrases recorded to show the contrast between the double and the single consonant. The attention of the subject was not called however to the fact that the same consonant appeared as single and as double in each word or phrase; instead he was asked to say the phrase so that the meaning would be clear; he chose his own rate of utterance. In most cases the two maxima show in the curve of the consonant and also in the curve of the air-pressure. It is difficult to record the air-pressure in the case of the "l" and nearly all the records are defective.

The difference in length between the single and the double consonant is pronounced, except in the case of the " $n$." The word chosen, "unknown," was not fortunate, as the single consonant occurs in the final position where there is a tendency to prolong the nasal consonant. Many of the recorded lengths of the single " $n$ " are greatly in excess of the average value of the consonant as given by Rousselot, e.g., and as shown in other records. "Unknown "and" un-own" give comparable forms, but were used with only one subject.

It is to be noted that liquids and nasals like " $l, n, m$," and fricatives, like $s / z$ give the same type of doubles as do the occlusives $t / d$ and $p / b$. Compare Rousselot's records for $v-v$ previously

The subject $S$. sometimes substitutes a prolonged releasing consonant in the second syllable for a double. (Cf. Fig. 27,6) It is probable that the series "Otto ought to," $A_{47} d$, and "Topic, top pick," $A 6_{4} b, d, e$ are of this type, but they have been included. (Cf. Fig. 3I and 32.) 


\begin{tabular}{|c|c|c|c|c|c|c|c|}
\hline Subject & Phrase & & $\begin{array}{c}\text { No. of } \\
\text { phrases } \\
\text { meas. d }\end{array}$ & $\begin{array}{l}\text { Extremes } \\
\text { of length } \\
\text { single } \\
\text { conson s. }\end{array}$ & $\begin{array}{l}\text { Extremes } \\
\text { of length } \\
\text { double } \\
\text { conson. s }\end{array}$ & $\begin{array}{l}\text { Air-pres. } \\
\text { curves of } \\
\text { double }\end{array}$ & $\begin{array}{l}\text { Conson. } \\
\text { curves of } \\
\text { double }\end{array}$ \\
\hline \multirow[t]{7}{*}{ C. } & Otto ought to & $A 43 e$ & 5 & $.06-.13$ & $.23-.33$ & $0 m r$ & om \\
\hline & & $42 d$ & 9 & $.12-.19$ & & $\begin{array}{ll}b m & b m r \\
h m l & \end{array}$ & $b m r(a f)$ \\
\hline & & $\begin{array}{ll}42 & e \\
38 & d\end{array}$ & $\begin{array}{l}4 \\
6\end{array}$ & $\begin{array}{l}.12-.14 \\
.10-.13\end{array}$ & $\begin{array}{l}.3 \mathrm{I}-.38 \\
.25-45\end{array}$ & $\mid \begin{array}{l}b m l \\
b m c c\end{array}$ & $\mid \begin{array}{l}a f(b m) \\
b m a(a)\end{array}$ \\
\hline & & $38 e$ & 5 & $.1 \mathrm{I}-.20$ & $.27-.40$ & & $b m a(a)$ \\
\hline & & $39 b$ & 7 & $.08-.10$ & $.24-.33$ & $b m c c$ & $b m(a)$ \\
\hline & & $39 c$ & 8 & $.09-.13$ & $.24^{-.47}$ & $c c(b m)$ & $b m, b m l)$ \\
\hline & & $70 f$ & I I & $.08-.12$ & $.19-.34$ & $b m r, b m$ & af (bmaf) \\
\hline \multirow[t]{4}{*}{$E$. } & & $53 a$ & 5 & $.12-.16$ & $\cdot 33-45$ & & bmal \\
\hline & & $\begin{array}{l}530 \\
53 c\end{array}$ & $\begin{array}{l}5 \\
5\end{array}$ & $\begin{array}{l}.18-.22 \\
.16-.18\end{array}$ & $\begin{array}{l}.34^{-} \cdot 4^{0} \\
.33^{-} \cdot 39\end{array}$ & bma & $\begin{array}{l}\text { Oma,bmal } \\
\text { bmaf }\end{array}$ \\
\hline & & $53 d$ & 4 & $.12-.17$ & $.25^{-.31}$ & $a i, c c i$ & $b m a$ \\
\hline & & $53 e$ & 4 & $.14-.18$ & $.23-.32$ & $a(b m)$ & $b m a(a f)$ \\
\hline \multirow[t]{4}{*}{$S$. } & & $47 d$ & I I & $.06-.12$ & $.17-\cdot 34$ & $i c c$ & $a i, a$ \\
\hline & & $47 e$ & 5 & $.07-. \mathrm{I} I$ & $.18-.22$ & acc & $a$ \\
\hline & & $40 c$ & 6 & $.06-.08$ & $.16-.20$ & $a b m(a l)$ & $a$ \\
\hline & & $\begin{array}{lll}40 & d\end{array}$ & 5 & $.10-.18$ & $.18-.23$ & $a b m$ & $a$ \\
\hline \multirow[t]{2}{*}{ C. } & Hit him, hit Tim & $\begin{array}{ll}40 & \mathrm{e} \\
4 \mathrm{I} & a\end{array}$ & 5 & $.14-.16$ & $.20-.24$ & $a b m, b m$ & \\
\hline & & $\begin{array}{ll}4 \mathrm{I} & a \\
4 \mathrm{I} & c\end{array}$ & $\begin{array}{l}5 \\
6\end{array}$ & $\begin{array}{l}.07-.10 \\
.06-.11\end{array}$ & $\begin{array}{l}.19^{-.28} \\
.22-.28\end{array}$ & $\begin{array}{l}b m r, b m \\
b m(b m c c)\end{array}$ & $\begin{array}{l}a f(b m a f) \\
b m l(a f)\end{array}$ \\
\hline \multirow[t]{2}{*}{$S}$. & $I$ do, I'd do & $40 \quad a$ & 3 & $.12-.17$ & $.2 \mathrm{I}-.28$ & $b m$ & $b m$ \\
\hline & & $40 \quad b$ & 3 & $.13-.20$ & $.28-.32$ & $b m$ & $b m$ \\
\hline \multirow[t]{5}{*}{$C$. } & I'm Ike, I'm Mike & $\begin{array}{ll}7 \mathrm{I} & d \\
68 & 0\end{array}$ & 3 & $\cdot 32-.50$ & $.45^{--48}$ & $\begin{array}{l}b m \\
b m\end{array}$ & bma (af) \\
\hline & & $\begin{array}{ll}08 & a \\
69 & a\end{array}$ & $\begin{array}{l}5 \\
6\end{array}$ & $\begin{array}{l}.08-.14 \\
.10-.13\end{array}$ & $\begin{array}{l}.10-.24 \\
.20-.30\end{array}$ & $b m, b m a$ & $\mid \begin{array}{l}a l, b m l \\
a f l(b m)\end{array}$ \\
\hline & & $69 b$ & 5 & $.10-.15$ & $.22-.26$ & bma & $b m a(a)$ \\
\hline & & $69 c$ & 6 & $.09-.12$ & $.20-.28$ & $b m$ & $a(b m)$ \\
\hline & & $\begin{array}{ll}69 & d \\
60 & e\end{array}$ & $\begin{array}{l}9 \\
8\end{array}$ & $\begin{array}{l}.07-.10 \\
08-.12\end{array}$ & $\begin{array}{r}.16-.21 \\
20-.27\end{array}$ & $\begin{array}{l}b m \\
b m\end{array}$ & $b m a, a$ \\
\hline \multirow[t]{4}{*}{ C. } & Whole ode, whole & $48 e$ & 3 & $.06-.16$ & $\begin{array}{l}.20-.27 \\
.22-.26\end{array}$ & - & $\mid \begin{array}{l}b m a l, a \\
b m\end{array}$ \\
\hline & load & $48 f$ & 3 & $.12-.18$ & $.23-.33$ & - & $b m$ \\
\hline & & $4^{8} \mathrm{~g}$ & 5 & $.08-.10$ & $.12-.20$ & - & $\mathrm{bm}$ \\
\hline & & $\begin{array}{lll}70 & d\end{array}$ & 6 & $.12-.16$ & $.26-.32$ & 一 & $b m$ \\
\hline \multirow[t]{2}{*}{$E$} & & $56 \quad a$ & 3 & $.19-.25$ & $.33^{-.34}$ & 一 & $b m r, a r$ \\
\hline & & $\begin{array}{lll}5 & b\end{array}$ & 2 & $.25^{-.25}$ & $\cdot 3^{2-.34}$ & - & $b m r$ \\
\hline \multirow[t]{3}{*}{$E$. } & I lie, I'll lie & $59 c$ & 3 & $.13-.28$ & $.31-.35$ & - & $b m r$ \\
\hline & & $59 d$ & 4 & $.18-.22$ & $\cdot 3^{2-} \cdot 3^{8}$ & - & $b m r(b m f)$ \\
\hline & & $5.9 e$ & 3 & $.17-.18$ & $.25^{-} \cdot 35$ & - & $b m(a)$ \\
\hline \multirow[t]{2}{*}{$H$. } & & $66 d$ & 5 & $.06-.13$ & $.32-.22$ & 二 & $a l$ \\
\hline & Hello & $\begin{array}{ll}66 & e \\
70 & a\end{array}$ & $\begin{array}{l}6 \\
6\end{array}$ & $.09^{-.13}$ & $.20-.22$ & 二 & bml \\
\hline$C$. & Hetro & $\begin{array}{ll}70 & a \\
70 & b\end{array}$ & 7 & & $\begin{array}{l}.43^{-.61} \\
.35^{-.45}\end{array}$ & - & \\
\hline \multirow[t]{2}{*}{ C. } & Unknown & $70 e$ & 12 & $.10-.18$ & $.30-.39$ & - & $b m(a l)$ \\
\hline & & $70 \mathrm{~g}$ & 3 & $.19-.34 ?$ & $.30-.40$ & - & $b m l, a l$ \\
\hline \multirow[t]{4}{*}{$E$. } & & $54 a$ & 6 & - & $.29-.3^{6}$ & - & $b m, a l$ \\
\hline & & $54 b$ & 5 & $.20-.25$ & $\cdot 32-.39$ & $\overline{-}$ & $b m, b m f$ \\
\hline & & $\begin{array}{ll}52 & a \\
52 & a\end{array}$ & 3 & $\begin{array}{l}.13^{-.21} \\
.17^{-.30}\end{array}$ & $\begin{array}{l}.21-.22 \\
.23-.36\end{array}$ & $\begin{array}{l}b m r, b m f \\
b m, a\end{array}$ & $\begin{array}{l}a \\
a l\end{array}$ \\
\hline & & $\begin{array}{ll}5 & b \\
5 & b\end{array}$ & 6 & $\begin{array}{l}.17-.30 \\
.18-.24\end{array}$ & $\begin{array}{l}.23-.30 \\
.20-.22\end{array}$ & $b m, n$ & $a$ \\
\hline
\end{tabular}




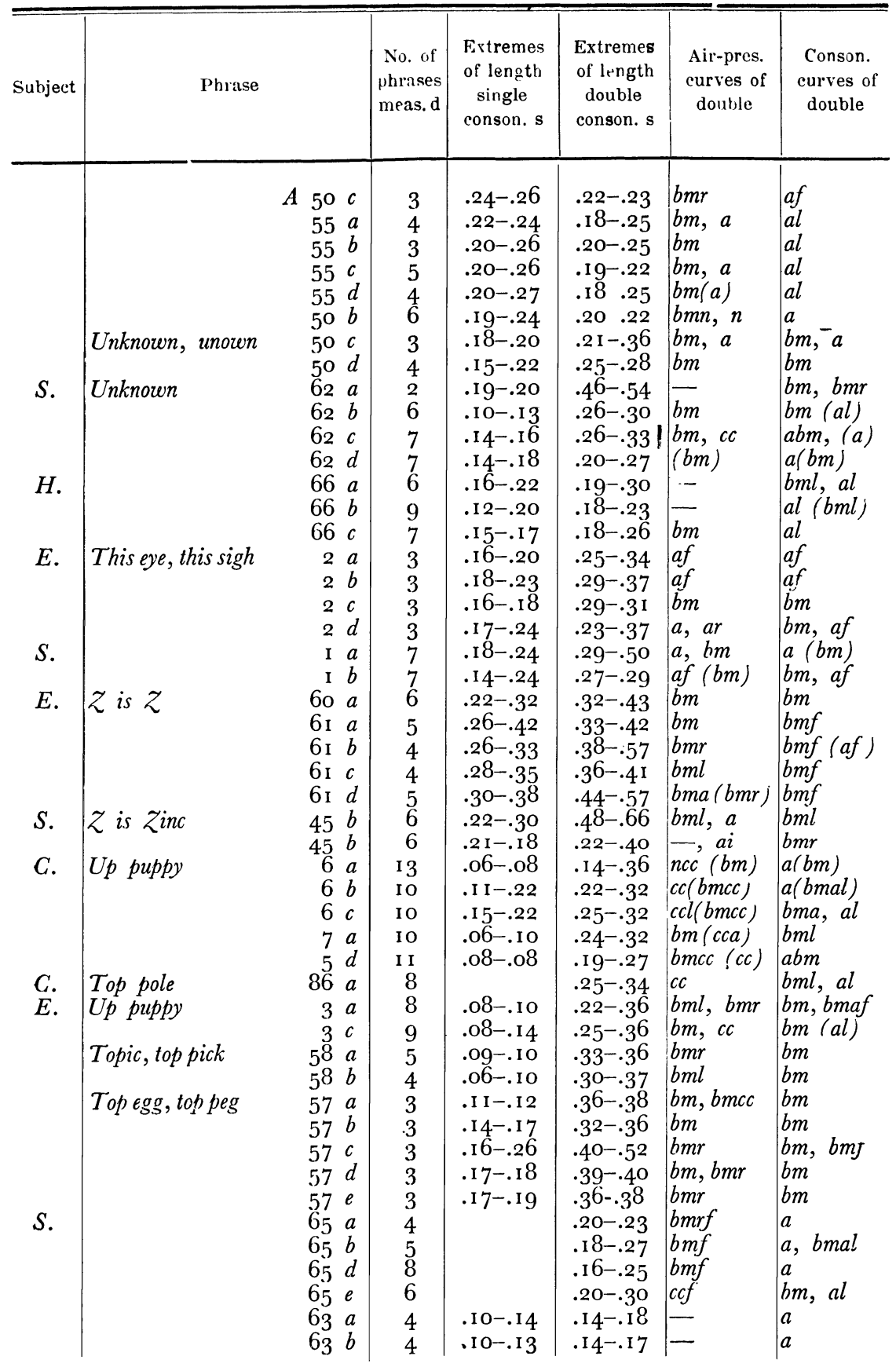




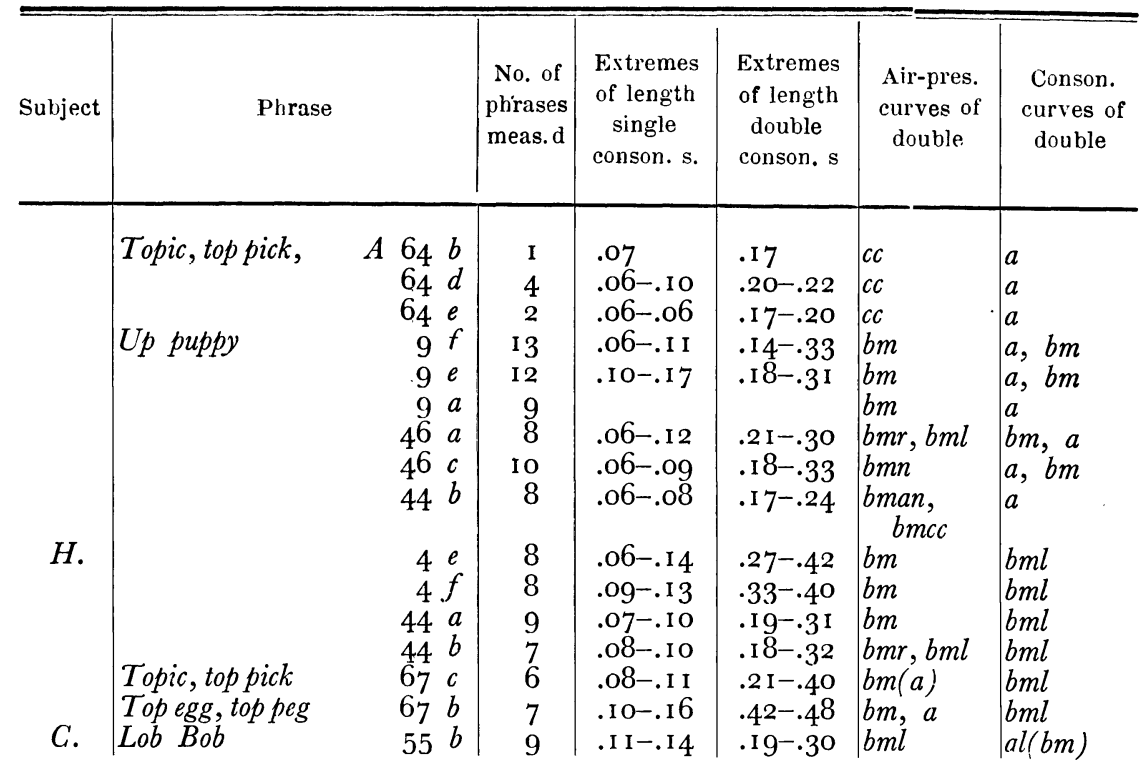

The following abutting consonants, quite like the "doubles," are added for comparison:

\begin{tabular}{|c|c|c|c|c|c|c|c|}
\hline$C$. & Hell no & $70 \mathrm{c}$ & 8 & & & & $b m a(a)$ \\
\hline$E$. & Unlike & $53 c$ & 6 & & $.23-.31$ & $a(b m)$ & bml (a) \\
\hline$H$ & & $\begin{array}{l}53 d \\
66 f f\end{array}$ & 3 & & $\begin{array}{l}.27-.36 \\
.18-.31\end{array}$ &,$-- b m$ & \\
\hline & & $66 \mathrm{~g}$ & 6 & & $.16-30$ & & al \\
\hline$C$. & $\begin{array}{l}\text { Up Bob } \\
\text { Humbug }\end{array}$ & $\begin{array}{r}5 a \\
86 a\end{array}$ & $\begin{array}{r}10 \\
8\end{array}$ & $.11-.16$ & $\begin{array}{l}.22-.32 \\
.19-.29\end{array}$ & & $\begin{array}{l}a, a l \\
a l, b m\end{array}$ \\
\hline$E$. & Half pay & $\begin{array}{l}86 c \\
58 c\end{array}$ & $\begin{array}{l}9 \\
6\end{array}$ & & $\begin{array}{l}.36-.41 \\
.35-.43\end{array}$ & & $\begin{array}{l}b m a r(a) \\
b m r\end{array}$ \\
\hline & & $\begin{array}{ll}58 & d \\
58 & e\end{array}$ & $\begin{array}{l}7 \\
5\end{array}$ & & $\begin{array}{l}.32-.36 \\
.31--3^{2}\end{array}$ & $\begin{array}{l}b m r \\
b m r\end{array}$ & $\begin{array}{l}b m r, b m f \\
b m f\end{array}$ \\
\hline$S$. & Up Bob & $9 c$ & 8 & $.08-.14$ & $.18-.23$ & bml & $a(b m l)$ \\
\hline & & $9 d$ & I I & $.09-.14$ & $.20-.32$ & $b m, b m l$ & \\
\hline & & $46 d$ & IO & $.07-.18$ & $.17-.26$ & $b m r, b m l$ & $a(a b m)$ \\
\hline & & & 12 & $.06-.15$ & $.19-.23$ & $b m$ & $(a b m)$ \\
\hline
\end{tabular}

Key to abbreviations for air- pressure- and consonant- curves:

bm bi-maximal, Fig. 27, 3, 4, both curves.

$f$ flat; affixed to abbreviation for curve form; Fig. 25, air-pres. " $b m f$."

$r$ stress on right doublet; affixed to abbreviation; Fig. 25, air-pres. " $b m r$."

$l$ stress on left doublet; affixed to abbreviation; Fig. 25, conson., " $b m l$ "

a rounded (" arch") Fig. 27, 6 and X, conson. curve; Fig. 25, syl 6, conson., "bmal"

cc "convex-concave," Fig. 27, 5, air-pres. curve; Fig. $18 b$ syl 5, air-pres. "cc"

$i$ pointed, Fig. 27, I, first air-pres. form.

$n$ "inflected curve," Fig. 79.

Abbreviations in $\mathrm{p}:$ renthesis indicate a curve form which appears but once. 


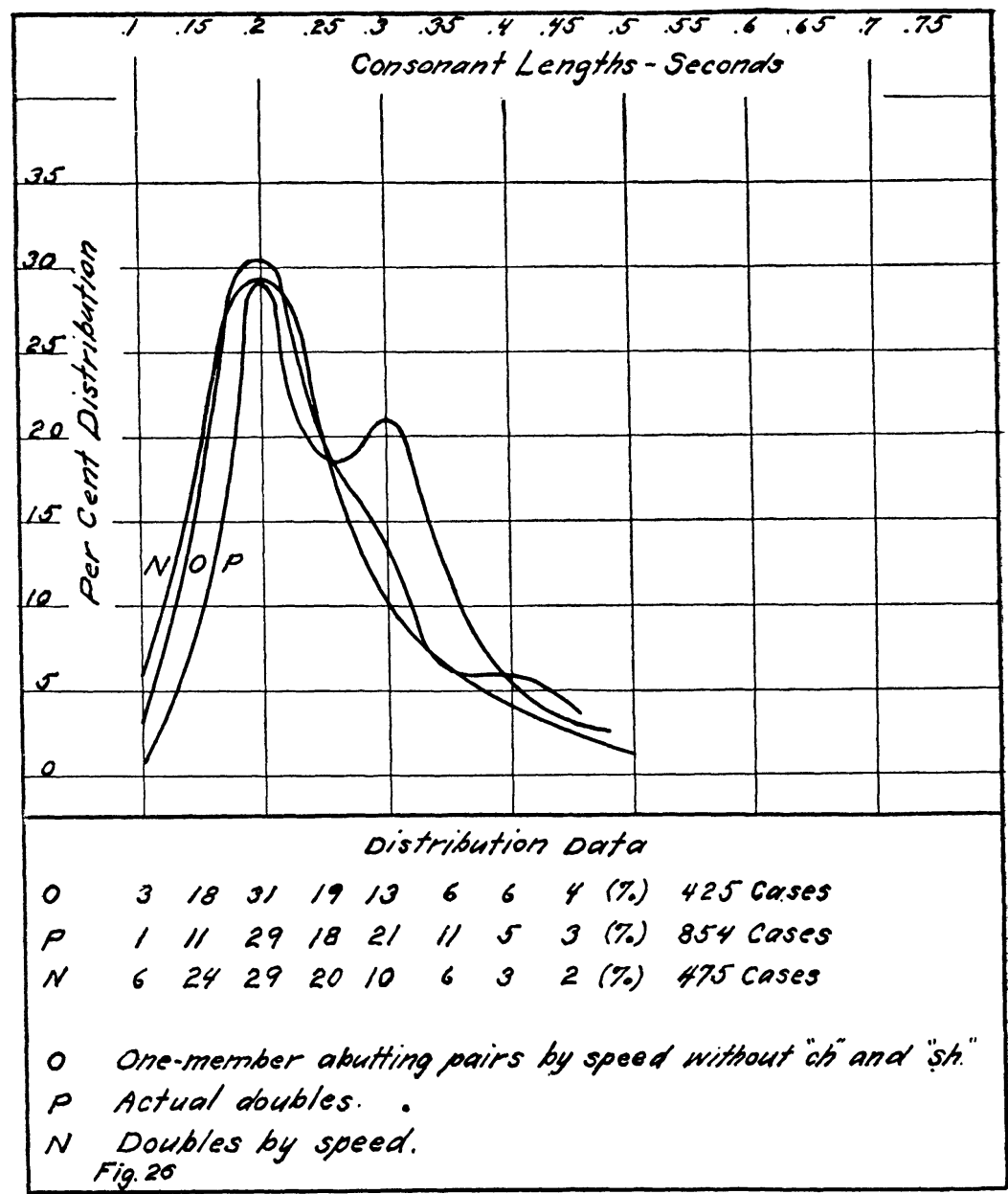

Comparison of the distributions of the lengths of

I) $\mathcal{N}$, doubles produced by increasing the speed

2) $O$, one-member abutting pairs; consonants unlike, but produced by the same member, e.g. "half-pay."

3) $P$, actual doubles, e.g. "up-pup."

The anomalous hump in the curve $P$, actual doubles, is due to a single group of syllables by the subject Ew.

Fig. 26, $P$ gives the distribution of the lengths of these double consonants. The graph shows that some $29 \%$ of all the cases lie between the lengths .2-.24 sec. There are very few indeed whose length is below .I5 sec; the distribution is much more extended 
above the mode $.20-.24$. There is a physiological limit to the speed with which the consonants may be spoken, and as speech always tends toward high speed, the lengths of the consonants cluster toward the lower limit. There is no assignable upper limit to the length of a consonant if a subject chooses to prolong it; the continuitive may obviously continue indefinitely and the occlusion of the other consonants may be held indefinitely.

The distributions are most significant in showing the limits of the doubles. The modes are significant in that they show that there is a single set of causes at work, and that they probably appear in the several similar groups. The modes do not represent constants which it is important to determine. The distribution must be somewhat general; there are variations from subject to subject, dependent on variation in "repetition time."

Single consonants measured in the same way show a distribution much less wide; especially single consonants at high speed. 76 single consonants from Rousselot ${ }^{1}$ ) show a mode below .io sec. (The measurements are not quite comparable but nearly so.) I 90 single consonants taken from the 1924 tracings show a mode at .IO-.I4. On comparing the length of the double consonant with that of the single consonant, it is apparent that the double is about twice the length of the single consonant at high speed. (Only a rough comparison can be made, for the processes measured are not the same; the tracing of the single consonant shows only the phase of contact with the opposing surface, while the tracing of the double consonant gives not only the phases of contact of the two doublets but also the back stroke between the doublets.)

Since the movements of the articulatory organs are rapid balistic movements, the minimum length of the double consonant should be in accord with the time limits of such movements. This means that the component consonants of the double at high speed should occur at the rate of some 8-io consonants per sec., depending on the subject. The subject's maximum rate of uttering consonants will correspond to his "repetition time." This gives .20-.25 sec. as the minimum length of the double consonant including the complete movement of both doublets. As the movement appears in the tracings, e.g. Fig. I 8 (p. 242) it is apparent that the double form includes the beat

1) Précis, p. $96 \mathrm{f}$. 
stroke of the first consonant, the back stroke of the first consonant, and the beat stroke of the second consonant, but not the back stroke of the second consonant. This second back stroke to be added can be estimated. When a series of movements is running at maximum speed the beat stroke and back stroke are equal; cf. Fig. 4 (p. 205.) Therefore the high speed double consists of three equal parts as recorded; the remaining back stroke will be one-third the length of the high speed double. When this third is added to the measurements of the tracings of the double consonants, the lengths agree very well with this theoretical value of .20- $.25 \mathrm{sec}$.

There are a number of exceptions to the typical form of tracing indicated. Of 854 cases studied, I I 7 or $14 \%$ do not show the doubling form in the tracings, either in the mouthpressure curves or in the consonant curves; $4 \mathrm{I} \%$ show the doubling in both mouth-pressure- and consonant- curves; $69 \%$ show the doubling in the mouth-pressure curves.

The tracings of two different abutting consonants made by the same member, like " $f-p$ " in "half-pay," " $m-b$ " in "humbug" show precisely the same curve forms as do the double consonants. But it is evident that the two different movements are managed with more care by the subjects. Of 25I cases studied, I3 or $5 \%$ only, do not show the "doubling."

In some cases the record of the pressure in the mouth is imperfect; in others the classification of the curve forms is uncertain. Only those pressure forms which show two obvious maxima have been classed as "bi-maximal" (bm.) The convexconcave form (cc) may be the result of two chest pulses; indeed many of the records show that it does actually result from such a succession, but it has not been included in the list of "double forms." Cf. Fig. I $8 b$ syl 5, 7, 8 (p. 242) and Fig. 33 syl г 2-1 3. p. $26 \mathrm{I}$.

The double consonant may take one of several forms which are typical also of the various cases of abutting consonants:

I. The consonant strokes are separate but the mouthpressure curve shows a definite doubling. Fig. 27,2; Cf. Fig. I9 (p. 243.)

II. Both the tracing of the consonant and of the mouthpressure show definite doubling. This is the common and one may say the typical form. Any of the.records show such tracings. Fig. 27, 4. 

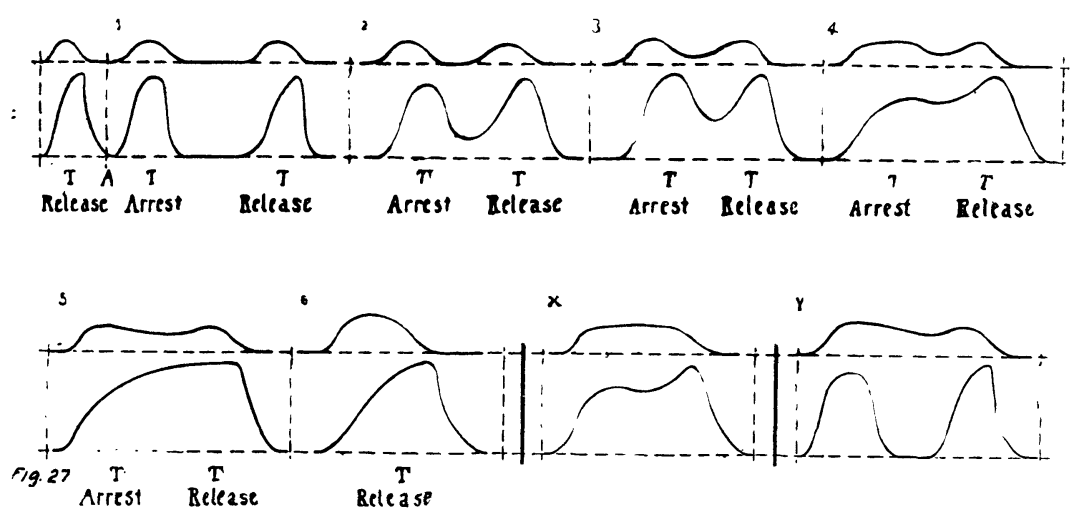

Curve Forms of the Doubling Consonant.

Drawings based on tracings of doubling and abutting consonants.

The series I- 6 shows the usual progress of the forms when "doubling" takes place because of gradual increase in speed of utterance.

I. The second consonant, arresting, of "tat," shows the normal rounded form in the air-pressure curve from mouth for a separate arresting consonant. The following consonant, releasing, shows the normal pointed form in the air-pressure curve for a separate releasing consonant. The proportions of the forms will depend on the speed of the kymograph drum. Cf. Fig. 33 syl 3-4; Fig. 34 syl 6-7.

2. The mouth pressure curve does not fall to zero between the arresting and releasing consonants which mark the end of one syllable and the beginning of the next. The consonant curve shows that the tongue barely remains in contact with the palate between the syllables; the consonant maxima are separate. Cf. Fig. 19; Fig. 33 syl 5-6; Fig. 35 syl 8-9; Fig. 46 line $c$ syl 6-7.

3. The maxima of the mouth pressure curve of the arresting consonant of one syllable with the releasing consonant of the next syllable have fused; it is apparent that the curve is a combination of the curves of $I$ or of 2. The tongue is in contact with the palate throughout the double, but the two maxima of the consonant curve are well defined. Cf. Fig. I 8 line $a$ syl $3 \&$ 6; Fig. 33 syl 6-7; Fig. 46 line $b$ syl 8-9.

4. Shows a more advanced stage of the doubling process. The form of the mouth pressure curve is very common $(b m r)$. Cf. Fig. I8 line $a$ syl 5, line $b$ syl 4, 6; Fig. 33, syl I0-I I; Fig. 34, syl. 8-9, 9-10.

5. Shows the "convex-concave" (cc) form of mouth pressure curve; this is like the form of the curve for a single releasing consonant very much prolonged. It is mathematically possible, also, that it be the combination of curve forms like those of 1 or of 2 , but it has not been classified as "bi-maximal" in this study. Fig. I 8 line $b$ syl 5, 7; Fig. 33 syl 9-10, I 2-I 3 ; Fig. 46 line $b$ 10-I I, etc.

6. Not a double, but a stressed releasing consonant which frequently appears. just after doubling in a series increasing in speed of utterance. Both the form of the curves and the length of the consonant process show that it is single. In Fig. 3 I syl 8. 9, Io such an emphatic releasing consonant has been substituted for a double. Cf. Fig. 32; Fig. 82; Fig. 83 .

$X$. A form in which the "doubling" shows in the air-pressure curve from mouth, but not in the consonant curve. Cf. Fig. 29; Fig. 30.

$r$. A form in which the "doubling" shows clearly in the consonant tracing, but the pulses of the mouth pressure tracing are separate. Fig. 28. 

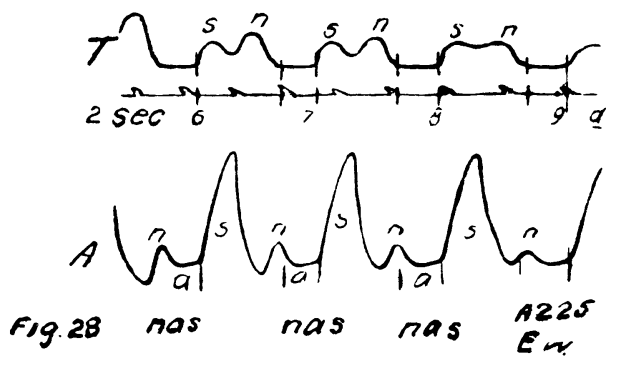

Orig. $6 \times 4 \mathrm{~cm}$. Abutting consonant in which the chest pulses are separate. The syllable "nas" repeated rapidly so that the arresting " $s$ " of one syllable combines with the releasing " $n$ " of the next syllable, "nas-nas-.." Cf. Fig. 27 r.

Air-pressure for the nasal " $n$ " was taken from the nose, therefore the difference when compared with the air-pressure for the " $s$ " taken from the mouth.

T, Tongue movement: Altho the two maxima are sharply marked the tongue remains well in contact between the " $s$ " stroke and the " $n$ " stroke.

$A$, Air-pressure in mouth: The chest pulses for the arresting " $s$ " and the releasing " $n$ " are quite distinct; the pressure falls to zero between the strokes, as compared with Fig. 25 in which the air-pressure curve for a nasal and occlusive is a combined form.

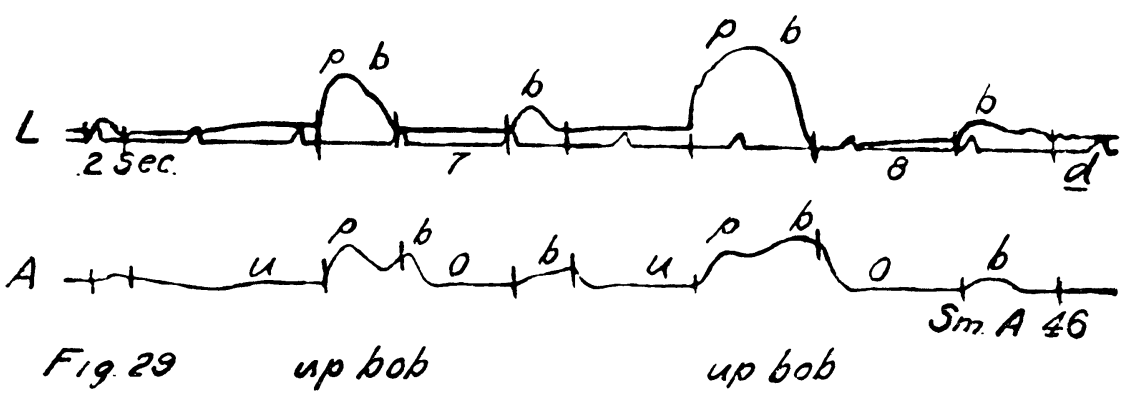

A single lip stroke for two abutting consonants. The "long consonant astride." A very unusual form by the subject Sm., most of whose records of these phrases were normal. To illustrate Fig. $27 X$. p. 256.

Fig. 29 Orig. $12 \times 4 \mathrm{~cm}$. "up Bob." " 30 " $7 \times 3$ " "pup, pup.." series spoken so rapidly that the arresting " $b$ " of one syllable combines with the releasing " $u p$ " of the next syllable. 


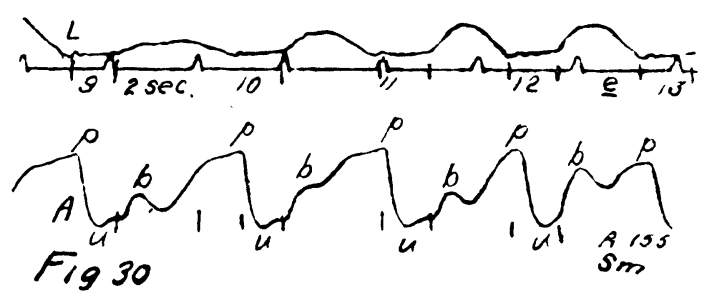

$L$, Lip movement: A single stroke with rather long contact.

$A$, Air-pressure in mouth: The arrest of the one syllable and the release of the next syllable are clearly marked; there is no question that one chest pulse terminates and another begins during the "long consonant astride."

Fig. 30 syl 9-10 and Io-I I show the "inflected" form of the curve of the " $b$." Cf. Fig. 8o.

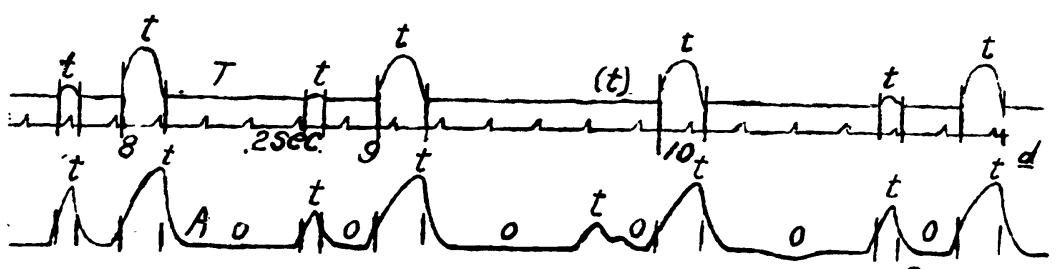

Fig.31 otto oughtto otto ought to

$\operatorname{sm} .447$

A prolonged releasing consonant where a double consonant was prescribed.

An unusual form by the subject $S m$. most of whose records of these phrases are normal.

The peculiarity is evident to the listener.

To illustrate Fig. 27,6 . p. 256 .

Fig. 3 I Orig. $12 \times 4 \mathrm{~cm}$. "Otto ought to" pronounced "Otto ough" to". " 32 " $16 \overline{\times} 4$,", "Topic, top pick" " "Topic, to' pick".

$L, T$, Lip- and tongue-movements: No distinction save in length of contact and stress between the " $t$ "s of Fig. $3 \mathrm{I}$, or between the " $p$ "s of Fig. 32.

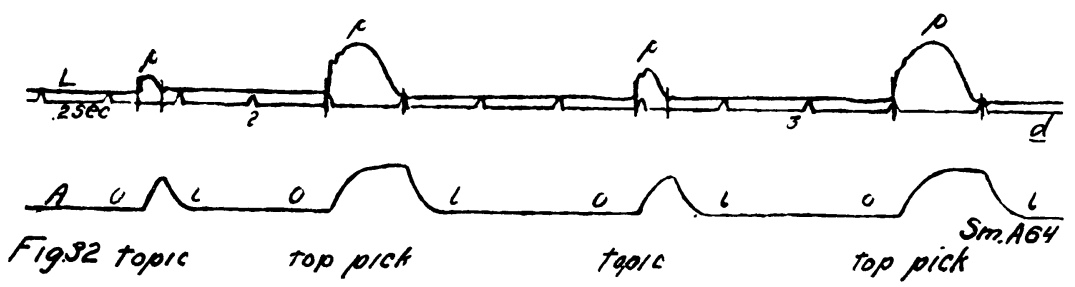

$A \quad$ Air-pressure in mouth: The form of the curve for "ought to" and "top pick" is precisely that of "Otto" and "topic"; the only difference is in length and force. A heavy releasing consonant has been substituted for a double. 
III. The tracing of the consonant is double, but the mouthpressure curves are separate; occurs when the interval between the syllables is rather long, but the subject keeps the lips or tongue in contact between the syllables. Fig. 27 Y; Cf. Fig. 28.

IV. The tracing of the consonant movement shows a single consonant prolonged but the mouth-pressure curve makes it clear that the syllable division occurs; there are two chest pulses. This "long consonant astride" is the form that Rousselot considered typical. In the tracings studied it is very rare, but it does occur with the subject $S$. who is inclined to substitute a single consonant movement for the double; this can easily be detected in his speech. Since the chest pulse may be controlled by the chest muscles alone (as in the syllable composed of a single vowel) it is possible that the shift from pulse to pulse take place while the lips or tongue are in contact. It may be called a pseudo-double. Fig. $27 X$; Cf. Fig. 29 and 30.

V. Not a double at all but a stressed releasing consonant at the beginning of the second syllable. It is listed here because in certain cases to be discussed later, such a stressed releasing consonant comes to take the place of a double in enunciation at high speed. Fig. 27, 6; Cf. Fig. 31 and 32 .

In general all the consonants function in the same fashion as releasing and arresting, doubling and abutting. There are some variations to be considered in the case of the continuitives, especially "s"; these will be discussed later when the various abutting consonants are considered in more detail.

\section{Influence of the Speed of Utterance on Abutting Consonants [including Doubles.]}

In all these cases we have seen the properties of the "double consonant" as it appears in ordinary speech, and the properties of an abutting pair. What leads the two consonants to assume a more or less continuous form? If the two chest pulses are actually present and if the abutting pair has actually the two functions of arresting and releasing the syllable movements, what causes the abutting? It is evident that if the syllables are spoken slowly in a word like "un-known," or in the phrase "up puppy," the consonants are separate. The speed of utterance is the thing which leads to the doubling of the consonants. Cf. Fig. 18 and 19 pag. 242 and 243 . 
In order to study the influence of speed on doubling (abutting) tracings were made of a series of syllables like "pup, pup.." in which the speed of utterance is gradually increased so that the syllables at first distinct, come closer and closer together. As the speed increases, the arresting consonant of each syllable doubles with the releasing consonant of the next syllable. "pup, pup.." becomes "pup-pup.." At a still higher rate of speed it is impossible to execute the prescribed number of consonant movements per sec., and the arresting consonant of each syllable drops. "Pup-pup.." becomes " $p u$ ' $p u$ '.." The whole series appears, then:

$$
\text { Separate: "Doubling" "Singling" }
$$

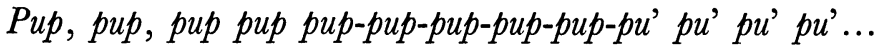

It is possible to note the beginning of the doubling process, the rate at which it occurs, and the point at which singling begins when the arresting consonant drops.

\section{Tracings of Double Consonants produced by Increasing the Speed.}

The full list of syllables developed into series by increasing the speed is given in Appendix, $A$.

The tracings of Fig. 33, 34, 35 show various forms of transition from the series "pup pup.." to " $p u$ ' $p u .$. " produced by the increasing speed of utterance. Fig. 33 gives the usual phases in which a stage of doubling, "pup-pup-.." occurs before the arresting consonant drops and the series becomes " $p u$ ' $p u$ '.." Both the tracing of the movement of the lips and of the pressure in mouth show the separate chest pulses and the distinct abutting consonants in the doubling forms, and it is clear that there is a definite change in the coordination when the arresting consonant drops, and "singling" occurs.

In the series Fig. 34, the subject does not get beyond the doubling stage of the record. Fig. 35 illustrates a case in which doubling does not occur at all. Instead; the arresting consonant drops abruptly; this happens perhaps once in six or seven series.

Fig. 36 and 37 are added that the doubling of a continuitive like " $s$ " or " $f$ " can be compared with that of the occlusives. It is clear that the process is exactly the same, that the continuitives function in doubling precisely as do the other consonants. 


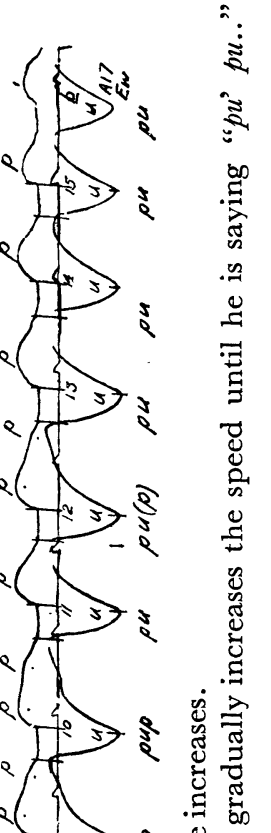

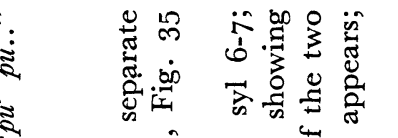

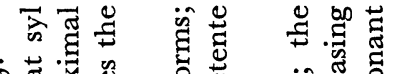

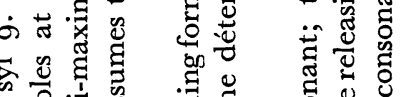

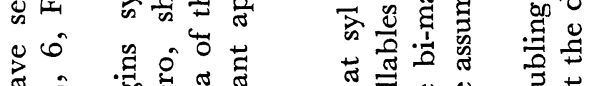

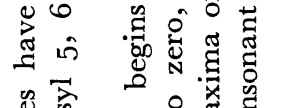

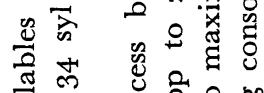
क त

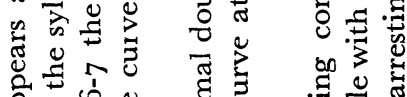

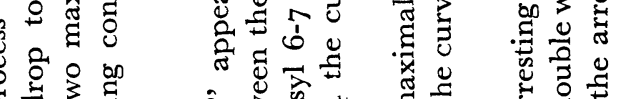

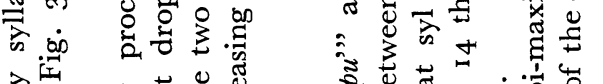

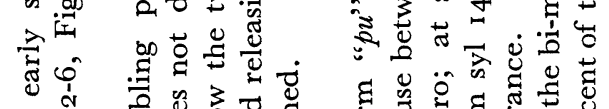

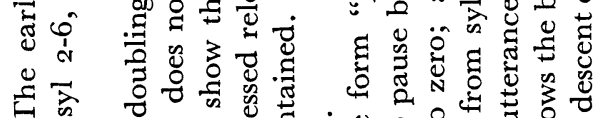
ปิ 总离 प्ष

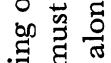

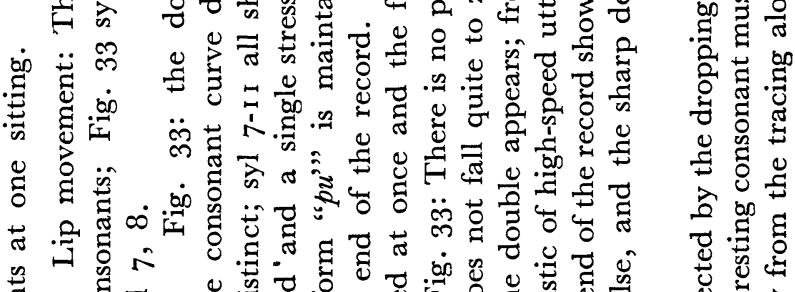

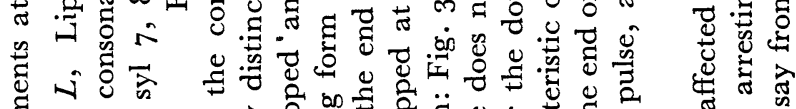

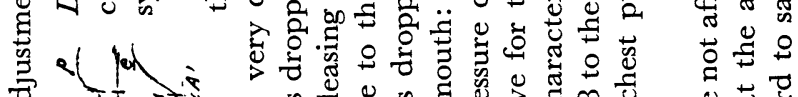

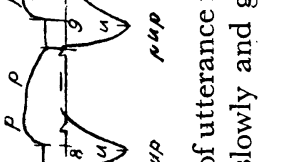
<. (2)

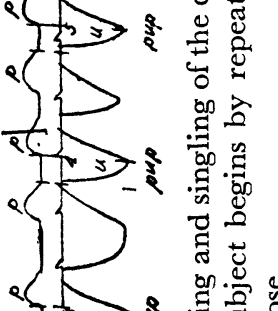

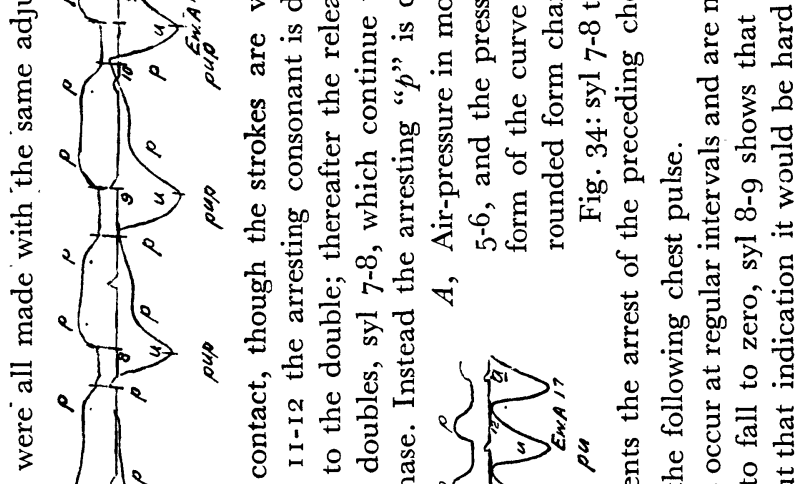

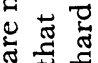
का สิ 赵 $\frac{0}{3}$

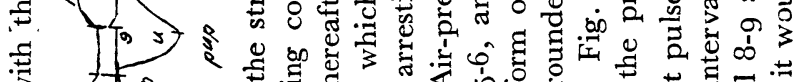
ली.

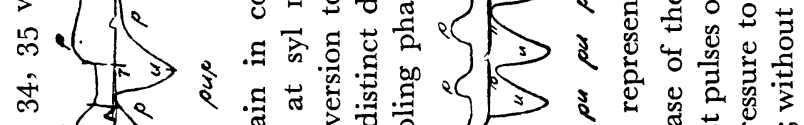

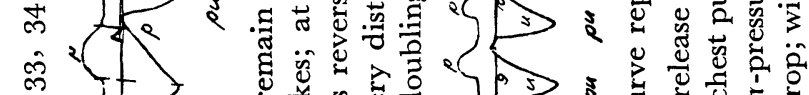

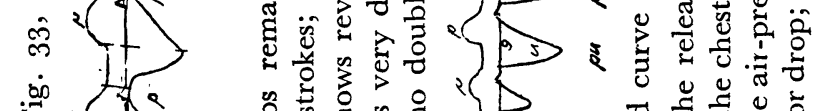

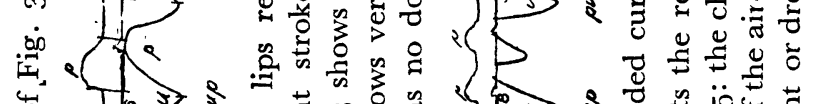

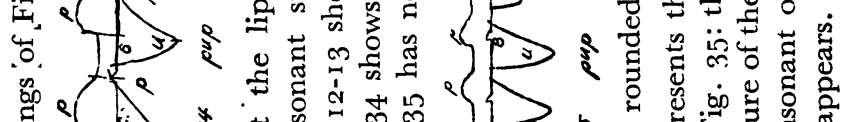

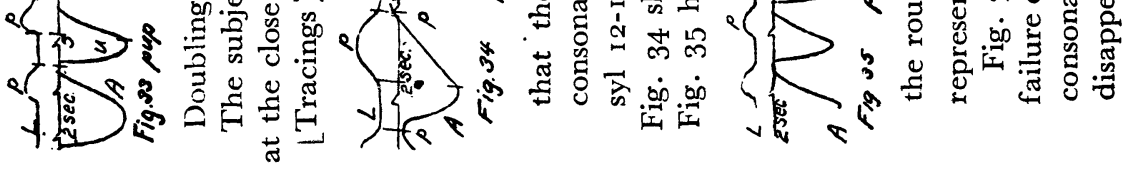




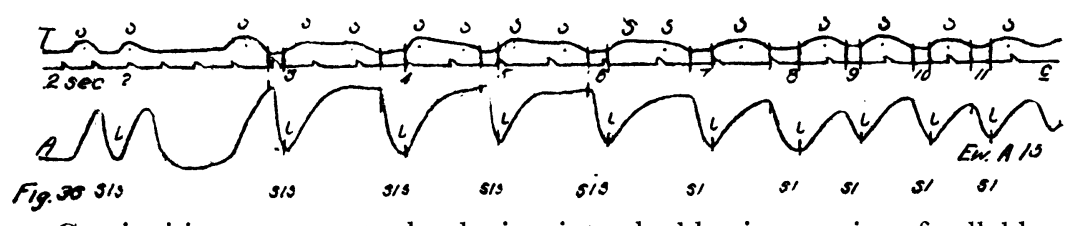

Continuirive consonants developing into doubles in a series of syllables as the speed of utterance increases.

Subject begins by repeating the syllables "sis" or "fuf" slowly and gradually increases the speed.

Fig. 36 Orig. $19 \times 3 \mathrm{~cm}$. "sis sis.." The "s" doubles like an occlusive. " 37 " $3 \times 5$, " $f$ f f fuf.." The " $f$ " doubles like an occlusive.

$L$, Lip movement: Fig. 37 syl 6-7 the " $f$ "s are adjacent; at syl $7-8$ they fuse into a double showing clearly the arresting " $f$ " and the releasing $f$. . After the single double the arresting " $f$ " drops. As usual the spacing of the consonant strokes just before and after doubling is fairly even.
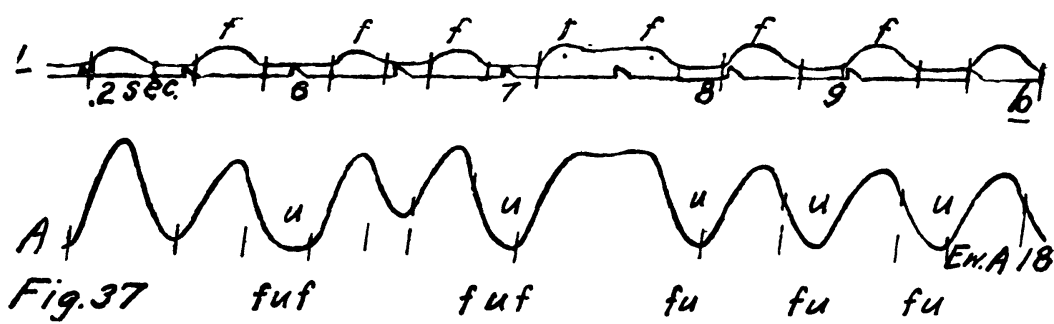

$T$, Tongue movement: Doubling of the " $s$ " begins rather abruptly Fig. 36 syl 3-4, and continues through syl 6-7. The bi-maximal forms indicate clearly the arresting and the releasing stroke in the double. The " $s$ " although a continuitive involves a stroke like any other consonant.

The single releasing " $s$ " of syl 8 is not longer than the releasing " $s$ " of syl 2 and 3 , as a reference to the time line will show, the kymograph is gaining speed throughout the record.

$A$, Air-pressure in mouth: The distinction between the releasing and arresting phases is fairly well marked for the " $\mathrm{s}$ " in Fig. 36 ; but it is not well marked for the " $f$ " in Fig. 37. The doubling forms are apparent, and the final form "si, si'.." or " $f u$ ' $f u$ '.." is like that of all syllables with releasing consonant at high speed.

Fig. 38 and 39 show tracings of the pressure outside and of the chest pressure for continuitives. The outside pressure runs high during the " $f$ " or " $s$ " but the chest pressure has its maximum as usual between the consonants.

Fig. 40 and $4 \mathrm{I}$ show the chest pressure tracings for occlusives with long vowels. It is to be noted that the rise in the chest pressure marking the inception of the second syllable occurs 
MOTOR PHONETICS.

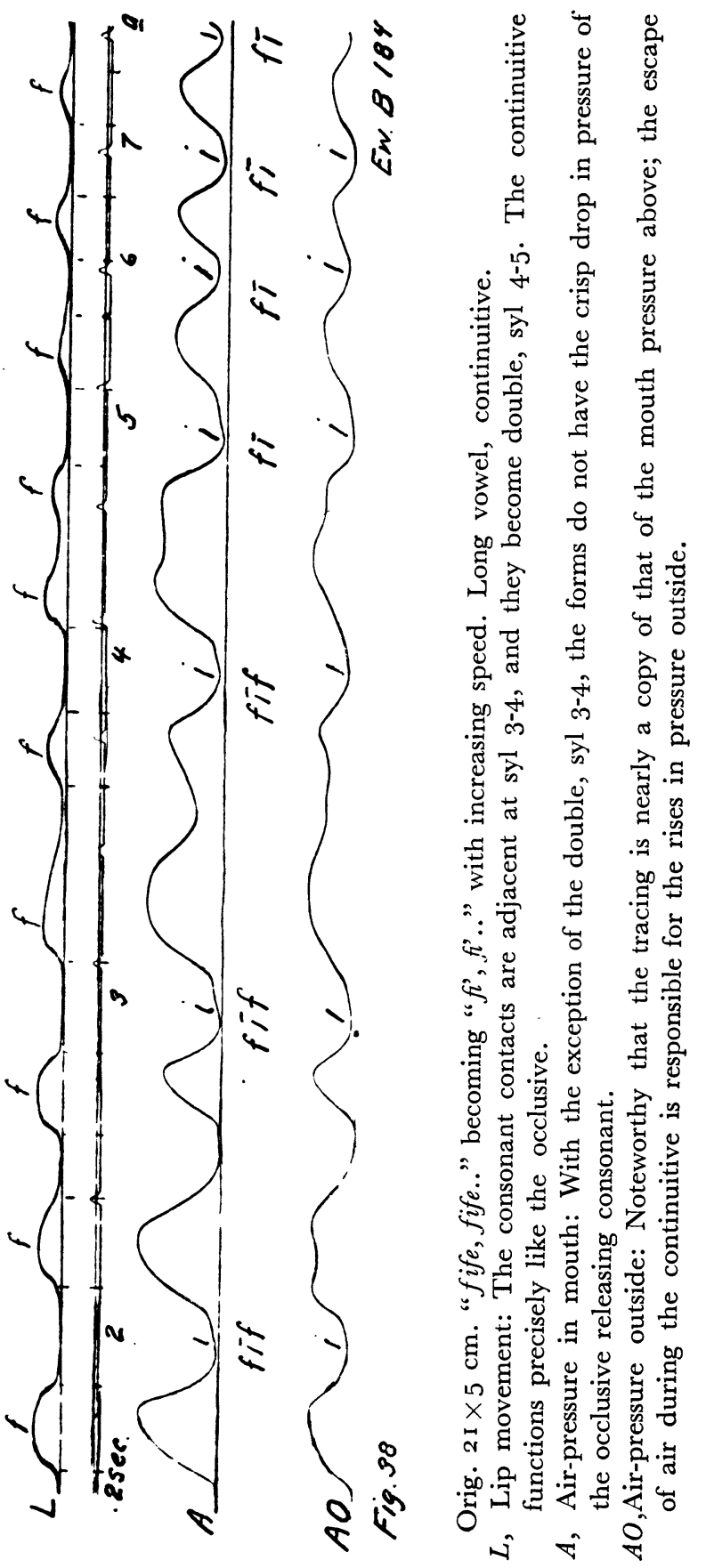


R. H. STETSON.

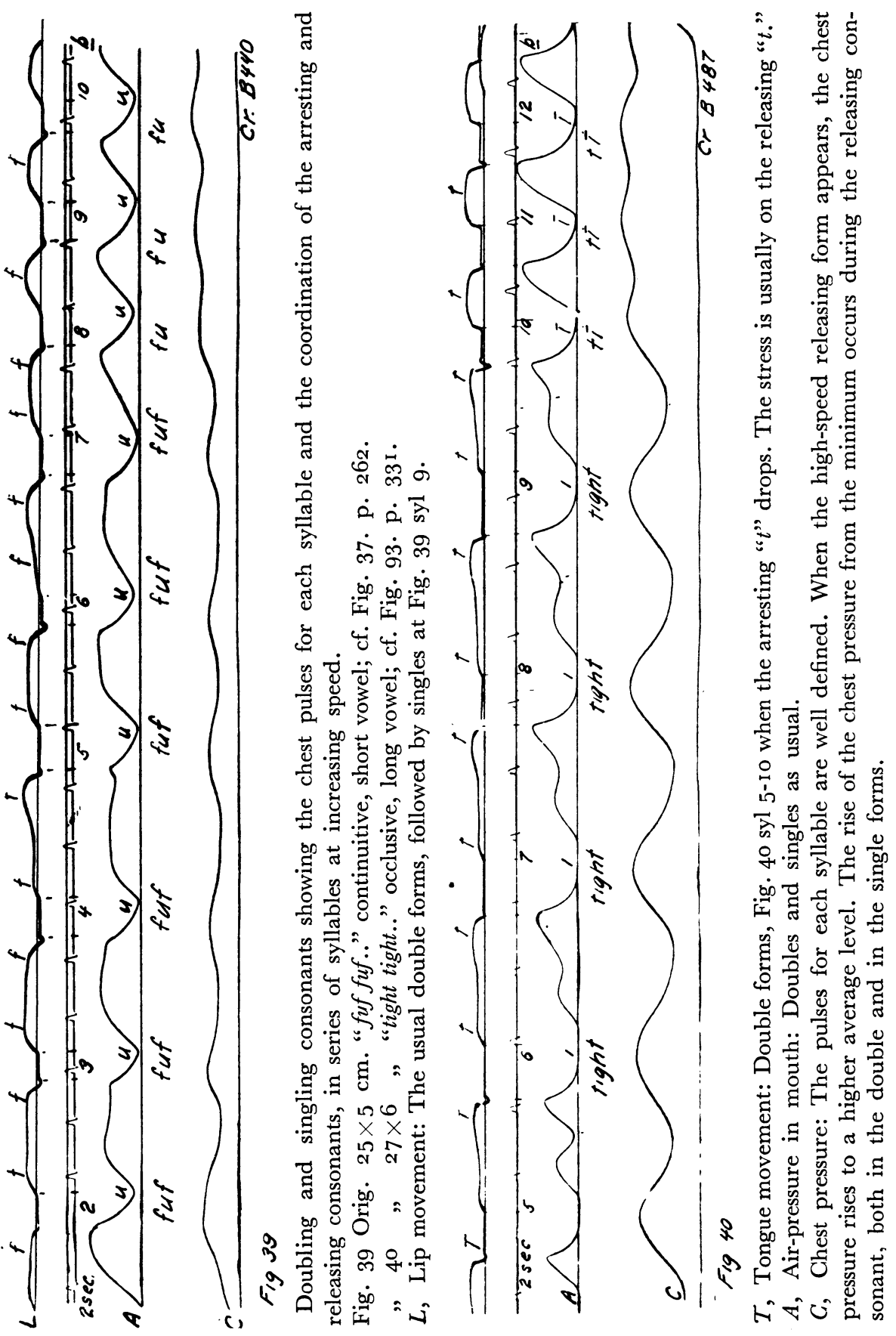


in the middle of the second doublet, not in the middle of the double consonant. Fig. 42 shows a single doubling form and has the striking rise in general pressure level which is usual with rapidly rising speed; this leads to the vocalization of a releasing surd.

The influence of speed on doubling can also be shown by making tracings of a series of syllables set to a rhythm with varied lengths of notes at the proper tempo.

One subject, C., gave the series of Fig. 43. The doubling has been marked by curves connecting the consonants. The results may be summarized:

(C. $\quad b o b . .270$ line $a-f ; p o p . .27$ I line $a-f ;$ tot.. 272 line $a-f$; tot.. 273 line $a-f, 24$ series.)

Sylables with value of quarter note, $\mathrm{I}-\mathrm{I} .5$ per sec., consonants separate.

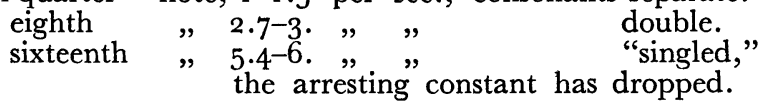

Fig. 26 (MS 67) gives the distribution of the lengths of such consonants doubled by increasing the speed; a comparison of the curve $P$ with curve $O$ shows that the general distribution of the lengths of these doubles by increasing the speed is very like that of the lengths of the actual doubles.

The speed at which doubling begins varies from $\mathrm{I}-.3 .5$ syllables per sec. It is apparent from curves $d, e$, in Fig. 44 that four-fifths of the series show the change from separate to double between the rates of $\mathrm{I}$ and 3 syllables per sec. And in no case do the syllables remain separate at a rate higher than 3.5 per sec. The doubles may continue from a speed of 2 syllables per sec. to a speed of 4 syllables per sec. where upon singling must occur with the dropping of the arresting consonant. Cases of singling may occur at as low a rate as 2.5 syllables per sec. The distribution of the rates at which individual series have singled, Fig. $44, f, g$, show a definite mode at $3.5-3.9$ per sec. This indicates a tendency to jump to a considerably higher rate when the doubling ceases.

These "doubles by increasing speed" show all the varieties noted in the case of actual doubles. On occasion type $V$, p. 259 (Fig. 27, 6 p. 256) appears just after doubling ceases with the increase of speed.

After a little practice in increasing the speed of utterance 


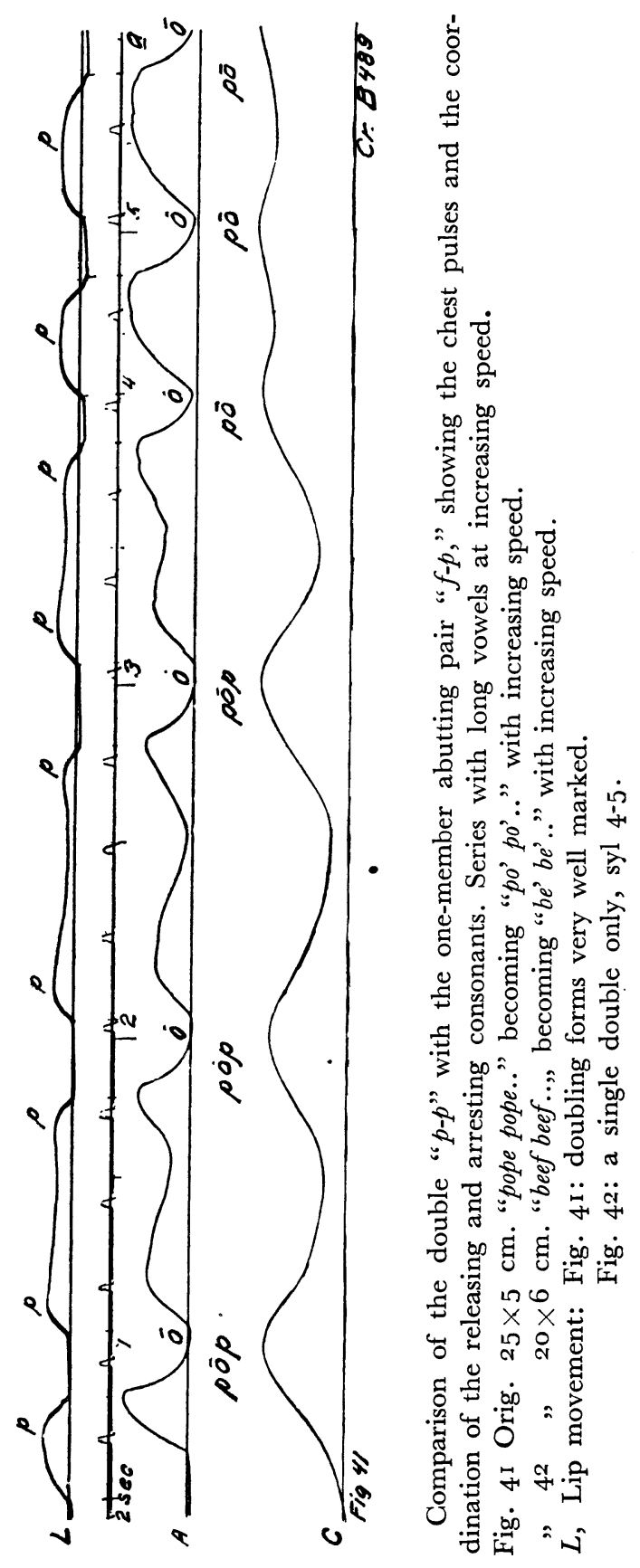


MOTOR PHONETICS.

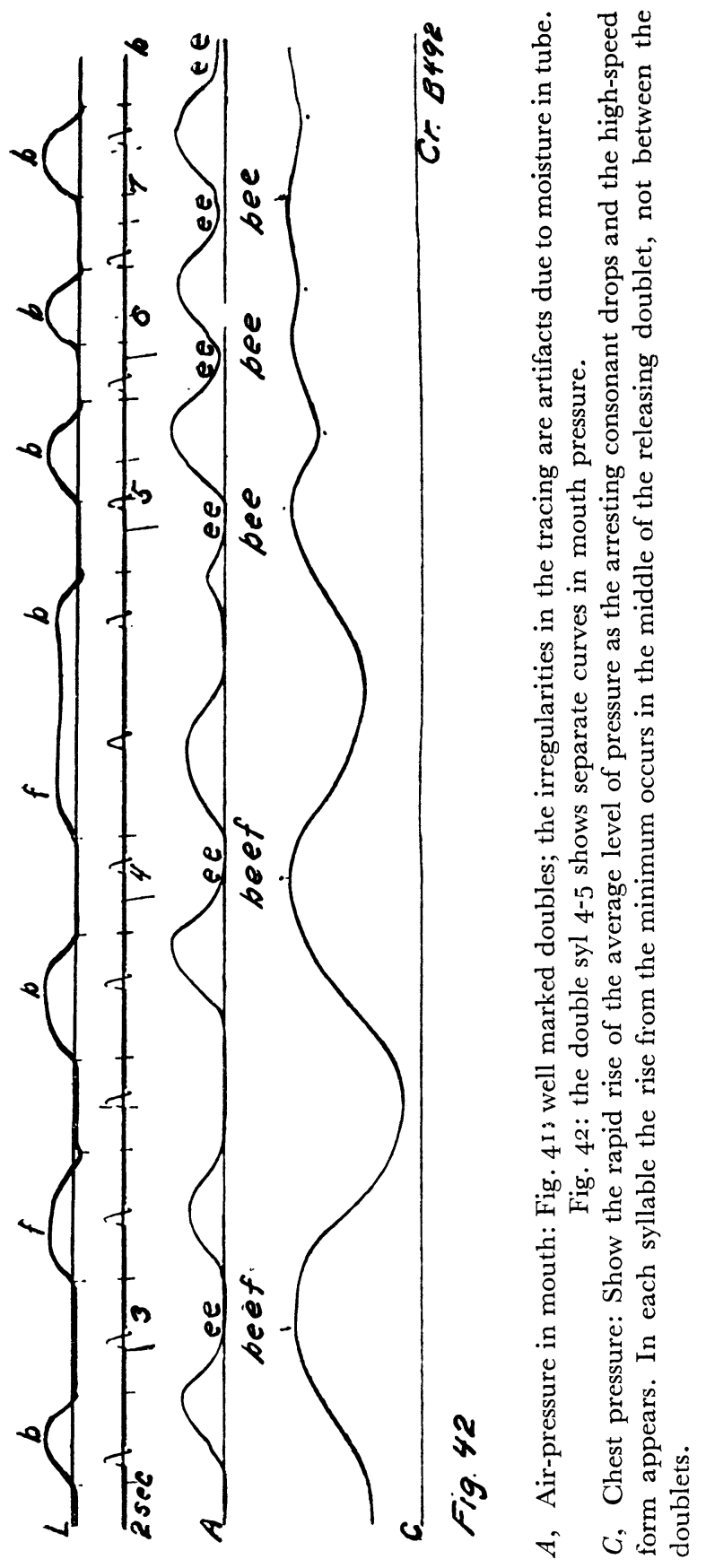


uniformly the subjects are apt to produce tracings with the doubling stage. Like the general group of one-member abutting pairs, only about one series in seven fails to show doubles.

Of 444 double consonants tabulated in series of this type, I24, $28 \%$, do not have a clear indication of the bi-maximal curve in either the consonant or the mouth- pressure tracings. This is a large fraction; but the mouth-pressure tracings of liquids and nasals are often unsatisfactory, and the consonants " $c h$ " and "sh" (Eng.) double with difficulty. Of the labial forms, $80 \%$ have a clear indication of doubling in the form of the curves. As in other cases only those curves have been counted "bi-maximal" in which the two maxima are apparent.

There are two discontinuities in these series. The first is between the separate syllables, "pup, pup.." and the doubling

$M .72=1$

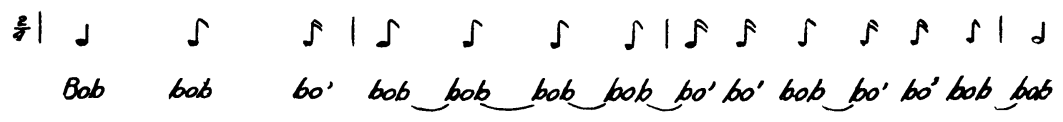

Fig. 43

form "pup-pup.." This is indicated by the closing up of the interval between the syllables, and by the double form of the consonantand of the mouth-pressure- curves. The length of the vowels tends to remain the same throughout the series.

At the initial low speed of utterance there is no difficuity in enunciating the closed syllable "pup"; there may be an indefinite interval between the syllables. With a slight increase of speed, the interval between the syllables equals the interval between the consonants of the syllable, and the consonant movements are evenly spaced. The coordination may be schematized:

Single syllables before doubling:

Releasing

Arresting

Releasing

Con.mvt: beat str. back str. beat str. back str. beat str. back str. beat str.

back str.

beat str.

The syllable movement is arrested by the arresting consonant. Although the movements are not in phase, there is ample time for the beat- and back- strokes of the consonant.

As the speed increases, the movement of the arresting conson- 


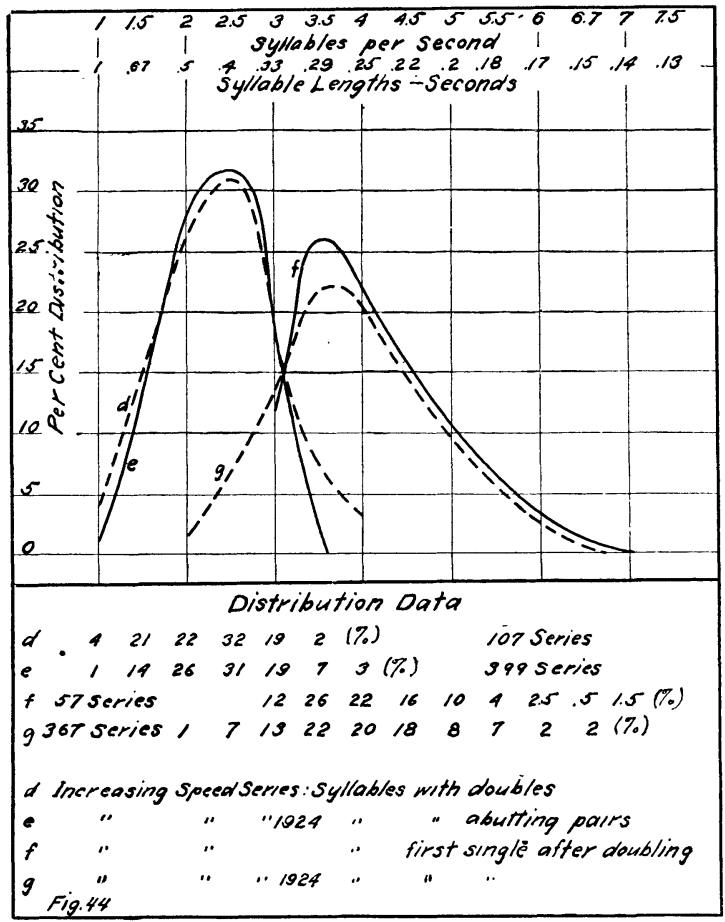

Distribution curves showing the rates at which "doubling" and "singling" occur, when a single syllable is repeated at varying speed. "Doubling" is used of all cases in which two consonants come to abut at the syllable frontier; it includes the formation of the ordinary double consonant, " $t-t$," as well as the abutting pair, " $d-t$," or " $p-t$. ." "Singling" is used of all cases where the speed is high enough to cause the arresting consonant to drop, leaving the single releasing consonant.

$d$ gives the distribution of series like " $p u$, $p u p . . p u$, pu.." recorded in 1926 . There were four per cent of all series in which doubling occured at the rate of one syllable per sec., twenty-one, per cent of all series in which doubling occured at I .5 syllables per sec., etc. It is apparent that by far the larger number doubled at the rate of 2.5 per sec. and that they do not double at all beyond the rate of 4 per sec. (In all these distributions, the upper limit does not signify $4-4 \cdot 4$, but 4 . flat).

$e$ gives the distribution of series rcorded in I 924 ; a larger number of series. The distributions are practically identical, save that doubling does not occur at quite so high a maximum (3.5 rather than 4 . per sec.).

$f$ shows the distribution of series recorded in 1926 . There were twelve per cent of all series in which the arresting consonant dropped at the rate of 3 per sec., twenty-six per cent at the rate of 3.5 per sec. and the upper limit at which singling began was 7 per sec. The position of the whole shows that there is a discontinuity between the rates of doubling and singling. When the arresting consonant drops and doubling ceases, there is a rather sudden increase in the speed, and the rate of the first, single syllables is apt to be decidedly higher than that of the last, double syllables.

$g$ gives the distribution of similar series recorded in 1924 . The distributions are practically identical. 
ant comes to abut that of the releasing consonant and there is no longer time for the back stroke to leave the opposing surface; the consonants have doubled. The coordination may be schematized:

\section{Releasing Arresting Releasing Arresting}

Con.mvt: beat str. back str. beat str. back str. beat str. back str. beat str. back str. Syl.mvt: beat str. ... back str. ... beat str. ... beat str. ...

This involves two consonant movements per syllable and the movements are unevenly spaced. The syllable movement is also unevenly spaced; the interval for the beat stroke is longer than the interval for the back stroke. This coordination however is the only one possible at this speed.

As the speed increases the syllable movement will tend to become regular; this will reduce the interval between releasing and arresting (beat stroke) and increase the interval between arresting and releasing (back stroke.) This tendency of the syllable movement to become regular will bring self-arrest for the syllable movement, as the consonants are irregularly spaced, and the arresting consonant will actually function less and less.

The second discontinuity, between the doubling form "pup$p u p-.$. " and the "singling" form " $p u$ ' $p u$ '.." is marked by the change in the consonant curves which again show a single maximum; the form of the mouth-pressure tracing also shows the change from the bi-maximal, arresting-releasing type to the simple releasing form. At the speed of $4-4.5$ syllables per sec. this change must occur; the doubling of the consonant is no longer possible for it entails 8-10 consonant movements per sec., a speed which is only possible when the movements are evenly spaced and is at best a maximum speed for repeating a movement. There must be fewer consonants per syllable.

And it is now apparent that the arresting consonant will be the one to go. The arresting consonant is losing its function because the syllable movement is becoming evenly spaced and self-arresting. It is not only becoming a superfluous item in the syllable, but it is off-phase, out of step with the syllable movement in that its beat stroke occurs with the back stroke of the syllable movement. At high speed the movements tend 
MOTOR PHONETICS.

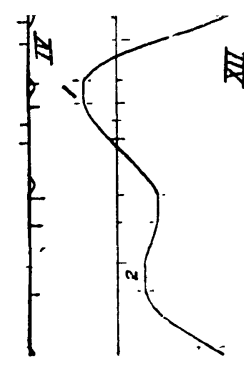

告

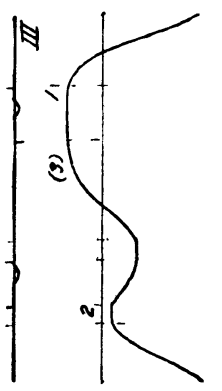

造

苋

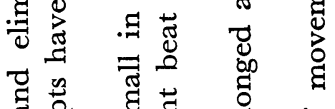

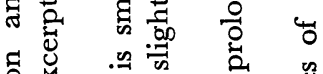

.

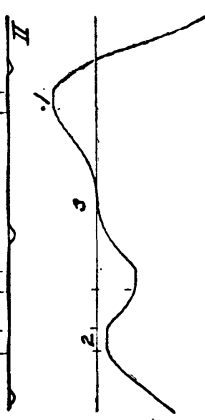

ज岸

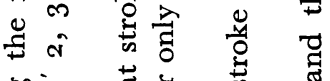

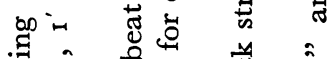

की के छ

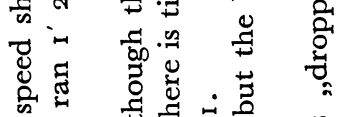

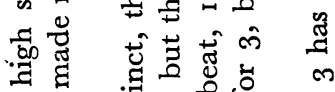

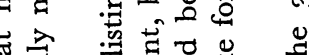

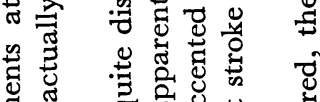

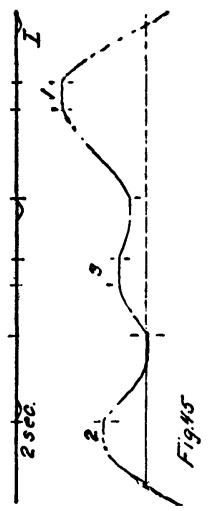

घू

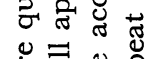

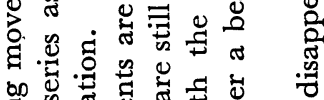

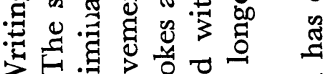

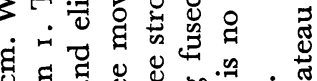

हु

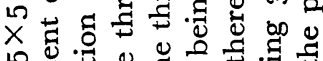

鴒记

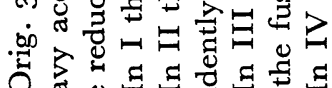

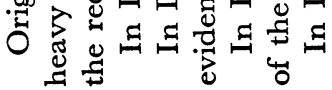


to get into step or to drop in order to simplify the coordination; therefore the arresting will drop while the releasing consonant retains its position because it comes in on the beat stroke of the syllable. This tendency is very marked in all phonetic coordinations; the case has already been mentioned in which the series " $a t, a t, .$. " becomes " $t a, t a, .$. " as the speed increases. Cf. Fig. 5, 6, 7, p. 218 and 219. The phenomena are very striking in the case of abutting consonants involving two members. Cf. Fig. 48 p. 278.

It is to be said however that the arresting consonant does not always "drop" without a struggle. Often the movements of the arresting consonant fuse with those of the releasing consonant; it is not a matter of mere omission. Tracings of series of writing movements in which the speed is so high that "dropping" occurs show that the amplitude of the movement crowded out is reduced because the beat- and back- strokes of the "dropping" movement come to overlap; a stasis may result; in the end the slight excursion, or the stasis, is absorbed into the back stroke for the coming movement.

In Fig. 45, I shows the beat actually present, but reduced in excursion, and becoming part of the back stroke of the coming beat. II shows the more advanced stage in which the beat appears as nothing but a slight inflection in the back stroke of the following beat. III shows the dropping beat represented by a stasis at the opening of the following beat. In IV the beat has disappeared but the back stroke of the following beat is lengthened. Such "dropping" of movements is very common in handwriting at high speed. It has played a part in the development of cursive forms, just as the "dropping" of phonetic movements has played a part in de development of pronunciations.

There is apt to be a sudden increase in the rate of utterance when "singling" occurs; there is a definite physiological limit to the speed of doubling; but when the arresting consonant drops there is nothing to prevent a rapid rise in speed. Cf. Fig. $44 f$ p. 269 .

At high speed, in the series " $p u$ ' $p u$ '.." the type of the consonant curve, and of the curve of pressure in the mouth, is invariable. The movements are perfectly regular, the phases are equal, and the movements exactly in step. The coordination may be schematized: 
"Singling":

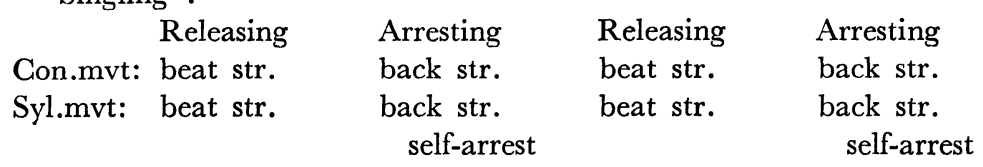

The study of these tracings of double consonants produced by increasing the speed shows that the criteria of doubling are quite consistent; the speed at which doubling begins and ends, the form of the consonant curve which shows the combination of the doublets, the bi-maximal form of the curve of mouth pressure during doubling, these are all in accord. And the results agree with the characteristics of the actual doubles (ordinary words and phrases) as determined above.

\section{Restoration of the original form when the speed decreases.}

The reverse processes occur if the subject is directed gradually to reduce the speed of utterance after reaching the maximum speed. If the form "pup, pup.." has been prescribed, as the speed rises it passes through the stages "pup-pup-.." and " $p u$ " $p u$ '.." As the rate slows again it passes from " $p u$ ' $p u$ '.." to "puppup.." and finally to "pup, pup.." The subject is not aware that he has doubled the consonants and dropped the arresting consonant, reducing the syllable to " $p u$ ' $p u$ "; neither is he aware that he has restored the arresting consonant as the speed slows, and that he has finally come back to the original form prescribed. Cf. Fig. 5 and 7, p. 218 and 219.

This restoration of the prescribed consonant when the speed permits is of importance because the process of elimination and restoration is constantly going on under the ordinary conditions of speech. It is not the case that a consonant has actually disappeared because it is for the moment suppressed by the speed of utterance; it is in abeyance and will promptly reappear when the speed permits. Much survives in the movements of a language which is not heard; the French aspirate " $h$ " still has a place in the pronunciation, though it is seldom heard. One may expect then great freedom in modifying the prescribed consonant forms; when the rhythms compel rapid utterance the consonants may "double," or "single," and they may be shifted from one syllable to another, but as the rhythm and the speed change, the original form will return; the subject has not 
lost the original pattern, though it is freely modified by phonetic exigencies.

This restoration of the consonant forms, and later of syllables forms, will be treated as other series at rising and falling speed are discussed, and also when the various accented groups of syllables are considered. This tendency to restoration is important in all these cases; it is the great conservative factor in pronunciation.

\section{One- member Abutting Pairs. Tracing of Abutting Consonants produced by the Same Articulatory Member.}

When series like "puf, puf.." and "sat, sat.." are uttered at increasing speed, abutting pairs of the form " $f-p$ " and " $t-s$ " result. Such abutting consonants are very like double consonants; the two consonants are different but they combine under much the same conditions.

The list of syllables which were developed into series by increasing the speed of utterance is given in appendix, $B$.

Fig. 46 shows series of the syllable "puf.." passing through the stages of "separate," "doubling," (=abutting) and "singling" Fig. 47 illustrates cases in which the doubling does not occur, instead the arresting consonant drops at once. It is significant that the presence or absence of a consonant does not depend on the articulatory stroke, but on the function of the consonant. If the consonant arrests the chest pulse it is audible; but if the chest pulse is self-arresting the consonant movement does not make a consonant. A consonant may drop, although the articulatory movement is vigorous. And it is interesting to see that although it fails to function as an arresting consonant, the " $t$ " movement may nevertheless combine with the " $s$ " movement, and actually produce the stroke of a compound consonant "ts." Cf. Fig. 65 p. 296.

The lengths of such one-member pairs abutting with increasing speed are comparable to those of the doubles by increasing the speed, and to those of the actual doubles in ordinary words and phrases. Fig. 26, p. 253 shows the practical identity in curves, $\mathcal{N}, O, P$.

The rates at which doubling takes place are practically identical with other doubling rates. Cf. Fig. 44, p. 269.

An inspection of the tracings makes it apparent that a rather 


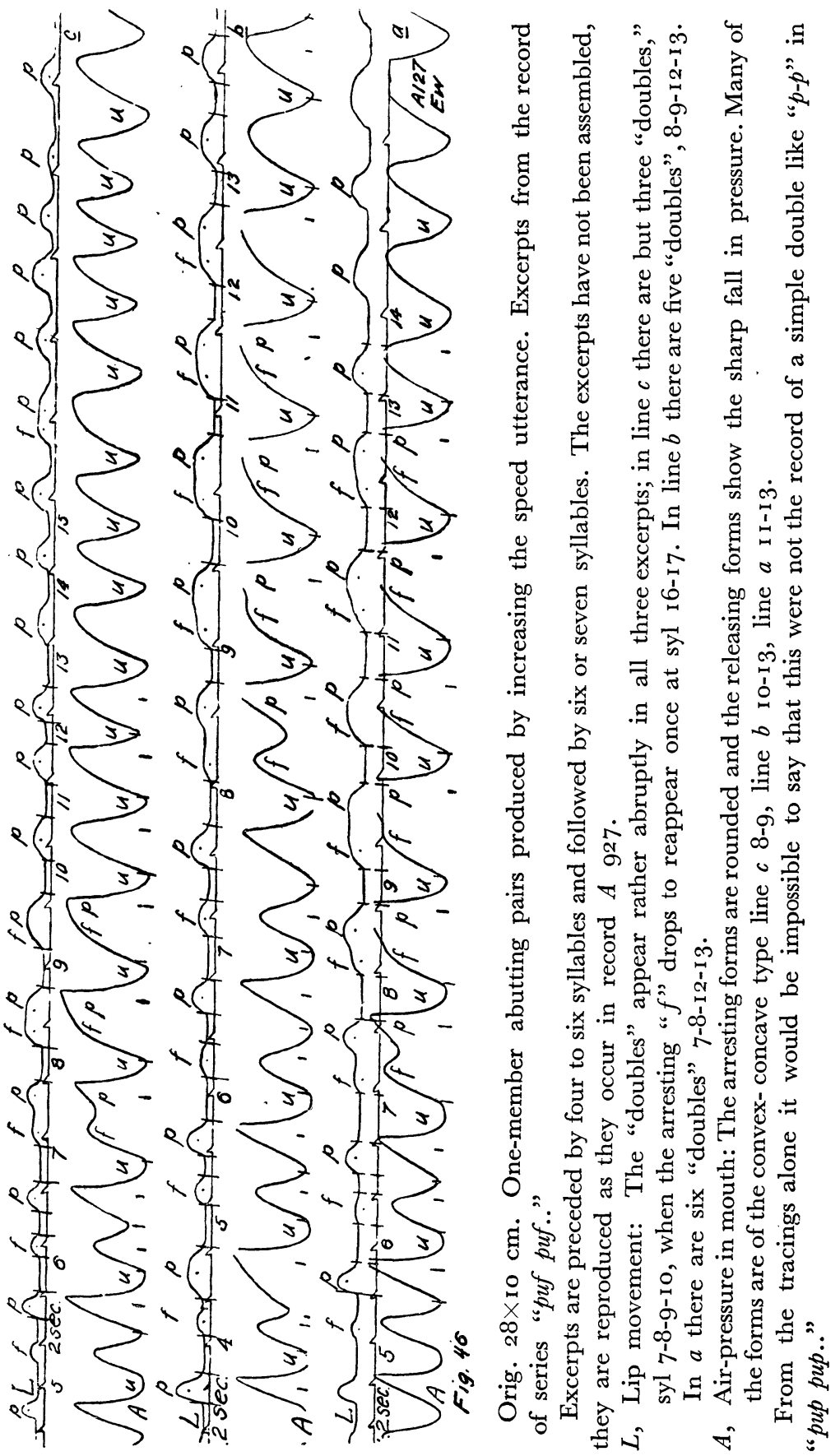




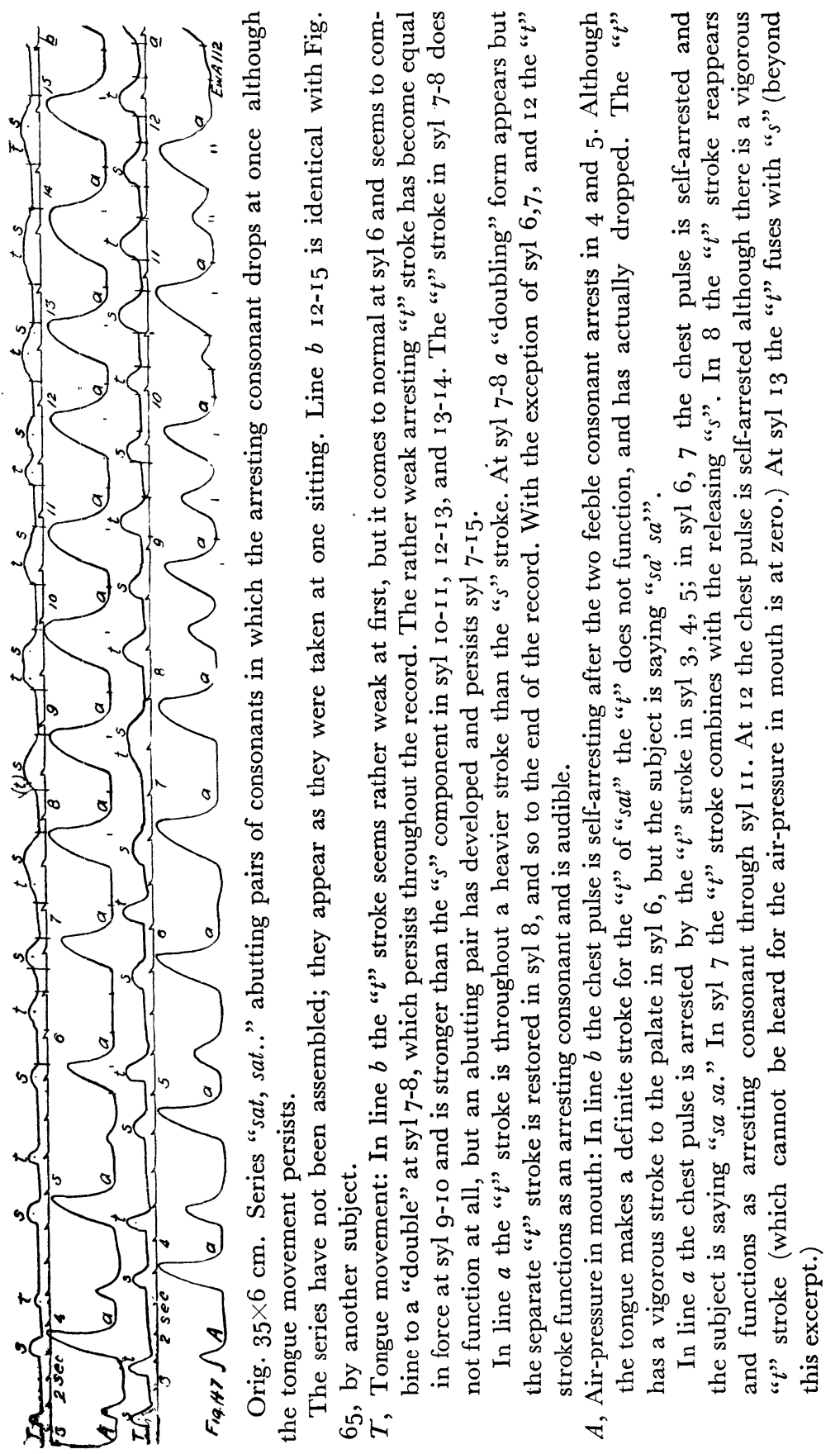


higher number of one-member abutting pairs have the doubling form clearly indicated in the consonant- and mouth-pressurecurves. Of 607 cases of front lingual pairs, like " $t-s, d-l$, th-n," etc., $12 \%$ only do not show the characteristics of the arrestingreleasing pair; $40 \%$ show the characteristics in both chest pulse and consonant movement; $76 \%$ have the characteristic abutting form in the mouth-pressure curve. Of 142 labial pairs, " $f-p$ ", " $v$ - $b$ " etc. $4 \%$ only do not show the arresting-releasing form; $56 \%$ show the characteristics in both chest pulse and consonant movement; $90 \%$ show the characteristic abutting form in the mouth-pressure curve. This is a decidedly larger number than in the case of the double consonants produced by increasing the speed of utterance. It is possible that the two distinct consonants tend to preserve the two consonant strokes and the two chest pulses. The difference in the force of the consonant strokes of the two components, and the difference in the mouth-pressure of the two components show clearly in the tracings of such one-member abutting pairs.

Series in which the speed decreases from the maximum show the return of the "doubling" and finally of the original form. This is the tendency to reversion mentioned in connection with the doubling series, p. 273 .

Two-member Abutting Pairs. Tracings of Abutting Consonants produced by Different Articulatory Members.

This method of study may be extended to abutting consonants of all types. It is possible when the arresting consonant is produced by one member, and the releasing consonant by another that the conditions are somewhat different.

Tracings were made of series in which such pairs of abutting consonants were produced by increasing the speed of utterance. "Top, top.." in which the arresting consonant is a labial and the releasing consonant a lingual will illustrate the general form. Independent tracings of the lip movement, and of the tongue movement were taken along side of curves of pressure in the mouth and in the chest.

A list of the syllables which were developed into series with two-member abutting pairs of consonants by increasing the speed is given in Appendix, $C$. 


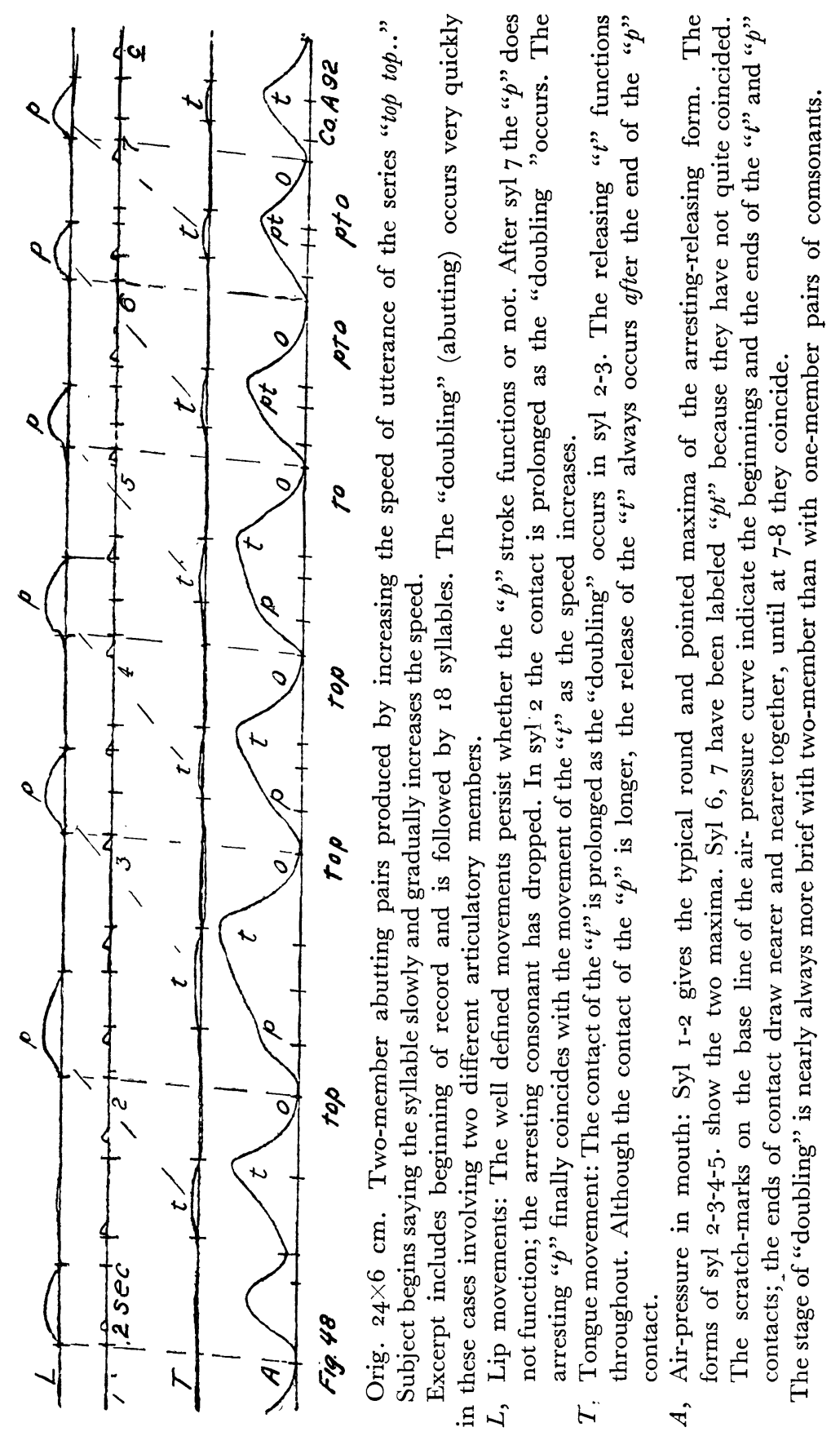




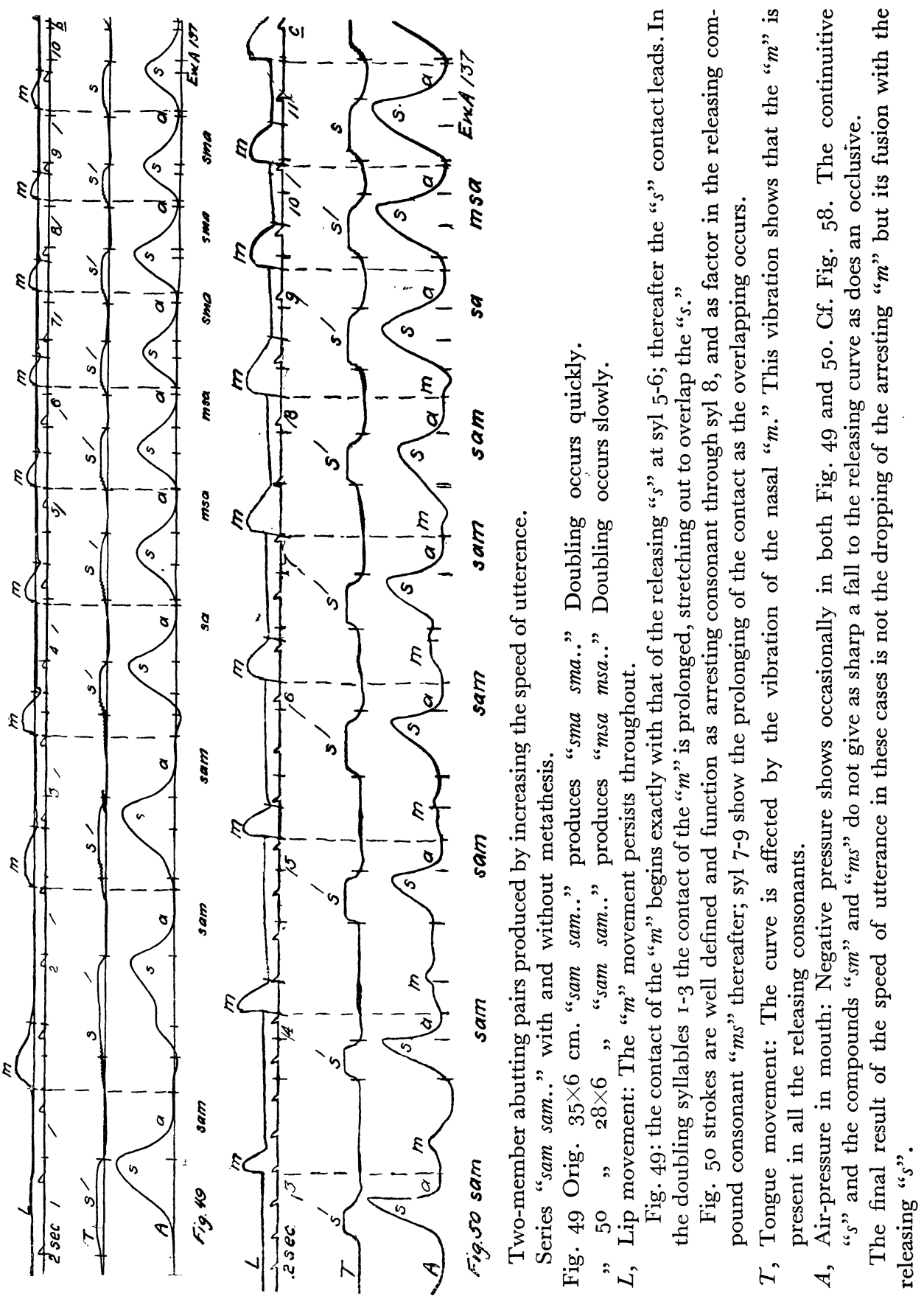


280

R. H. STETSON.

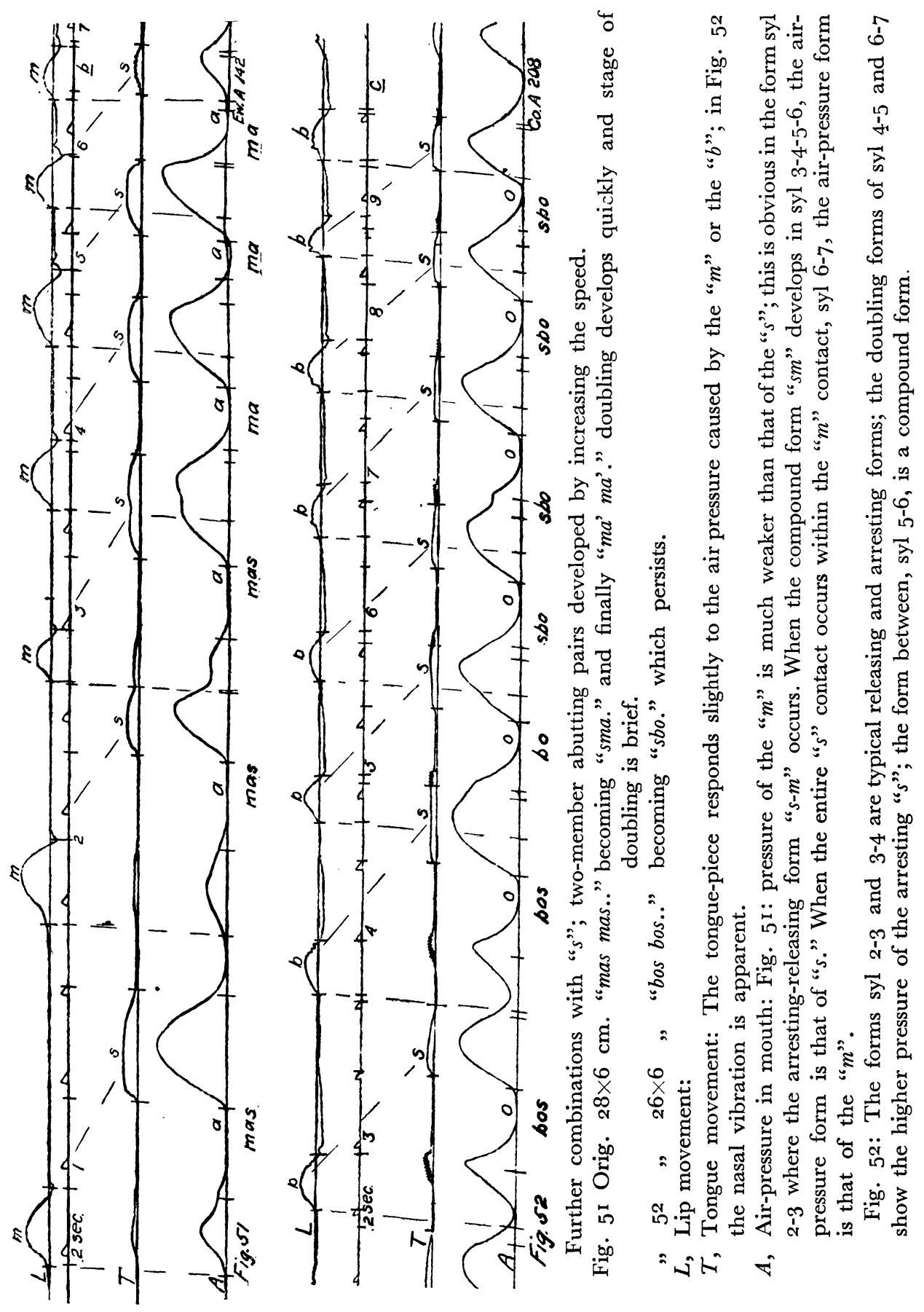


MOTOR PHONETICS.

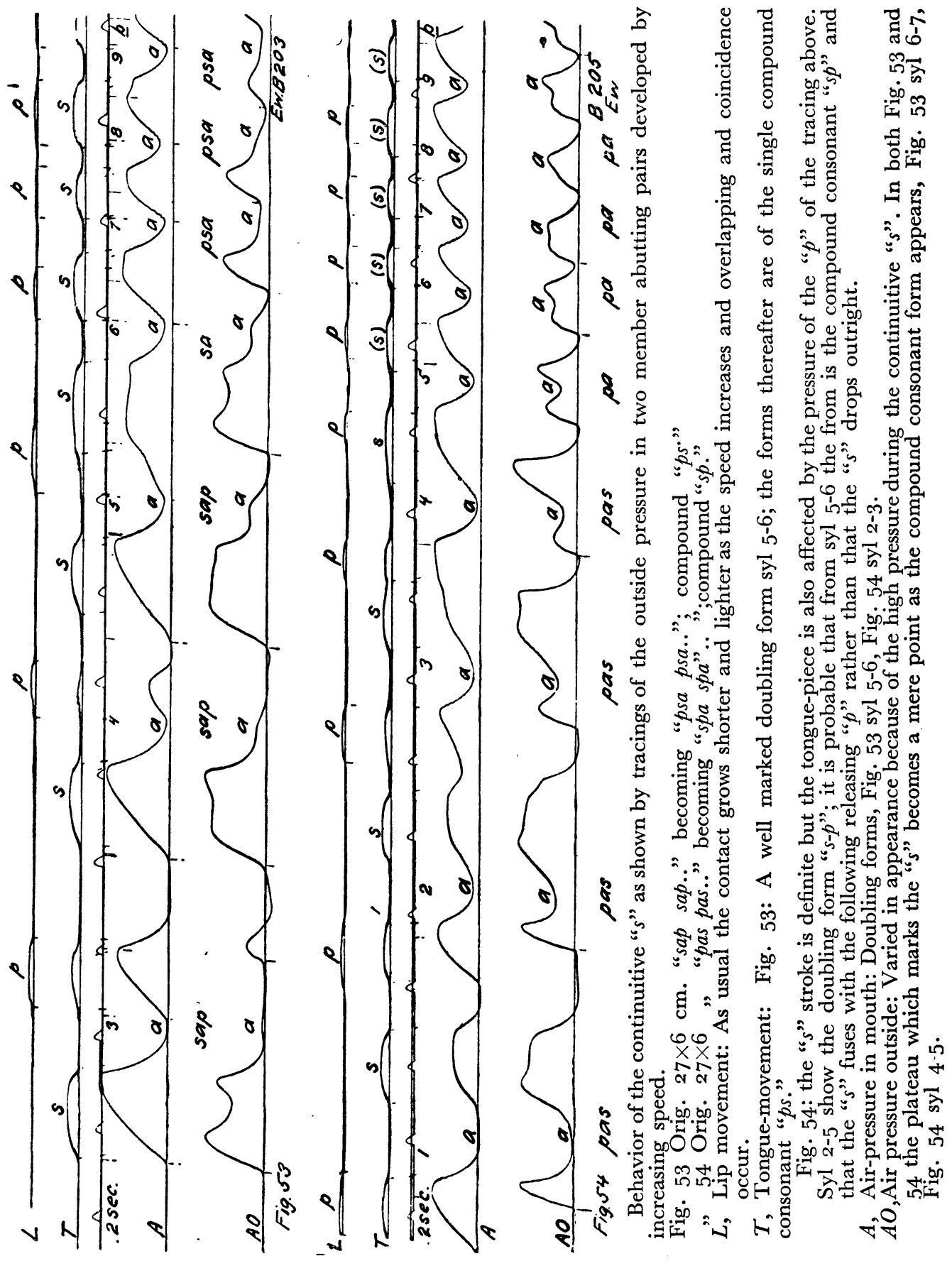


Various types of two-member abutting pairs are shown in Fig. 48-54. Fig. 48 "top, top.." shows the abutting of a labial occlusive with a lingual occlusive; the arresting " $p$ " drops and the series becomes "to' to.." In Fig. 49 "sam, sam.." shows the abutting of a continuitive labial, the nasal " $m$," and the continuitive lingual " $s$ "; the movements are almost in step; and it is easy for the movement of the " $s$ " to shift slightly so as to form " $s m$ " and metathesis has occured. In such cases the overlapping brings coincidence and then progresses to a point where the two movements slide past each other, as it were, into an easier compound consonant. In Fig. 50 the overlapping does not go beyond the stage of a releasing " $m s$ ". The forms in which " $s$ " figures as part of a compound consonant may be counted normal. Fig. $5 \mathrm{I}$ and $5^{2}$ are cases in which the syllable is released by a labial; "mas, mas.." is the reverse of "sam, sam.." The phenomena of doubling in all these cases are very similar. The " $m$ " is not easy to record and often shows negative pressure. The " $s$ " usually leads to the formation of a compound releasing consonant. Fig. 53 and 54 show the doubling forms in the mouth pressure alongside a tracing of the outside pressure. The tracing of the outside pressure shows that the " $p$ " stroke dominates in the compound consonant " $s p$ " but that the " $s$ " stroke dominates in the compound " $p$ ".

The process of combination of abutting consonants in such cases is very interesting; the arresting consonant movement of one syllable and the releasing consonant movement of the next syllable quickly overlap and soon become simultaneous. ${ }^{1}$ ) Unless one of the components is a fricative (like the " $s$ " in Fig. 49-52) the abutting pair does not persist more than a few syllables with any of the subjects; the arresting consonant disappears quickly as the speed increases.

The movement of the releasing consonant does not replace the movement of the arresting consonant; instead the movements tend to slip together, to fall into step, and it is apparent that the movement of the arresting consonant persists long after it has ceased to function in the syllable. It is a striking illustration of the tendency of the movements of speech to get

1) Rousselot has studied this juxtaposition of consonants, Princips II, p. 949-959. Précis, p. 8I-85. Cf. Millet, A., Précis d'Expérimentation Phonétique, Didier, Paris, '26, p. Io8-ii 5 . 
in phase. The movement of the arresting consonant in the twomember combination can shift its position in the coordination without affecting the releasing consonant, and it actually slides into phase, so that the beat strokes of both consonant movements and of the syllable movement occur together; in reality, both consonants have the releasing position, but one of them does not function and cannot be heard. This persistence of the original arresting consonant as a movement in step with the releasing consonant is invariable, all the records of all the subjects show it. As the arresting movement shifts so as to coincide with the releasing consonant of the next syllable, the chest pulse becomes self-arresting; the form of the curve no longer indicates the end of the one pulse and the beginning of the next, for there is no rise in pressure at the end of the stroke; the pressure falls at the end of the beat stroke as in all cases of self-arrest of the chest movement.

This illustrates a possible method of formation of such unusual sounds as the Slavic " $b$ mouillé" reported by Rousselot. ${ }^{1}$ )

It is easier to see how the speaker retains the prescribed form in these two-member series. Although the speed has forced the "dropping" of the arresting consonant; both consonant strokes are actually retained, but they coincide; they merely slide apart again as the speed reduces. Fig. 55 shows the restoration of the original prescribed form in a two-member series.

A comparison of the lengths of such two-member abutting pairs with the lengths of the one-member abutting pairs of consonants shows that the mode has a value slightly less than that of the one-member pairs (including doubles.) Fig. 56 shows that the difference in the two distribution curves $Q$ and $R$ is not great; but it is probable that there is a slight difference in the play of the movements which makes the two-member pairs slightly shorter. The average of the 984 readings represented by curve $R$ is $.22 \pm .04 \mathrm{sec}$. The minimum lengths of the two-member abutting pairs lie well whithin the limits of speed of two balistic movements. Fig. 57 gives a comparison of the distributions of the lengths of doubles and of abutting pairs recorded in ' 26 with records made in '24. It is apparent that the distributions are practically identical.

The rates of the syllables in these series containing two-member

1) Principes I, p. 605 . 
R. H. STETSON.

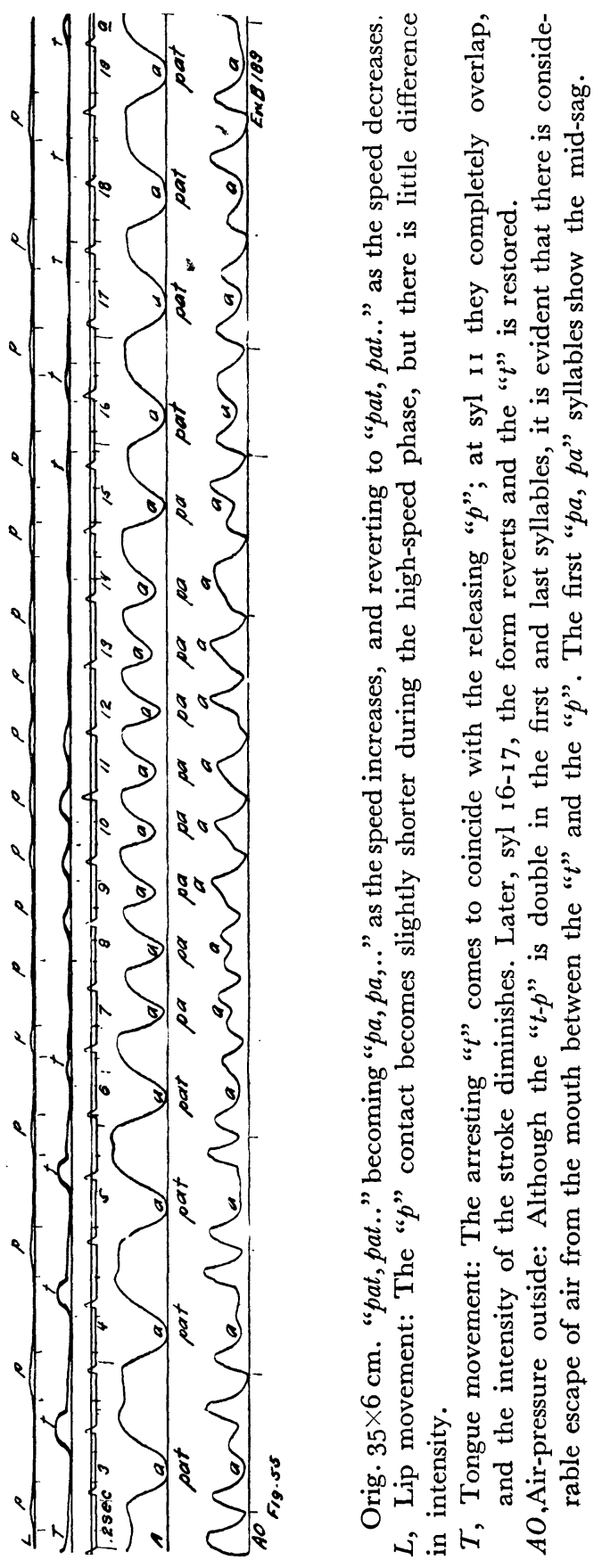


abutting pairs as given in the distributions of Fig. 44, p. 269 show that they agree very closely with those of the one-member pairs. ( $e$ as compared with $d$ ).

There is no fundamental distinction to be made between the two-member pairs of abutting consonants, the one-member pairs of different abutting consonants, and the actual doubles; they all result from one and the same process. Combinations like "bit-bit-" and "fub-fub" and doubles like "pup-pup-" and "sis-sis-" are all analogous. It is true that singling in the course of the two-member series does not mean that the arresting consonant stroke drops out; instead it shifts into the releasing position in step with the next releasing consonant and becomes functionless. But the elimination of the arresting consonant in the two-member abutting pair, the shift of the arresting consonant series like "up- up," tot " $p u$ ' $p u$ '.." are precisely like the processes of singling which appear in the series of doubles by increasing the speed, or in the series of one-member atbutting pairs produced by increasing the speed.

These abutting consonants made by two different articulatory members cannot occur more rapidly than the abutting consonants made by a single member. In the playing of key-board musical instruments and in many other forms of skilled movements, it is possible by the use of two or more fingers in coordination to attain a speed of $\mathrm{I}^{-1} 8$ per sec. Nothing of the sort appears in the case of the consonants in speech; the number of consonantal movements which can be made by two different articulatory members is 8-1o per sec.; it is no greater than the number of consonants per sec. produced by one articulatory member.

This fact emphasizes the difference in type of coordination. In the case of the combined finger movements of typing or piano-playing the separate pulses have their separate functions as beats in the process; each finger movement is an independent movement. But the coordination of the consonants does not make them independent; they are accessory movements, only; they delimit the chest pulse, and in that function they can occur no oftener than required by the process of releasing or arresting the chest pulse. The finger movements in piano playing give strokes which are individual elements in the rhythms but no rhythms are built of separate consonants singly or in combinations - the rhythms of speech all have as units 
the syllables, the chest pulses, and never the consonants.

In the two-member pairs the abutting consonants seem to

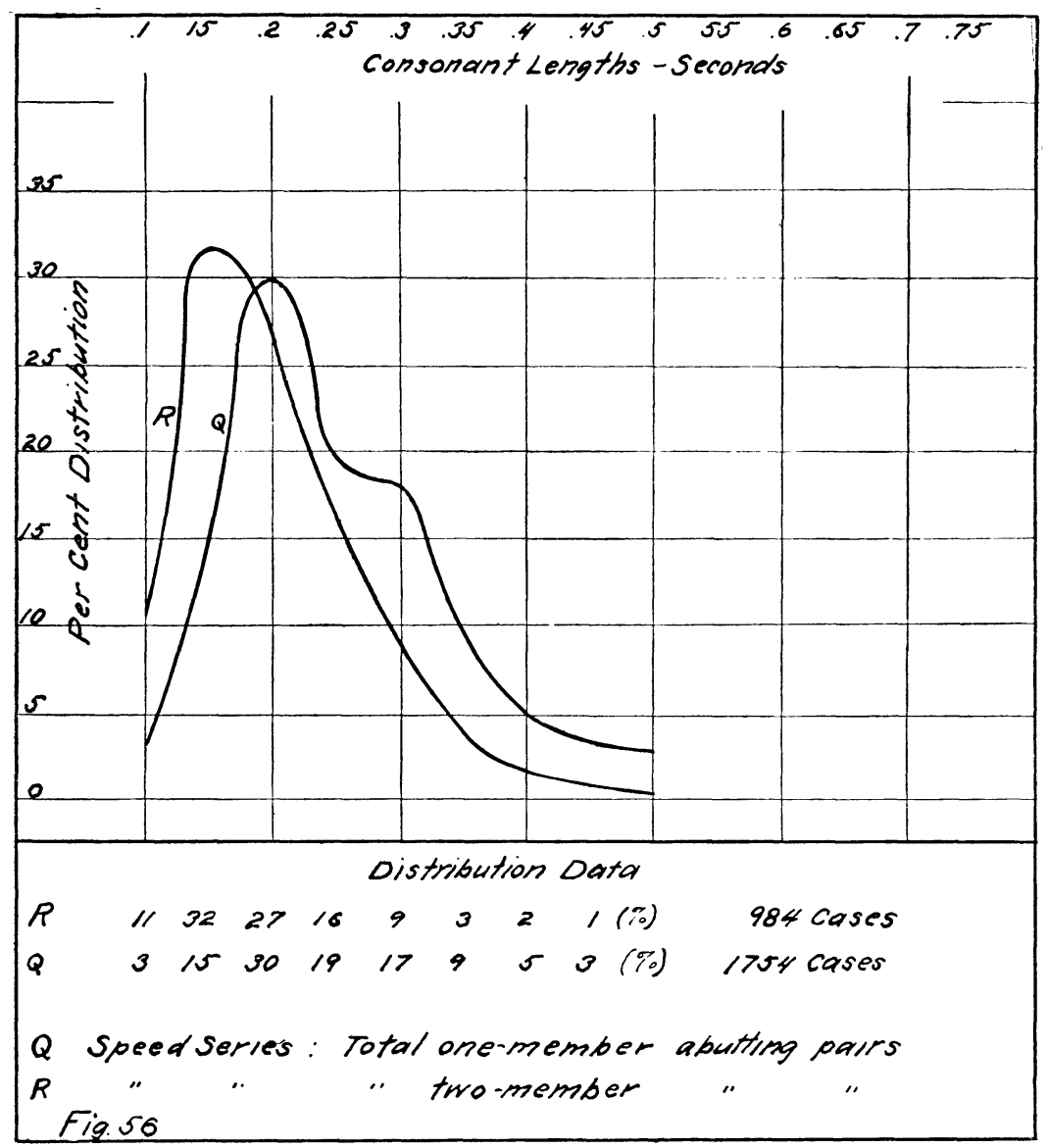

A comparison of "one-member" abutting pairs (including doubles) with "two-member" abutting pairs.

A ,one-member" pair consists of two consonants produced by the same member, either tongue or lips. tut-tut, puf-puf, tas-tas, etc.

A "two-member" pair consists of two consonants produced by different members, lips and tongue. "bus-bus, dip-dip, fuz-fuz, etc."

The distribution of the two-member abutting pairs indicates that they tend to be somewhat shorter than the one-member abutting pairs.

stretch toward each other. The tracings of the contacts of the consonants show that they elongate each in the direction of 


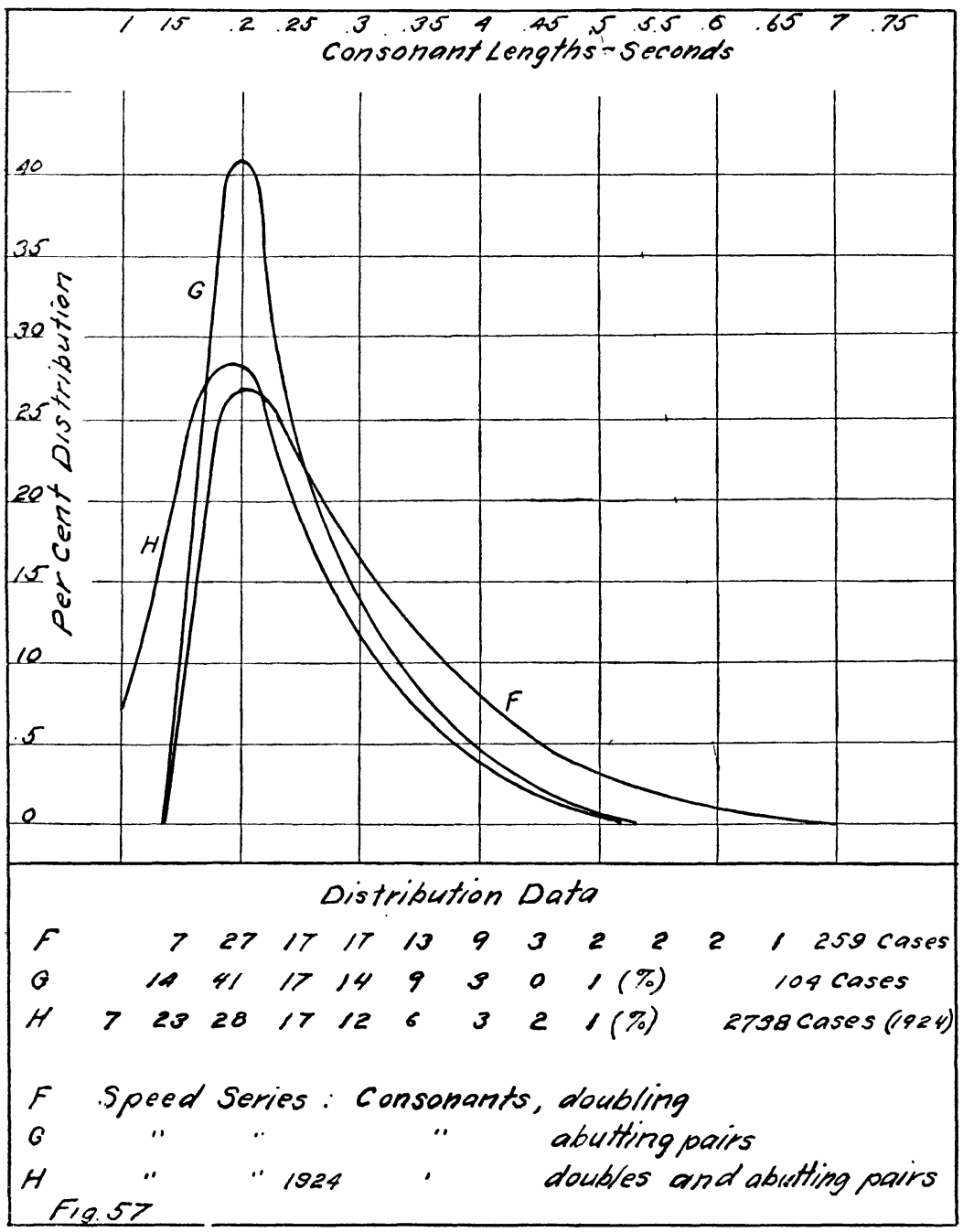

Distribution of the lengths of doubling consonants produced by increasing the speed in a series of syllables, either one-member forms like "pup, pup.. pu, pu.." or "ted, ted.. te, te.." or two-member forms like "pet, pet.. pe, pe.." $F, G$, series recorded in 1926 .

$H$, series recorded in 1924 . The distribution, involving a large number of cases, is practically identical with that of $F$ and $G$ above.

the other. This is part of the tendency of the movements to fall into step, to coincide. The first consonant stroke is held ARCHIVES DE PHYSIOLOGIE, TOME XIII. 
in anticipation of the one to come, and the second consonant stroke occurs early in order to fuse with the previous stroke. Like drops of liquid they tend to run together. Of 95 series taken at random, 72 show such "attraction" of the consonants. The average length before doubling of the individual consonants is .I 7 sec. (2 I4 readings.) The average length of the individual consonants while doubling is .20 sec. (284 readings.) The difference in these averages is significant, as the readings were made in pairs and in every case the value of the consonant before doubling was lower than the value of the consonant while doubling. Any influence of the increasing speed of utterance would work against this tendency to lengthen the consonants as they come to abut. Figures 58 and 59 give cases in which the "attraction" of the doubling consonants is very marked.

\section{Arresting Consonants as "Constructive Doubles."}

It is possible to consider any arresting consonant as virtually a double, although it may not be followed by a releasing consonant. In the case of a series of syllables with double consonants, the increase of speed forces the dropping of the arresting consonant. It cannot shift position and persist because the releasing doublet is produced by the same member. In the case of a series of syllables with two-member abutting pairs, the arresting consonant does shift position and come to overlap the actual releasing consonant as a functionless consonant stroke. Likewise in a series with single arresting consonants as the speed increases the arresting consonant shifts to the unoccupied releasing position in the next syllable; and the shift occurs at about the same rate as does the dropping of the arresting doublet. The "constructive double" has for one doublet the single arresting consonant, and for the other doublet the zone of self-release of the next syllable; when the speed increases, the arresting consonant slides into the releasing position like the arresting doublet of the two- member abutting pair. In all cases the arresting consonant disappears and a releasing consonant remains.

The graphs representing the distribution of "constructive doubles" show the fact that there is no distinction between the "long" vowels and the "short" vowels in the matter of doubling. The long vowel can be shortened, but the short 
MOTOR PHONETICS.

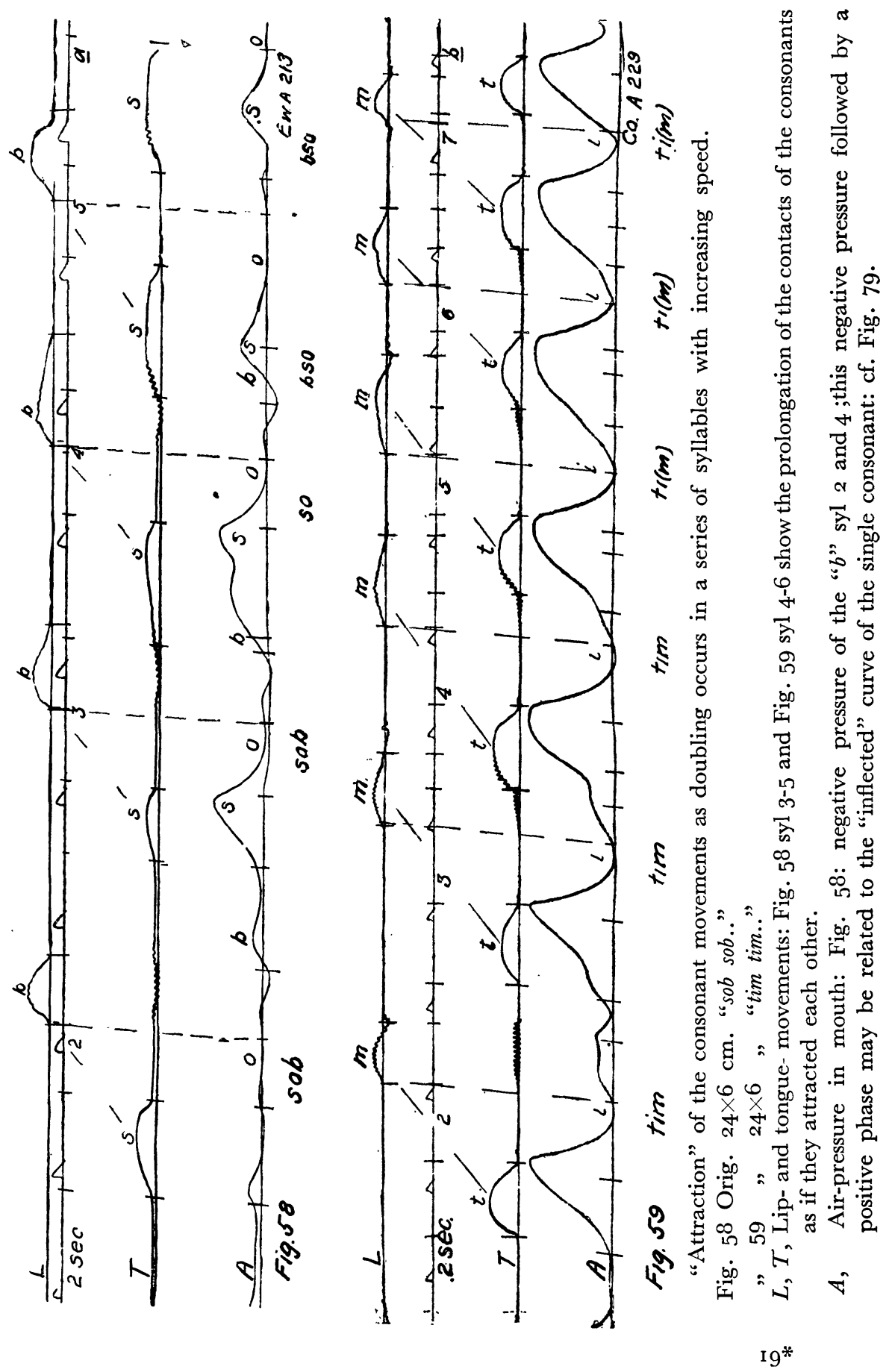


vowel cannot be lengthened. As these changes occur at a fair rate of speed all vowels are actually of short duration.

The tendency to restoration of the original form is apparent in these series in which the "constructive double" is affected by changing speed of utterance. When the speed is reduced, so that the original arresting form is again possible, the consonant shifts back to the arresting position; the original prescribed form is restored; later it will be obvious that the same thing occurs in accented groups of syllables.

The distribution curves of the constructive doubles Fig. 63 p. 294 when compared with the distribution curves of other abutting pairs, Fig. 44 p. 269 , show that the rate at which the change takes place is slightly higher. It is evidently easier to retain an arresting consonant than an actual double as the speed increases. Cf. Fig. 5, p. 2 I8.

Fig. 6o shows the mouth pressure and the chest pressure tracings for the phrase "at $E$, at $C$." The doubling form of the mouth pressure is apparent in "at $C$ "; the maximum of the chest pressure occurs immediately on the détente of the double; the minimum occurs as usual during the releasing doublet. But in the case of "at $E$ " the maximum of the chest pressure does not occur until .10-.20 sec. after the détente of the " $t$ " and the minimum occurs at the détente.

Fig. 6I shows the same relations in terms of the pressure outside; the vocalization occurs immediately at the détente of the " $d-t$," and the chest-pressure minimum is indicated in "add $E$ " by the drop in the curve .20 sec. after the détente of the " $t$ "; the vocalization of the " $E$ " does not begin until that point.

Fig. 62, "at $E$, at $P$ " shows the same contrast in the case of a two-member abutting pair, " $t-p$. ."

If "constructive doubles" of this type are measured as the arresting consonant plus the self-release, and tabulated, the result is a curve of distribution of lengths, Fig. 63. It is evident that the "constructive double" when the speed increases, has the same limits as the same constructive double when the speed decreases. These values are evidently of the same order as the rates for abutting pairs to be seen in Fig. 44 p. 269. 
MOTOR PHONETICS.

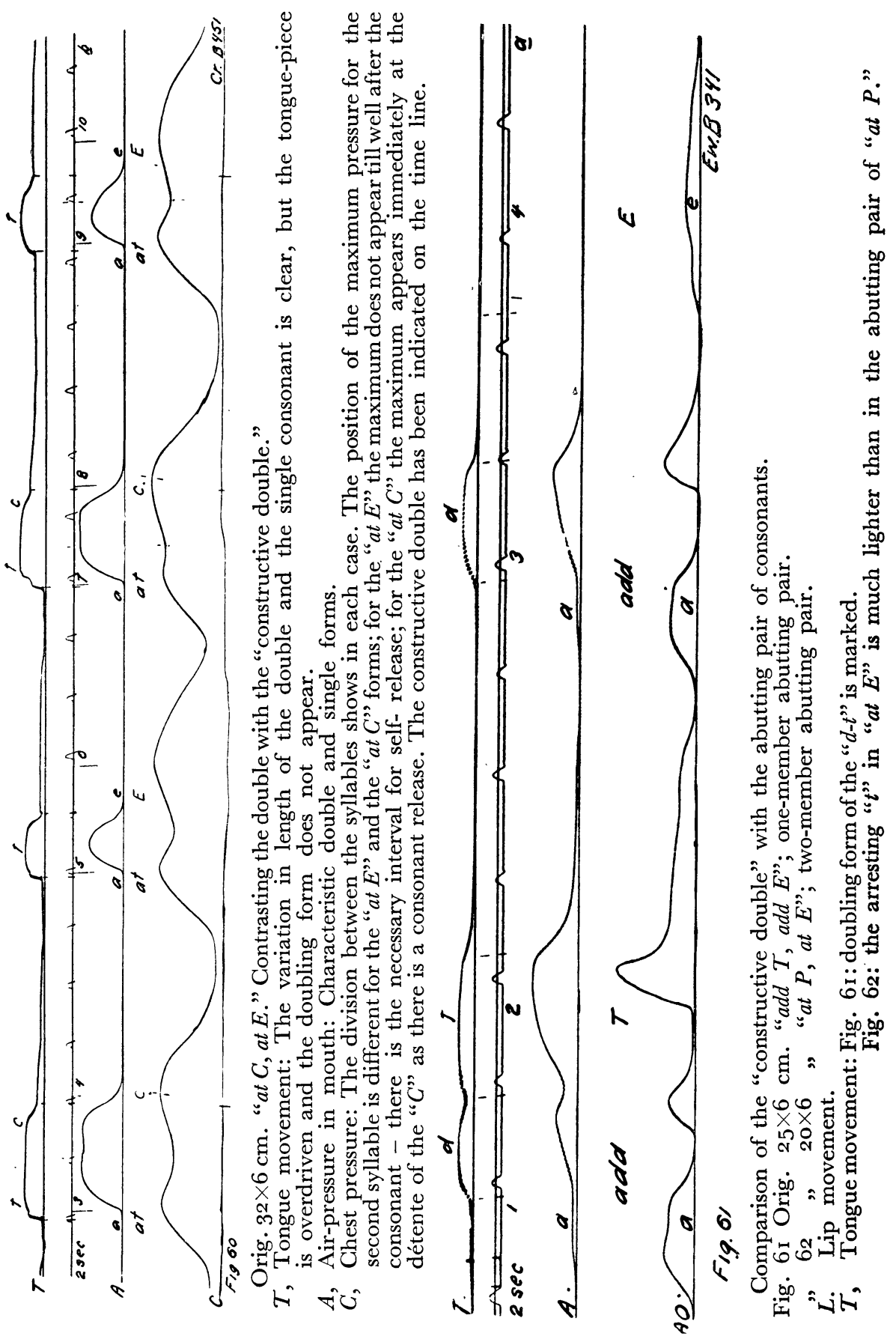




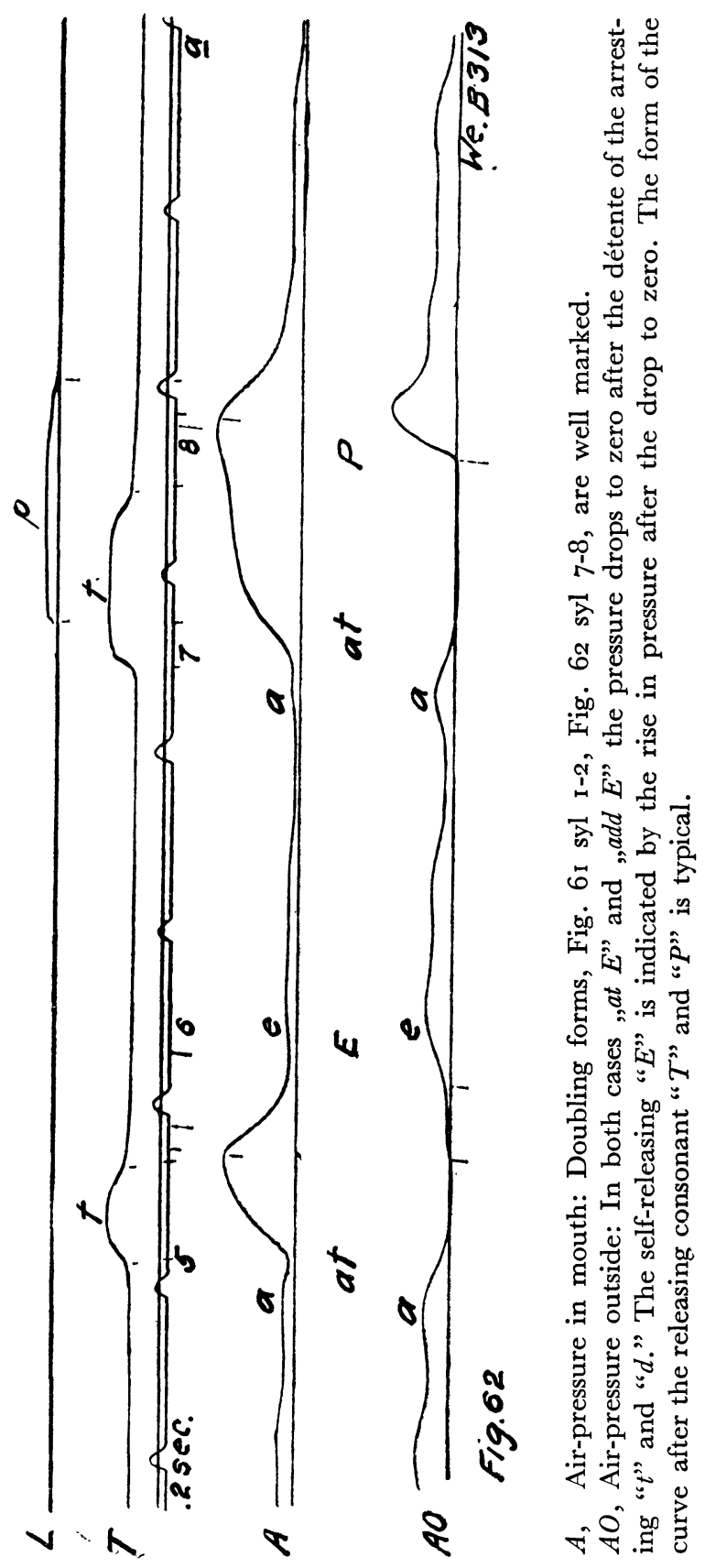


Compound and Multiple Consonants. Consonant Groups which Function as a Single Consonant.

Two or more adjacent consonants may be classed as an intrasyllabic group when the group figures as a compound consonant in releasing or arresting the syllable movement, as contrasted with abutting consonants each of which has a different function in two different syllables. It is possible of course that a compound consonant figure as one of the abutting consonants.

In the group the consonant movements are as nearly simultaneous as the nature of the movements combined will permit. Together they function as a single arresting or releasing factor in the syllable and frequently they are so brief and so close together that they must contribute qualities, rather than distinct elements, according to the "law of discrete succession."

RousseLOT's analysis of such intrasyllabic groups is masterly:

"If the consonants are produced by two different members, they are prepared together, and the movements of uttering them may be simultanous - which is quite true of "pla" and "fla." In every case at the moment when the first consonant is being articulated, the second is fully prepared. The two détentes follow each other more or less rapidly... If the consonants involve the same member, there are two cases: I) the articulation takes place at the same point, e.g. "tla;" the articulations occur at separate points, e.g. "kla." In I) a single initial movement is made for both and a slight deviation in the tracing marks the entrance of the second consonant; in 2) the movements are inevitably successive." ${ }^{1}$ )

The intrasyllabic groups differ somewhat according as their function is arresting of releasing, but there are certain common features of them all.

There is the group which is a compound consonant, and which has but the one consonant beat stroke; the primary quality of the group occurs at the beat stroke, the auxiliary qualities occur during the preparatory phase of the beat stroke, or during the relaxation phase, the back stroke. In such common groups as "sp," "st," "sk," the fricative occurs during the pre-

1) Principes II p. $950 \mathrm{f}$. 


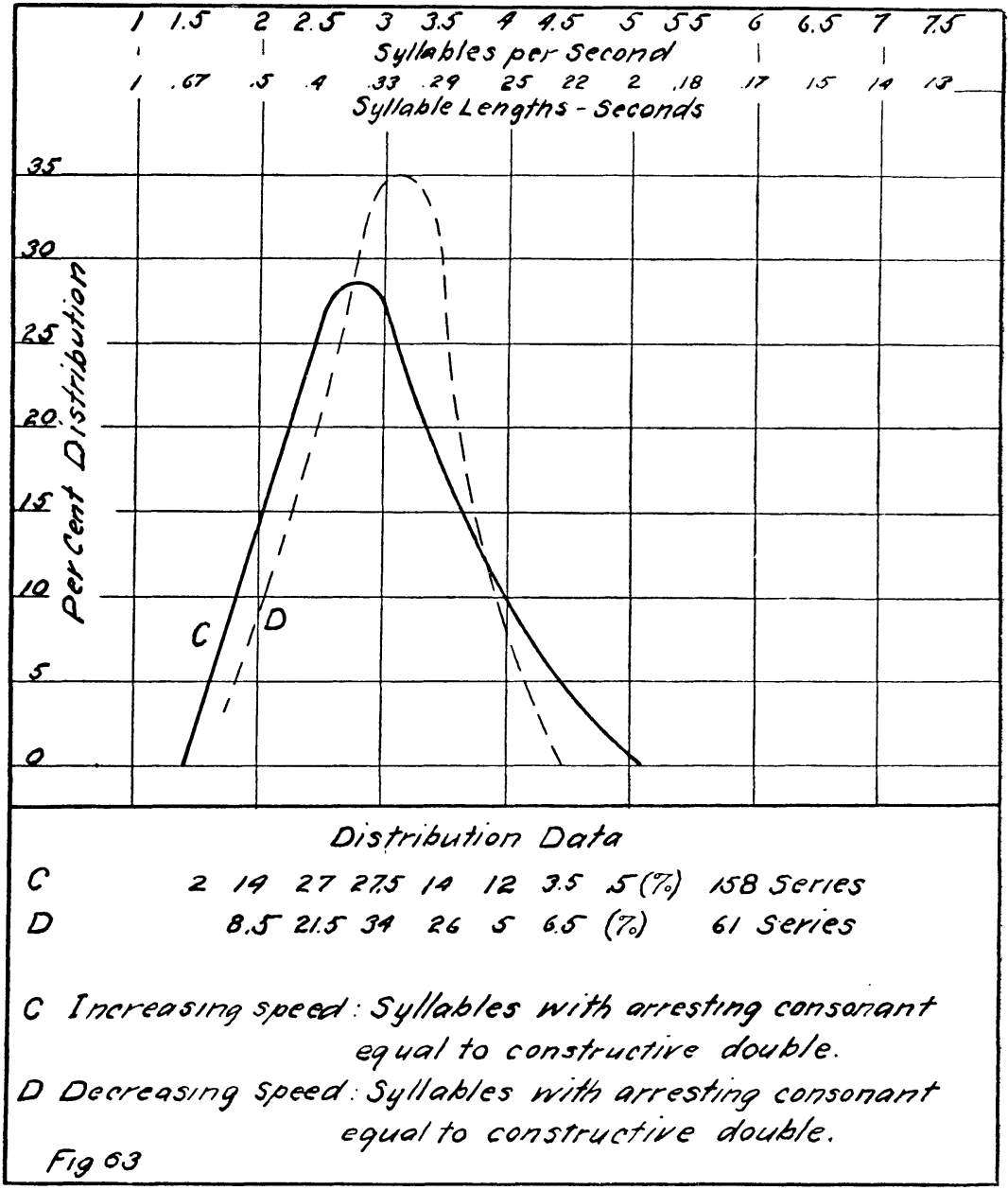

Distribution of the rates of „constructive doubles” developed by increasing the speed, and by decreasing the speed, in the same series.

The rates at which syllables with an arresting consonant become syllables with releasing consonant, and vice versa. Cf. Fig. 5 and 7. p. 218 and 219.

Comparison of a process which appears as the speed increases, with the same process in inverse order appearing as the speed decreases, in the same series of syllables.

$C$, Distribution of the rates per sec. at which a series of syllables with arresting consonant becomes a series with releasing consonant, as the speed increases; „up, up.. pu, pu..”

$D$ Distribution of the rates per sec. at which the same series reverts from ,..pu, pu.." to , ,up, up.." The distributions are identical. It is probable that all the types of series, doubling and singling, would show the same identityfor increasing and decreasing speed, had the study been made. 
paration of the beat stroke. In forms like " $t s$," "tch," " $d z$," " $k s$," the auxiliary sound occurs during the back stroke. It is often difficult to say whether the group represents a single "sound" or a combination; languages differ in their handling of many of these groups. The German spells a group "tsch," which the French spells "tch," and the English "ch." The English spells " $t s$ " a group which the Polish represents by the single " $c$." The Greeks analyze the voiced occlusives into " $m p$, $n t$, $n k$ " which other languages treat as simple sounds. The Greek sigma is possible a simple sound but it can be represented by "sy" ( $y$ consonantal.) The French "chuintantes," and some sounds certainly simple like " $s$ " in many words, have passed through all the stages from distinct consonants combined, to a simple "sound."

Such groups appear when certain series are uttered at increasing speed; instead of dropping, the arresting consonant fuses with the following releasing consonant. Thus "tas, tas.." gives rise to "sta, sta.." Such compounds appear in the releasing position. Compound consonants in the arresting position are also common, e.g. apt, apse, asp, etc.

The series involving a fricative often results in such compound consonants when the speed of utterance is increased.

The compound consonants " $t s$," "st," and "sht" appear in Fig. 64,65 , and 66; the process is apparent by which they are produced. Such compound consonants often persist as a stable releasing consonant and may be present at high speeds, at 5-7 syllables per sec.

In the releasing form of the compound consonant with an initial fricative component like " $v$ " " $f$," and especially " $s$," the air-pressure curve is apt to show a slightly prolonged and rounded form "convex-concave," cf. Fig. 27, 5, p. 256 . In some cases there develops an unvoiced preceding syllable and a bi-syllabic form results. This shows rarely in the records of these English-speaking subjects. But the history of the Romance languages shows this development of the preceding syllable, especially in the case of " $s$," cf. "spiritus, esprit," etc.

The very common group of a consonant and a liquid is of a different type. The liquid $(l, r)$ is so open a conformation that it permits the puff of the syllable movement to begin, and although the liquid component involves a distinct stroke, this occurs during the beat stroke of the syllable; this type of 


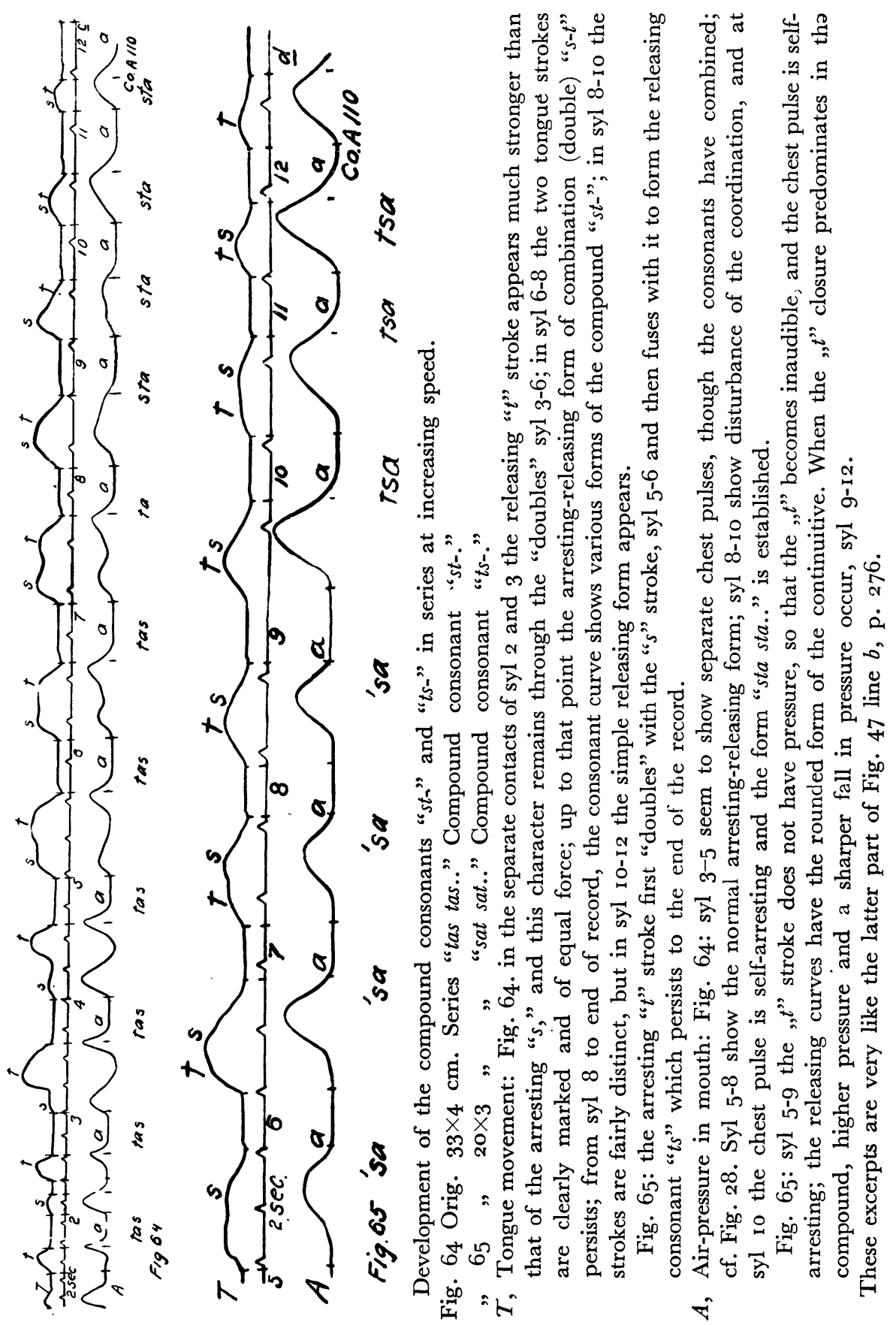


MOTOR PHONETICS.

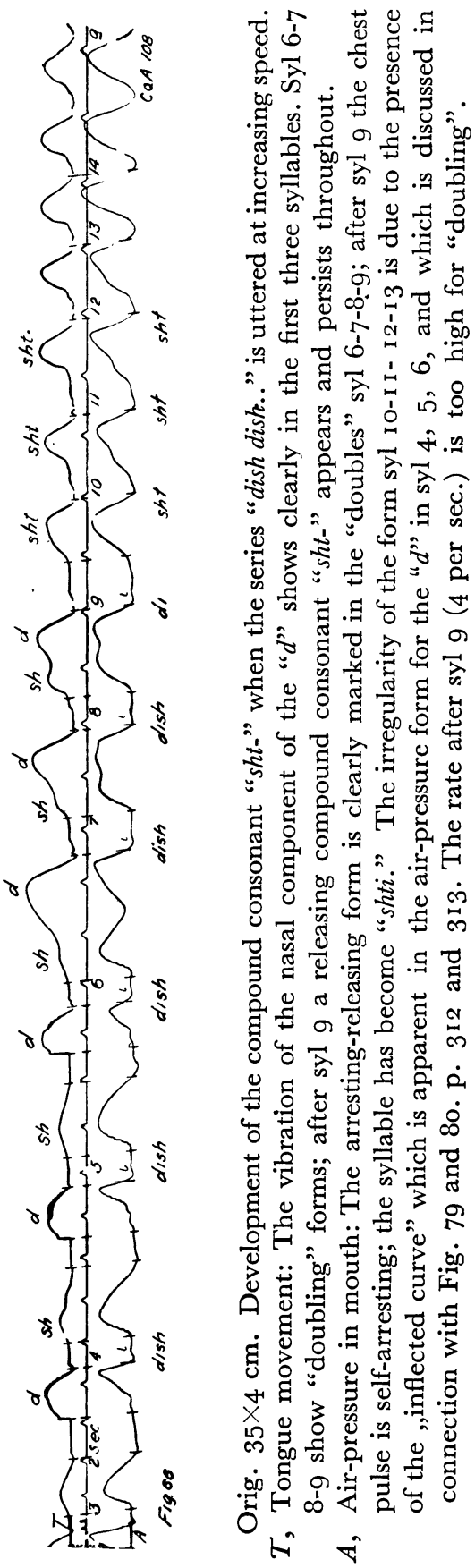


R. H. STETSON.

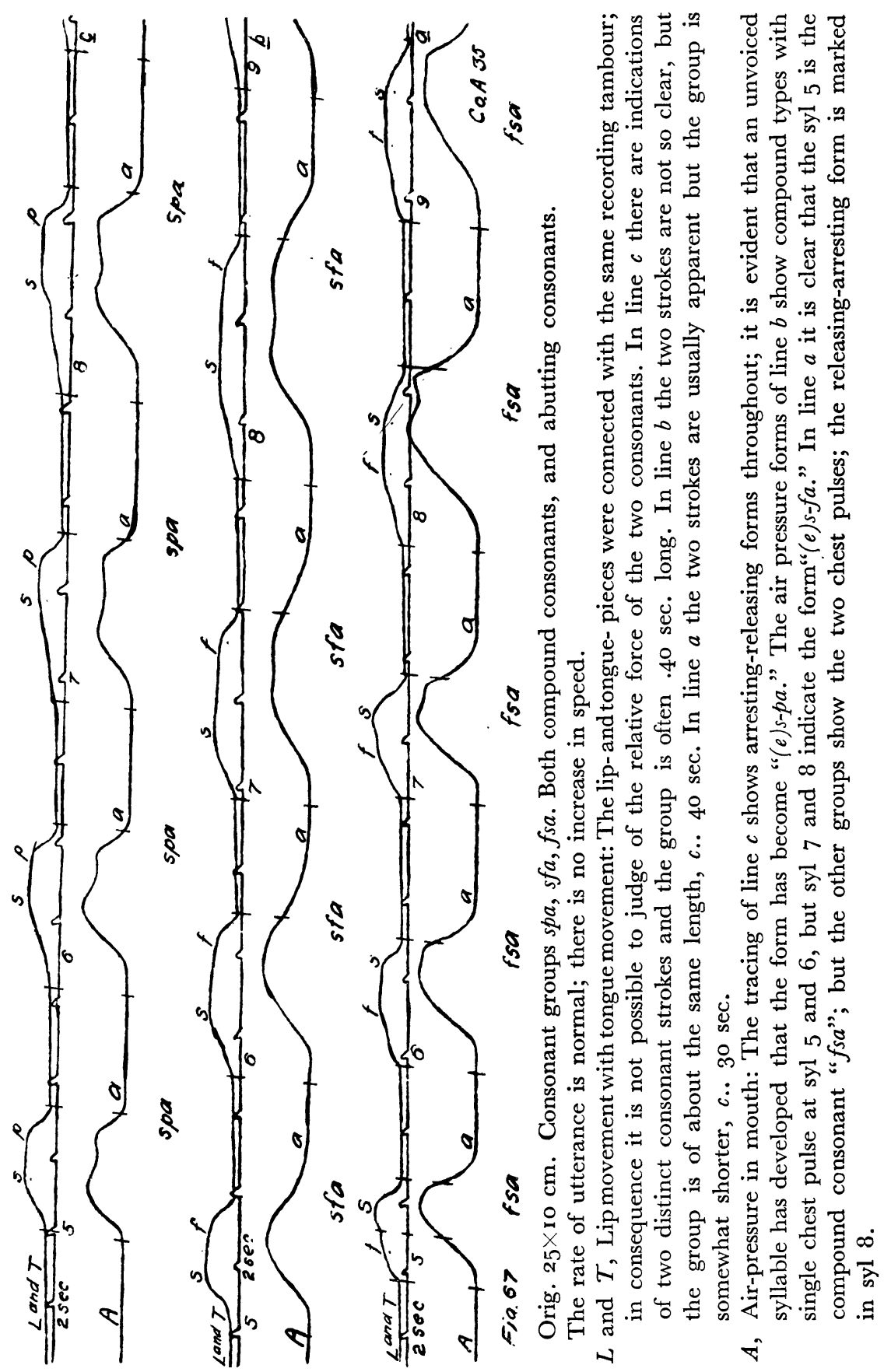


liquid might be called an "internal consonant." Like the conformation of the vowel, the conformation of the liquid may be assumed before the preceding consonant is uttered and retained while the consonant is being executed; the conformation of the " $l$ " or " $r$ " does not interfere with the enunciation of the consonant; this is often the case with the vowel. Releasing groups with a liquid are very common, e.g. "glide, crow, try, blow, pry." For some reason " $t l-$ " and " $d l-$ " do not appear in most of the western languages.

In arresting groups the liquids figure as "internal consonants." SweEt long ago observed that the liquid continues the vowel, or rather occurs with the vowel. In a form like "grilled" there is no vowel to be heard save the two internal consonants " $r$ " and " $l$ ". The nasals also appear as possible components of arresting groups e.g. "hand, unkempt, Kampf."

These compound consonants are to be distinguished from abutting consonants. In the phrase " $a$ tall $D$ told $E$ " the succession " $l$, $d$ " occurs as an abutting pair in "tall $D$," and as a compound consonant in "told E." In Fig. 70 the doubling " $l-d$ " is indicated in the mouth-pressure tracing, whereas the " $l d$ " is a single arresting form; the releasing " $d$ " of " $l-d$ " contrasts with the arresting " $l d$ " in the position of the maximum in the chest pressure in each case. In Fig. 7 I, the "pl" in "plate" has a sharp releasing form due to the " $p$ " stroke. In the " $p-l$ " of "up late" the " $p$ " is arresting and the " $l$ " is the releasing consonant; the mouth pressure for the releasing " $l$ " is much lower.

There is also the multiple consonant in which the components maintain their identity and each has its own beat stroke, but the beat strokes occur so close together that they fuse with each other in arresting or releasing the syllable movement. In the French pronunciation of "pneumatique, psychologie, psaume," in the Greek pronunciation of "bdellum, ptyalin, kteino," and in the German pronunciation of "Pfeil," the two beat strokes of the beginning consonants are apparent; but a breath pulse does not occur between the strokes; there is little escape of air. (It is to be said however that tracings betray the fact that such groups often break up into a preliminary silent syllable followed by a voiced syllable; Cf. Fig. 67 p. 298.) In English forms like "lugg'd, act, apt," (Cf. Fig. 74 p. 306 "apt.") and in the German "Kampf," the succession of beat strokes is obvious.

The grouping in time of such components of a multiple con- 
R. H. STETSON.

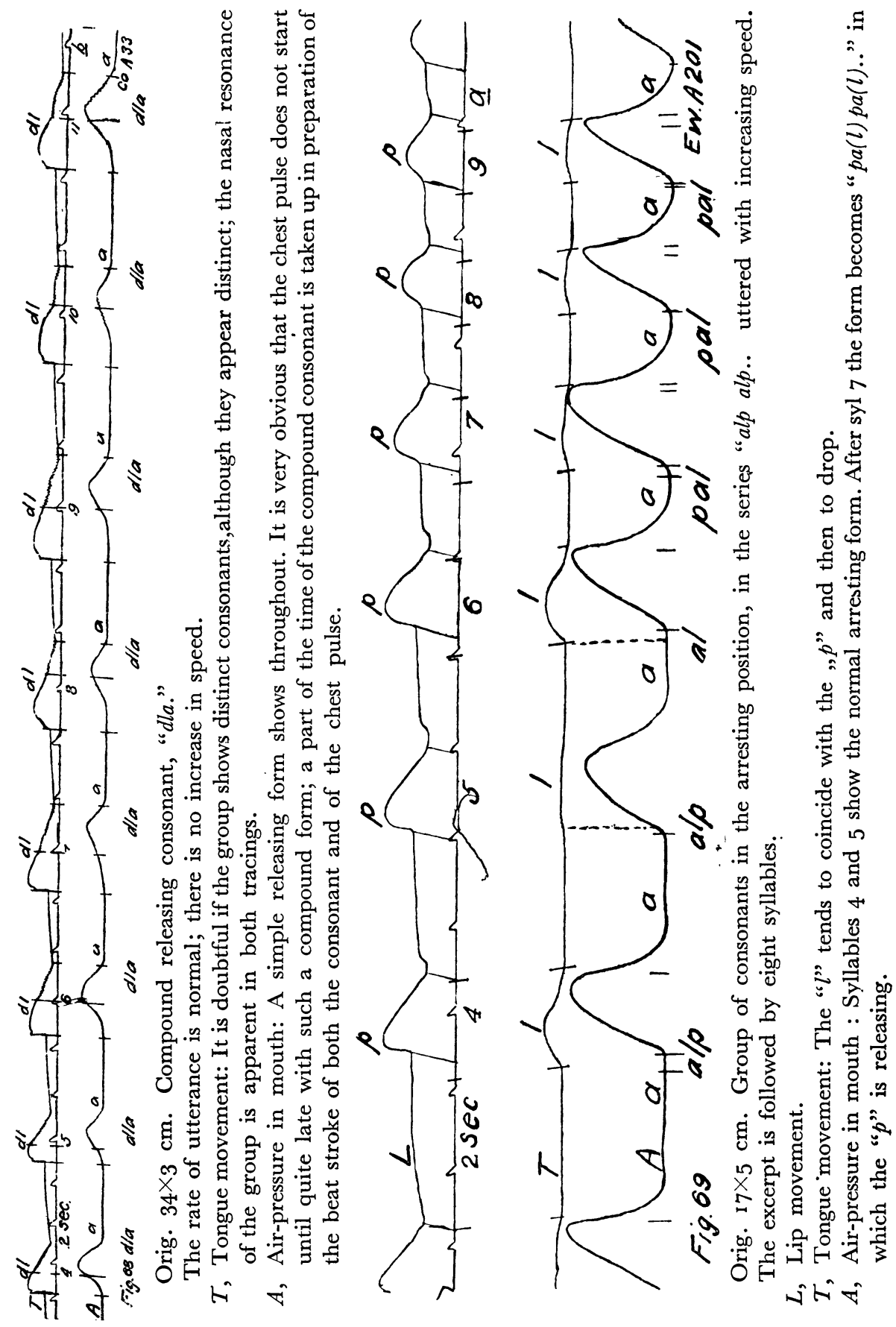


MOTOR PHONETICS.

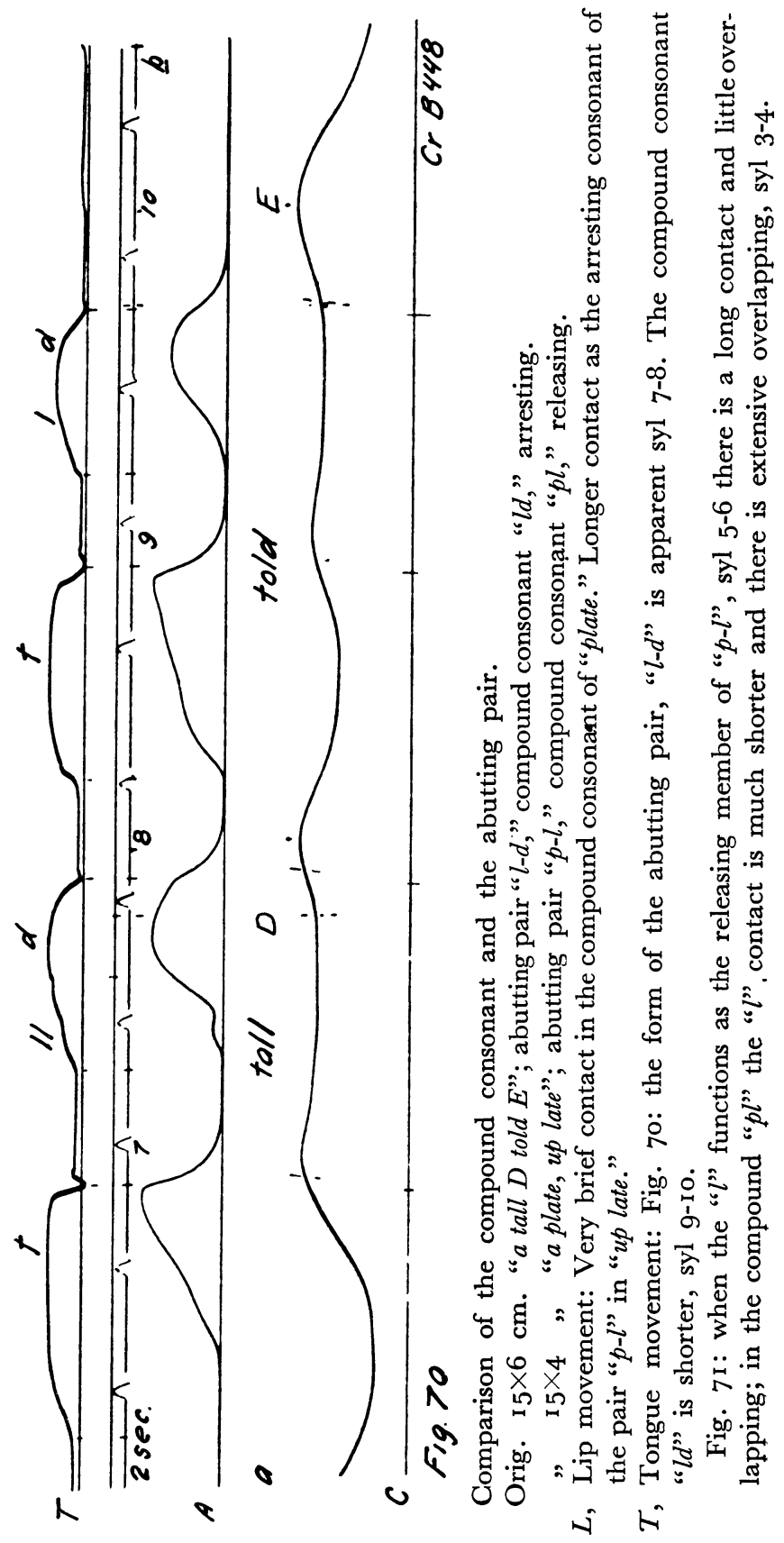




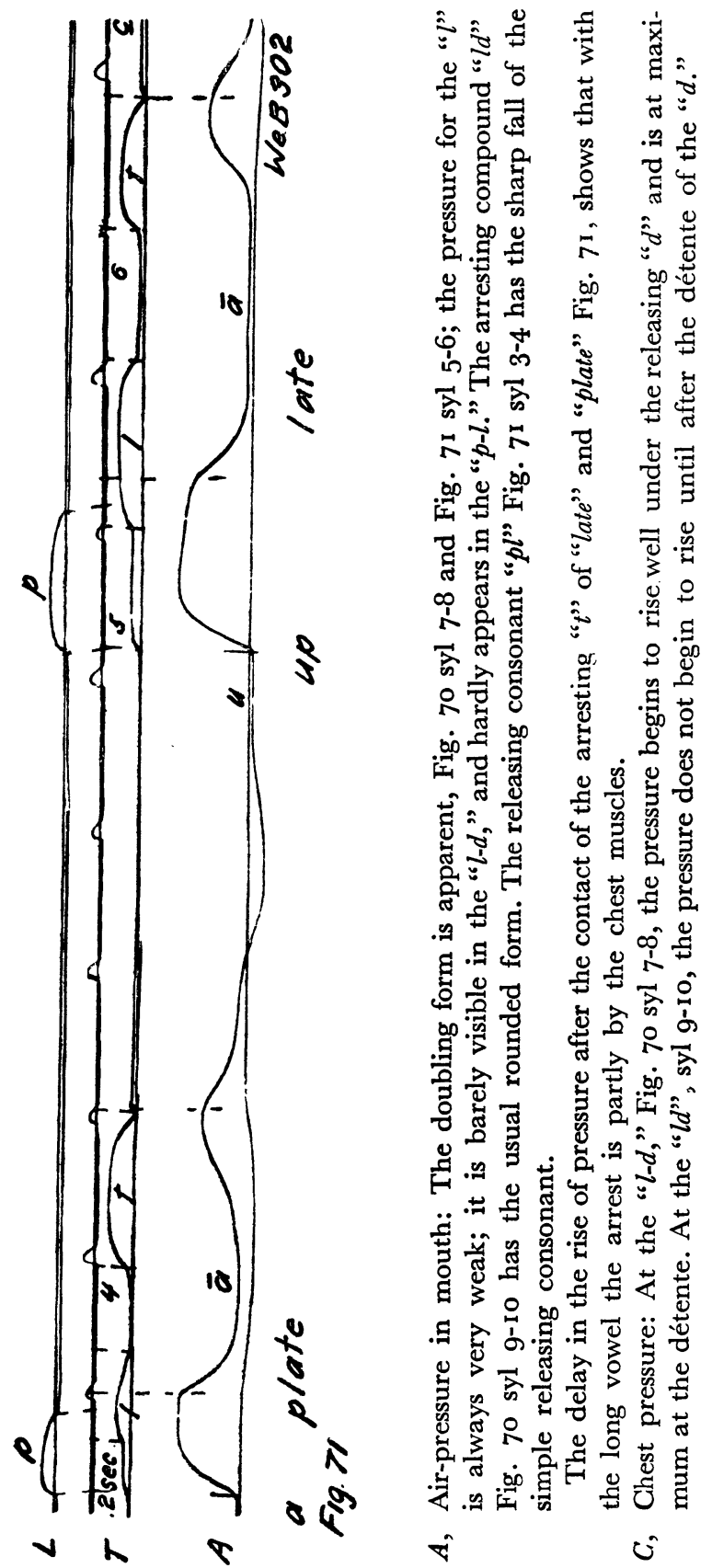


sonant is very close; the group of two or three beat strokes often occurs in the interval of .08-.10 sec. They are close enough to fuse in the syllable movement to a single rhythmic beat. ${ }^{1}$ )

The tracings of " $f s a, s f a, s p a$," and of "pta, tpa," in Fig.67 and 72 illustrate the alternate forms of such groups. If the monosyllabic form is preserved, the two beat strokes of the consonants must occur close enough together so that they are part of one releasing movement. Although not quite simultaneous in these cases they must cluster on the beat like "grace notes" or the componants of a "broken chord" in music. Such multiple consonants show a single form for the release of the chest pulse. But the pronunciation is often facilitated by breaking up the group into two abutting consonants; the first consonant becomes the arresting consonant of an adventitious syllable, and the second consonant releases the chest pulse of the original syllable. The word becomes bi-syllabic; "ef-sa," "et-pa," etc. have developed. Sometimes the adventitious syllable is un-voiced but it shows clearly in the arresting-releasing forms of the airpressure curve. Cf. Fig. 67 line $b$, and Fig. 72 line $c$ syl 8 .

The releasing multiple consonant composed of an occlusive followed by a liquid, " $r$ " or " $l$ " is very like a simple releasing consonant. The " $l$ " stroke permits considerable escape of air but the release is definite. Cf. Fig. 68 p. 30o, "dla."

In the arresting form of the compound consonant with an initial fricative like " $s$ " the mouth pressure curve is rounded if no second syllable develops. But an unvoiced second syllable often occurs, the form becomes bi-syllabic and the characteristic arresting-releasing form appears in the air-pressure tracing. This development of the bi-syllabic form is not as apt to occur with the fricative-occlusive arresting compound ("asp") etc. as it is with the occlusieve-occlusive type like "apt."In all cases the consonant strokes tend to coincide if the true multiple consonantoccurs. ${ }^{2}$ ) The development of the bi-syllabic form "ap-te" is marked by the prolongation of the contact of the second occlusive, and by the arresting-releasing form of the air-pressure curves which indicates the two chest pulses. As the speed increases such bi-

1) Hofbauer, Arch. f. d. ges. Physiol (Pflüger's) 68, p. 553.

Stetson, R. H., Mot. Theory Rh and Discrete Succession, Psy. Rev. I2, '05, p. 346-7.

2) Rousselot, Principes II, p. $95^{\circ}$. ARGHIVES DE PHYSIOLOGIE, TOME XIII. 


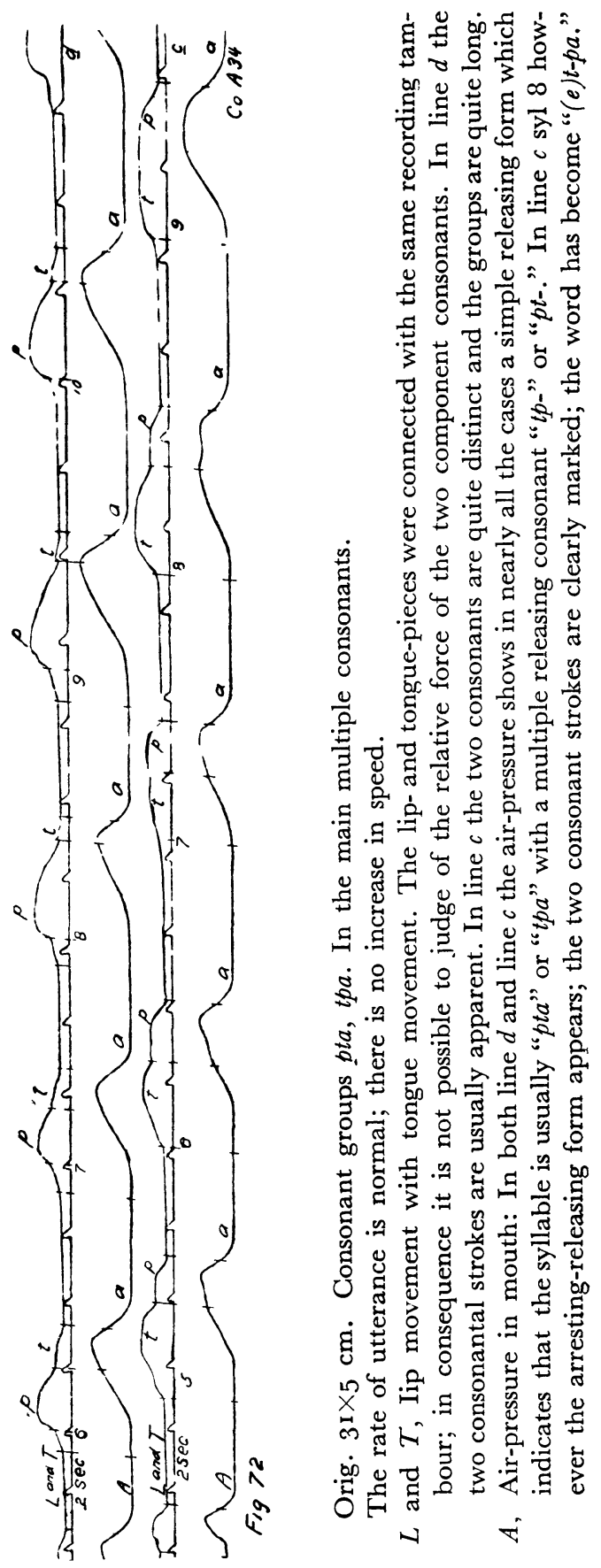




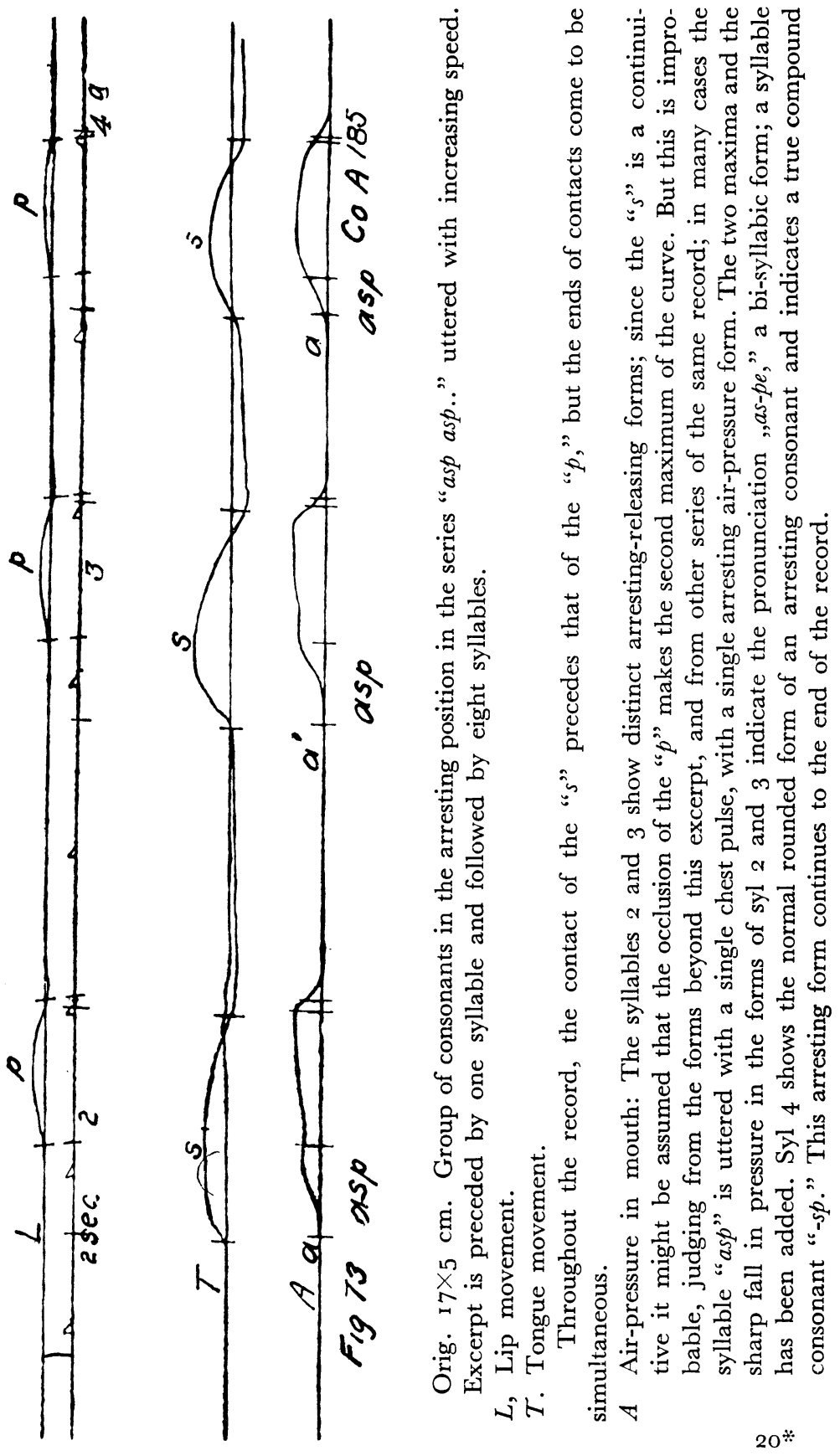


R. H. STETSON.

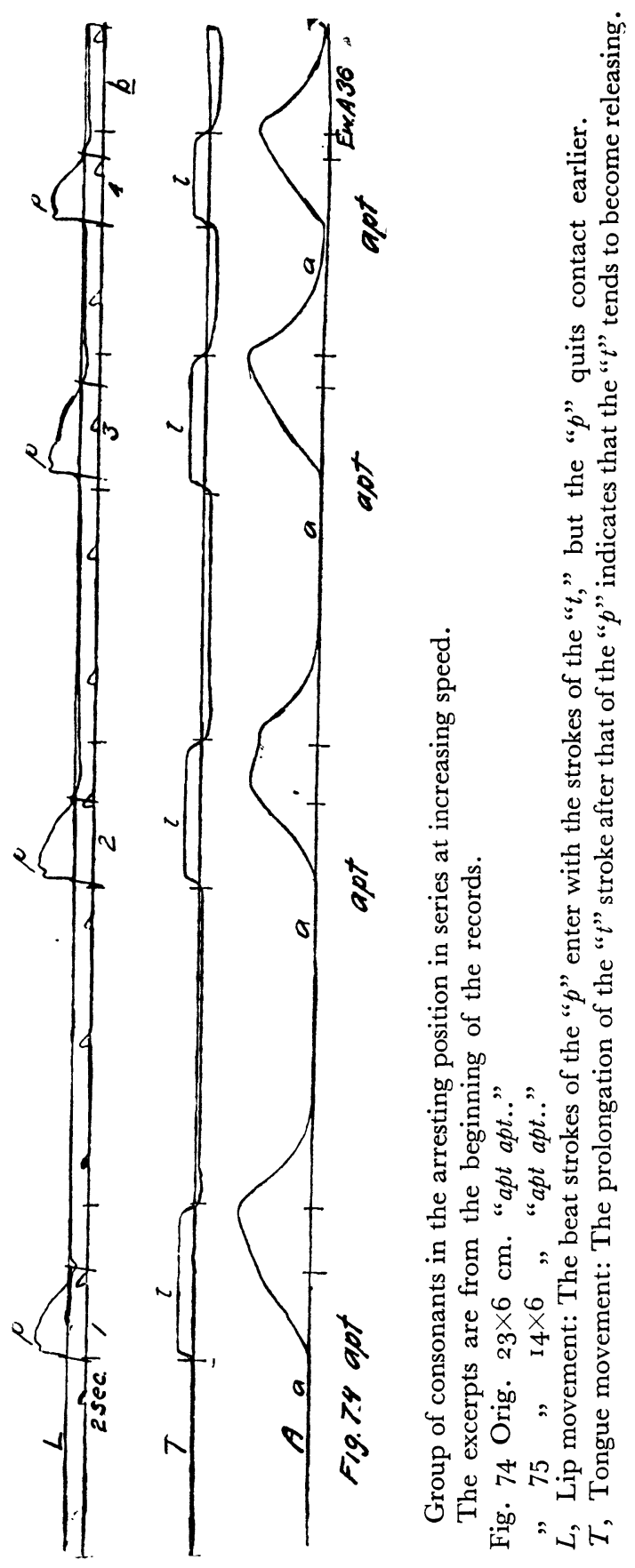



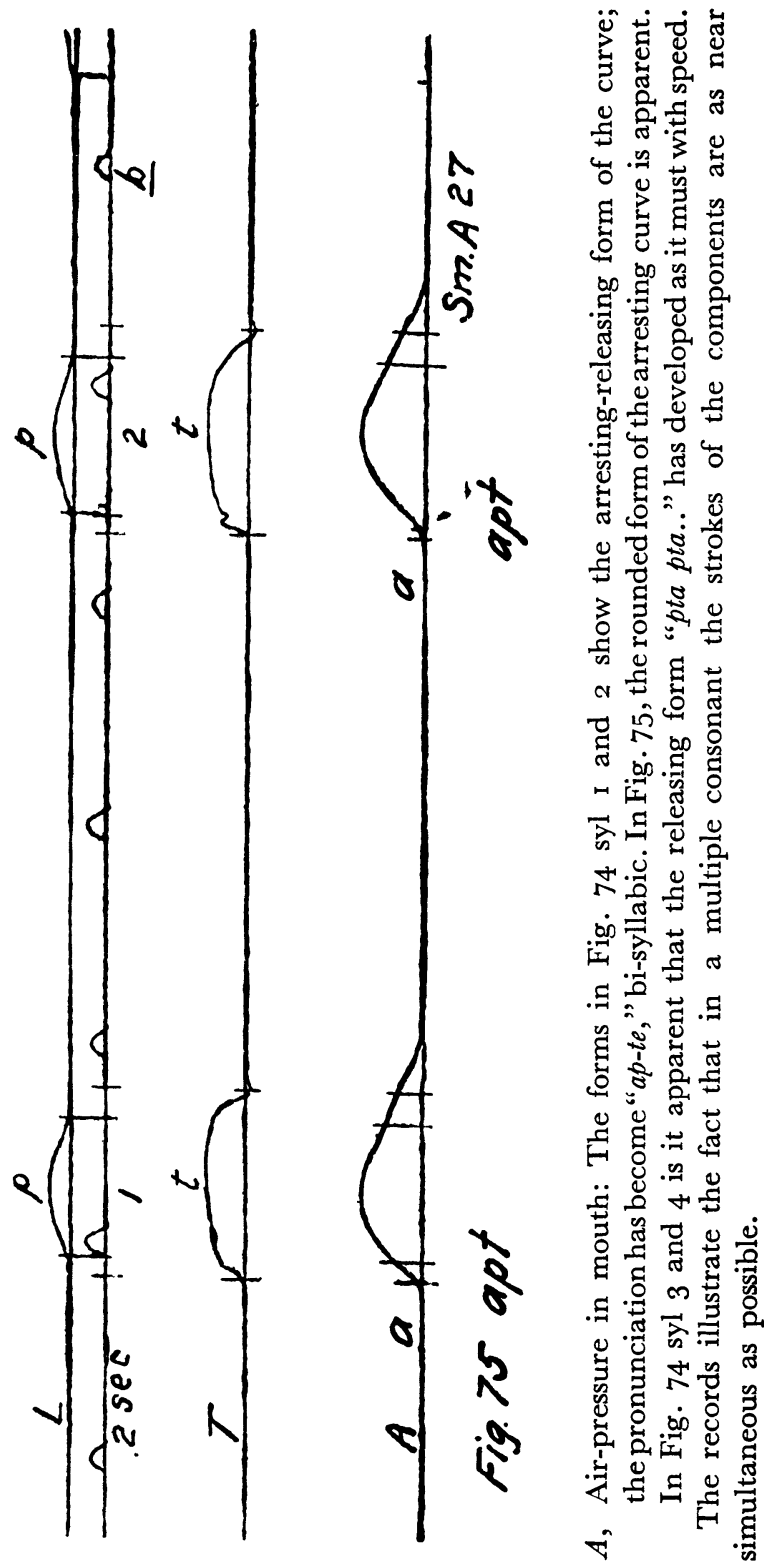

syllabic forms cease and at maximum speed the coordination shifts to a releasing consonant. Cf. Fig. 73, 74, 75.

With a liquid or a nasal as the first component of the multiple 
consonant, the forms do not differ from that of the ordinary simple consonant. There may be a slight elongation and rounding of the air-pressure curve. Increasing the speed of utterance shifts the coordination to the releasing position, and the multiple consonant may simplify, losing its liquid component. Cf. Fig. 69. p. 300 .

\section{Tracings of Bi-syllabic Consonant Groups.}

Rousselot has shown that in the case of an elaborate consonant group like "aptma" the movements of the consonants " $p$ " and " $m$ " tend to fuse, in spite of the intervening " $t . " 1$ ) Tracings of such bi-syllabic groups uttered at increasing speed show that one-member abutting pairs tend to develop, across the intervening movement of the different articulatory member. This is a variation of the "doubling" process and illustrates the fact that when the consonant movement is repeated at a certain speed, whatever the accompanying movements, it takes on the "doubling" form. Fig. 76, 77, p. 209 and 210.

At the same time such complicated groups are important for observation of the releasing and arresting functions of the consonants. It is not the case that a bundle of consonants is tumbled in "between two vowels." Instead, whatever the speed, the consonants are definitely grouped so that they act either as arresting or as releasing factors, either singly or as compounds. In the word " $a f t-p a$ " Fig. 76, p. 209, the " $f$ " coincides with the " $t$ " forming a compound in the arresting position; the " $t$ " keeps its definite arresting position until the word becomes mono-syllabic; only then does it shift to the releasing position and become practically coincident with the " $p$." Mutatis mutandis the same thing is true of " $s$ " and " $p$ " in "isp-da." Fig. 77, p. 2 го. In the words "upspring" and "upspringing," the " $p$ " is the arresting stroke and the " $s p$ " the releasing stroke throughout. But in the more rapid "upspring," the " $p-p$ " may form a doublet over the intervening "s." Cf. Fig. 78.

1) Principes II p. 957 , f. 


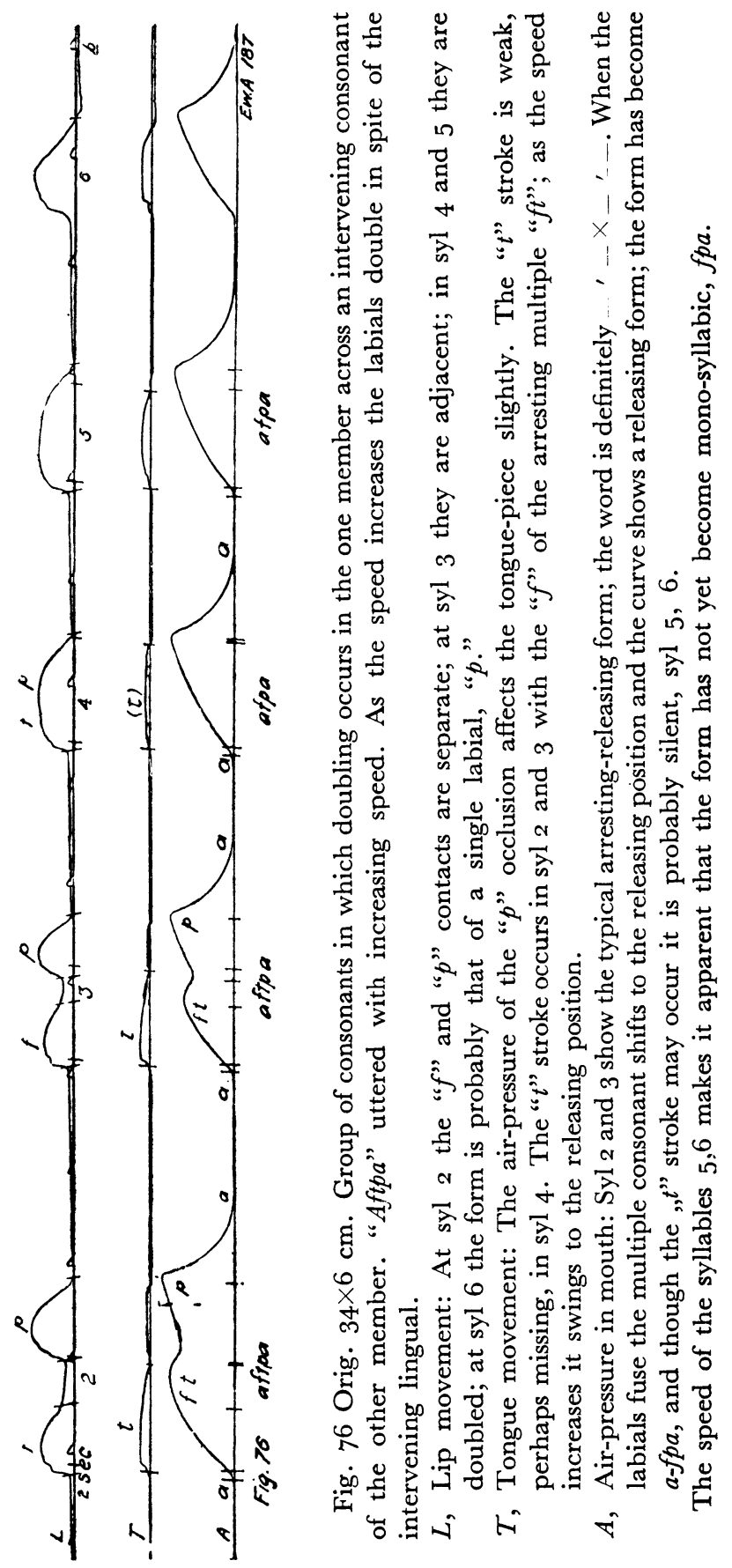




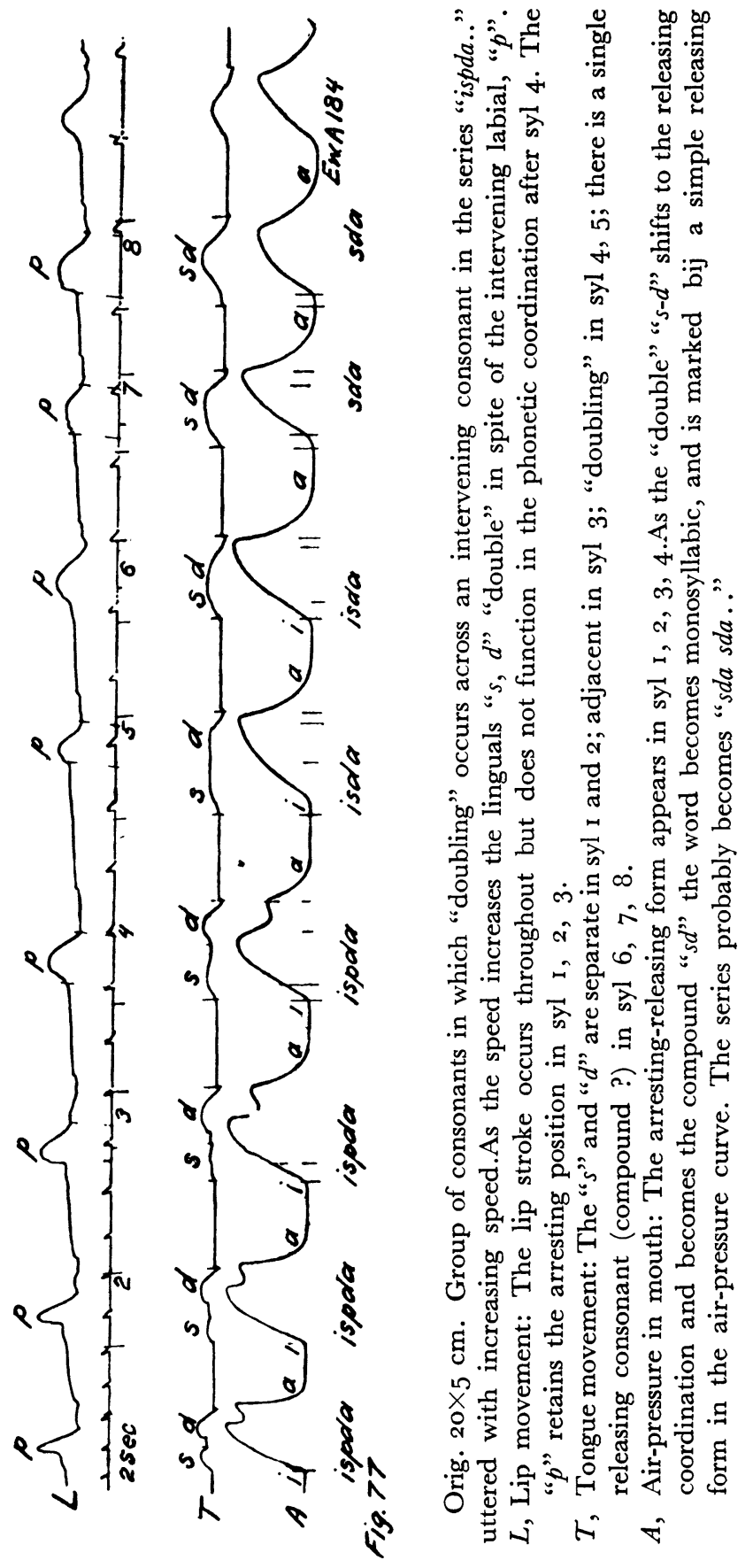


MOTOR PHONETICS.

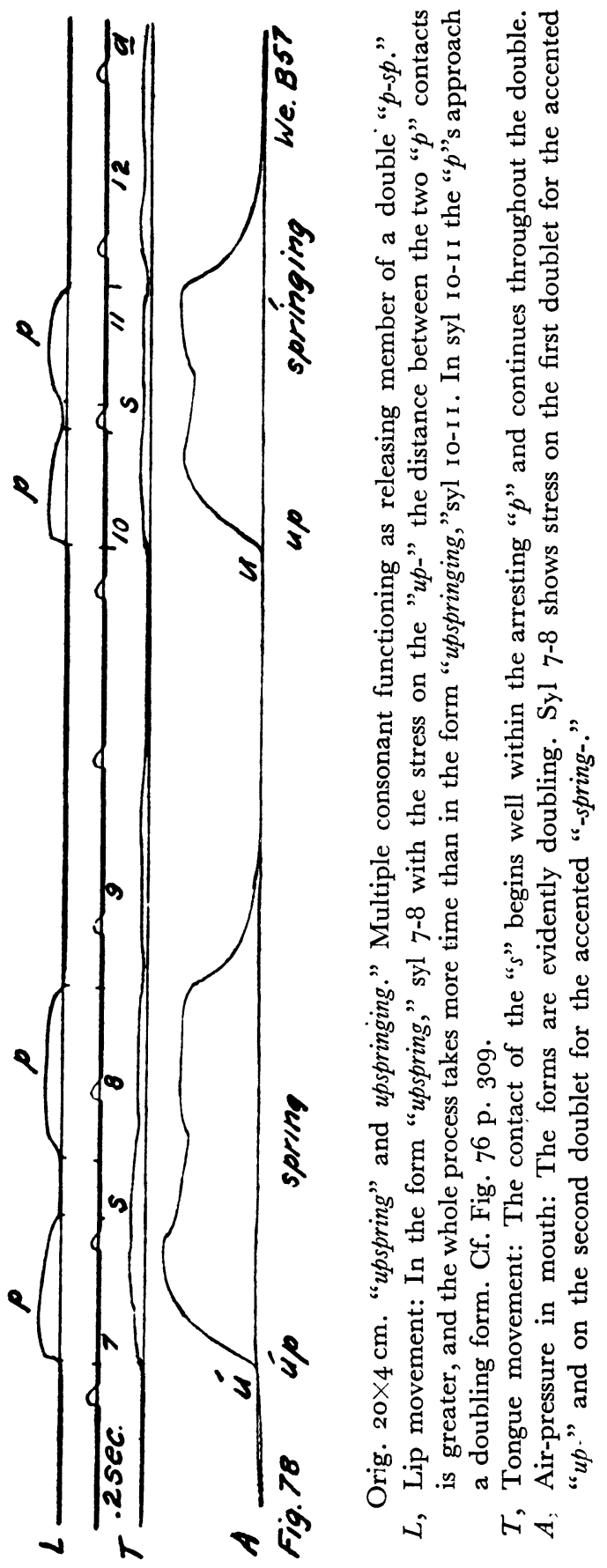




\section{The Inflected Air-pressure Curve of the Single Consonants.}

At first sight this inflected air-pressure curve is like the "bimaximal" curves of the double consonants and of other abutting pairs. But there is no difficulty in distinguishing the curve forms.

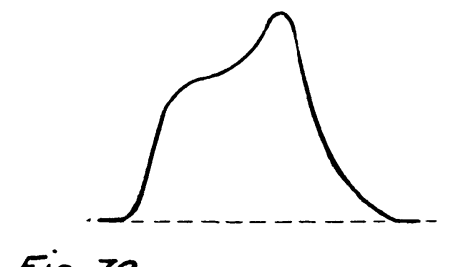

\section{Fig 79}

Diagrammatic Drawing of the "inflected" Air-pressure Curve.

There is a definite variation in the pressure, but the form is too brief to be a double, and occurs with simple and often isolated consonants. Cf. Fig. 80 and Fig. 30. Fig. 5o shows the inflected curve associated with negative pressure; probable that they are due to the same cause.

The lengths of the consonants involved are those of the single consonant. Cf. p. 254 .

The form of the curve is shown in Fig. 79.

This slight fluctuation in the air-pressure in the mouth is more apt to occur with nasals and with occlusives with a nasal phase, like " $b . "$ It occurs in both the arresting (Fig. 30) and in the releasing positions, (both arresting and releasing in Fig. 8o.) Records of whispered syllables with both voiced an unvoiced consonants show the inflected form of mouth pressure curve. Tracings of the air-pressure taken at the same time from the mouth and from the nose show the same inflected form in both tracings.

The air-pressure forms in which negative pressure appears, as in Fig. 50, and the "mid-sag" in outside pressure resemble this fluctuation. Although records of nasals often show negative pressure in the mouth, it is not probable that such negative pressure occurs in ordinary speech. When the air-pressure record of nasals is taken from the nose, the "olives" in the nostrils lead into a closed chamber. It is probable that the negative pressure of the records is due to a rapid increase in the volume of the mouth, just as the mid-sag of the outside pressure is due to the change in mouth volume. Cf. p. 220. The inflected curve of the nasals and of an occasional occlusive is probably due to 
MOTOR PHONETICS.

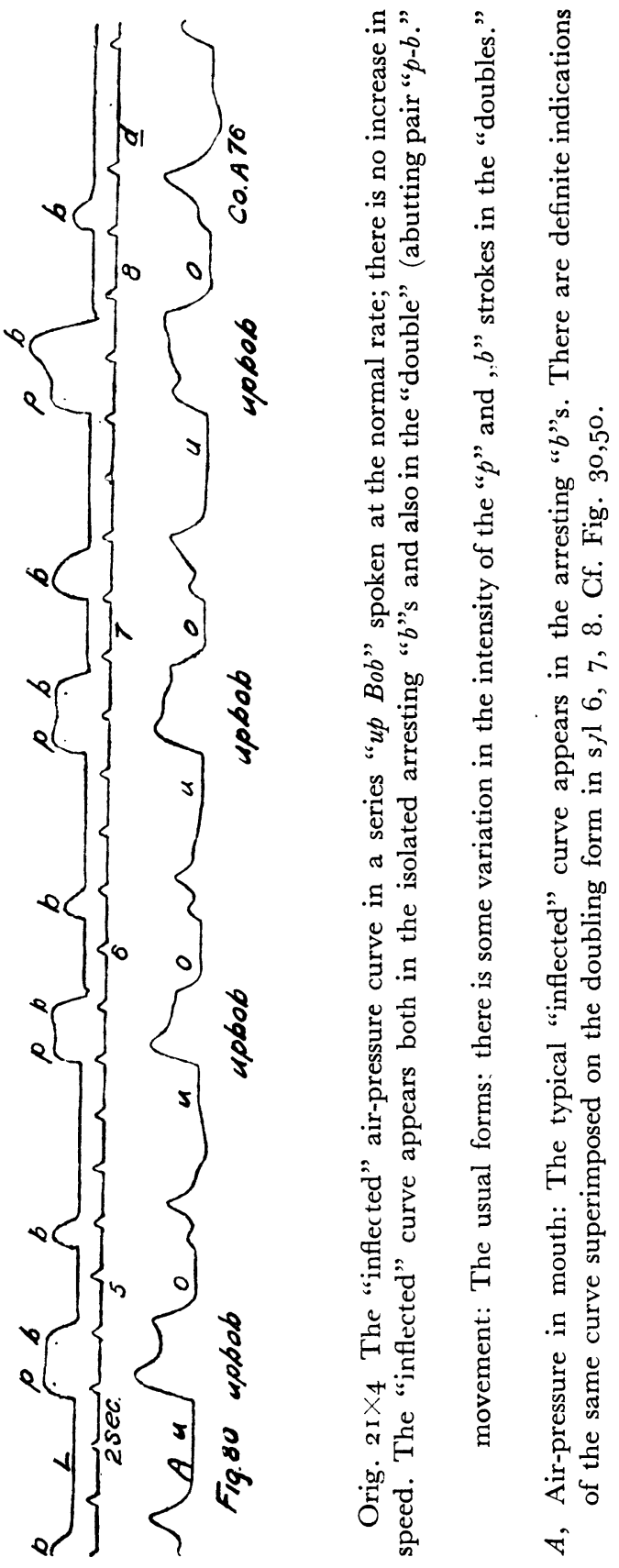


the same cause, a rapid change in the mouth volume produced by action of jaw and tongue.

The published tracings of Rousselot illustrate the inflected form of curve. As a rule Rousselor took his tracings of breath pressure from a mask outside the mouth, but in the case of the nasals the tracings register the air-pressure behind the consonant occlusion. ${ }^{1}$ ) In one case Rousselot publishes a tracing of the air-pressure in the mouth which is interesting as it shows the inflected form of air-pressure curve of " $b . "{ }^{2}$ )

\section{Word Agcent and its Relation to the Syllable and to the Breath Group.}

\section{A. Definition of the Word Accent. Its relation to other factors in grouping.}

The "breath group" is a division recognized by phoneticians of all schools. In the breath group the dynamic pattern which constitutes the "group" is made by the word accents. That the syllables have varying degrees of stress, and that they are subordinated and grouped in rhythmic forms has been a commonplace since Aristotle. In poetry we have called the rhythmic unit-groups "feet" and have noted the regular patterns; feet may also be observed in prose, following ARistotle, but the patterns are not regular.

There is still a difference of opinion as to what constitutes "word accent." There are many who insist that pitch may be the important factor; ever since MITFORD, in $1804,{ }^{3}$ ) there have been those who believe that change of pitch can produce an "accent." So Coleman, ${ }^{4}$ ) cited with approval by Daniel Jones, believes that accent is due to a turn in the pitch. The

1) Principes II p. 908, Fig. 588 , ,n.”955, Fig. 64I , „m.” p. 956, Fig. 642, „n.” p. 966, Fig. 652, general form of ,n.” p. 967, Fig. 653, „," 3 cases, each different subject. Précis, p. 79, Fig. 7I, ,m."

2) Principes I, p. 496, Fig. 256.

3) Inquiry into the Principle of Harmony, etc. London, 1804, Cited by E. W. Scripture, Xptal Phon., '02, Scribners, N.Y.

4) Coleman, H. O. Intonation and Emphasis, Miscellanea Phonetica, 1914; International Phon. Assoc. Cited by D. Jones, An Outline of Eng. Phon. p. iv, reprint Stechert, N.Y., '22. 
earlier advocates of this theory of pitch accent assumed a rise in pitch, but the experimental findings have made them fall back on some change in pitch, either rise or fall; so ABAs, ${ }^{1}$ ) so MORRIS. ${ }^{2}$ )

It is only in the field of speech that "accent" has been assumed to be a matter of pitch change. A comparison with the conditions of accentuation in other rhythmic fields makes the notion very doubtful. In music it is apparent that a change of pitch cannot be the determining factor in accent. It is possible to make abrupt pitch changes within a musical figure without changing the accent pattern; in fact such changes of pitch with an undisturbed accent pattern are a commonplace. And if changes of pitch might in any circumstances determine an accent, composers for the organ would certainly avail themselves of the device, because there is need of every resource for indicating accent at the organ.

It is not surprising that in speech changes of pitch should be noted at the accent; it is often the significant point in the group; and the heavy stroke of the accent involves the chest pressure and is apt to change the pitch because the laryngeal musculature is often affected by tensions in the other musculatures of speech. But if changes in pitch were in any way essential to word accent it would be impossible to train the deaf mute to speak with a word accent, and impossible for the subject with an artificial larynx, or for one who whispers to mark the word accent.

The logical analysis of sound as involving duration, pitch, and intensity, is responsible for the belief in pitch as an accentual factor; if duration and intensity affect accent, then why not pitch? But accent is not a matter of the properties of sound, it is a matter of the coordination and culmination of a movement; a movement must involve a stress, a pulse, and a movement must involve time; but a movement does not involve pitch. Rhythm is in no sense a matter of pitch; there is no rhythmic series however elaborate, no rhythmic grouping however complicated, which cannot be expressed without pitch. In speech all accent involves

I) Azas, A. L'Accentuation syllabique en néerlandais, Arch. Néerl. de Phys. Io, '25, p. 82-154, No. I, Mar.

2) Morris, A. R. The Orchestration of the Metrical Line, Badger, Boston, '25, p. I6 and f. 
increased force of the syllable movement, i.e. of the chest pulse. This is WundT's position:

"Therefore the customary distinction between pitch accent and dynamic accent is mistaken. There is only one real accent and that is the dynamic or expiratory accent." ${ }^{1}$ )

\section{Measurement of Intensities in Speech.}

It is not an easy matter to measure the intensities of speech, whether they are conceived as intensities of sound, or intensities of expiratory force. If one were willing to assume that speech is a matter of acoustics, the measurement of the intensities of the series of acoustic combinations would be very difficult. The comparison of sounds at various pitches, of different vowels with varying acoustic patterns, of vowel sounds with consonant sounds, is a serious problem. The question is further complicated if it is assumed that duration and pitch somehow figure in the word accent.

Neither is the measurement of the expiratory force an easy matter. The commonest form of record has been of the pressure just outside the mouth; and this has been supplemented by occasional studies of the pressure changes in the chest during speech. The force of expiration is due to the contraction of chest muscles, but the flow of expired air does not depend on the contraction of the chest muscles alone; the flow of expired air is affected also by the conformation of the vocal canal. It the glottis and mouth are relatively open, the flow is large; if the glottis and mouth are relatively closed, the flow is small. Since the pressure just outside the mouth depends on the flow of expired air, tracings of that pressure are subject to correction for the articulation involved.

Pressures taken directly from the trachea below the larynx are also subject to correction for the conformation of the vocal canal. If the vent through which the air escapes is nearly closed, as by an occlusive, the pressure rises rapidly; if the vent is relatively open as in the case of a whispered vowel and an unvoiced " $l$," there is little rise in pressure following the chest contraction.

If one is to measure the expiratory force in terms of the pressures produced, it is obvious that only artifical material can be

1) Völkerpsychologie, Die Sprache, Ed. I, p. 273. 
used; it is impossible to handle the varying complexities of ordinary speech. The articulatory conformation must be the same from syllable to syllable if the changes in pressure are to correspond to the force of the muscular contraction of the chest. This is the case whether the pressure is taken above or below the glottis.

The pressure just outside the mouth will vary with the chest contractions if the conformation remains the same. But of course this outside pressure will drop to zero during any consonant occlusion, and such changes of chest pressure as occur during the occlusion are lost. The opening and closing of the mouth also introduces an artifact, the ,,mid-sag" already mentioned. Cf. p. 220.

It happens that some important changes take place during the consonant occlusion. The minimal pressure marking the end of one chest pulse and the beginning of another occurs during the releasing consonant, whether single or member of an abutting pair. Only in the case of the single, arresting consonant does the pressure minimum show in the outside pressure. On the other hand the pressure maximum which marks the climax of the stroke may show in the pressure outside, but it is often masked by the ,,mid-sag."

Pressure in the mouth (assuming that the articulatory conformation is the same from syllable to syllable) is an excellent indicator of changes in chest pressure during the consonant occlusion; it will show the minimum between the chest pulses during the abutting and releasing consonants. When the mouth opens the pressure falls to zero, and there is no indication of the maximum marking the climax of the stroke of the chest pulse. If the diaphragms for recording the pressure outside and the pressure in the mouth are properly adjusted to respond to the available pressures, the range for the mouth-pressure tambour (0-I50 mm. water) must be much higher than those of the outside-pressure tambour (o-6o mm. water.)

Tracings of the pressure in the chest, taken directly from the trachea below the glottis give a definite indication of the chest pulses, both maxima and minima. As the tambour must be set to record pressures as high as $200 \mathrm{~mm}$. water, the membrane cannot be very sensitive. Variations of pressure in the mouth are usually not apparent, because of the intervening glottis vent. The chest pressure tracings are valuable also because 
they show very strikingly the grouping of syllables; the continued slow expiratory movement which makes the grouping maintains the pressure well above zero throughout the group.

The time may come when we shall have direct records of the movements of the expiratory muscles involved in speech, as we now have records of the movements of the articulatory members; it may be that action-current tracings may be made when the actual muscles involved in the forced expiration of speech have been isolated. But for the present the measurement of the accent stress must be either in terms of the amplitude of the sound vibrations where the vowels and consonants are the same from syllable to syllable and where the amplitude is therefore directly dependent on the expiratory force; or it must be in terms of breath pressure so taken that the pressure varies directly with the expiratory force.

\section{The Accent and the resulting Dynamic Form in the Troo-syllable, Three-syllable, and Four-syllable Groups.}

In the two syllable unit-groups, the iamb and the trochee, there are but two degrees of force. But the dactyl shows not only small variations in the duration of the three component syllables, but also gradations in the force of utterance. The accented syllable is merely the climax of the stresses of the dactyl. Cf. Fig. 81, 82, 83, 84.

Fig. 82 and 83 are excellent examples of the uniformity with which a subject often repeats a particular form of utterance. The extreme emphasis on the initial consonant is unusual, but it persisted through the three series of the sitting. The two ecxerpts are taken from two different series (B 259b, and $B$ $259 c$,) and yet they are almost replicas. There are slight differences in rate and a few small differences in detail, but the identity is striking.

Like the organization of the unit-group, the organization of the breath group is due to a single movement of which the single syllables and the feet form a part, like the ripples on a larger wave. The notion of the accent or stress as a single isolated peak rising from the plain, a mere marker for the phrase or foot, is inadequate. In reality the accent or the primary stress is the climax of the single slow movement which underlies and constitutes the unity of the foot, and of the breath group. 
MOTOR PHONETICS.

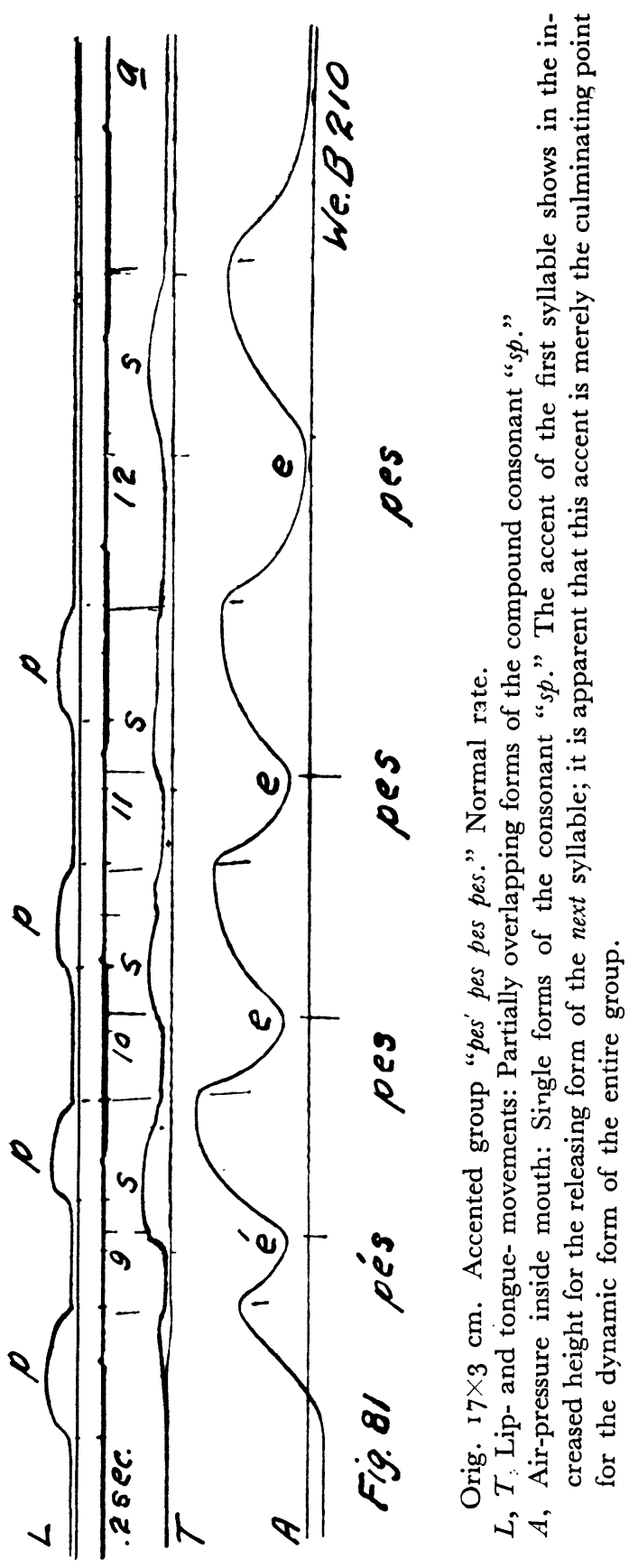


R. H. STETSON.

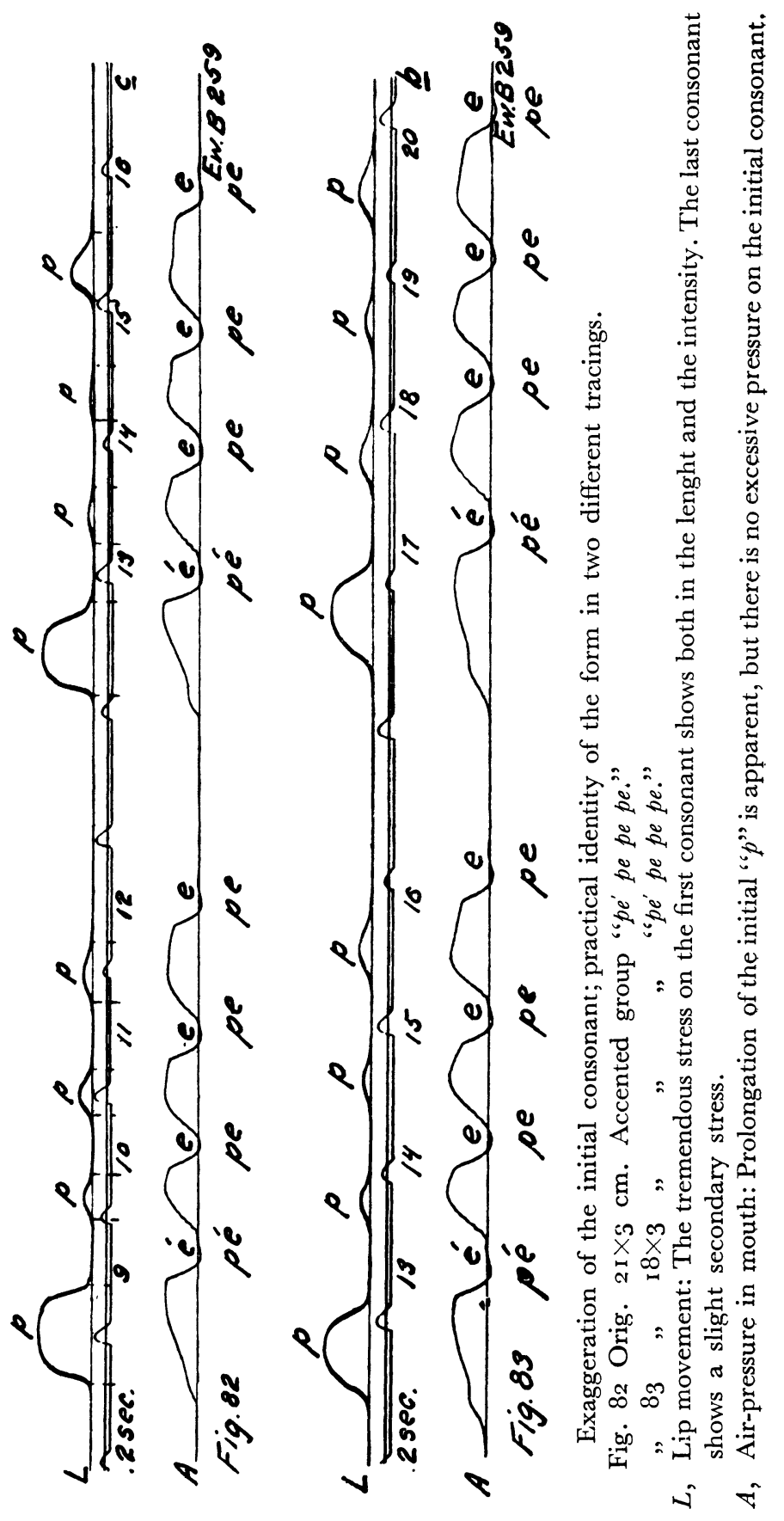


MOTOR PHONETICS.

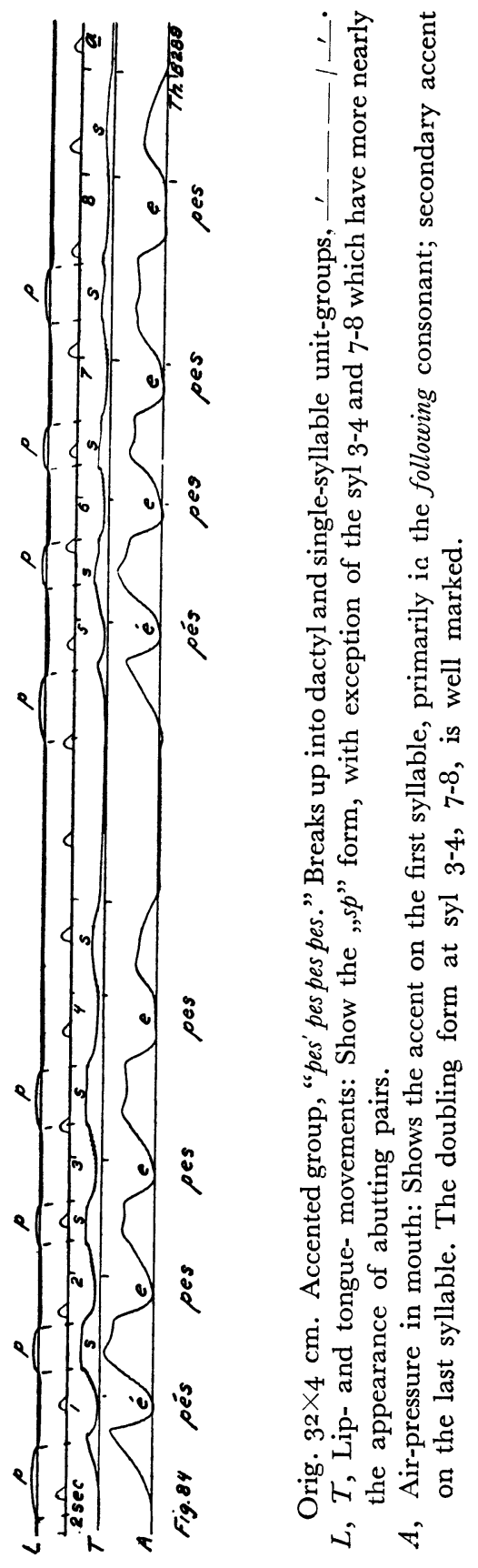


Compare studies of rhythm. ${ }^{1}$ ) As the name indicates it is a breath group in the sense that the phrasing movement is a movement of expiration, and therefore it appears in the tracing of the chest pressure, or in the tracing of the pressure variation just outside the mouth, which represents the chest pressure. Compare Fig. 81 , 82, 83, 84 and Fig. I Io, I I I , p. 356 and 357.

A study of the stresses of trochees and iambs shows that the subject seldom fails to mark the accent. The measurement of 23 trochees, $\overline{t^{\prime}}$ tet, $\overline{t o}^{\prime}$ tot, $t a^{\prime}$ tat, shows five reversals of the accent. The measurement of 29 iambs shows two reversals of the accent ${ }^{2}$ ) 29 dactyls, form prescribed " $p u p$ ' up up," show the normal accent in 25 cases. Cf. Fig. 85, 86, 87, 88.

In none of these is the arresting consonant of the first two syllables "pup up" actually given; instead the form uttered by the subjects is " $p u^{\prime}$ pu pup." Such modifications are very common; in the case of this dactyl it illustrates the tendency to eliminate abutting consonants and "constructive doubles" within a unitgroup.

A form prescribed as "up' up pup" vacillates between -."$\times{ }^{\prime}$ and $\_\ldots \times \ldots$. The double appears "up pup-pup" as essential to distinguishing the word " $p u p$," and this determines the division into two unit-groups. ( 5 cases, $B 353$, 354, subj. $W$.) The same subject gave the series " $u p$ " up up" (alternating with the " $u p^{\prime}$ " up pup"). The result is " $u$ ' pup up" sometimes with the primary stress on the initial and sometimes on the final. The constructive double dividing the second syllable from the final marks the division ㄴ..1 1 . "Up up up" may be uttered so that the separate words appear with a constructive double after the first syllable and with a double well separated between the second and third syllables, "up, up-pup." Cf. Fig. 86. The forms "pup up' pup" and " $p u p u p$ pup" " both result in a marked double between the median and final syllables; there is usually an intersyllabic space between the doublets. Cf. Fig. 85, 86, $87,88$.

The determining factors in such groupings are the stresses prescribed and the tendency to preserve the identity of the words.

1) Stetson, R. H. Rhytm and Rhyme, Harvard Psy. Stud.s I, (Psy. Mon. 4) 'o3, p. 445-6. Mot. Theory Rhythm and Discrete Succession, Psy. Rev. 12, '05, p. 315 .

2) From $B$ 5, 6, 7, 8, 9, subj. W., whispered series. Heights of outside pressure tracing measured and compared. 
MOTOR PHONETICS.

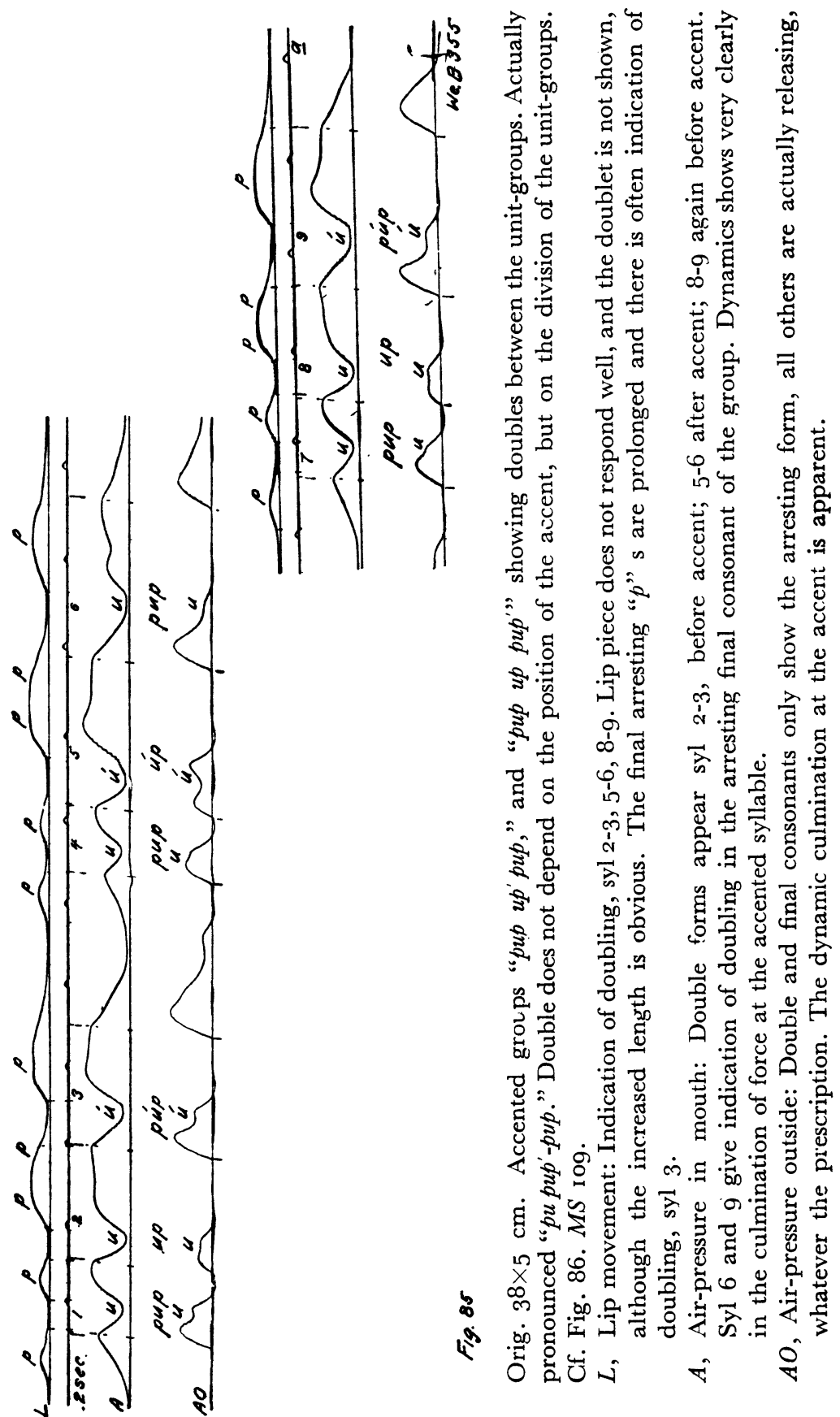




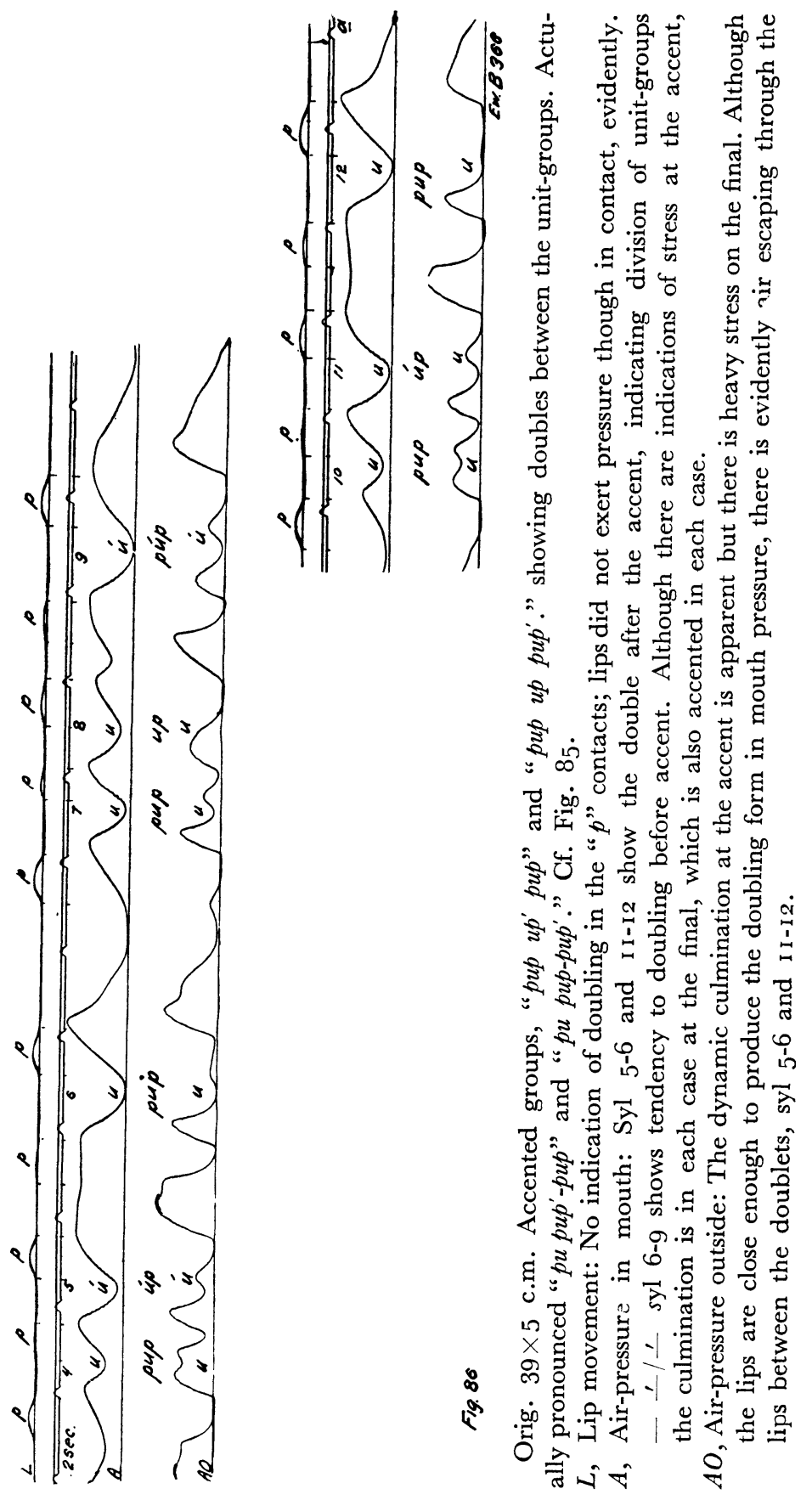




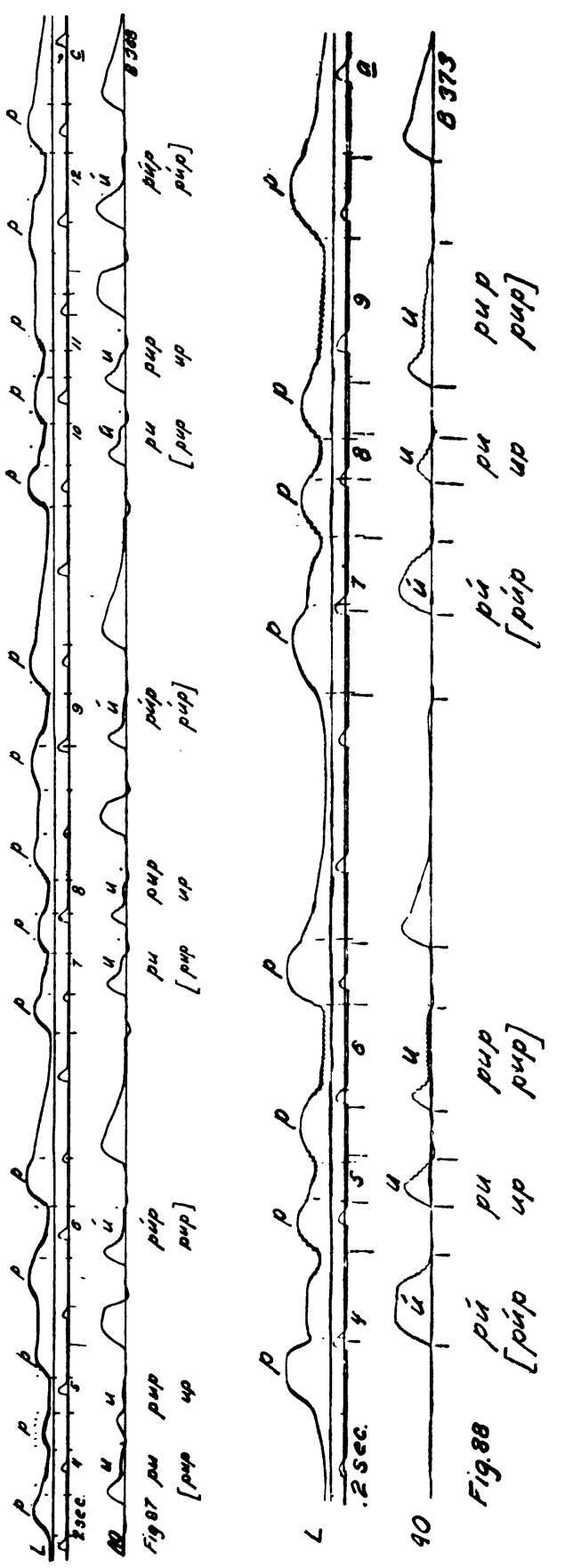

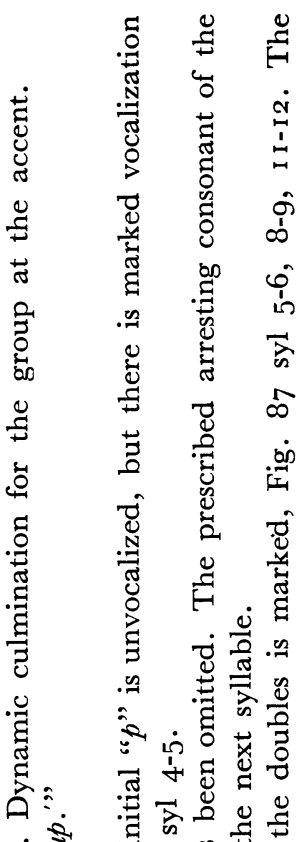

कि

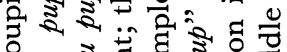

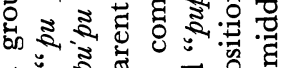

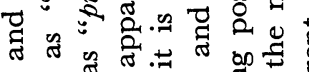

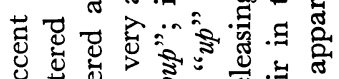

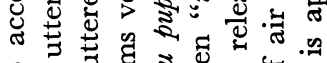

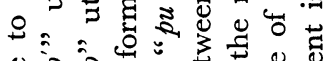

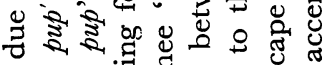

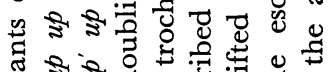

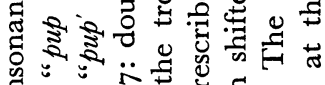

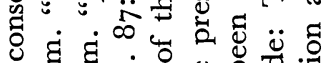
ठद्व द्व 造 $m \times$ + 凯员

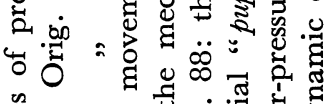

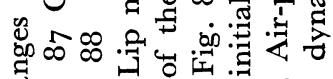
考完 
In English it is possible to make a distinction between "up up up" and " $u p u$ pup" which would be impossible in French. But such distinctions are made by introducing a constructive double as in "up- up- up" or an actual double as in "up- up-pup."

If a heavy stress is prescribed in a group of four syllables like te te te tet, the prescription is usually carried out. In 53 cases, three subjects, the prescribed stress is not given in 8 series. In 25 of the 53 cases, the primary stress is clearly on the second syllable; but it often happens that while the second syllable gets a definite stress, there is a heavier stress on the third or fourth syllable. There is a strong tendency to prolong and to stress the later members of such a series. No uniform pattern for the other syllables is apparent; the form is apt to open with an iamb, and doubling, "te tet-te tet," often appears; but the second unit-group may be a trochee or iamb; the iamb is the more common, repeating the first foot, and bringing stress on the final syllable. Such doubles which appear when a single is prescribed may be called "adventitious doubles"; they mark the division between the unit-groups and often precede or follow heavy accents. Cf. p. 335 .

In the prescribed form "te te te' tet" (short vowels), of 36 cases, three subjects, 33 have the prescribed stress; and it is obviously the primary stress in 24 cases. The exceptions are cases in which the grouping is " $t e t e t e^{\prime} / t^{t}$ '" $^{\prime}$ and a heavy stress has been thrown on the final syllable. Here again adventitious doubles often appear, usually following the stress, marking the division. The grouping of the syllables is usually " $t e^{\prime} t e / t e$ ' $t e t^{\prime}$ ", or ' $t e$ ' $t e l t e t$ ' $t e t^{\prime}-1-t e t$ '"; but variants may appear in the first foot.

With long vowels the results are similar. __ _ _ _, 63 cases, four subjects, $5^{\mathrm{I}}$ have the prescribed stress; it is easily primary in 36 cases, in others a heavier stress appears later.

With long vowels, _._....., I 7 cases, two subjects, I 6 show the primary stress on the prescribed syllable; the one exception has in addition a heavy stress on the last syllable. The unitgroups are very like those of the four-syllable groups with short vowels. Adventitious doubles are not apt to appear; though they are found in some cases. Cf. Fig. 89, 9o.

When the group of syllables is as long as a series of four, the tendency to break up into two groups is apparent; there is a tendency to put a heavy stress on the final syllable. Although all of the four subjects are English-speaking there is a pronounced 
MOTOR PHONETICS.

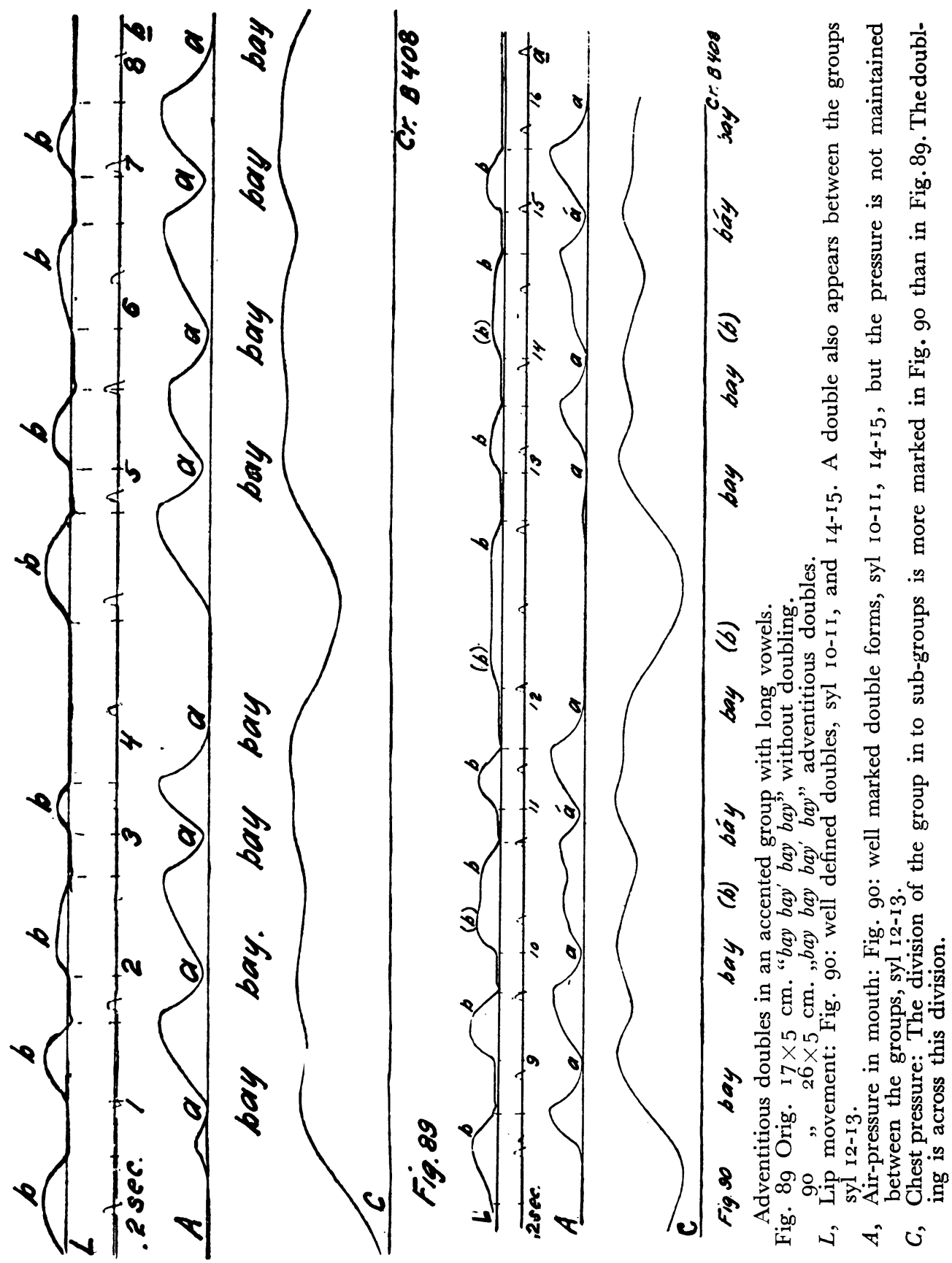


tendency to prolong and to stress the last syllable of the foursyllable group.

Abutting consonants (doubles and constructive doubles) appear only between unit-groups; within the unit-groups an arresting consonant is dropped. It makes little difference whether doubles are prescribed; either "tet tet tet' tet" or "te te te' tet"; the unit-groups are apt to be separated by a double (adventitious when the single consonant is prescribed) and only the releasing consonant appears within the unit-group in any case.

A sentence like " $L i l$ ' ' $l l$ lie low" gives the same forms as the four-syllable group. But with no stress prescribed, the results are more varied. The main stress falls in I I of I 5 cases on the first syllable, 3 times on the second and once on the third syllable. There seems to be no tendency to stress the last syllable with the one subject uttering this particular phrase. The records are from measurements of chest pressure; the variation in the vowels makes the interpretation somewhat doubtful. Cf. Fig. 91, 92 .

The five-syllable phrase "pop up a pop up" as uttered by a single subject $(W$.) has a definite climactic stress on the penultimate "pop-". But the form is not a dactyl "pop' up a" plus a trochee "pop" up," instead the form is $-1, \ldots+1, \ldots$, with a definite arresting consonant marking the initial syllable "pop" and thus making a constructive double between the first foot (a single-syllable) and the second (a trochee); this avoids the form "po pup" and keeps the identity of the two words "pop" and "up." In I 7 of I9 cases the primary stress falls on the penultimate syllable; the secondary stress occurs sometimes on the initial and sometimes on the second syllable of the group. No heavy stress falls on the final syllable; the grammatical subordination of the word prevents it. (In strictness, the syllables which may be compared are the initial and the penultimate syllables, "pop", and the second and final syllables " $u p$ "; the vowels are not otherwise comparable.) Cf. Fig. I 26 p. 375 .

"Runnin' ' $n$ ' neighin"" also gives a five-syllable group but it is impossible to say more than that it is easy to utter it in a single "breath group," for the long vowel in "neighin"" is not comparable. Cf. I 24, p. 373 . 
MOTOR PHONETICS.

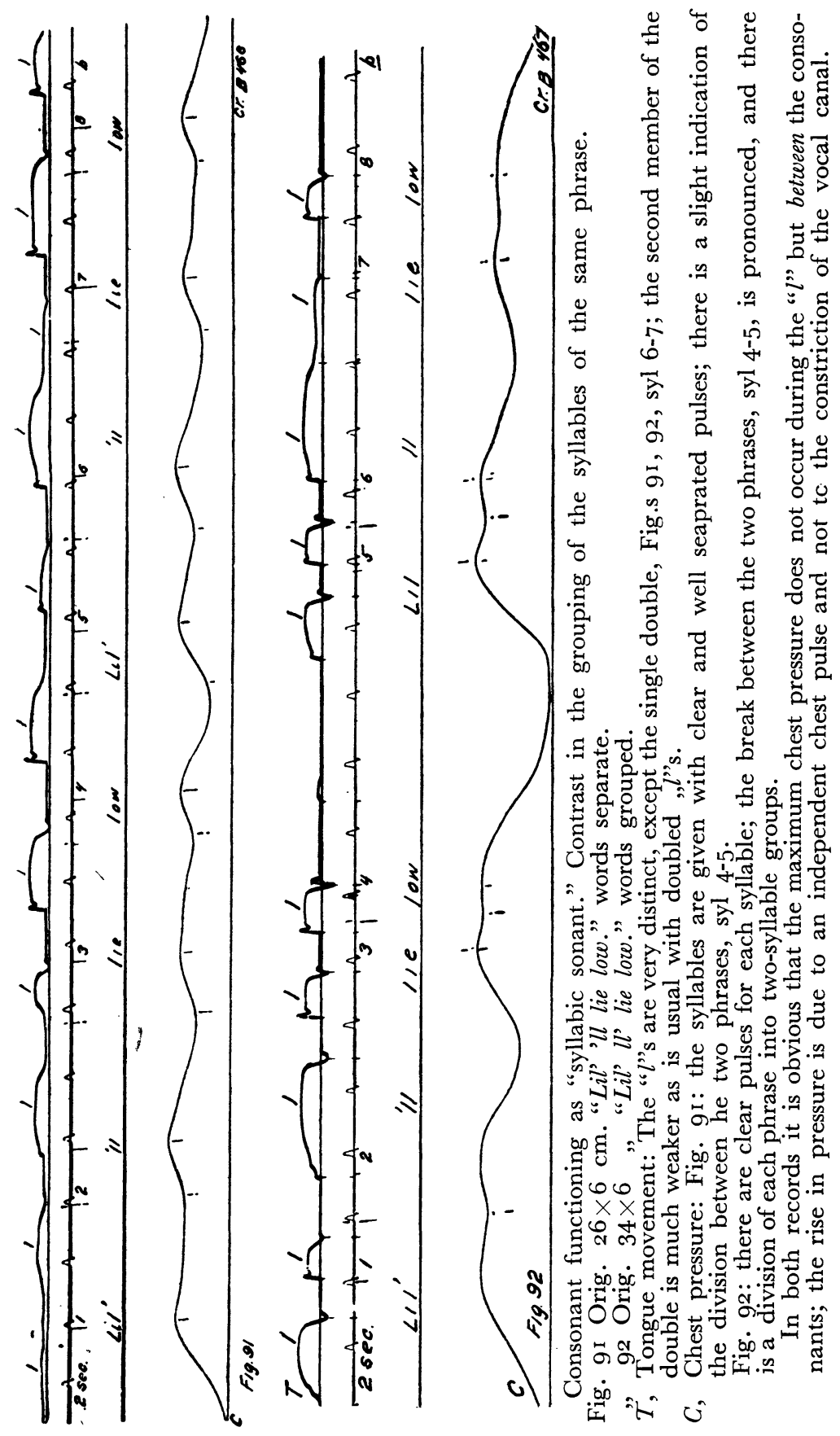


The Separating and Connecting of Syllables as a Result of Speed.

The device of increasing or decreasing the speed of a uniform series of syllables makes it possible to study in some detail the types of connection and of division which depend on speed. The speed of a series is an important factor in grouping for several reasons. In the first place, the absolute length of a group has limits so that increasing the number of syllables in a group increases the speed of the component syllables. This is apparent in the studies of Rousselot et al. who note the decrease in the length of syllables when something is added. In the second place, speech tends always to high speed, and the increasing speed of a rhythmic series with long and short syllables will modify the short syllables while the long syllables are still unaffected by the speed. And finally increasing the speed of utterance will throw together into larger unities small groups which are ordinarily uttered separately.

As the speed of a uniform series increases, the adjacent syllables begin to group together; this shows the formation of "doubles" or "abutting consonants" between the syllables having both releasing and arresting consonants. Cf. Fig. 93.

If the syllables in the series have only releasing consonants the change is not apparent. If the syllables in the series have arresting consonants, the intersyllabic space disappears and a "constructive double" results. A second type of grouping occurs at still higher speed when the arresting consonant drops from the abutting pair, (or shifts to the releasing position in a constructive double.) In these uniform series in which the speed is gradually increased or decreased, the indefinitely long grouping developed is artificial and unusual, and corresponds to the trill or tremolo in piano music; such prolonged groupings very seldom occur in actual speech.

\section{Functions of Doub ing and Singling in the Grouping of Syllables.}

The same types of connection seen in these uniform series with increasing speed are to be found in syllables uttered in ordinary groups. When the individual unit-groups (of one, two, or three syllables) are uttered separately an intersyllabic space occurs during which the chest pressure goes down to zero. When this space closes up and an abutting pair or a con- 
MOTOR PHONETICS.

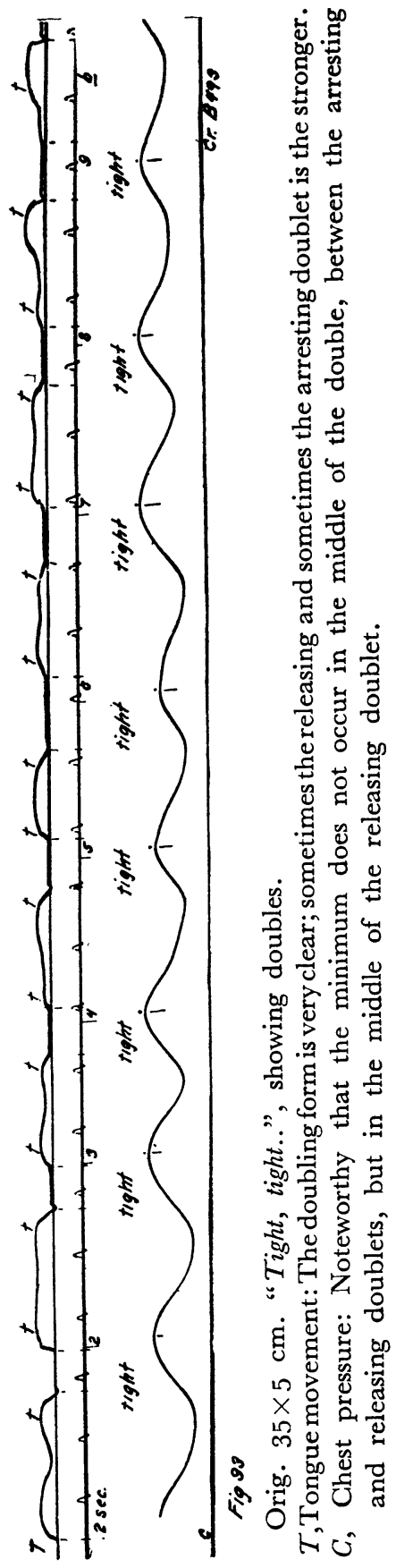


structive double results, the linkage indicates the connection of one unit-group with another in a larger unity; $1 \times 1$ represents a two-syllable group composed of two single-syllable unit-groups connected by a double. $\_, \times \ldots+$ represents a four-syllable group composed of two iambs connected by a double. It often happens that subjects actually regroup into larger unities what were intended to be separate breath groups. This shows in the development of the abutting form between such prescribed groups. Fig. 94 is a case in which breath groups are accidentaly connected by abutting pairs.

In such cases it is not necessary that the double occur either at the beginning or the end of the accented syllable; doubling may occur between two unaccented syllables. Cf. Fig. 95, 96. As it often happens that the accent begins or ends the group it is frequently the case that the abutting pair occurs just before or just after the accent.

"Singling" occurs when the connection is so close that the syllables involved form parts of a unit-group. When $b u b^{\prime}-b u b$ becomes $b u^{\prime} b u b^{\prime}$, the two-syllable group $\perp \times$, has become the iamb - 1 .

\section{Function of the Word Accent in the Grouping of Syllables.}

In actual speech another factor plays a part in grouping; as already stated the "word accent"figures in the organization of the unit-group. The accented syllable is in general lengthened; this prolongation of the accented syllable may appear as a pause after the beat-stroke, as in the iamb and anapest, _ + and - + - . In the case of the trochee, the pause may appear before the beat stroke. Often the prologation of the final member of the group masks the lengthening due to the accent and the two syllables may be of approximately the same length. This relation of length and accent has been considered at some length by the rhythmists.

One might expect that the prologation of the accented syllable would naturally appear in a "double" (abutting pair) before or after the accent. Such doubling can occur, however, only when the accented syllable occurs at the beginning or end of the unit-group. Thus a double may precede the trochaic accent in a series $1 \ldots+\ldots+\ldots$, ; a and double may precede the 
MOTOR PHONETICS.

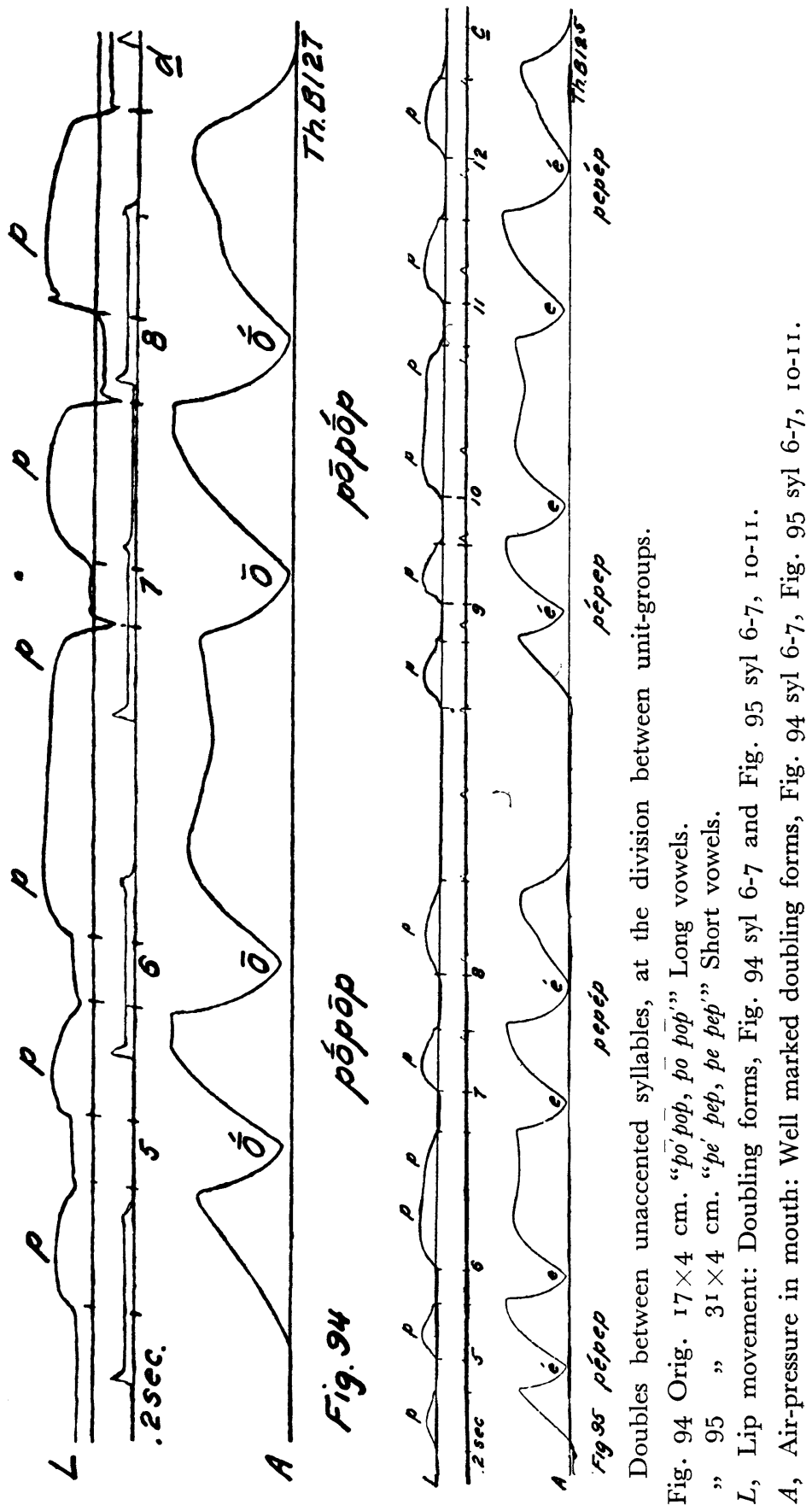


R. H. STETSON.

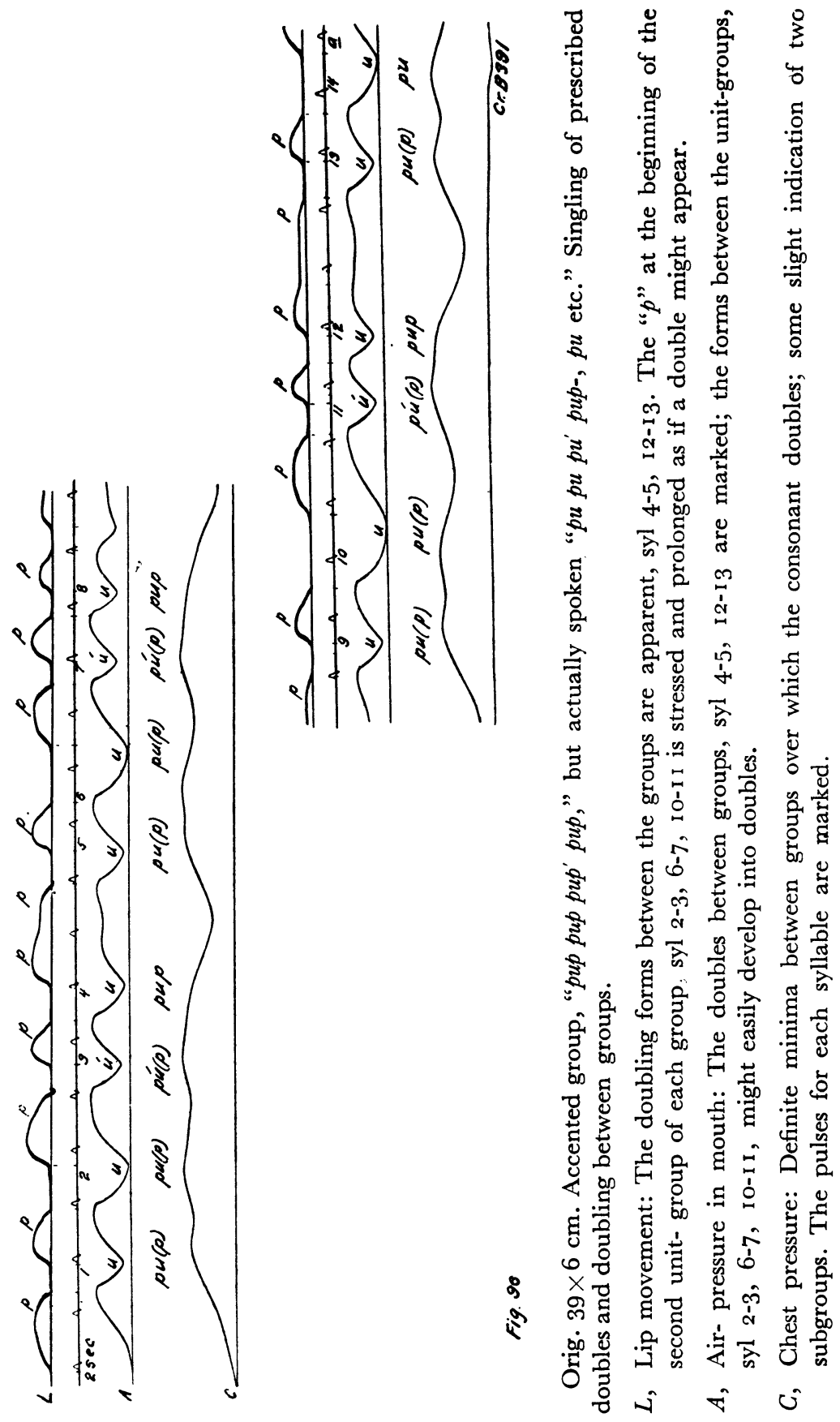


dactylica ccent in a series:,$\ldots+\ldots+\ldots$ And also a double may follow the iambic accent in a series $\ldots+X_{-}, X_{-}$, . But in a mixed series like,$\ldots+x_{-}$ the double neither precedes. nor follows the accented syllables. Cf. Fig. 95, p. 333 .

If the accent is fixed, then the groups are formed to accommodate themselves to these accents. In such cases the nature of the vowels sometimes figures in the formation of the groups and sub-groups.

If the forms are trochaic or dactylic, the heavily stressed accent is not prolonged; the slightly increased length of the accented beat stroke appears in the preparation of the blow. Therefore there will be no double (abutting pair) following the trochaic or dactylic accent, however heavily the word accent may be stressed. Indeed, a very heavy stress on the accent may lead to a "reduction" of a single median consonant to be discussed later. If the vowel of the preceding syllable is short, doubles are apt to appear before the stressed accent, and so mark the division of the unit-groups. If the vowel of the preceding syllable is long, a single consonant will not be doubled; (a prescribed abutting pair may appear however.)

In the case of iambic (including anapestic) unit-groups, the syllable receiving the accent must be somewhat prolonged (apogogic accent.) This increased length is due to the heavier blow of the accent. If the syllable involved has a "long" vowel (i.e. a vowel that can be prolonged) the increased force of the accent shows in the increased length of the chest pulse, and the vowel is somewhat longer. If however the accented syllable of the iamb has a "short" vowel (i.e. a vowel that cannot be prolonged) the increased chest pulse meets the obstacle of the arresting consonant. The consequent truncation of the blow results in the prolonging of the occlusion of the arresting consonant which provides for the increased length of the beat stroke as well as of the back stroke. The stress on the iambic accent may force the single, releasing consonant of the next syllable into the arresting position, and the consonant may double. This is the "adventitious double". If the shift from the releasing position to the arresting position occurs without repeating the consonant the result is a "constructive double" which marks the limit of the unit-group.

Neither the "unit-groups" (single-syllables, iambs, trochees, ARCHIVES DE PHYSIOLOGIE, TOME XIII. 
dactyls) nor the larger groups are necessarily words. The identity of the word is lost in utterance. The breath groups of the phoneticians constitute the larger groups; sub-groups are composed of unit-groups, of feet, within these breath groups; but none of them need coincide with words. The tracings of chest pressure during speech show these groupings surprisingly well. One finds not only the breath groups indicated but also various subordinate groupings within the breath-group.

It is natural to think of the "long" and "short" vowels as important in the construction of rhythm forms, and the consequent organization of breath groups. A little study of the tracings shows that the one difference between the "long" and the "short" vowels of the English is the possibility of prolonging the "long" vowel; the "short" vowel is the one that cannot be prolonged. On the other hand it is always possible to shorten the "long" vowel wherever the rhythm demands; in consequence we may find "long" vowels shorter than the "short" vowels With the "short" vowels elongationis obtained by someform of double with or without an intersyllabic interval. This is apparent in the series with changing speed with long and short vowels, and is exemplified in the study of the accented groups which will be handled later. When the short syllable receives a heavy accent, there is a tendency to close the syllable with an arresting consonant; the heavy stroke runs into the releasing consonant stroke of the next syllable and so converts it into an arresting consonant. Since the syllable movement is arrested by this obstacle, the increase in force cannot lengthen the movement. Thus in the case of a closed syllable (i.e. with consonant arrest) increase of stress will not greatly lengthen the vowel; the coordination between the pulse of the beat stroke and the arresting back stroke is automatic. ${ }^{1}$ )

The increase of stress means that the moving member reaches the obstacle with a higher momentum; the contraction of the negative muscles, therefore, will be correspondingly greater, and the back stroke of the arresting consonant will take a correspondingly longer interval. If the arresting consonant is a continuitive, the consonant will be prolonged. Cf. Fig. 8I , 84, p. 3 I9 and $32 \mathrm{I}$. If the arresting consonant is an occlusive the back stroke

1) Levy F. H. Die Grundlagen des Koordinationsmechanismus einfacher Wilkürbewegingen, Zschr. f. d. ges Neurol. u. Psychiat., 58, '20, p. 3 I I. Tonusproblem in die Neurologie: Untersuchungen zur Bewegungkoordinationen, ibid. 63, '2 1, p. $25^{8}$. 
(or the equivalent relaxation phase) will take a correspondingly longer time; this will appear as a "pause" (intersyllabic interval) after the syllable. At the end of the group, the occlusion may be held. Cf. Fig. 97, 98, 99 .

Such a long pause (= relaxation phase of the vigorous " $t$ ") is noted by BELL in the phrase "To be or not to be" following the "not." 1)

It happens in this example of BELL's that the long pause occurs in the midst of a double consonant.

The incorporation of a releasing consonant, the elongation of a "long" vowel in the open syllable, the incorporation of both a releasing and arresting consonant in the syllable with a short vowel, are all comparable to the agogic and apogogic accent of the musical note. ${ }^{2}$ )

In music the accented note is preceded by a slight pause and is slightly lengthened by the accent. In the case of the accented note additional time is required to prepare for the heavier stroke and additional time is required to take up the momentum of the stroke and prepare for the next stroke. In the case of the accented syllable in speech, the preceding consonant is drawn in to assist in the preparation of the heavy stroke, and if the vowel is "short" the following consonant is drawn in to assist in the arrest of the heavy stroke. The increase of the interval just before the chest pulse of the accented syllable makes the beginning of the accented stroke always an available place for a consonant in highspeed utterance; if the vowel of the accented syllable is short the end of the accented syllable is also an available place for a consonant. It is not so much that the consonant can be tolerated at the beginning of all accented syllables, and at the close of accented syllables with short vowels, but rather that they are needed in the releasing and arresting coordination of the syllable movement.

It is possible to offer an explanation of the influence of the double consonant on the preceding vowel, so patent in the study of Italian phonetics by Josselyn. When the consonant is doubled, the preceding vowel is closed. The first consonant of the double becomes the arresting consonant of the preceding syllable. The closed syllable with an arresting consonant is short in duration that is the inevitable limitation of the syllable with consonant

1) Mech. of Speech, p. 77.

2) Cf. Riemann, Dynamik u. Apogogik, Hamburg, '84. 


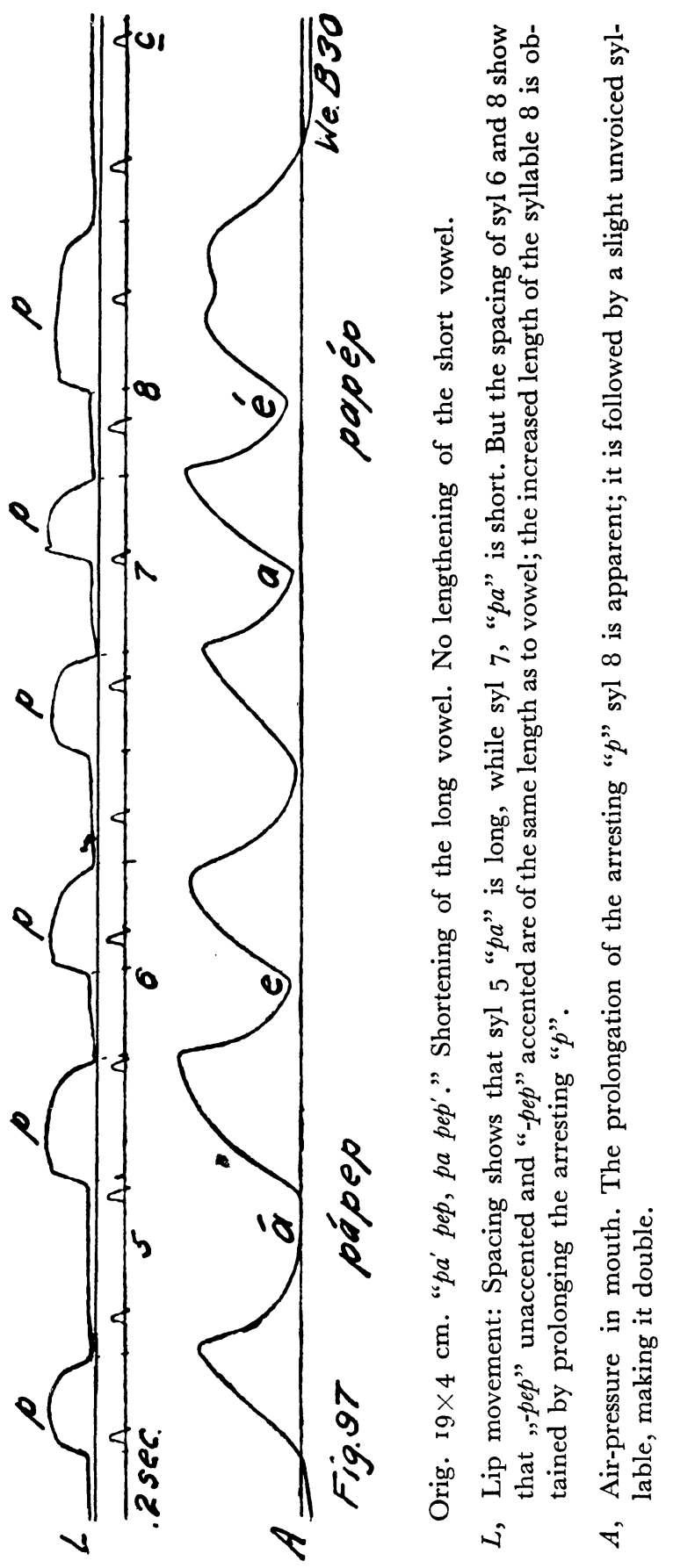




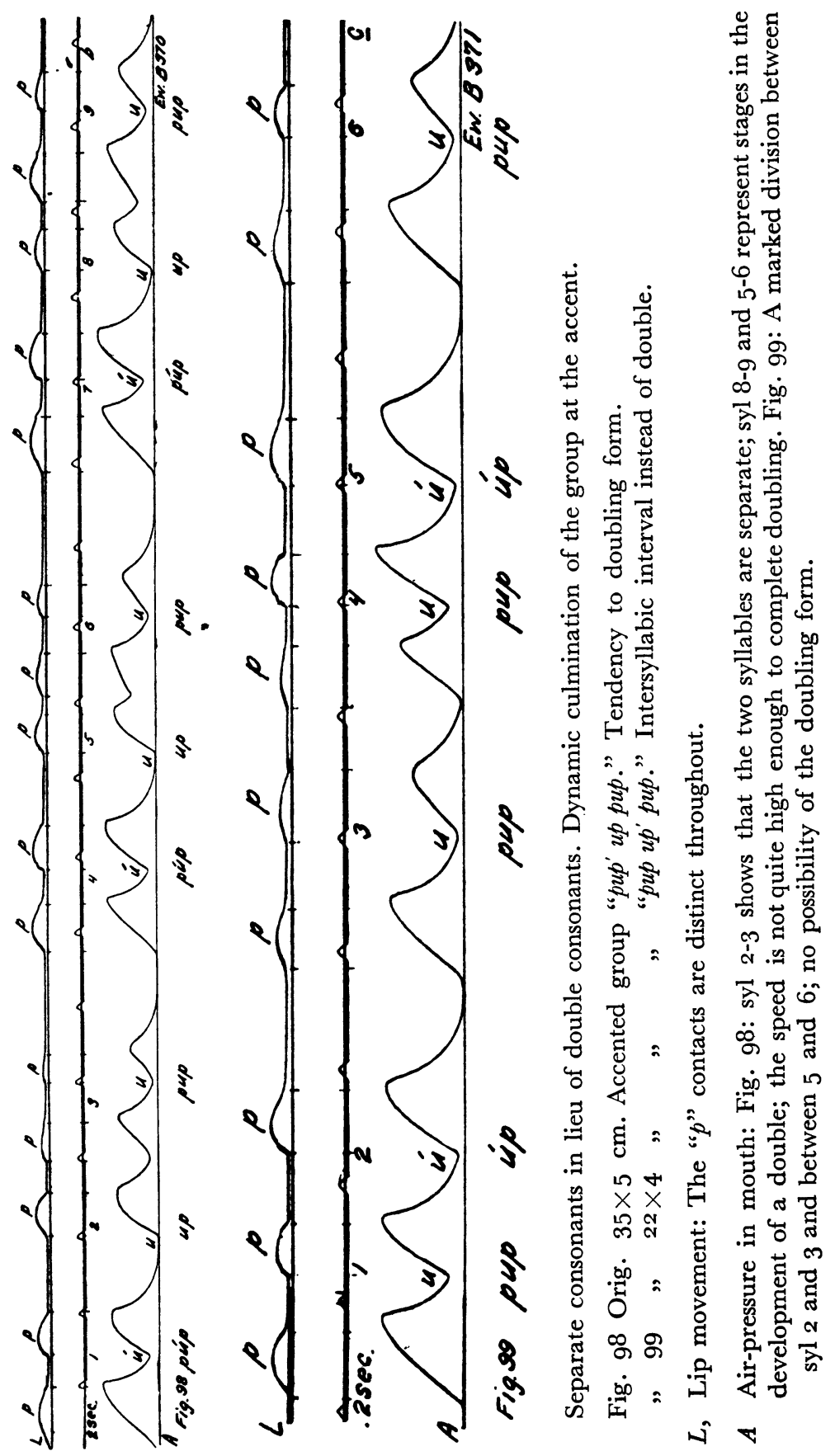


arrest. E. W. Saripture quotes Meyer's measurements of WANGER's records showing that a consonant is lengthened after a short vowel, which is the reciprocal effect on the consonant; the arresting consonant is apt to be more vigorous than the releasing consonant and its occlusion is really part of the syllable. ${ }^{1}$ )

The basis of the rhythmic organization of the "breath group" is the accent pattern of the words, although the word as such does not appear in the breath group. In some languages the word accent is fairly variable, and several accentual patterns are possible for the syllables of a given phrase. But in English there is little "déplacement de l'accent" the rhytmic pattern is determined by the fixed word accents. The rhythmic pattern is composed of unit-groups (feet); the etymological and grammatical connections of the words determine the grouping of the syllables about the accents. If every other syllable is accented in the series, the unit-groups will consist of iambs and trochees, with transition made by an occasional single-syllable and by a compound form:

$-\frac{1}{\text { iamb }} /-\frac{1}{\text { iamb iamb-trochee trochee }}\left|\frac{1}{\text { trochee }}\right|-\frac{1}{\text { single }} \mid-\frac{1}{\text { iamb }} /-\frac{1}{\text { iamb }}$

The third foot is a combination of the iamb and trochee, which is only a transitional form. (If repeated this "amphibrach" becomes a dactyl.) If every third syllable in the series is accented, various combinations may appear:

$+\frac{1}{\text { dactyl }}\left|+\frac{1}{\text { dactyl }}\right|-\frac{1}{\text { trochee }} \mid-\frac{1}{\text { iamb }} /--\frac{1}{\text { anapest anapest-trochee iamb }}$

anapest-dactyl $1+-\frac{1}{\text { dactyl }}-1+\frac{1}{\text { dactyl }}-1 \frac{1}{\text { single }}(=$ dactyl catalectic.)

$-\frac{1}{\text { iamb-trochee iamb-dactyl }}+\frac{1}{\text { dactyl }}-1+-\frac{1}{\text { dactyl }}-\frac{1}{\text { single }}$

Other more irregular patterns are presented of course by the word accent of ordinary speech. The choice of the grouping will depend on the syntax, and also on the presence of abutting consonants between the syllables. Doubling will tend to occur between the unit-groups (feet) and neither doubles or any other form of abutting consonants are apt to appear within the unit-

1) Meyer, Maitre Phonétique, 16, 'or, p. I14. 
group. A decided increase in speed may work further changes by eliminating certain unaccented syllables. Changes of that type will be considered later.

The larger groups, the breath groups, and often minor component groups are marked off by low points in the chest pressure. Every unit-group has its accent, and every breath group has a dynamic climax at its primary stress. The unity of the breath group is constituted by a slow movement of expiration of which the minor movements of feet and syllables form a part like the partails of a sound wave.

B. Experimental Study of Groups of Syllables.

The Group of Two Syllables.

Rousselot has made observations on the group of two syllables. ${ }^{1}$ ) There are several possible groupings of two syllables:

I. the iamb, - ,

2. the trochee,, -

3. the separation into two feet of single-syllables,, 1, .

Types $\mathrm{I}$ and 2 occur when there is a single consonant between the syllables, and the accent is not over-stressed. Type 3 occurs if there is an abutting pair of median consonants.

In case the accent on the first syllable is heavily stressed, there are several possibilities:

I) a single median consonant is doubled, and type 3 -! 1 " occurs.

2) the median consonant I) vocalizes, 2) reduces, 3) drops.

This occurs when the first syllable is heavily stressed and the group is uttered at high speed.

\section{Discussion of the Iambic Group.}

The accented syllable is usually longer than the unaccented; the averages of lengths are:

for the entire iamb .56 sec. (extremes $.41-.67 \mathrm{sec}$.) Average

1) Les Modifications de la Parole, '9r, Paris; cited bij E. .W Saripture, Xptal Phon., Scribner's, N.Y. p. 492 f. 
of 234 iambs the average percentage is c. $40-60 \%$ (extremes $.27-.73$ and $.45^{-} .55$ )

If the speed is normal median abutting pairs become single releasing consonants. It happens however that the resulting single consonant is often a hybrid form in which partial vocalization appears if the arresting doublet was a sonant and the releasing doublet a surd. If the abutting consonnants are retained a form consisting of two single stressed syllables, $+\times$, , develops and the speed is slowed. The grouping is no longer that of an iamb; it has become a phrase of two unit-groups, each a single-syllable. Cf. Fig. I00, IO I, I02 .

No cases were observed of "adventitious doubling" of the single median consonant in a two-syllable group with the accent on the second syllable; there is no tendency of such a group to divide under heavy stress into two single, accented syllables.

The elimination of a syllable does not occur in the case of an isolated iamb, no matter how high the speed of utterance, nor how emphatic the stress on the accent. In larger groups, phrases, the median iamb is subject to reduction; the short unaccented syllable tends to "telescope" leaving the releasing consonant of the syllable in come cases. This abbreviation is evidently the result of vis a tergo; if there is material preceding the unaccented syllable, it is first compressed and then forced out. We shall consider the cases of "telescoping" and of elimination of the unaccented syllable of the median iamb as we come to them in groups of three and four syllables.

\section{Discussion of the Trochaic Group.}

The two syllables, accented and unaccented are usually of about the same length. The averages of length follow:

for the entire trochee .6I sec. (extremes .37-.8I sec.) av. of 207 trochees the average percentage is c.50-50\% (extremes $.4 \mathrm{I}-.59$ and $\left..63^{-} \cdot 47\right)$. The fact that the unaccented syllable is the last syllable tends to prolong it; this is more apparent in final trochees in larger groupings, but it has some influence in isolated trochees. A heavy stress on the accent of the trochee tends to lengthen the accented syllable. Both these tendencies have been noted by Rousselot.

It is interesting to note that the average length of the isolated trochee is slightly longer than that of the isolated iamb. In lar- 

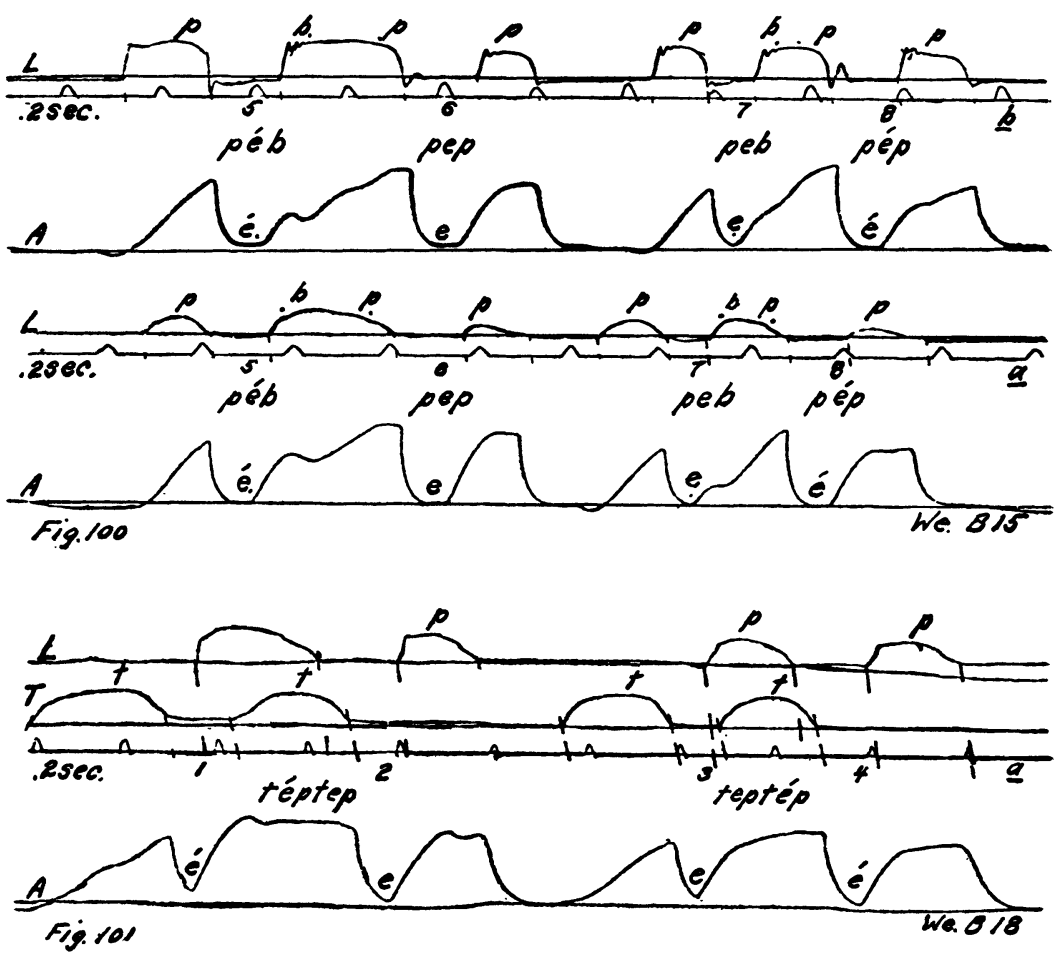

Doubling form marking the division of group into two single-syllable unit-groups; Singling form of consonant within a unit-group.

Fig. 100 Orig. $16 \times 8 \mathrm{~cm}$. Accented groups " $p e b$ ' pep"." and "peb pep'." " го " $\quad$ I $7 \times 5 \mathrm{~cm}$. " " "tep' tep"." and "tep tep'."

$L$, Lip movement: Fig. Ioo: the abutting pair shows line $a, b$, syl 5-6; the single consonant in the iambic group is just as marked, line $a, b$, syl 7-8. The form "peb' pep" is given as two single-syllable unit-groups with a double at the division.

$L, T$, Lip- and tongue- movements: Fig. Ior: the abutting pair " $p-t$ " is apparent in the placement of the contacts of the consonants, syl I-2; in the iambic group "tep tep" the " $p$ " and " $t$ " overlap, giving but a single consonant.

$A$, Air-pressure in mouth: The doubling form is well marked, Fig. 100 line $a, b$, syl 5-6, and Fig. Ior syl $1-2$.

Fig. I0o, line $a, b$, syl 7-8 shows an intermediate form between the " $b$ " and " $p$ "; there is partial vocalization, and the first part of the form shows the " $b . "$ 


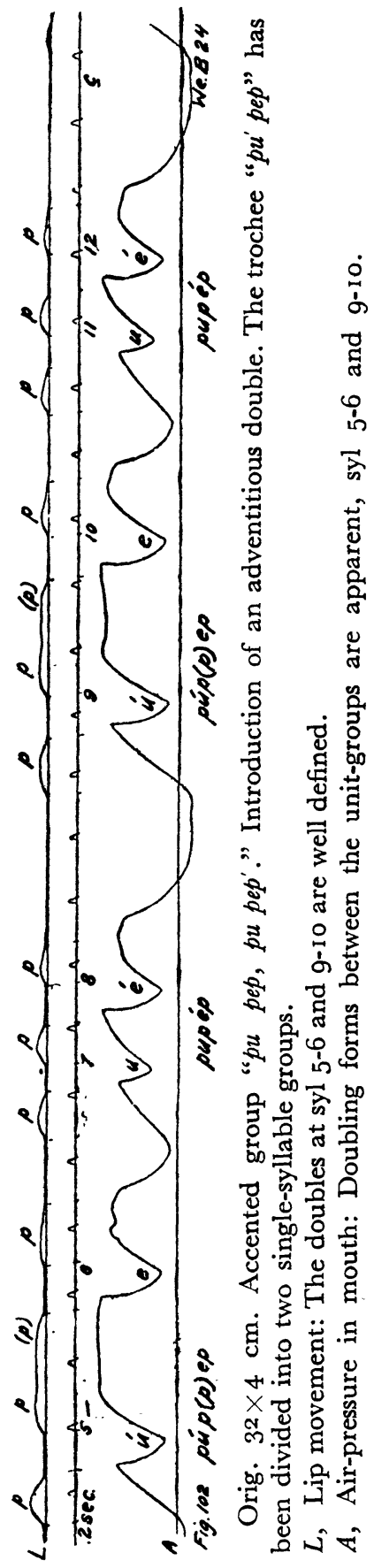


MOTOR PHONETICS.

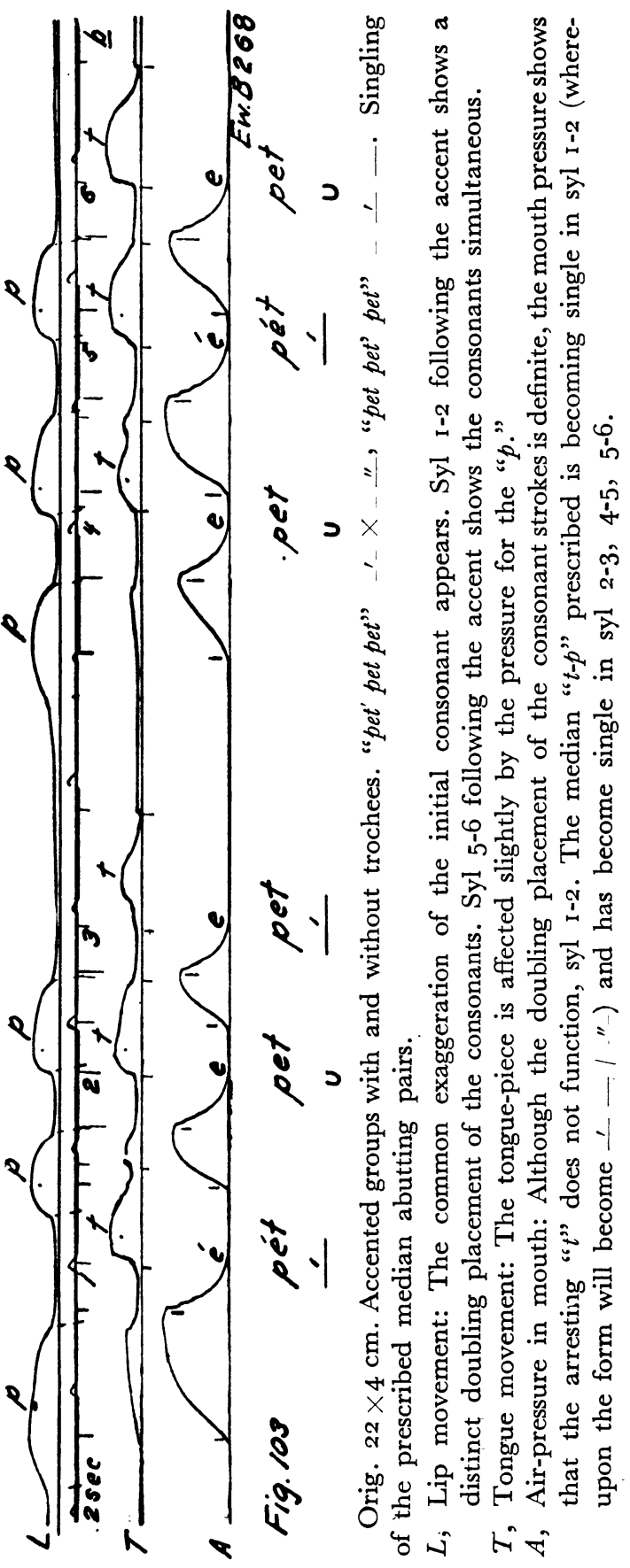


ger groupings of which trochees and iambs are constituents no such difference in the average length is apparent.

If the speed is normal, abutting medians become single consonants.

In this the reduction is somewhat like that of the iamb. One may say in general that all abutting consonants between the constituent syllables of a foot are reduced to single consonants, and in every case it is the releasing consonant which persists. Cf. the series in which the consonants double with increasing speed. The speed of the elements in the foot is responsible for the elimination of the arresting consonant of a median abutting pair.

Reduction and Elimination of the Median Consonant of the Trochee.

The isolated iamb is not subject to modifications which abbreviate the syllables, but this is not the case with the trochee. If the trochee is uttered very quickly, or if a heavy stress is put on the accented syllable, internal modifications occur.

The median consonant of the trochee, the releasing consonant of the unaccented syllable is I) "reduced," 2) vocalized if a surd, 3) finally eliminated. The "reduction" means that the contact of the consonant becomes much briefer and the stroke to the opposing surface much lighter, and the pressure in the mouth for the consonant becomes much less. Much the same thing is to be seen in all series of syllables at very high speed. A heavy stress on the trochee increases the speed of the unaccented syllable for it leaves less time for the unaccented syllable.

At the same time, the consonant becomes a sonant if it is a surd. It has been explained that an intervocalic consonant is vocalized because it is less effort. ${ }^{1}$ )

But the fact is that the vocalization is inevitable; the consonant occlusion grows less and less, and breaks the flow of air through the glottis for a shorter interval. It is not a sudden process as Fig. I04 and 105 show. It is easy to see that the vibration of the vowel creeps into the occlusion and finally runs quite through it; the closure of the consonant becomes so brief that it does not interrupt the flow of air through the cords.

When the contact has become so brief, there is little rise of

1) Clédat, Man. de Phon. et de Morph. sec. 93, p. 9 I. 


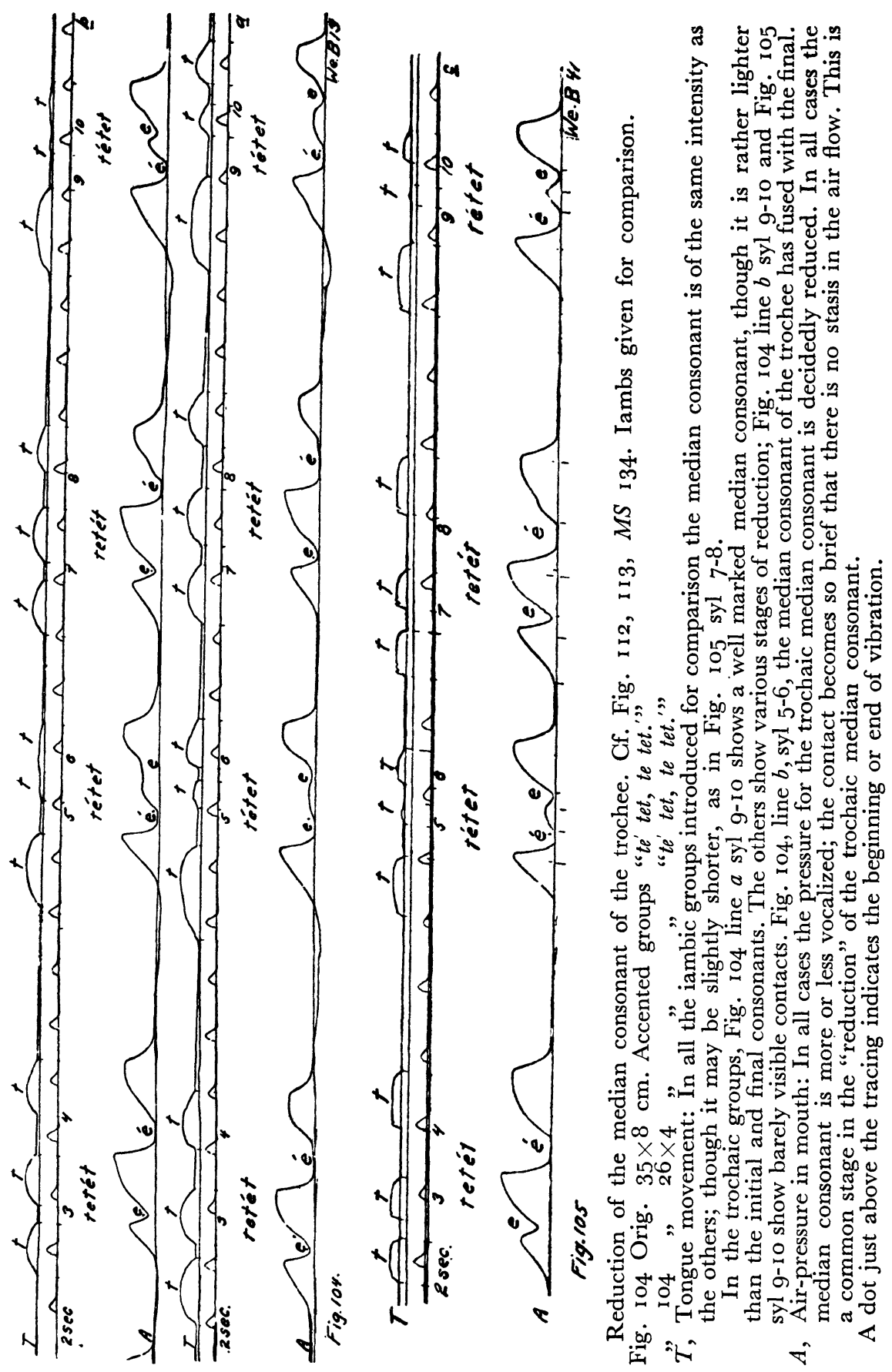


the mouth pressure; the consonant functions almost not at all, and the syllable movement becomes practically self-releasing. Since the median consonant stroke no longer functions it may disappear entirely, as a consonant stroke is certain to do if it has no part to play in the syllable movement. The trochaic median consonant has dropped. The two vowels tend to fuse, and a single syllable with a modified vowel may be the result.

If the vowel of the unaccented syllable is extremely short and if the trochaic median is sonant and especially if it is a continuitive, the median consonant stroke may fuse with a final consonant, while the second syllable movement fuses with the accented chest pulse. Thus debit if heavily stressed and rapidly uttered becomes deb't; which soon loses its internal consonant and becomes $d e$ " $t$. Tes'et becomes tes' $t$ which persists because the two arresting consonants fuse to a compound consonant, "st." Some 50 cases occur in a total of 207 trochees studied.

Sometimes the reverse process takes place, and a syllable like "elm" or "help" opens into a trochee and becomes "elum, helup"as often in the Dutch pronunciation of English.

The causes of this reduction, vocalization, and elimination of the trochaic median consonant are to be found in the speed at wich the unaccented syllable is uttered. If the first, the accented syllable is heavily stressed, the arrest must occur before the release of the unaccented syllable is possible. The releasing consonant has to occur in the very brief syllable at such speed that the blow is very swift and therefore very light. If the unaccented syllable is not closed the reduction process does not occur as readily.

If the subject takes the opposite way out, giving time to pronounce both syllables adequately in spite of the heavy stress on the accent, the result is two unit-groups, each a single-syllable; the form becomes $\_\times{ }_{-\prime}$. In this case the abutting consonants persist if present; and a single consonant is apt to be doubled. Cf. Fig. 100, ror, 102. p. 343 and 344. It is much easier to terminate the heavily stressed syllable with an arresting consonant, therefore the consonant is shifted to the arresting position; this would involve at best a "constructive double" if the second, the unaccented syllable were left self-releasing. It seems easier to repeat the consonant, and the result is the "adventitious double." Adventitious doubling is much more apt to occur if the preceding vowel is short. A heavy accent, then, may 
cause the prolongation of a "long" vowel; but a short vowel with a heavily stressed accent demands an arresting consonant.

The peculiarities of the "long" and "short" vowels are well demonstrated in forms like totet in which the accent is thrown alternately on the first and second syllables, forming a series of alternating trochees and iambs, to'tet, to tet'; po'pop, po pop'; debit, debate. In such cases the "long" vowel shortens when unaccented; but the "short" vowel does not lengthen when accented. Instead the accented short vowel is followed by a double or a constructive double, which gives the syllable its rhythmic length. Cf. Fig. 97. p. $33^{8}$.

The simple grouping, the re-grouping, and the actual position and function of the abutting pair (including the double) is remarkably well shown in these two-syllable groups. The trochee illustrates the method of dropping the trochaic median consonant, and also of dropping a syllable by fusion. And the trochee furnishes the first illustration of the "adventitious double" marking the division of the group into two sub-groups with single-syllables.

The iambs and the trochees are of much the same average length; at maximum speed the trochee can be shorter than the iamb. The average of these two-syllable groups, $5^{6-.60 ~ s e c . ~ i s ~}$ much higher than the average length of the single-syllables into which the two-syllable group is divided on occasion. These one-syllable sub-groups when initial have an average of .28 sec. (extremes .18-.50 sec.), 7I 7 cases. When final the one-syllable sub-group averages .3I sec. (extremes .20-.44 sec.) 657 readings. It is easy to see that while the average length of the one -syllable group overlaps the shorter of the two-syllable groups, the distribution is quite distinct. But it is to be remembered that temporal equality is not to be expected of spoken rhythms. Minimum time intervals for movements are important because they condition the form of the movement and may compel profound phonetic changes. But the wide variation in time intervals above the minimum has no particular rhythmic significance. 


\section{Groups of Three Syllables.}

There are a number of unit-groups which may appear in the three syllable group:

$$
\begin{aligned}
& \text { I }{ }_{\text {sing. }}^{\prime} 1-1-\overline{\text { trochee }} \\
& 2 \frac{1}{\text { sing. }} \text { iamb } \\
& 3 \frac{1}{\text { sing. }} 1 \frac{1}{\text { sing. }} 1 \frac{1}{\text { sing. }} \\
& 4 \frac{1}{\text { trochee }} / \frac{1}{\text { sing. }} \\
& 5-\frac{1}{\text { iamb }} / \frac{1}{\text { sing. }} \\
& 6+\frac{1}{\text { dactyl }} \\
& 7-\frac{1}{\text { anapest }} \\
& 8 \text { "amphibrach.", }
\end{aligned}
$$

Of these groups, I, $2,3,4,5$ have each two unit-groups; they are varying combinations of iamb or trochee with one singlesyllable unit-group. 3 consists of three single-syllables. 6 is a dactyl; 8 is a similar form with the accent on the median syllable. 8 is a form which occurs in isolation; a series of such am phibrachs would reorganize into the dactylic form 6 . If all the syllables involved were closed syllables, the groupings would be indicated by the doubling and singling of the consonants.

In groups of three syllables certain characteristics due to the length of the group are apparent. The initial single-syllable of such a group is shorter than the final single-syllable. There is a tendency to prolong the final element of such a group; and as the expiratory wave of the group has rather definite limits, the earlier members of a group tend to become shorter and shorter as the group increases in length.

This appears in the case of the iamb and the dactyl; the initial iamb or dactyl is shorter than the final.

The pronounced tendency to prolong the last syllable of a series is apparent in these three-syllable groups, and is often the factor which determines the grouping. If the series is continuous, , - - $1+\ldots$ etc., the dactyl may be preserved. But a group of three syllables with the accent on the first syllable is apt to drop into the form $1,1-1$, or the form +-1, . And the prolongation of the last syllable is apt to give the three-syllable group with accent on the median syllable the form $-1,1$, rather than either $\ldots+\ldots$ or $1,1, \ldots$. 


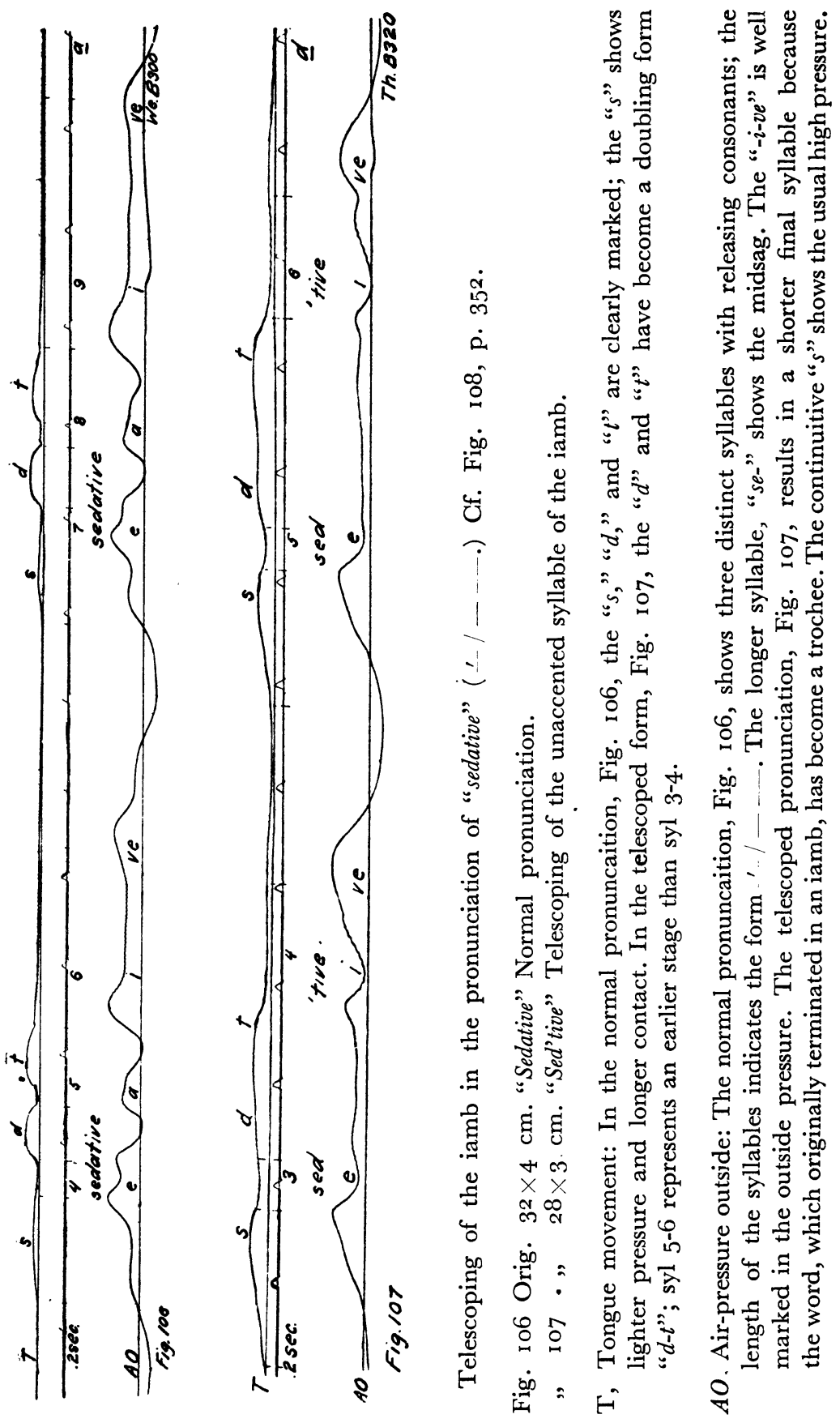

ARGHIVES DE PHYSIOLOGIE, TOME XIII. 
R. H. STETSON.

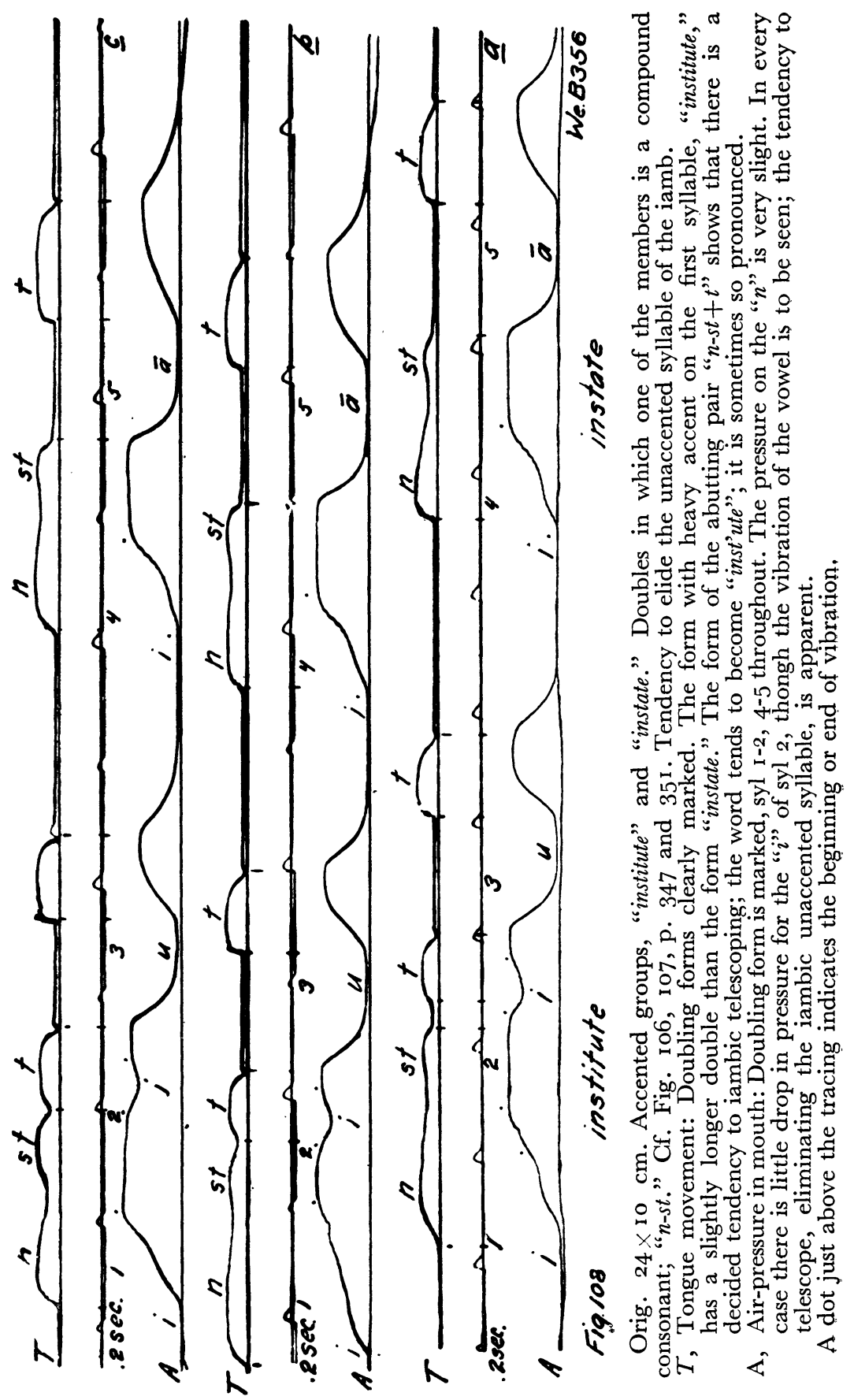


The presence of doubling consonants and of long vowels will be determining factors. Thus "ex'quisite" $=\perp \times-\Perp$; but "exquisite thing" $=\perp \times,-\times$, . With a pronouncedly short vowel in the final syllable, ,harmony" has the characteristic dactylic form; but "harmonize" becomes _ - 1, .

In the three-syllable group both the iambic and the trochaic unaccented syllable may be elided as the speed is increased. The iamb has a pronounced difference in the length of the two syllables, and if it occurs in succession at high speed, the rate may be too fast for the occurence of the short syllable. If the original form gives an arresting consonant to the unaccented syllable, this will drop early of course leaving the unaccented syllable with releasing consonant only. At a higher speed the unaccented syllable stroke is fused with the following accented chest pulse, but the releasing consonant may persist by shifting to the arresting position in the preceding syllable. Cf. 106, 107, 108.

Thus "beautiful" becomes "beaut'ful"; "business" has become "bus'ness"; "plentiful" becomes "plent'ful" "lab'oratory" becomes "lab'ratory."

In case the syllable preceding the eliding syllable of the iamb already has an arresting consonant, the releasing consonant of the syllable becomes functionless; it must either fuse with the releasing consonant of the accented syllable or drop. In a form like "institute" becoming "in'stute", the median consonant of " $n s t$ " fuses with the releasing " $t$ ". Cf. Fig. I08. In "hospital" becoming "hostel" the " $p$ " does not fuse with the following " $t$ " and there fore it drops; so the " $b$ " in "presbyter" becoming "pres'ter." Cf. Fig. 76, 77. p. 309 and 3 10. In "abdicate" becoming "ab'cate" the " $d$ " drops, although the " $b$ " and " $c$ " are not formed by the same member.

It is worth noting that in these cases with a continuitive like " $s$ " an intersyllabic sound does not develop; in the form "instate" if one attempts to prolong the syllables one finds that the "in-" can be prolonged by continuing the " $n$ ", but the "st" is given very briefly as the releasing consonant of "-stute." Such a prolongation of a syllable often occupies the time of the elided syllable, but it is not equivalent in the phonetic sense that the continued sound becomes a syllable; instead the fact is that something like the same length is maintained for the rhytmic unit-group. This is the explanation of "épenthèse," discussed by Rousselot. ") The transitional "sound" which develops as

1) Principes II, p. 989, tendre, teneru, etc. 
"teneru" becomes "tendre" is not the equivalent of the syllable; actually the releasing consonant has besome " $d r$-" and the increased length means that the two syllables represent the same ryhthmic unit-groups that the three syllables did before.

Rousselot suggests the steps whereby "cabitale" (capitale) becomes "ca-b-tal" with " $b$ " explosive; then "cab-tal", " $b$ " implosive; then "captal", " $b$ " surdifies, then $c h a$ " tel with the implosion still apparent and finally chetel in which the implosion has disappeared. ${ }^{1}$ ) The analysis is good save that the function of the consonant has not been noted; there can be no "explosive" (releasing) function for the " $b$ " when the syllable "-tal" has the releasing " $t$." And the same causes which force the arresting consonant out of the syllable "cha-" must prevent the formation of a hiatus at the close of the syllable; were there room for the hiatus there would be room for the arresting consonant. The problem of a single releasing (explosive) consonant functioning as a syllable is treated below. The steps would be: "cabitale (capitale) cab-tal, chatal, chetel."

The surd between two vowels often reduces to a sonant, as noted in the example cited by Rousselot above. This is the usual transformation of the trochaic median which has previously been discussed. Cf. Fig. I04, I05. p. 347.

RousseLot assumes that in the case of a syllable with " $e$ muet", the consonant alone may sometimes figure as the syllable when the "e muet" drops; la femm' se l'va" shows the elision of the " $e$ muet" after " $m$ " and after " $l$ ", and yet the syllable " $f e-$ " of "femme" is not closed, nor the syllable "se" preceding "l'va". ${ }^{2}$ ) In such cases it is of course impossible that the consonant ${ }_{i}$ alone become a syllable; a chest pulse is essential to a syllable. But it is possible for the compound consonants " $m s e$ " and "lva" to develop as the releasing consonants of their syllables, and the lengths of the rhythmic groups are adjusted as suggested above.

\section{The Group of Four Syllables.}

The group of four syllables presents a wide variety of combinations of the unit-groups; the dactyl may be preceded or followed by a single-syllable; the iamb or the trochee may appear in

1) Principes II p. 977 .

2) Principes II p. 98I. 
various successions with single-syllables; and trochees and iambs may occur together as initial or final. Combinations of trochees or iambs with dactyls are the only groupings which are not represented; and they would give no new arrangements of accented and unaccented syllables, or of combinations of syllables with single consonants and with abutting pairs (including doubles). All possible modifications of the syllables are to be found in such groups.

The tendency to prolong the final members of a group appears on comparing the trochees and iambs:

Initial trochees, .48 sec. 370 cases Final trochees, .6 I sec. 207 cases. iambs $.48 \mathrm{sec} .225$ cases iambs $.5^{8} \mathrm{sec} .102$ cases. single-syl. $\quad .28 \mathrm{sec} .717$ cases single-syl .31 sec. 657 cases.

These four-syllable successions develop series of unit-groups between which abutting pairs are given full value, or between wich adventitious doubles appear.

The adventitious double develops in the four-syllable group as it does in the three-syllable group. It usually occurs just after a heavy stress, but it may also occur just before a heavy stress. If the vowel of the preceding syllable is "short" the pause during which the heavy stress is prepared may be occupied by a double. The alternative would be a hiatus after the self-arrest of the short vowel. In 130 four syllable groups, four subjects, adventitious doubles occur in 47 cases.

\section{The Elision of Syllables, Modification and Contraction in Four-syllable Groups.}

The four-syllable groups are a good field for the study of the tendencies to drop syllables; there are two processes by which the four-syllable group is reduced to three syllables, reduction of the trochee and the telescoping of the iamb. Cf. Fig. I09, I Io, I I I I I 2, I I 3, I I 4, I I 5, I I 6 .

Since the adventitious doubles appear before and after the accent for reasons given above, and since the fusion of the syllables of the trochee must involve the accented syllable, and since the telescoping of the iamb occurs just before the accent, it is easy to formulate a general rule that the various modifications of the consonants and syllables will appear just before and just after the accented syllable. As the accents may be in several patterns, this means that adventitious doubling, persistence of 


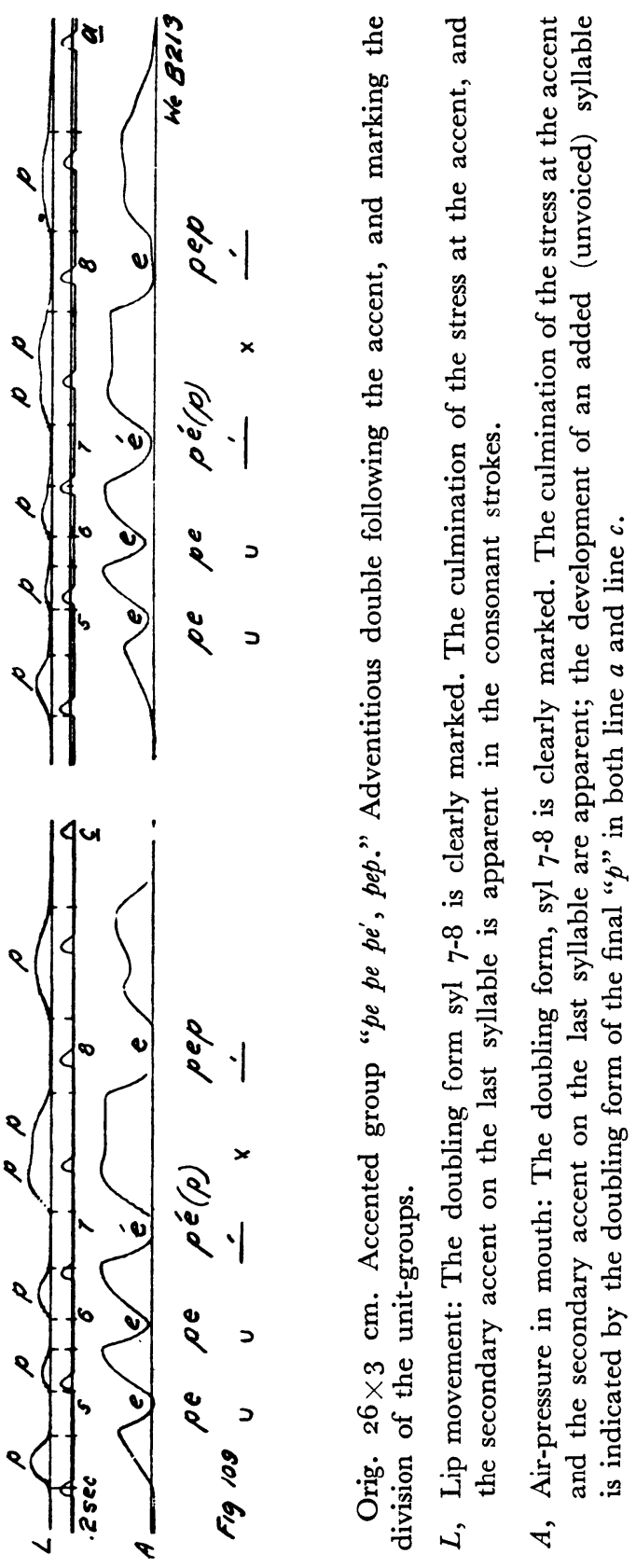


MOTOR PHONETICS.

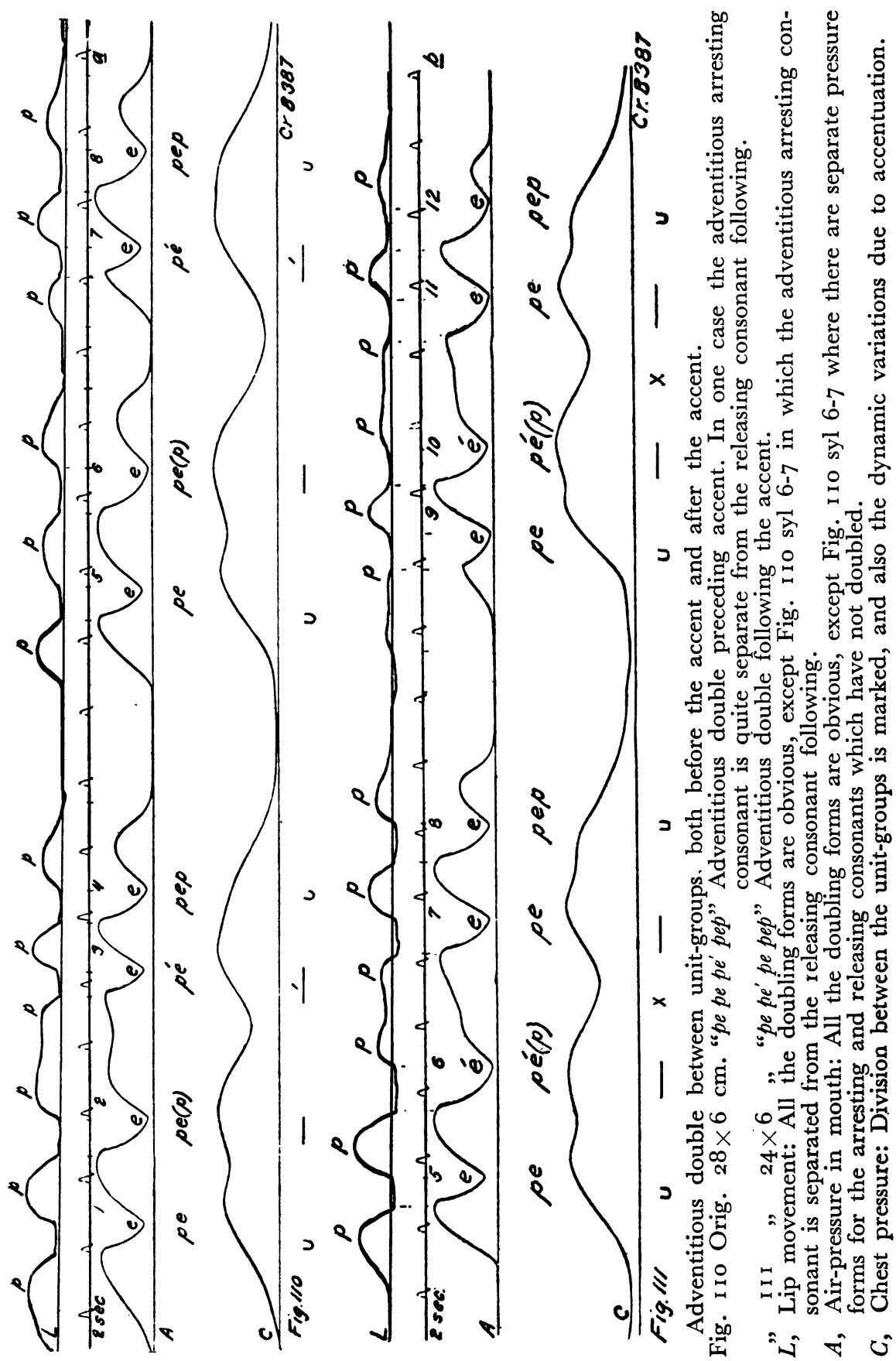




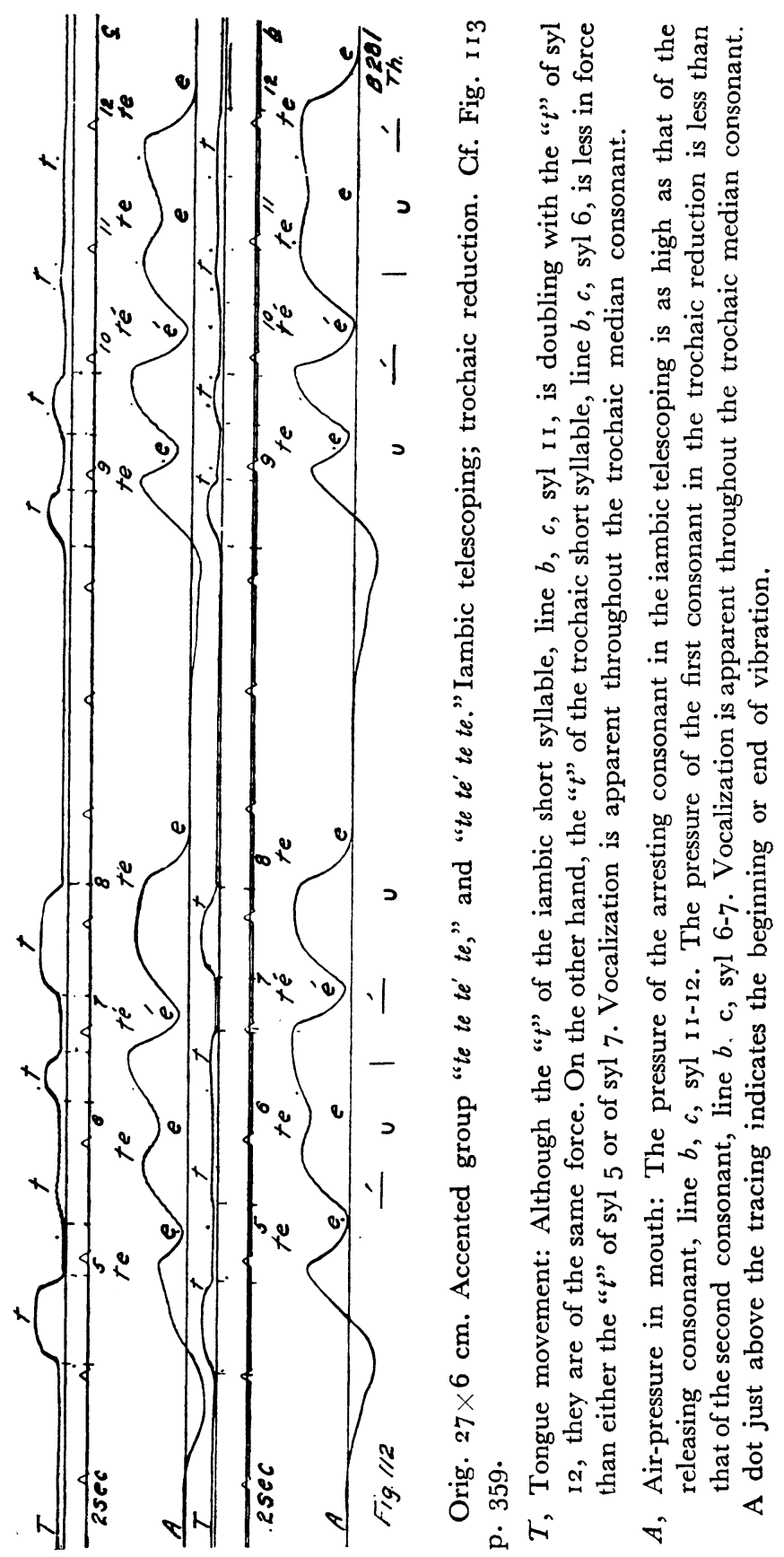


MOTOR PHONETICS.

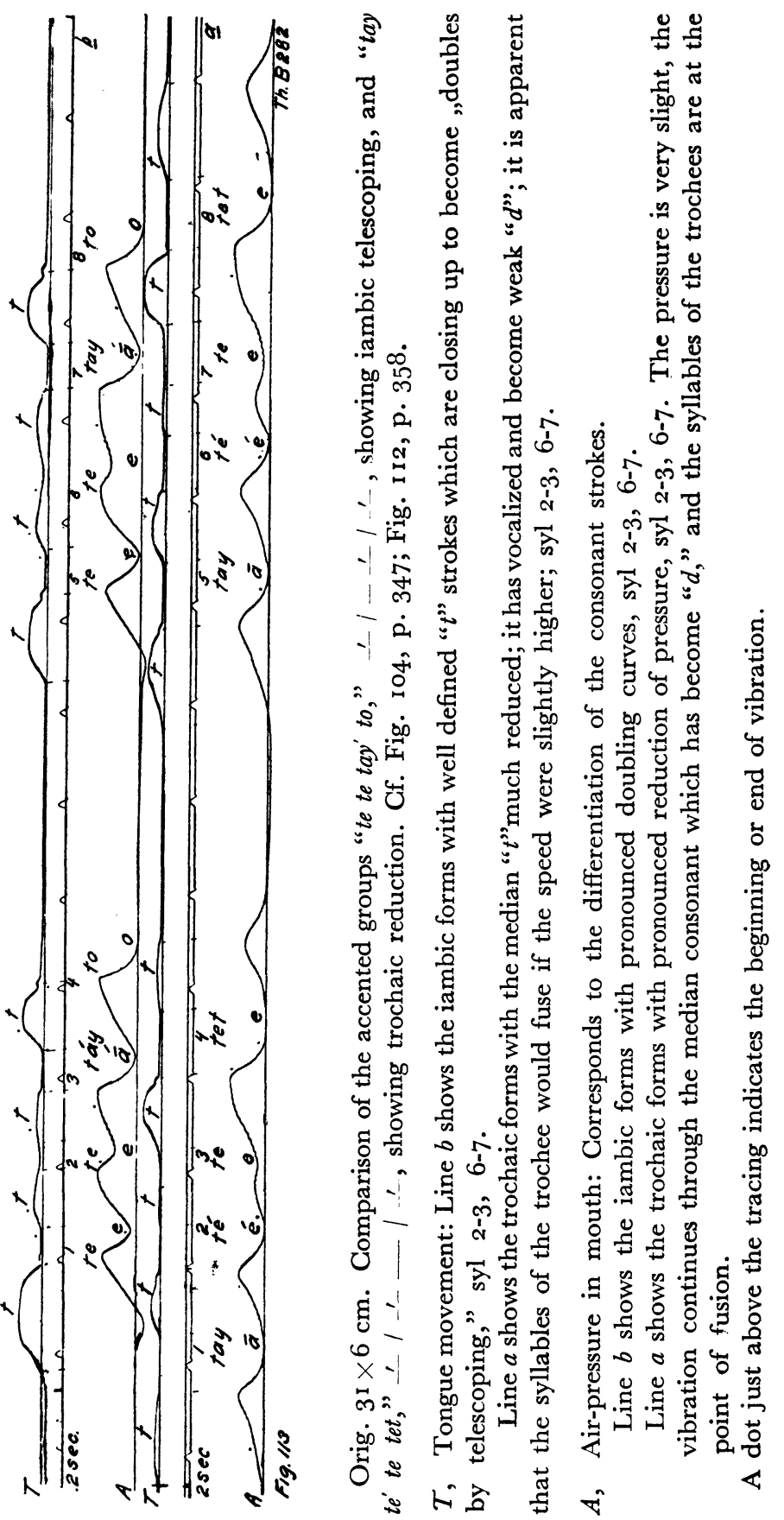




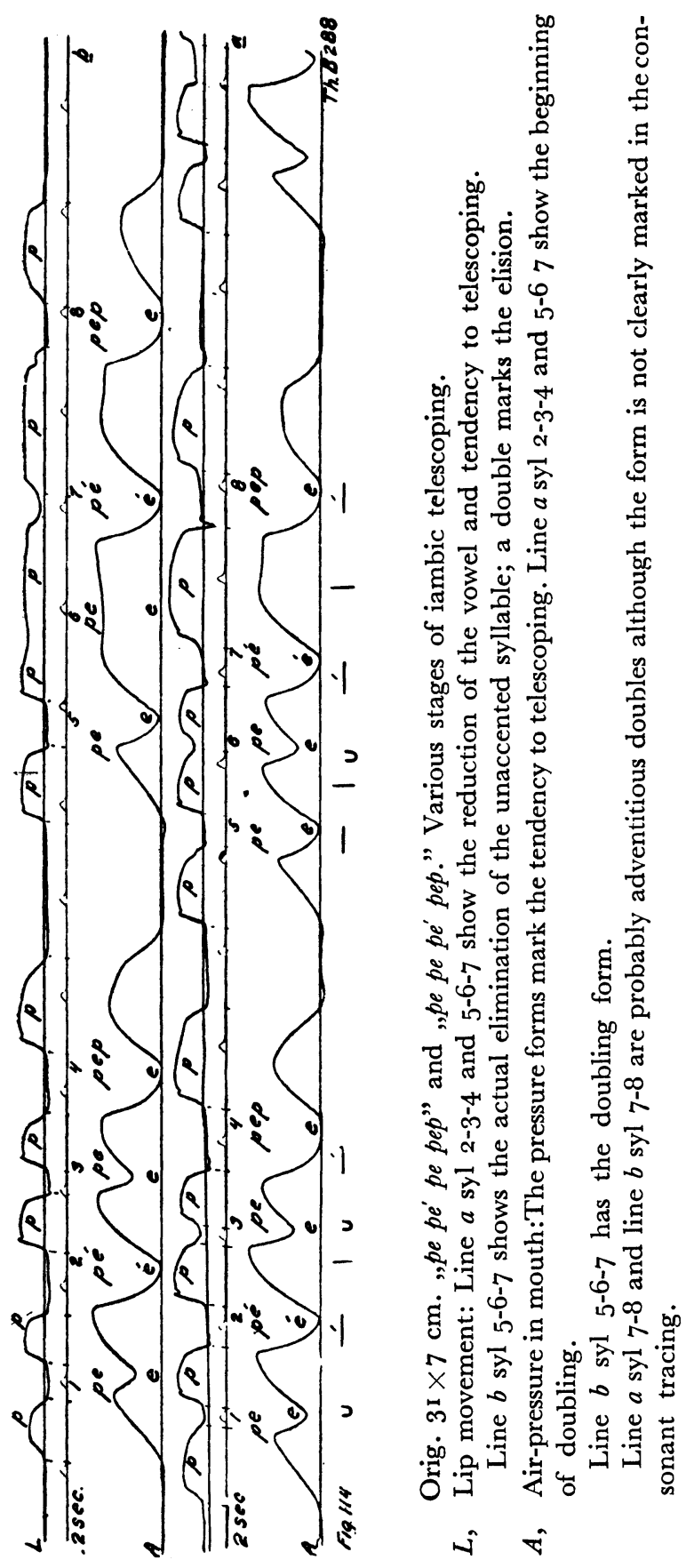


MOTOR PHONETICS.

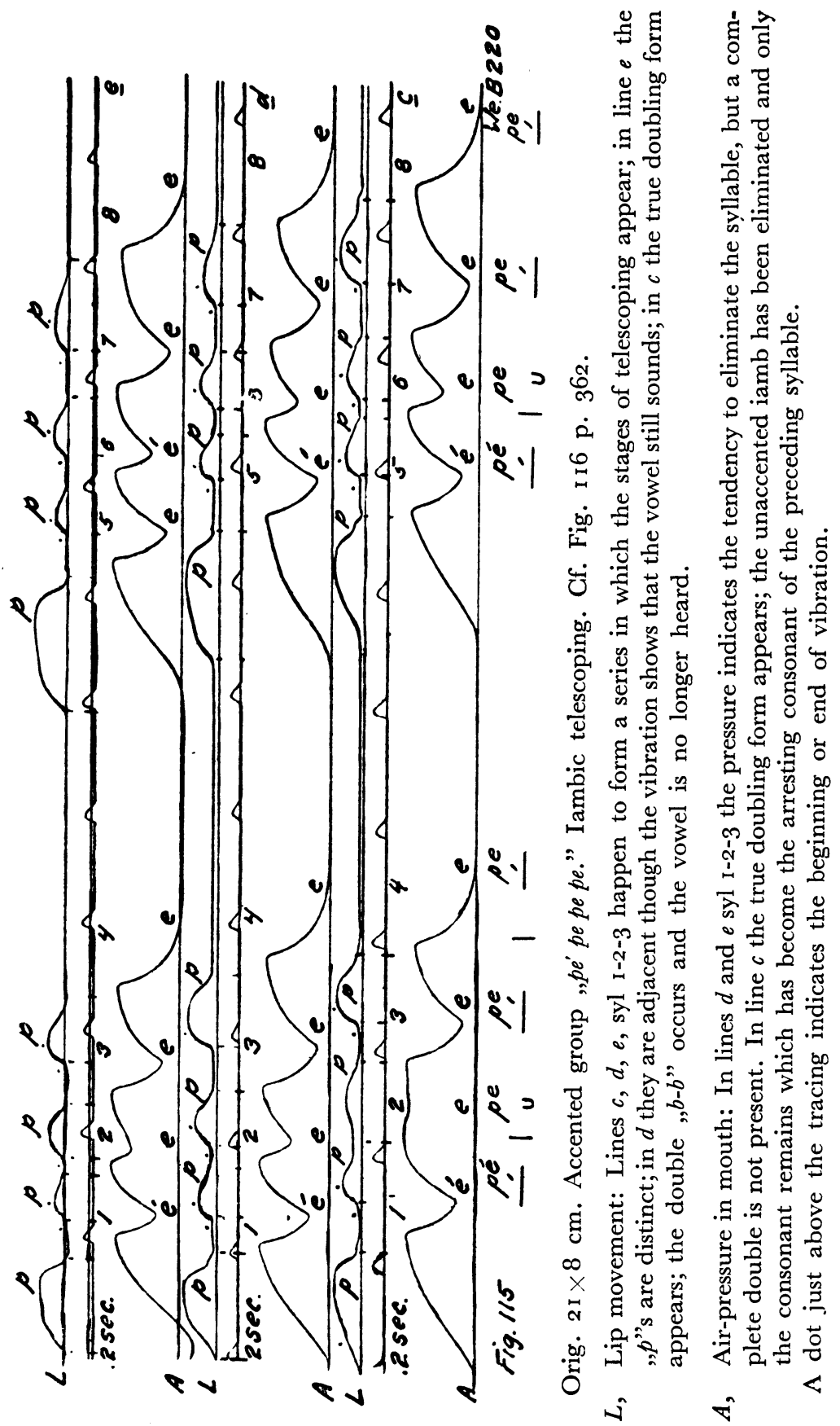


$3^{62}$

R. H. STETSON.

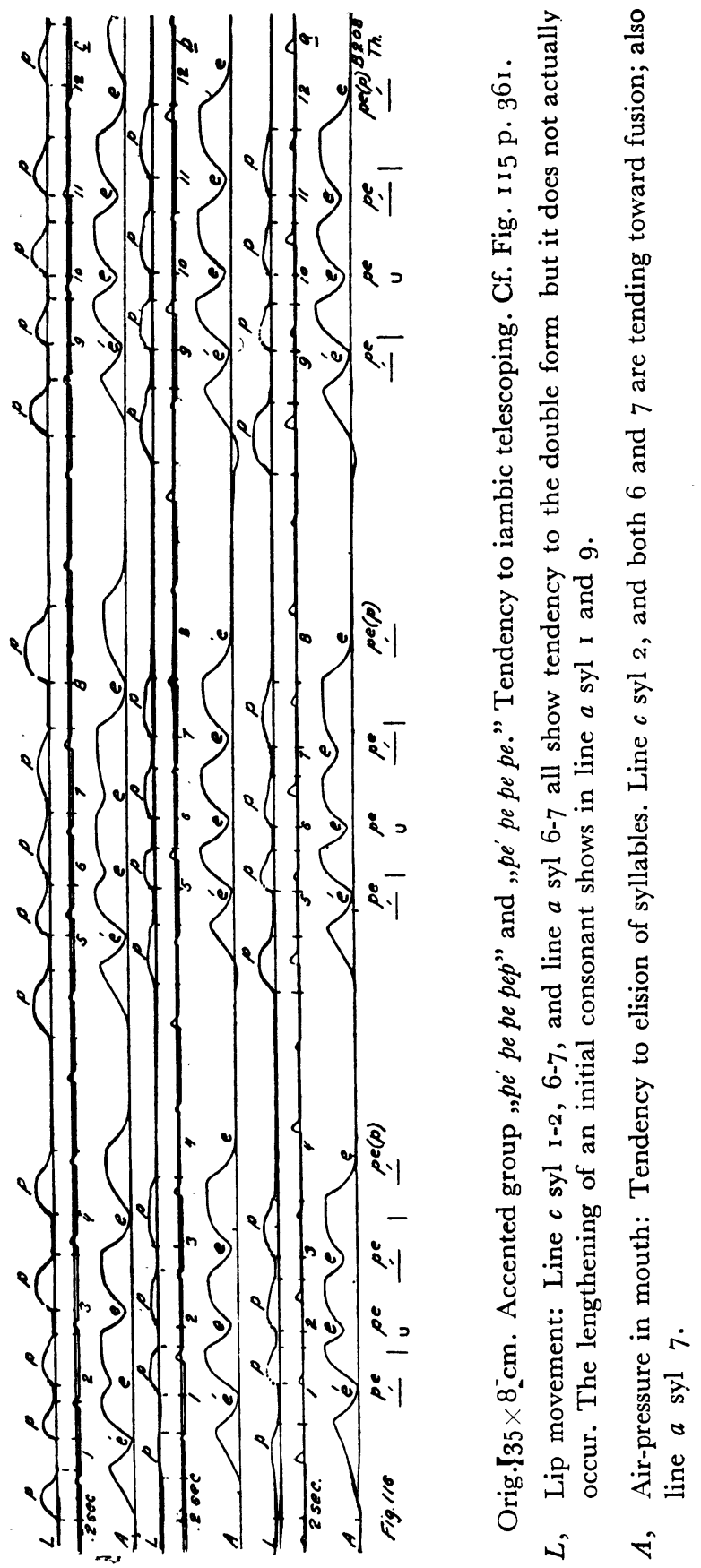


abutting consonants, telescoping, and fusion may appear between syllables $\mathrm{I}$ and 2 , between 2 and 3 , and between 3 and 4 . It is only the initial and final syllables and consonants which are not affected.

Here as elsewhere, abutting consonants, long or short vowels, along with the prescribed accents, determine the precise series of unit-groups developed within the four-syllable group.

It is convenient to schematize the changes in both consonants and syllables which occur in a series of syllables grouped in various types of feet, when the speed is increased. It is easy to see that in the case of the trochaic series, and of the iambic series, that all arresting consonants finally drop with the increase of speed; and that the releasing consonants of unaccented syllables drop also. The unaccented syllables invariably drop with the increase of speed. The accented syllables and their releasing consonants persist whatever the speed. Cf. Fig. II7, II8, II9.

C. Comparison of the Abutting and Single Consonants of Accented Groups with the Abutting and Single Consonants of Series developed by Increasing the Speed.

Distribution curves of the consonant lengths make it possible to compare the lengths of doubling and singling consonants when produced by increasing the speed in artifical series, and when produced in the course of uttering the various accented groups discussed. In Fig. I 20, the curves $I$ and $\mathcal{F}$ represent the distribution of the lengths of double and abutting consonants in the various accented groups studied; they show that the double and the abutting pair are one and the same thing; the limits of distribution and the mode of the distributions of the measurements of length are practically the same.

In Fig. I 2 I curve $K$ represents the distribution of the lengths of all the doubles and abutting pairs recorded in 1924 and I926, 3 I I cases. Curve $M$ represents the distribution of the lengths of the doubles and abutting pairs in accented groups recorded in 1926,705 cases. It is apparent that the distributions are practically identical, and that the process of doubling in the accented group is precisely the process in the artificial series of syllables with changing speed. The curve $L$ represents the 
distribution of 23I cases of "constructive doubles." They are added to show that while the process of constructive doubling is nearly the same, there is a slight difference; the constructive doubles are slightly longer than the actual doubles or abutting pairs.

\section{SAMBIC TELESCOPINO}
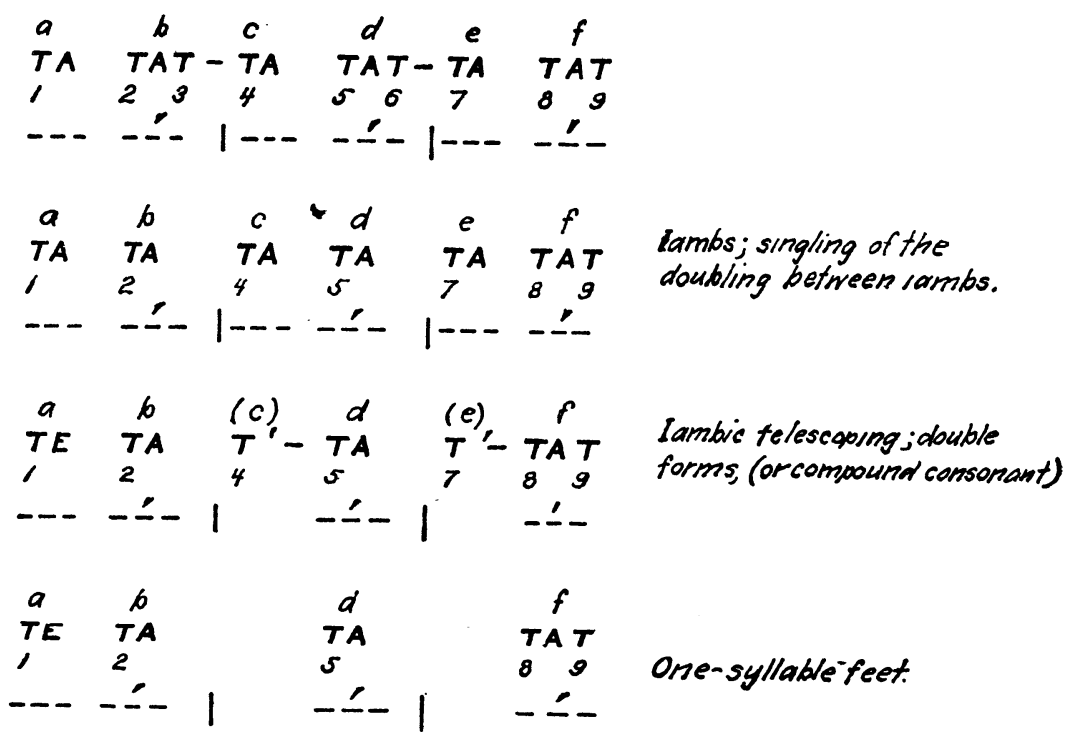

Fig. $/ 17$

Stages, as the speed is increased, of the elisions in a series of three iambs: "'ta tat', ta tat', ta tat'."

In the second line the doubles between the unit-groups have disappeared.

In the third line the syllables $c$ and $e$ have ,telescoped," i.e. only double consonants remain, arresting the syllable $c$ and releasing the syllable $f$. Introductory syllable is not affected.

In the fourth line the speed has eliminated the arresting consonant of the doubles, and only the syllables $a, b, d, f$, remain; $b$ and $d$ have become open syllables. Introductory syllable is not affected save that the vowel is reduced.

The rates of utterance in accented groups, and of syllables in series with changing speed, show much the same identity as do the consonant lengths just discussed. In Fig. 122, the curves $A, B$, are composed of $d, e, 506$ series, and of $f, g, 424$ series, thrown together from Fig. 44 p. 269. $c$ represents the distribution of 96 cases in wich a prescribed double in an accented 
group has been uttered as a single (due to the influence of the grouping of the syllables.) The syllable lengths have been reduced to rates. It is apparent that the distribution is practically the same; i.e. the single consonant which appears in place of a

\section{TROCHAIC REDUCTION}

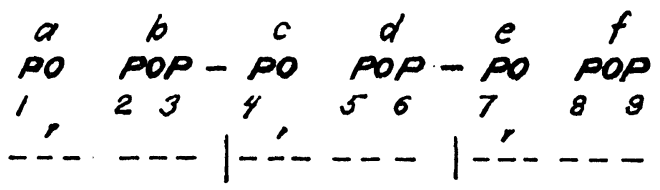

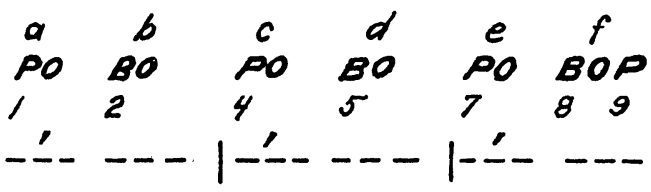

\section{Vocalization; singling of doublesbetween trochees.}
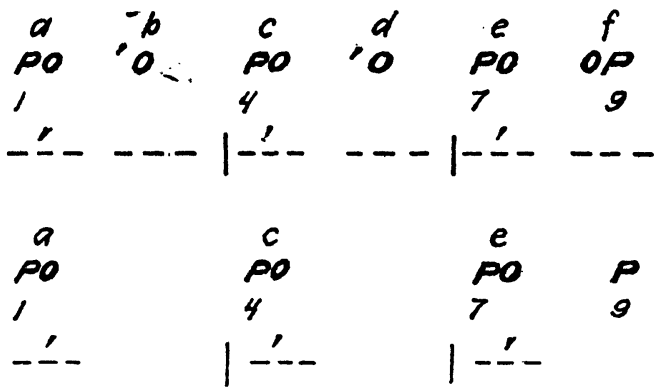

\section{Fusion of syllables; onewyllable feet.} median consonart.

Fiq. $1 / 8$

Stages, as the speed is increased, of the elision of the unaccented syllable from the trochee in the series, of three trochees: " $p o^{\prime} p o p$, $p o^{\prime} p o p$, $p o$ ' $p o p$. ."

In the second line the doubles between the unit-groups have disappeared; the median consonants, which become very brief, are vocalized if originally surd.

In the third line, the median consonant has been eliminated, but the syllables remain.

In the fourth line, the syllables have fused and a series of single-syllable unitgroups remain.

double in an accented group is as near to the doubling rate as possible, and therefore is very like the single which appears just after doubling in the speed series.

Fig. I 23 shows the curves $A, B$, which summarize the distributions of rates of syllables determined in "speed series;" and 


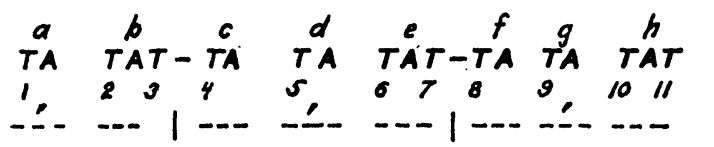

Trochee + amphibrachs; doubling between feet.

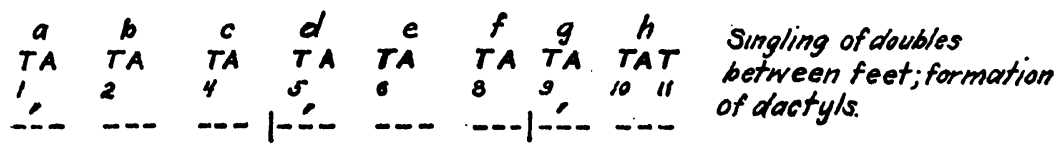

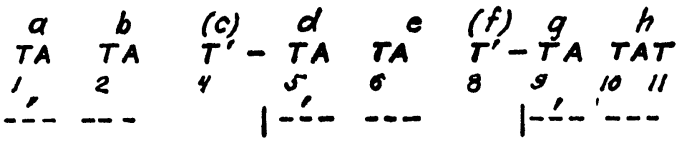

Iambic telescoping.
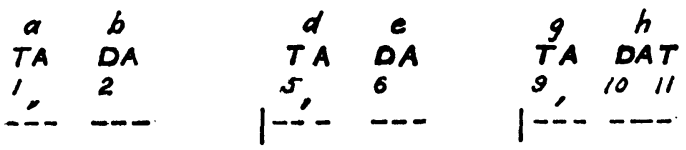

Vocalization of trochaic mealian consomant.
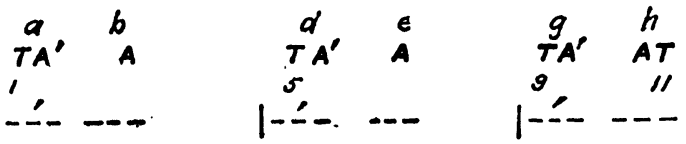

Realuction of trochaic mealian consonant
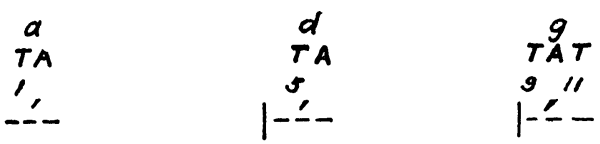

Ore-syllable feet

Fig. 110

Changes, as the speed is increased, from amphibrach to dactyl; iambic telescoping; trochaic reduction; all in the single series: " $t a$ ' $t a t$, $t a t a$ ' $t a t$, ta ta' tat."

The second line shows the singling of the doubles and the formation of the dactyls.

The third line shows the iambic telescoping which reduces the dactyls to trochees.

The fourth line shows the vocalization of the reducing trochaic median consonants.

The fifth line shows the trochiac median consonant eliminated.

The sixth line shows the entire series reduced to three single-syllable unitgroups.

the curve $a$, which gives the distribution of the rates of syllables in accented groups which have double or abutting consonants; 
curve $b$ which gives the distribution of the rates of syllables in which a single consonant was prescribed. The distribution of the rates of syllables with doubles and abutting pairs in the

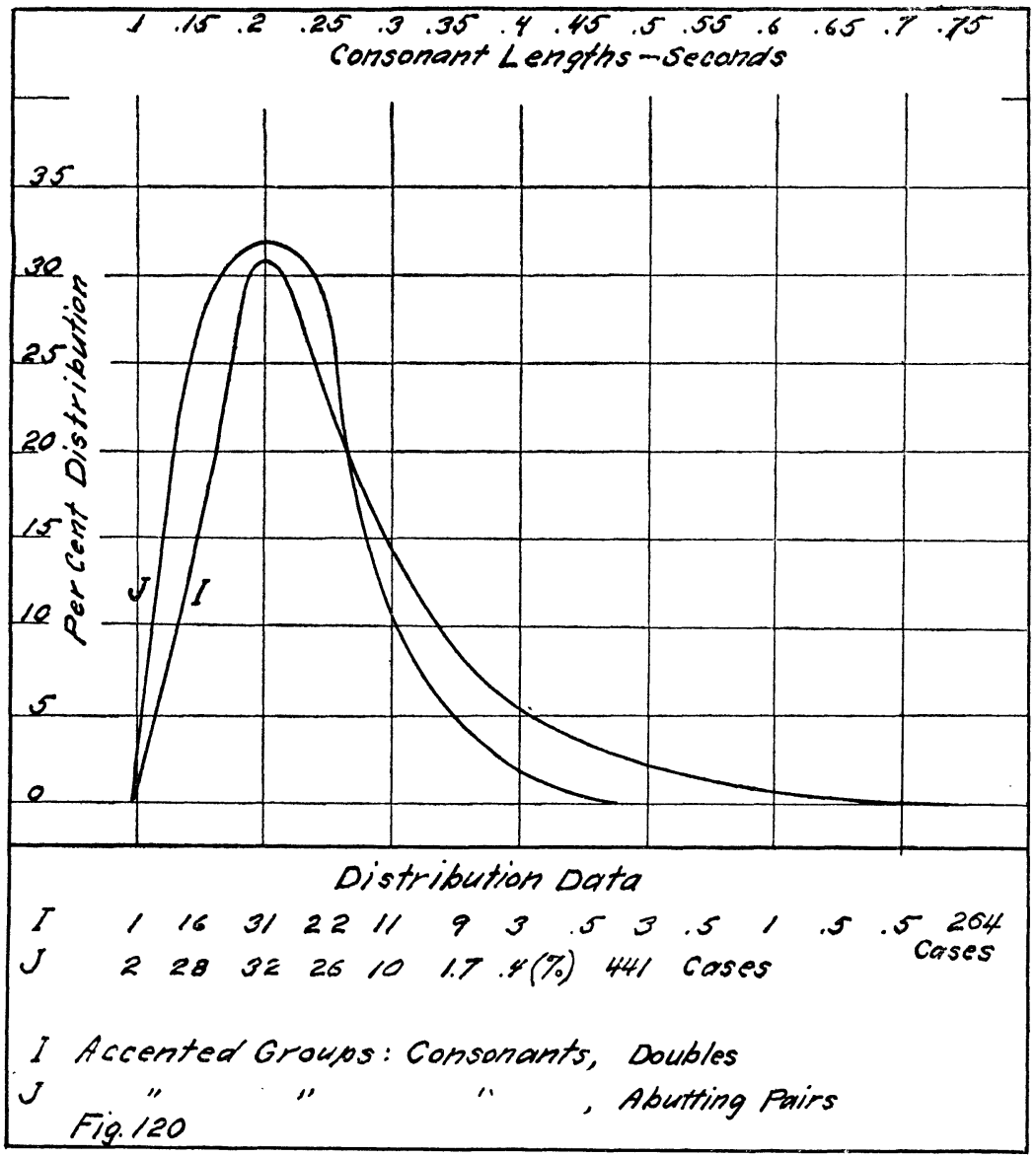

Distribution of the lengths of abutting pairs, including doubles, as they appear in accented groups of syllables.

$I, \mathcal{F}$, A comparison of the distribution of the abutting pairs and of the doubles showing that they are practically identical.

accented groups coincides with the distribution of the rates of syllables in the speed series. But the syllables with a single consonant which does not take the place of a prescribed double, but which is single according to instructions, are decidedly ARGHIVES DE PHYSIOLOGIE, TOME XIII. 


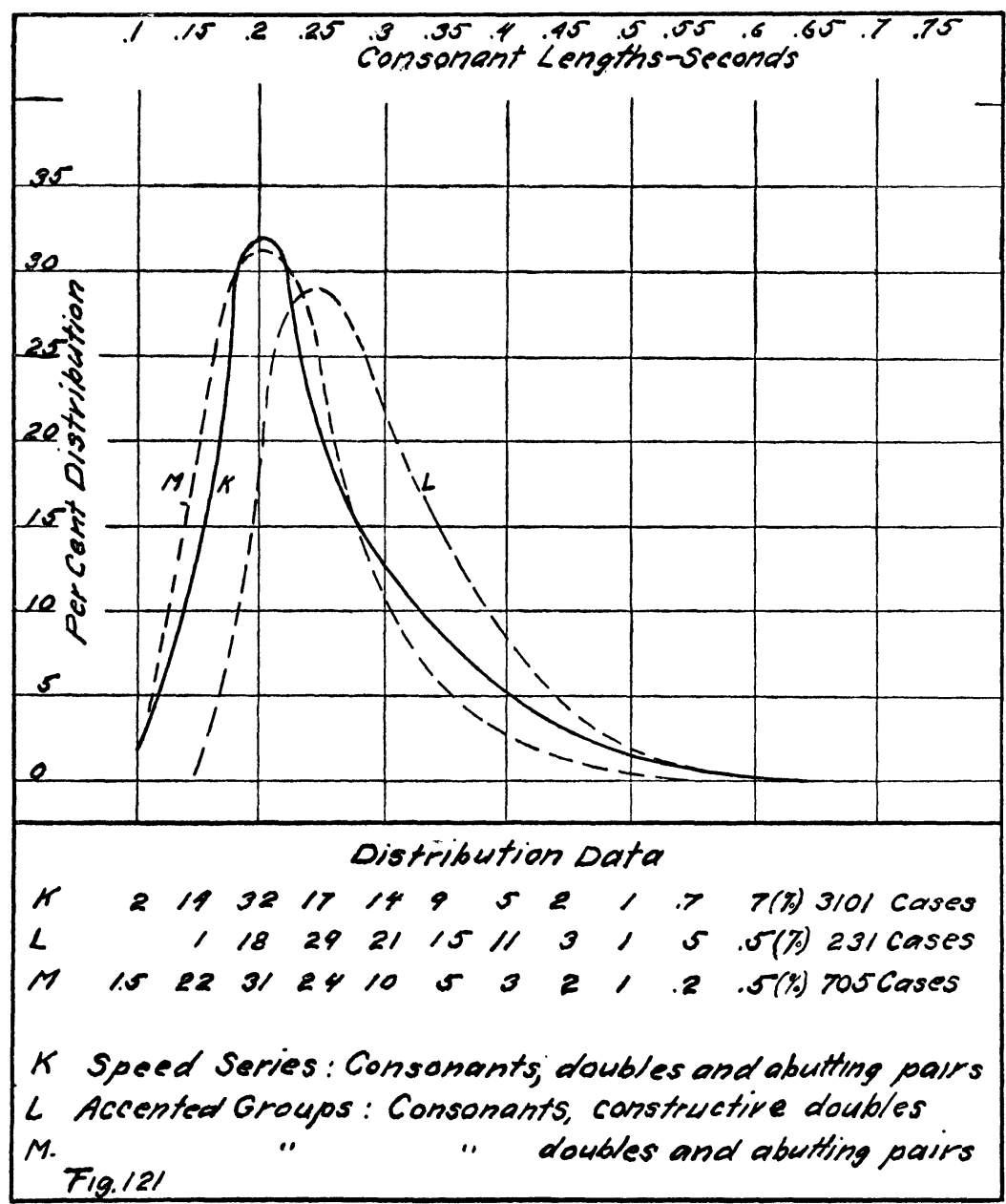

Distribution of the I) lengths of doubles and abutting pairs, and of 2) "constructive doubles," as compared with doubles and abutting pairs developed by increasing the speed. (A constructive double is an arresting consonant followed by a syllable with self release; the duration of the arresting consonant + the releasing phase $=$ a double.)

$K$ is the combination of $F, G, H$, representing all the speed series of 1924 and 1926 . Fig. 57, p. 287 .

$L$ constructive doubles as they appear in accented groups.

$M$ combination of $I$ and $\mathcal{f}$ representing all the doubles and abutting pairs which appear in the accented groups. Fig. 120, p. $3^{67}$.

It is apparent that the distributions are the same with the exception of the "constructive doubles," which show a slightly longer form than the abutting pairs (including doubles.) 


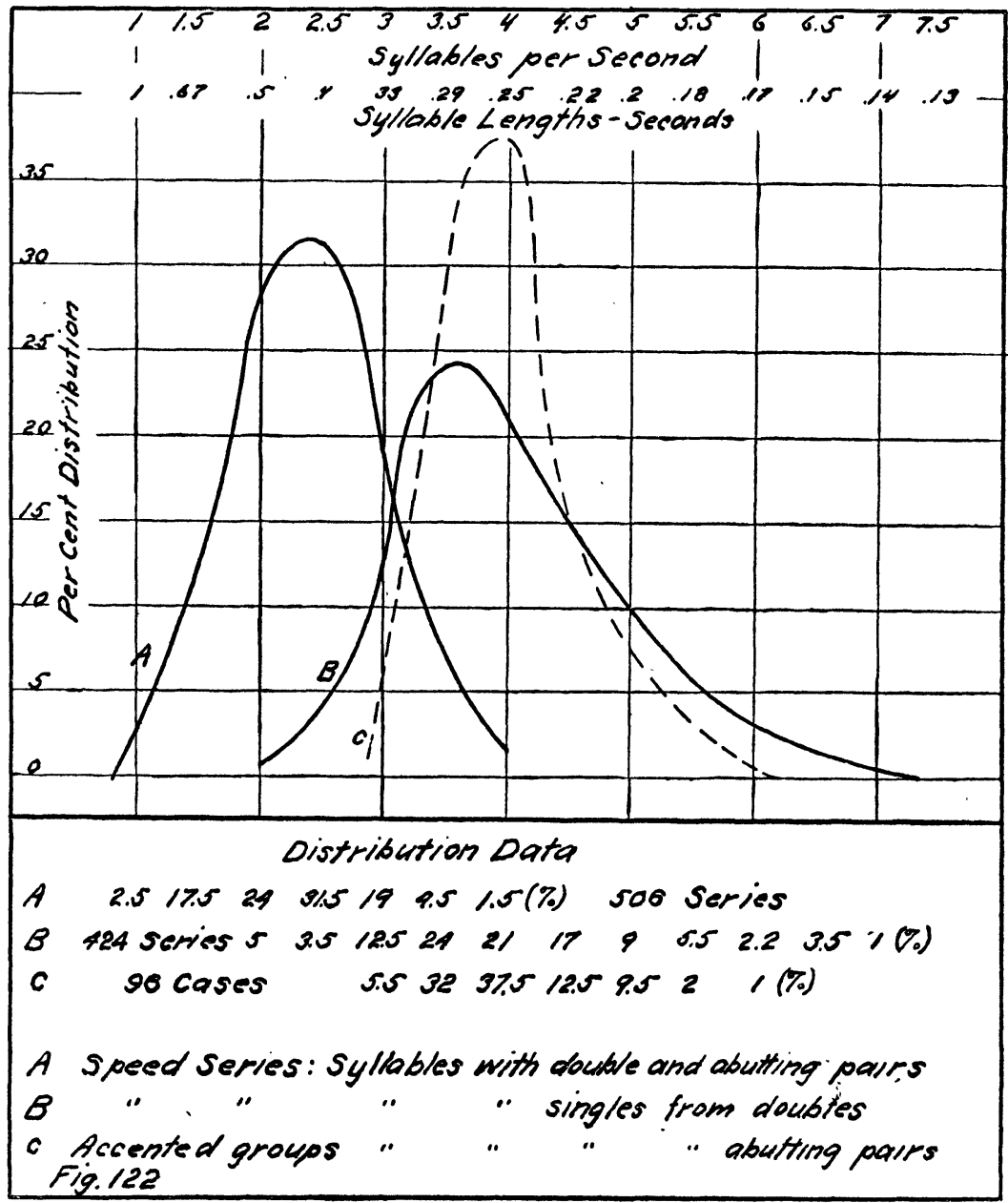

Distribution of the rates of syllables occuring in accented groups, compared with the rates of syllables in series with increasing speed. The lengths of the individual syllables in the groups were measured and reduced to rates per sec. $A, B$, combinations of the doubling curves, $d, e$, and singling curves, $f, g$, of Fig. 44, p. 269.

$c$, Distribution of syllables in groups in which double consonants were prescribed, but the exigencies of the rhythm compelled singling. The distribution is identical, which tends to show that the process is the same in the speed series and in the accented groups.

faster than the syllables with a single sonsonant which represents a double; the distribution is symmetrical and represents a normal 


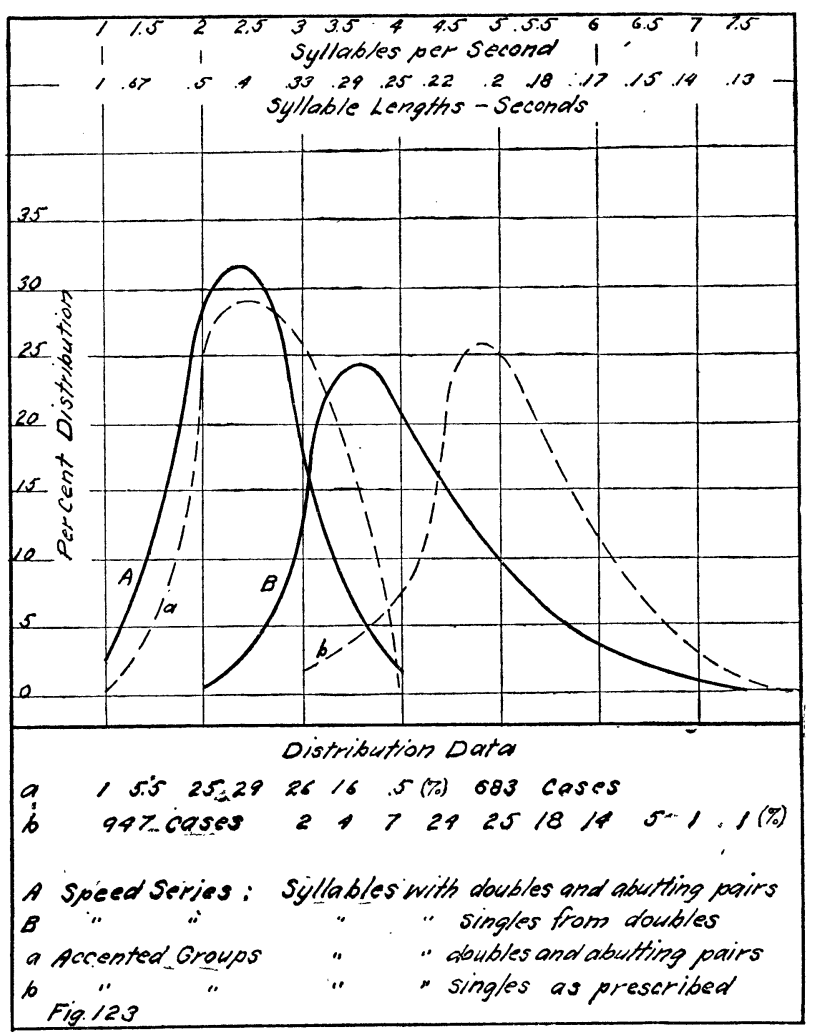

Distributions of the rates of syllables in accented groups in which abutting pairs (including doubles) were prescribed, of syllables in which single consonants were prescribed, as compared with rates of doubling and singling in speed series. The lengths of the individual syllables in the accented groups were measured and the lengths reduced to rates per sec.

$A, B$, Combinations of the doubling curves, $d, e$, and of the singling curves, f, $g$, Fig. 44, p. 269 .

$a$, Distribution of the rates of syllables in accented grou $\mathrm{s}$ with abutting pairs (including doubles.) The distribution is nearly identical with that of the rates of doubling by increasing speed.

$b$, Distribution of the rates of syllables with prescribed single consonants. Interesting to note that while the maximum rate is no higher than that of the rate of singling by speed, the distribution as a whole is decidedly higher. Where doubles have been prescribed and the rhythm has forced singling, the distribution of the singles is close to the distribution of the doubles, as in $C$, Fig. 63 , p. 294. But where the singles are prescribed in accented groups and therefore there is no tendency to stay close to the doubling rate, the distribution is higher in mode and is symmetrical; the number of cases involved makes the curve definitive. 
distribution between the limits of the rates of syllables with a single consonant, from $3-7.5$ syllables per sec. There is no tendency to keep as close as possible to the rate of doubling.

These comparisons of the lengths of the doubles and abutting pairs, and of the rates of syllables with double consonants and abutting pairs, show that on the one hand, the speed of utterance will determine the form as "doubling" or "singling." On the other hand the form of "doubling" or "singling" as it appears in accented groups of syllables will determine the rate of utterance of the syllable in question. The form of doubling and singling and the appropriate rate of utterance go together.

\section{Reversion to the prescribed form when the rhythm permits.}

The tendency to restoration, to reversion, after a phonetic modification, plays a part in groups of syllables with an accent (arranged in rhythmic feet) just as it does in series in which the speed changes. Cf. p. 273. The prescribed consonants and syllables may be profoundly modified by the rhythm and the consequent rates; but the original form is still with the subject, and appears whenever the conditions will permit. Therefore stem forms remain through the varying modifications which result from the addition of terminations and the shift of the accent. In forms like "sled," the " $d$ " is arresting; in "sledding" an adventitious double might appear as the spelling indicates, but this is very seldom the case; instead the arresting " $d$ " becomes the releasing consonant of the next syllable, and the syllables are really "sle-ding."

In forms like "adverti'sing," and "adver'tisement," the "s" reverts from the releasing to the arresting position when the abutting pair " $s-m$ " is produced by adding the "-ment." Shifting the accent often changes the division of the syllables, and often leads to the elision of syllables. The American pronunciation "lab'oratory," (, $1-\ldots / \perp-)$ leads to the dropping out of the short of the iamb, leaving "lab'ratory," with an abutting " $b-r$. " The British pronunciation "labor'a tory (- +1 ") tends to the dropping of the short syllable of the iamb, "labor'at'ry," and finally to reduction of the trochaic median, leaving "labor't'ry, three syllables. 


\section{Groups of more than four Syllables.}

It is possible to get an unbroken series of five syllables; the phrase "runnin' ' $n$ ' neighin"" may be given in a single series, as in Fig. I24. And of course any series of syllables repeated with increasing speed gives a long series of connected syllables without break. But such unbroken series are not necessarily groups; instead one has a continuousprocess which may continueindefinitely. It is much like the trill or tremolo at the piano, wich may consist of an indefinite number of elements with no definite accentual organization save the accent with which the series of rapid, uniform notes begins. In such a series, the first indication of grouping will be the formation of simple unit-groups (singlesyllable, trochee, iamb, dactyl) which breaks the series into groups of one, two, or three syllables. Two, three, or possibly more of these unit-groups (feet) may combine into a larger grouping, indicated by the subordination of the pauses (pressure minima) by the linkages (abutting consonants) and by the dynamic structure of the larger phrase. Such phrases of five or more syllables may easily occur; but they are not common. A series like "Zeep Ope will be pope" is apt te be given as two distinct phrases, "Zeep' Ope' / will' be pope'." The form "Zeep Ope will be pope" ( $+1+\ldots-1+)$ is possible; but the form "Zeep Ope will be pope" (-1, _ _ I , results in "Zee pope "ll be pope" in which both the " $p$ " of "Zeep" and of "ope" have become releasing consonants. "Zeep Ope 'll be-p ope" is also possible; the arresting form of "Zeep" is imitated by " $b e-p$ " in the second sub-group. Cf. Fig. I25. In verse, series of six, eigth, and more syllables are common; but it is usually the case that lines of more than four feet (eight to twelve syllables) are broken by cesurae. In prose, the phrases, i.e. the longer breath groups, may not be as long as in verse.

The prescribed formula " $p o p u p p^{\prime}$ a $p o p^{\prime} u p$ " was uttered so as to make an interesting variation of the five-syllable group. The subject gave it " $p o p^{\prime}\left|u^{\prime} a\right| p o p^{\prime} u p$," with a primary stress on the final " $p o p$ " up." In I 8 of the I 9 cases measured the primary stress occurs on the final accent. In Io of the I9 cases, the initial single-syllable "pop" is marked off by a constructive double; the adventitious double "pop-pup" is avoided to keep the verbal "up" quite clear. Cf. Fig. I 26.

Of cours many phonetic changes of the consonants are not 
MOTOR PHONETICS.

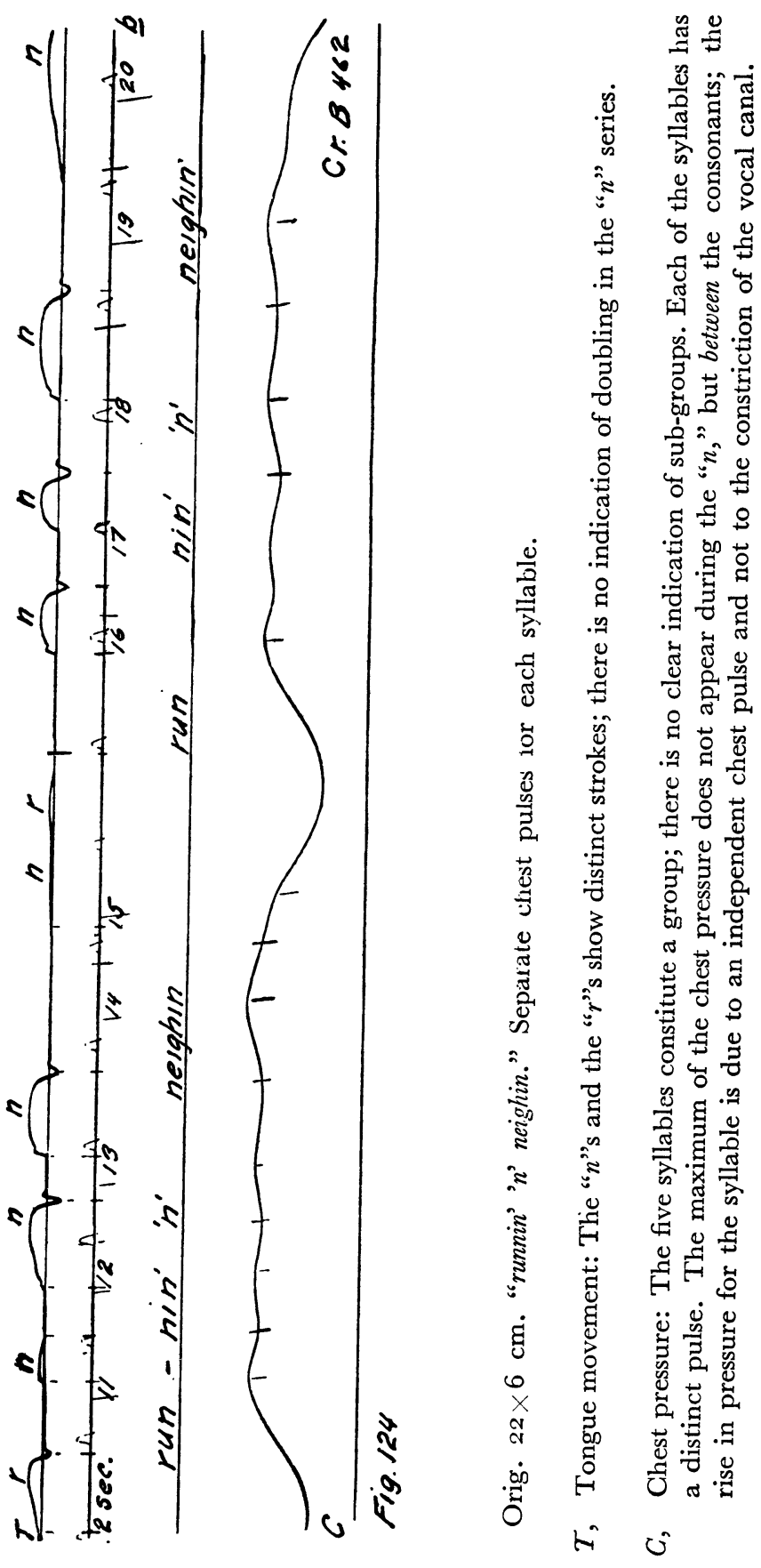


R. H. STETSON.

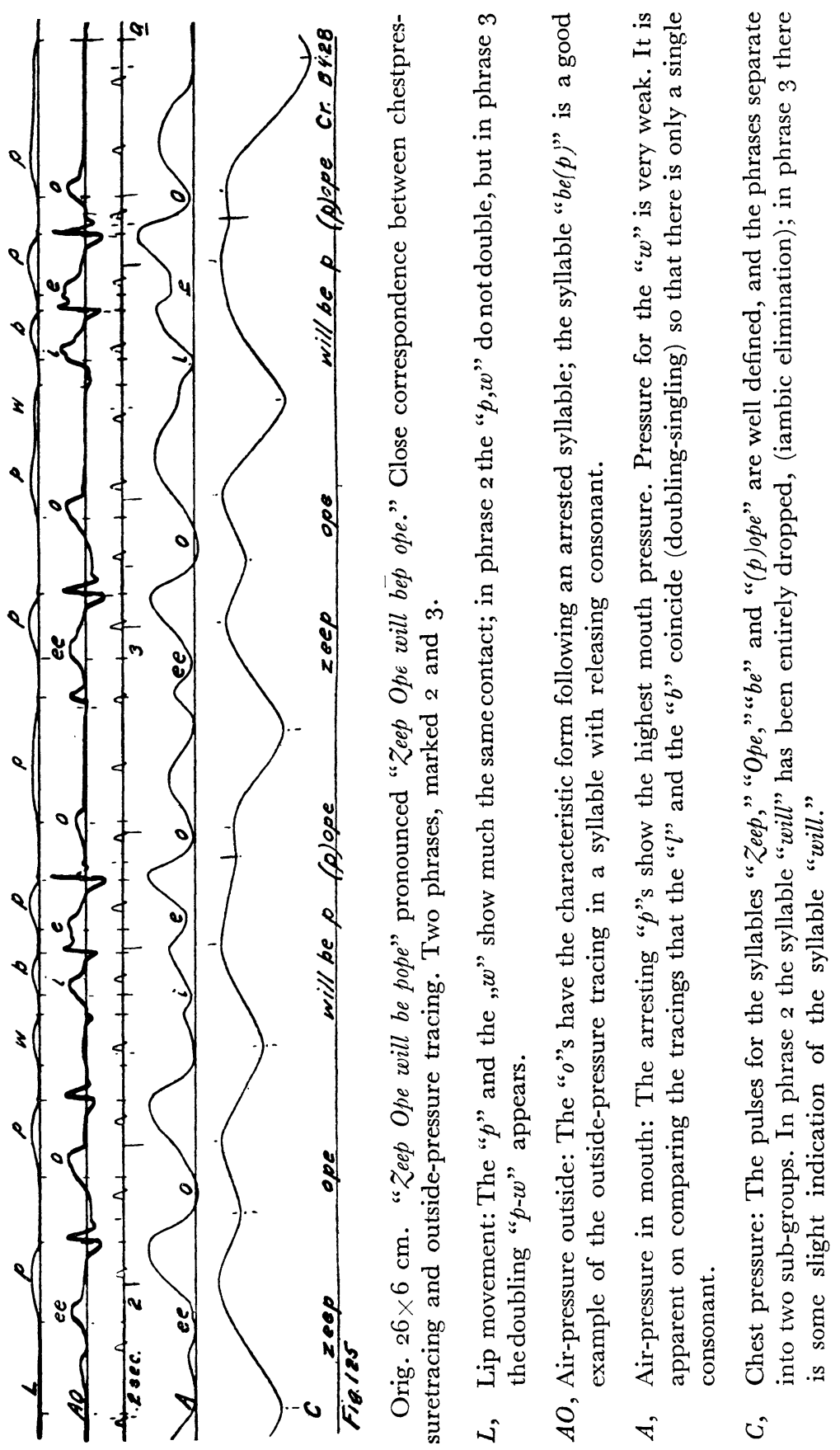




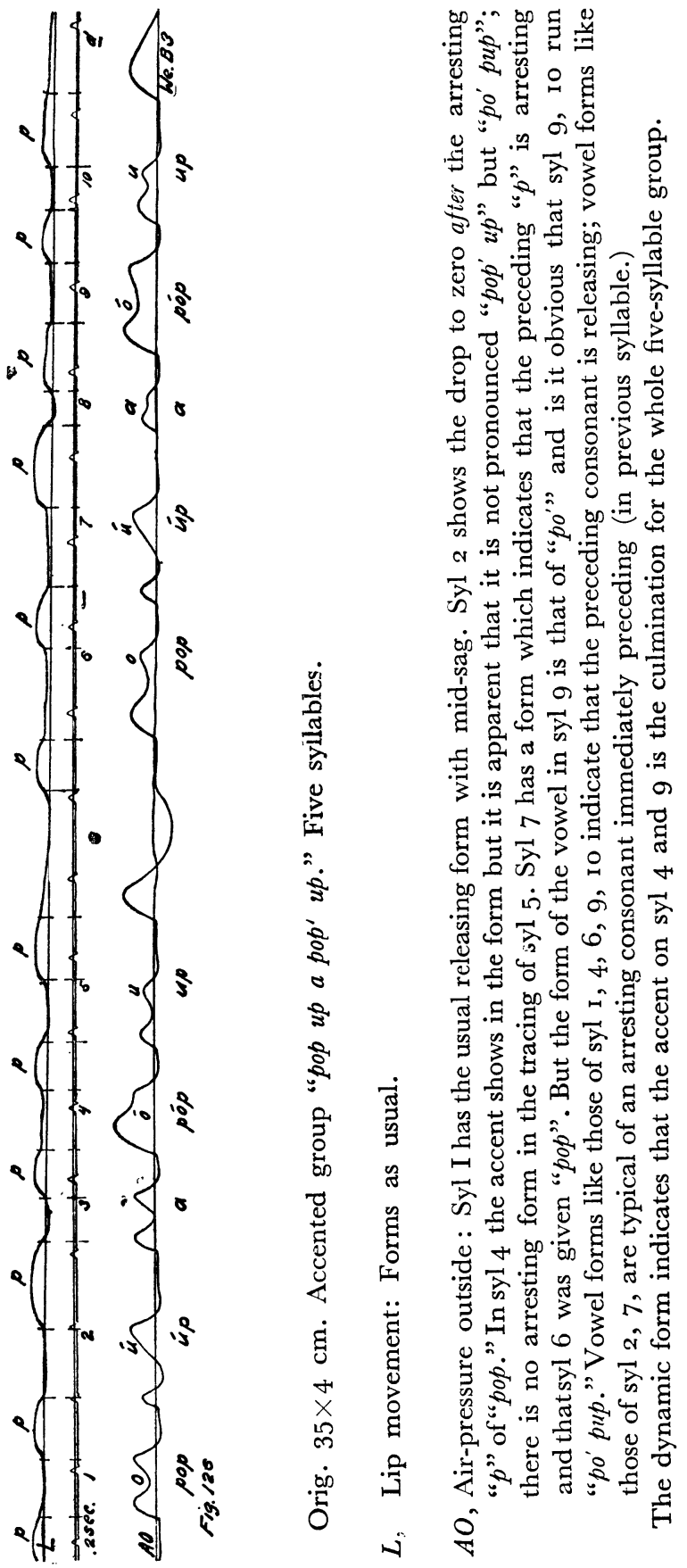


included in these processes of dropping the arresting consonant, of doubling and singling, and of reducing the trochaic median consonant. The changes involving aspirates, soft gutturals, nasals, semi-vowels, and liquids are often not of this group of changes. The influence of vowels on each other, and of consonants and vowels on each other, has not been discussed. Syllables are eliminated by other processes than iambic telescoping and trochaic reduction.

It will not be difficult, however, to devise series in which such elements are brought together, and by increasing and decreasing the speed to produce in the laboratory the changes which occur in the history of a language.

E. Influence of the Word Accent and the Syllable Movement in the Modification of Sounds.

The quality of the sounds of the vowels may be affected by the stress. Even in French it is possible that the accentuation may produce slight differences in the vowels. Rousselot and La Clotte note changes of the vowels from open and closed to median qualities when the vowels become atonic. " $a$ " (fermée) becomes " $a$ " (moyenne) in bas de soie; " $e$ " (fermée) becomes " $e$ " (moyenne) in bonté de coeur; "ó" (fermée) becomes "o" (moyenne) in côtelette; "oe" (fermée) becomes "oe" (moyenne) in feu de joie." 1) In every one of these cases the elision of the "mute $e$ " leaves a consonant in the arresting position for the syllable in question; they are all cases of the elimination of the unaccented syllable of the iamb with the resulting abutting pair formed when the syllable telescopes. Bonté $d(e)$ coeur, bas $d(e)$ soie, côt (e)lette, feu d(e) joie.

In English the shifting of the accent modifies the vowels profoundly. Note the " $i$ " of ad'vertise, adver'tisement; the " $a$ " in profane, profanation; the " $a$ " in circulate, circulatory; the " $y$ " in analyse, analysis. The syllables which do not have the primary or secondary accent tend toward "darke." The sense of the quality of the vowel persists and the proper vowel reappears in derivatives and in calling and singing.

1) Précis, p. 100. 
This change of quality with the change of accent is a matter of speed of utterance of the syllable. There is not time enough for the vowel movement to occur in normal fashion. The English "dark $e$ " and the " mute $e$ " of the French is merely the vowel reduced to its simplest and briefest form; it is the vowel "sound" produced when there is the least movement possible from the neutral position. The "dark $e$ " is even briefer than the "short" English vowels.

If the syllables are chosen and the accent prescribed so that the unaccented vowels cannot reduce to "dark $e$," the maximum speed of utterance is much slower. "Tee'too tay . ." can be repeated at a maximum rate of $4.5-4.8$ per sec. " $L a^{\prime}$ pee yo . ." at a maximum rate of 6 syllables per sec. While " $t a t a$ ' ." (becoming te $t a^{\prime}$. .) can be repeated at a maximum rate of 8-10 syllables per sec.

The relation of the word accent to the quality of the vowel has been built into an elaborate system in the Hebrew. Possibly it is rather artificial as we have it now, but it undoubtedly represents something of the ancient practice. Vowels in syllables with the accent are systematically lengthened; vowels preceding the accent are regularly reduced to "dark $e$," the sch'wa. The vowel is a more variable factor to the Semite, because of the variations of the vowels of the stem in the course of inflection.

The effect of the actual movements on each other has been carefully described by Rousselot (consonant and vowel, vowel and consonant, vowel and vowel, consonant and consonant.) The inflectional changes bring together various elements, and the elision and modification of syllables in the course of historical changes subject phonetic movements to each other's influence. Spelling and printing can only delay such changes, they cannot prevent them. In general the movements of speech are shaped by rapid utterance. Rhythm and accent will be preserved and the phrase must be comprehensible, but with these reservations the influence of mere velocity will dominate. It is a general law of language that all phonetic coordinations shape themselves by and for the maximum speed of utterance.

Generalizations have been made on the reciprocal influence of sounds. There is a "law of assimilation" whereby the movements tend to become alike; "law of prevision", whereby movements are prepared in advance as in all fields of skilled movements; the "law of economy" whereby only the movements 
necessary for the given "sound" occur; the "law of fusion" in the case of two contiguous vowels. ${ }^{1}$ )

All such generalizations must finally be referred to the skilled movements involved; the elaborate acoustical studies of transitional forms, "glides", etc. do not touch the fundamentals. The word accent and the syllable movement play an important part in such reciprocal modifications. The back stroke of the releasing consonant must occur during the syllable and must modify the vowel. The preparation and beginning of the beat stroke of the arresting consonant must occur during the syllable movement and may modify the vowel. The back stroke of the arresting consonant may occur during the intersyllabic pause, or it may modify a following initial vowel; since it is separated from a following releasing consonant by the preparation of this releasing consonant, there may be no influence.

Consonants occur in juxtaposition in two cases: "groups" in which the fused consonants function as a single releasing or arresting element; abutting consonants in which each member has a different function in a different syllable.

The simplest fusions in "groups" are those in which a continuitive becomes the preparation or the back stroke of an occlusive. The mechanism of voicing is dependent on the articulatory organs and on the breathing apparatus and changes of voicing are very difficult to manage in the very brief interval of the group; therefore the group tends to be either voiced or unvoiced.

With the abutting consonants the conditions are quite different, for the members of the pair belong to different syllables. In many languages "assimilation", the influence of one abutting consonant on the other, is very common.

If the differences of stress and of length of syllable are not extreme, the releasing consonant is the dominant movement, and the arresting consonant is modified toward the releasing consonant. This is the rule in Greek and Latin, and in French. As the speed of utterance increases in a fairly uniform series of syllables, the arresting consonant must be given very rapidly just before the releasing consonant. A similar movement or an

1) Rousselot and La Clotte, Précis p. $73 \mathrm{f}$, give a good summary of such tendencies. CLÉDAT speaks of a „law of least effort." Man. de phon. et de morph. p. 9I, 93, 127. 
identical movement can be given in sequence more rapidly and certainly than a different movement.

But the Teutonic languages with heavy word accent, series of "short" vowels in accented syllables, and great variety in length of syllable, show much less assimilation. And the changes are not always in the direction of the releasing consonant. This is not due, as SweEt quaintly suggests, to an English "striving for distinctness" - there is too much against that idea - but to the function of the arresting consonant in a stressed syllable with "short vowel." Passy calls attention to the frequent "progressive assimilation" in English and German, as in the English "observe." 1) On occasion the form of the movement of the arresting consonant holds over to the releasing consonant. But as PAssy indicates the assimilation is not invariable. "observe" may be compared with "subserve" in wich there is no assimilation.

The words "blackboard", and "flagpole" have a secondary stress on the second syllable and the sylables remain distinct. When the two consecutive stresses are lost in rapid utterance, all sorts of changes are possible, as "forehead", (for'ed) "forecastle", $\left(f \circ k^{\prime} s l\right)$ boatswain $\left(b_{0} s^{\prime} n\right)$ "blackguard", (bla'gard).

Nothing has been said of the influence of habit, "association", in modifying phonetic movements. It is certain that this factor plays an important part.

\section{Rhythm and the Charagteristic Pronunciation of a Language.}

The rhythm is certainly one of the most fundamental characteristics of the pronunciation of a language, and is often most difficult for a foreigner to acquire. The play of the word accents, the rhythmic grouping of the phrases, the differences in the length of the syllables are all difficult, and all important for a good "accent." And it is not the case that one can first master the "elements" of the pronunciation, the "sounds" and then set them in the rhythm .It is easy to see that the rhythm has a vital influence on the details of pronunciation; the word accent often

1) Phon. Comp. p. I2I . 
determines the function of the consonant as arresting or releasing and also determines the syllable in which the consonant shall function; the rhythm at high speed determines the slurring or the full pronunciation of syllables. In the end the rhythm guides the phonetice changes which every languageis undergoing.

SwEET takes a practical view of the subject of stress- and pitchaccent in the early Aryan languages. He is certain that what happened in Greek was not that a pitch accent was replaced by a stress accent - which would be impossible for a variety of reasons - but that the early Aryan accent involved the essential stress factor along with a pitch factor; the pitch factor was lost but the essential stress factor remains.

The Romance languages and the Slavic languages do not have pronounced differences in the length of syllable. ${ }^{1}$ ) This is equivalent to saying also that they are the languages in which there are no extreme differences in the stress of the syllables. The French, along with the Spanish, modern Greek, and the Slavic languages, has a decided tendency to the open syllable, while the English and the German have many closed syllables. ${ }^{2}$ )

In French the pattern of the alternating accented and unaccented syllables may vary in the same phrase from speaker to speaker, and may vary from time to time with the same speaker; the variation depends on a difference of emphasis or on personal choice. As the syllables are not greatly varied in length, the rhythm is in the main trochaic and dactylic - the forms in which the length of the syllable is nearly the same. The frequent "mute $e$ " and the occasional closed syllables make iambs possible; anapests are very rare.As it occurs in the phrase, the "word" accent of the French is not fixed. As a rule the "mute $e$ " does not not have the accent, but it may on occasion; thus in a series of monosyllables with "mute $e$ " there is an accent on the alternate syllables. The conventional accent of the isolated word is on the final syllable, of the word in context on the tonic syllable; but frequent "displacements" of this accent for emphasis and for rhythm are essential to a good French pronunciation. PASSY and Mrchaelis note the possibility of pronouncing "impossible" and "excellent" with an accent on any one of the three syllables. ${ }^{3}$ )

1) Sweet, Hist. Eng. Sounds, p. 30.

2) Cf. Sievers, Grundzüge, p. I9I.

3) Dict. Phon. 2 d ed. p. XXIII. 
In English and German on the contrary, there are very pronounced differences in length of syllable and great differences in the force of the accents. SwEET speaks of the possibility of distinguishing three different grades of length, and the customary notation of "primary, secondary and nul" distinguishes three grades of accent. With very rare exceptions the English contrasts with the French in having a fixed pattern of the word accents. In French the accentuation of the phrase determines the accent of the word; in English the accents of the words determine the accent pattern of the phrase. The prevalence of syllables short in duration, and the extreme force of the word accent combine to give the English a prevailingly iambic rhythm. It is not unusual to find consecutive syllables stressed. Trochees and dactyls are common. While there is perhaps more variety of rhythmic pattern than in the French, the general character of the English is iambic.A. W. DE GROOT comments on the rhythmic difference between the English and German, and the French. ${ }^{1}$ )

This system of great difference of stress and of length of syllable makes it possible to give important functions to the consonants which tend to preserve them; the pronounced differences of lengths of syllable and the variety of rhythmic grouping make a place for the arresting consonants, whether followed by a vowel or a releasing consonant.

In French on the other hand the tendency is to eveness of stress on the syllables and to an even length of syllable. All consonants tend to become releasing in high speed utterance, and all consonants in the arresting position tend to shift or drop; there are no heavy accents and no great variations of length of syllable which would accommodate the arresting consonants and give them definite function.

The tremendous changes which have taken place in the "sounds" of the French as it developed from the vulgar Latin must have been due to something beside the ordinary changes to which a language is subjected. Side by side with the Latin, the Greek also has had a continuous history of development into a modern language; but the Greek presents no such extensive changes. There can be little question that a profound change in

1) La Syllabe, Bul Soc. Ling. Paris, 27, '26; cited by L. KAIser, Arch. Néerl. de Phon. Exp. I, '27, p. I29. 
the rhythm underlies the extensive alterations during the transition from Latin to French. A new rhythm has produced a new language, reshaping the ancient words, eliminating syllables and shifting the accent to an alternation from syllable to syllable. Gradually the French tended to the open syllable, probably under the influence of a rhythm which prefers rapid and even syllables. The tendency to equalize the syllables, and the inevitable speed of utterance, resulted in the elimination of the arresting consonants (final and "appuyantes.") Other consonants brought into juxtaposition by the dropping of the syllables affected each other profoundly. Such a change of rhythm and of accent is apparent in the Hebrew over against the Arabic, and in the Bohemian over against the Polish, and in the French over against the Italian.

\section{APPENDIX.}

A. Syllables developped into series with doubles by increasing the speed of utterance; (Pronounced with Eng. short vowels, if without indication.)

\begin{tabular}{|c|c|c|c|c|c|}
\hline Syllable Number of series, & '24 & '26 & Number of doubles measured & & '26 \\
\hline$b \iota b$ & & 8 & & & I \\
\hline$b o b$ & I I & 2 & & 87 & 8 \\
\hline church & I & & & I & \\
\hline dead & & IO & & & 2 \\
\hline$d u d$ & I I & 8 & & $7^{8}$ & 17 \\
\hline fife & & Io & & & I I \\
\hline fuf & 5 & 5 & & I 6 & 25 \\
\hline lul & I I & & & 78 & \\
\hline mom & 2 & & & I0 & \\
\hline non & 6 & & & $3^{6}$ & \\
\hline peep & & 2 & & & 2 \\
\hline pep & & 3 & & & 1 \\
\hline pope & & 4 & & & 5 \\
\hline pup & 13 & 10 & & 85 & 33 \\
\hline shish & 2 & & & Io & \\
\hline sis & 8 & IO & & 54 & 6 \\
\hline tet & & 5 & & & 5 \\
\hline tight & & 4 & & & I 5 \\
\hline tut & 9 & 4 & & 56 & 6 \\
\hline
\end{tabular}


$B$. Syllables developed into series with one-member abutting pairs by increasing speed:

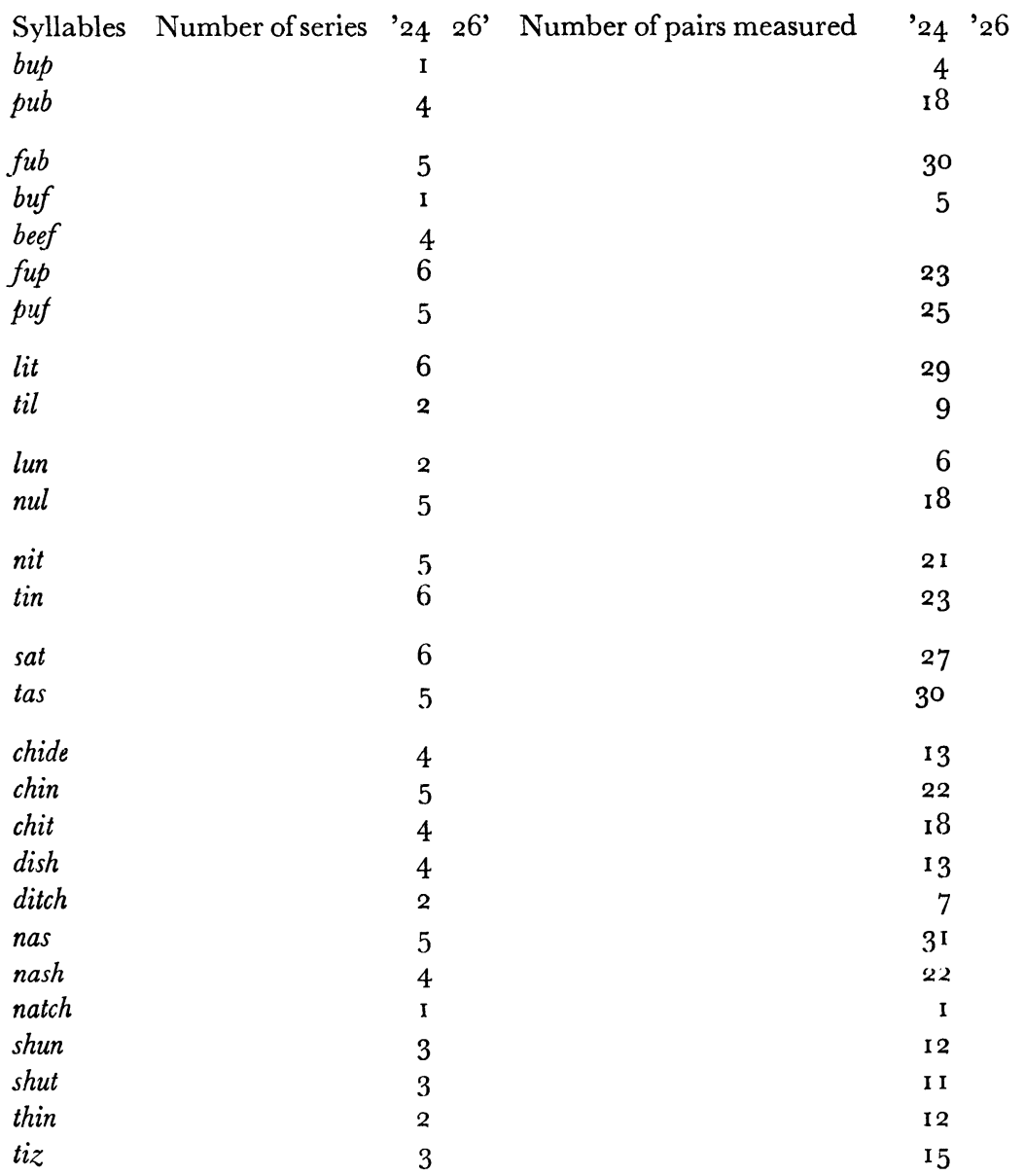

C. Syllables developed into series with two-member abutting pairs of consonants by increasing the speed:

$\begin{array}{lrrr}\text { Syllable Number of series, '24 '26 Number of pairs measured } & \text { '24 '26 } \\ \text { bat } & 3 & 9 \\ \text { bit } & 5 & \text { I } 7 \\ \text { tab } & \text { I } 5 & 79 \\ \text { bin } & \text { I } 7 & 48 \\ \text { bone } & 3 & 7 \\ \text { nib } & 4 & 2 \text { I } \\ \text { nob } & 3 & \text { I } 4\end{array}$


Syllable Number of series. '24 '26. Number of pairs mesured '25 '26

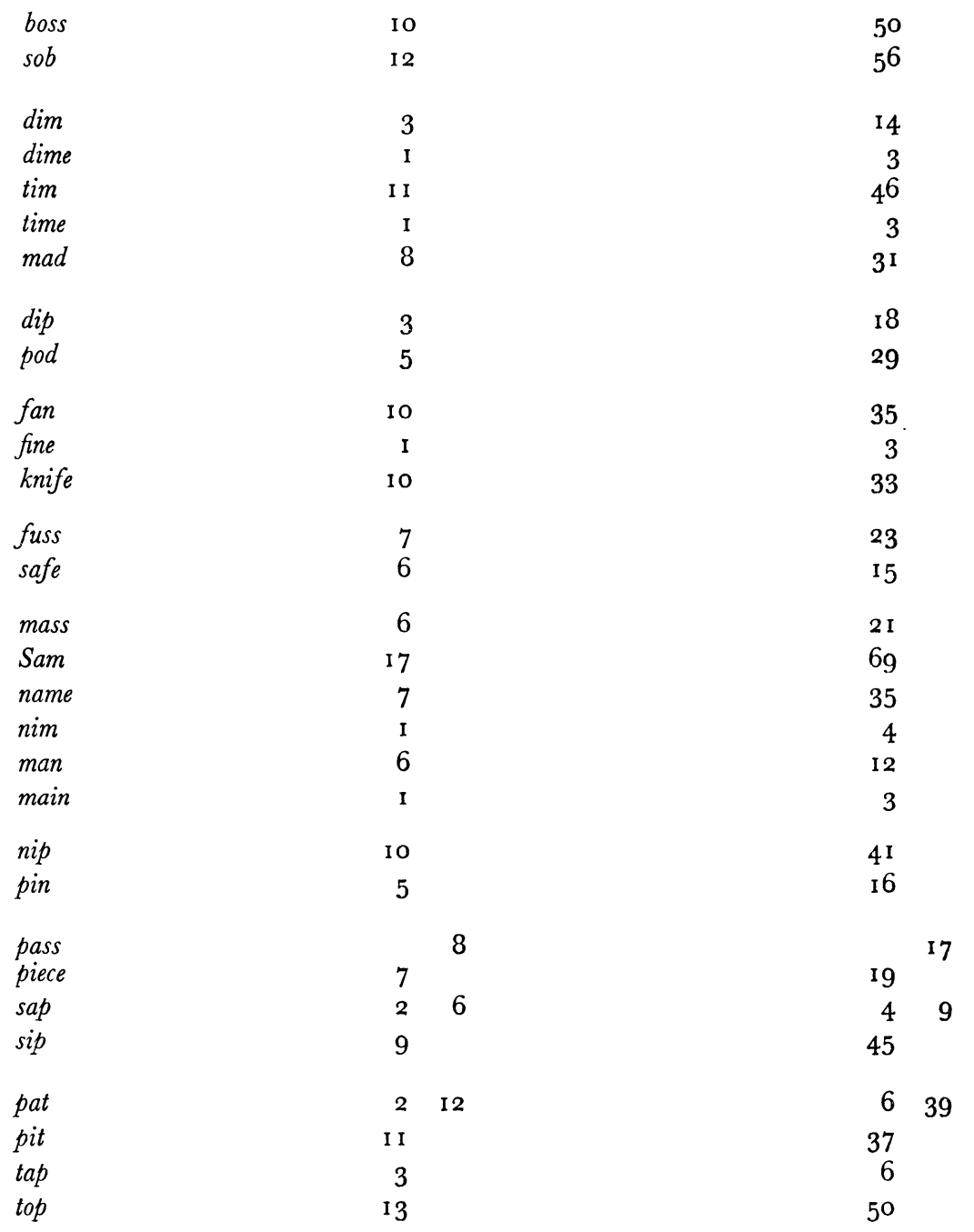

$D$ Abutting pairs, and arresting consonants ,constructive doubles.”

\begin{tabular}{|c|c|c|c|}
\hline $\operatorname{add} A$ & 23 & add $\mathcal{T}$ & 12 \\
\hline$a d a y$ & 22 & a tall $D$ & 47 \\
\hline add $C$ & 5 & told $E$ & 39 \\
\hline add $P$ & 5 & at $C$ & 2 \\
\hline add $E$ & 20 & at $E$ & 2 \\
\hline
\end{tabular}


Abutting pairs, and arrestıng consonants ,"constructive doubles."
a tea
32
pop up a
I6
at $E$
24
pop up
I 2
at $P$, at $E$
35
Zeep Ope
will be pope
68
59

E. Accented groups of two syllables:

\section{Words}

$a t^{\prime}$ it

a $t i t^{\prime}$

$b a^{\prime} b y$

ba boo'

$d e^{\prime}$ bit

de bate'

hit' him

hit' Tim'

in stall'

in state'

Ot'to

ought' to'

pup'py

pup pie'

Nonsense syllables

ma' mam

ma mam'

pa' pap

pa pap'

$p a^{\prime}$ pep

pa pep'

paw' pep

paw pep'

pay' pay

pay pay'

\section{Words}

4 state

4 to state'

test' it

test $i t^{\prime}$

tes' tale

es tate'

test' $S$ (ess)

test $S^{\prime}$ (ess)

too' tight

too tight'

up' late

a plate

$u p^{\prime} p u p^{\prime}$

$u p^{\prime} u p$

$u p^{\prime}$ spout

$u p^{\prime}$ spring

Nonsense syllables

$18 \quad$ peb' pep 33

I3 peb pep' 28

$6 \quad$ pé $p e p \quad 37$

6 pe pep' $3^{\mathrm{I}}$

$12 \quad \overline{o^{\prime}}$ pep $\quad 9$

9 pö pep' 9

I2 $p o^{\prime}$ pep $\quad$ I2

8 po pep' II

$5 \quad \overline{p o}$ pop 12

5 po pop' $\quad 8$
6

5

2 I

20

12

9

20

I 6

I 3

18

I6

I 5

16

59 8

\section{7} I 9 9 2

I
2

8


Nonsense syllables

Nonsense syllables

$p o p^{\prime} u p$

pop up'

I6

$t a^{\prime}$ tat

12 ta tat'

$p u^{\prime}$ pep

pu pep'

I 2

ted' tet

set' set

set set'

sit' sit

sit sit'

12

ted $t e t^{\prime}$

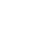

I8

I0 tep' tep 6

sot' sot

tep tep'

5

I5

12

te' tet

33

6

te tet' $^{\prime}$

30

sot sot'

5

$\overline{l e}$ tet

12

soots' tsoot

soots tsoot

3

soot' soot

te tet'

12

Io to tot $\quad 6$

soot soot'

Io to tot'

4

$F$ Accented groups of three syllables:

Words

in'stitute

lob' Bob'by

sed'a tive

Nonsense syllables

pat pat' pat

pet' p:t pet

pet pet' pet

pet pet pet'
$50 \quad u p^{\prime} p u p^{\prime} p y$

25 up spring'ing

$29 \quad$ up spout'ing

Nonsense syllables

6

pup' up up

рup up' pup

pup up pup'

$u p^{\prime} u p p u p^{\prime}$

$u p^{\prime} u p u p^{\prime}$
I 4

64

40

26

I 8

$G$ Accented groups of four syllables:

$b a \quad b a^{\prime} \quad b a b a b$

$b a b a b a^{\prime} b a b$

I5 bub bub' bub bub

8

8

bay bay' bay bay

bay bay bay' bay

$5 \quad \operatorname{dot} \operatorname{dot}^{\prime} \operatorname{dot} \operatorname{dot}$

2 I

$4 \quad$ dot dot dot dot

12

bo bo' $\overline{b o}$ bo

$8 \quad m a m a^{\prime}$ ma mam

18

bo bo bo' bo

$8 \quad$ ma ma ma' mam 
Accented groups of four syllables :

\begin{tabular}{|c|c|c|}
\hline$p a p a^{\prime} p a p a p$ & 6 & sap $s a p^{\prime}$ sap $s a$ \\
\hline$p a p a p a^{\prime} p a p$ & 5 & $s a p$ sap $s a p^{\prime} s a$ \\
\hline pas pas' pas pa & 14 & sep' sep sep se \\
\hline pas pas pas' pa & 10 & sep sep' sep sep \\
\hline pat pat' pat pat & 47 & \\
\hline pat pat pat' pat & $3^{2}$ & $\begin{array}{l}\text { ta ta ta tat } \\
\text { ta ta ta tat }\end{array}$ \\
\hline pe pe' pe pep & $6 \mathrm{I}$ & \\
\hline pe pe pé pep & 55 & tay te te tet \\
\hline$b e^{\prime}$ pe pe pe & 40 & $\begin{array}{l}\text { ted ted' ted ted } \\
\text { ted ted ted' ted }\end{array}$ \\
\hline$p e^{\prime}$ pe pe pep & 29 & te te' tay tet \\
\hline pes pes' pes pes & 5 & te te' tay to \\
\hline pes pes pes' pes & 6 & te te tay to \\
\hline pes' pes pes pes & 53 & $\begin{array}{l}\text { te } \overline{t e} \overline{t e} \text { tet } \\
\overline{t e} \overline{t e} \text { té } \overline{t e t}\end{array}$ \\
\hline po po po pop & 35 & te $t e^{\prime}$ te te \\
\hline$\overline{p o} \overline{p o} p \bar{o}^{\bar{p}} \overline{p o p}$ & 44 & te te té $t e$ \\
\hline po po' po pop & 4 & te te' te tet \\
\hline po po po' pop & 4 & te ie $t e^{\prime}$ tet \\
\hline pup pup' pup pup & 9 & to to' to tot \\
\hline pup pup pup' p'ip & 8 & $\overline{\text { to }} \overline{\text { tn }} \overline{t \rho^{\prime}} \overline{\text { tot }}$ \\
\hline
\end{tabular}

List ot the words, phrases, and syllables discussed in the text:

Words (dots following a word indicate that it is developed into a series.)

$\begin{array}{lcl}\text { apt... } & \text { fig. } & 74,75 \\ \text { asp... } & 73 & \\ \text { bay... ac. group: } & 89,90 & \\ \text { bee... } & 42 & \\ \text { beef... } & 42 & \\ \text { boss...: } & 52 & \\ \text { dish...: } & 66 & \\ \text { eat... } & 6 & \\ \text { fie... } & 38 & \text { p. 205 } \\ \text { fife... } & -38 & \\ \text { halfpay } & 24 & \text { p. 252 Table I } \\ \text { hello } & & \text { p. 250 Table I } \\ \text { humbug } & 25 & \text { p. 252 Table I }\end{array}$


List ot the words, phrases, and syllables discussed in the text:

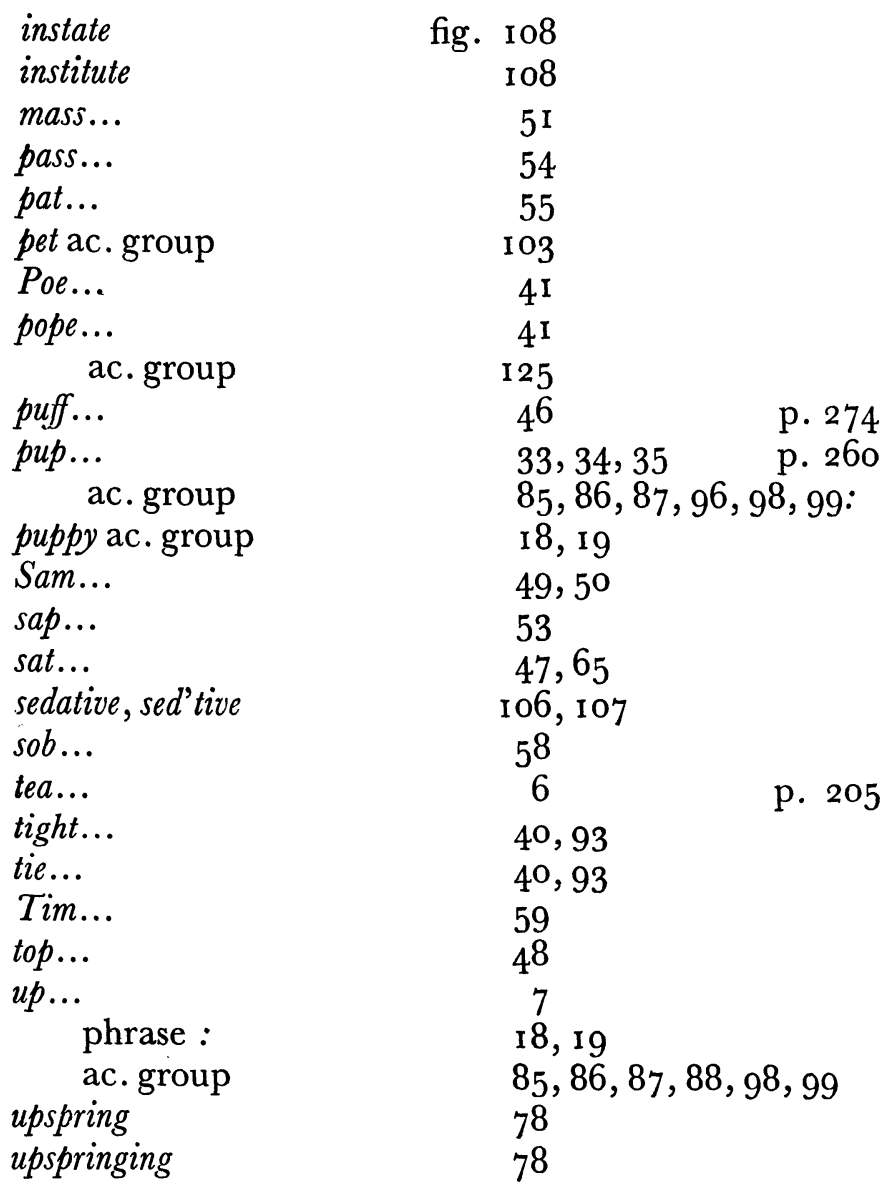

Phrases.

add $T$, add $E \quad 6 \mathrm{I}$

at $C$, at $E \quad 60$

at $P$, at $E \quad 62$

a plate $7 \mathrm{I}$

an aim, a name

hit him, hit Tim

Hell, no

p. 220

p. 250 Table I

p. 252 Table I 
Phrases.

\begin{tabular}{|c|c|c|c|}
\hline$I^{\prime} d d o, I d o$ & fig. & p. $25^{\circ}$ & Table I \\
\hline I'm Ike, I'm Mike & & p. $25^{\circ}$ & Table I \\
\hline Ilie, I'll lie & & p. 250 & Table I \\
\hline$l o b, B o b$ & & p. 252 & Table I \\
\hline Lil' 'Il lie low & $9 \mathrm{I}, 9^{2}$ & & \\
\hline Otto ought to & $3 \mathrm{I}$ & p. 250 & Table I \\
\hline рор ир а рор ир & I 26 & & \\
\hline runnin' 'n' neighin' & 124 & & \\
\hline topic, top pick & 23,32 & & \\
\hline top egg, top peg & & p. $25^{\mathrm{I}}$ & Table I \\
\hline this eye, this sigh & & p. $25^{\mathrm{I}}$ & Table I \\
\hline top pole & & p. $25 \mathrm{I}$ & Table I \\
\hline thus $E$, the $C$, thus $C$ & & p. $24 \mathrm{I}$ & \\
\hline up late & 71 & & \\
\hline unknown & & p. $25^{\mathrm{I}}$ & Table I \\
\hline$u p, B o b$ & 29,80 & p. $25^{2}$ & Table I \\
\hline unlike & & p. 252 & Table I \\
\hline$u p u p, u p p u p$ & $20,2 \mathrm{I}$ & & \\
\hline up, puppy & I8, I9 & & \\
\hline whole ode & & p. $25^{\circ}$ & Table 1 \\
\hline hoe load & & p. $24 \mathrm{I}$ & \\
\hline whole load & & p. 250 & Table I \\
\hline Zis Z & 22 & & \\
\hline Zeep Ope will be pope & I 25 & & \\
\hline
\end{tabular}

Nonsense syllables (dots following a syllable indicate that it is developed in series) (Eng. short vowels, unless indicated.)

$\begin{array}{ll}\text { af tpa... } & 76 \\ \text { alp... } & 69 \\ \text { dla... } & 68 \\ \text { fsa... } & 67 \\ \text { fuf... } & 37,39 \\ \text { ispda... } & 77 \\ \text { nas... } & 28 \\ \text { op... } & 5 \\ \text { po... } & 5 \\ \text { pta } & 72\end{array}$




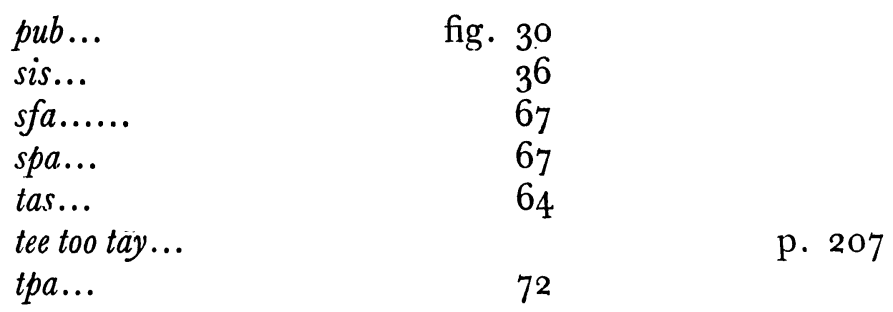

Nonsense syllables in groups.

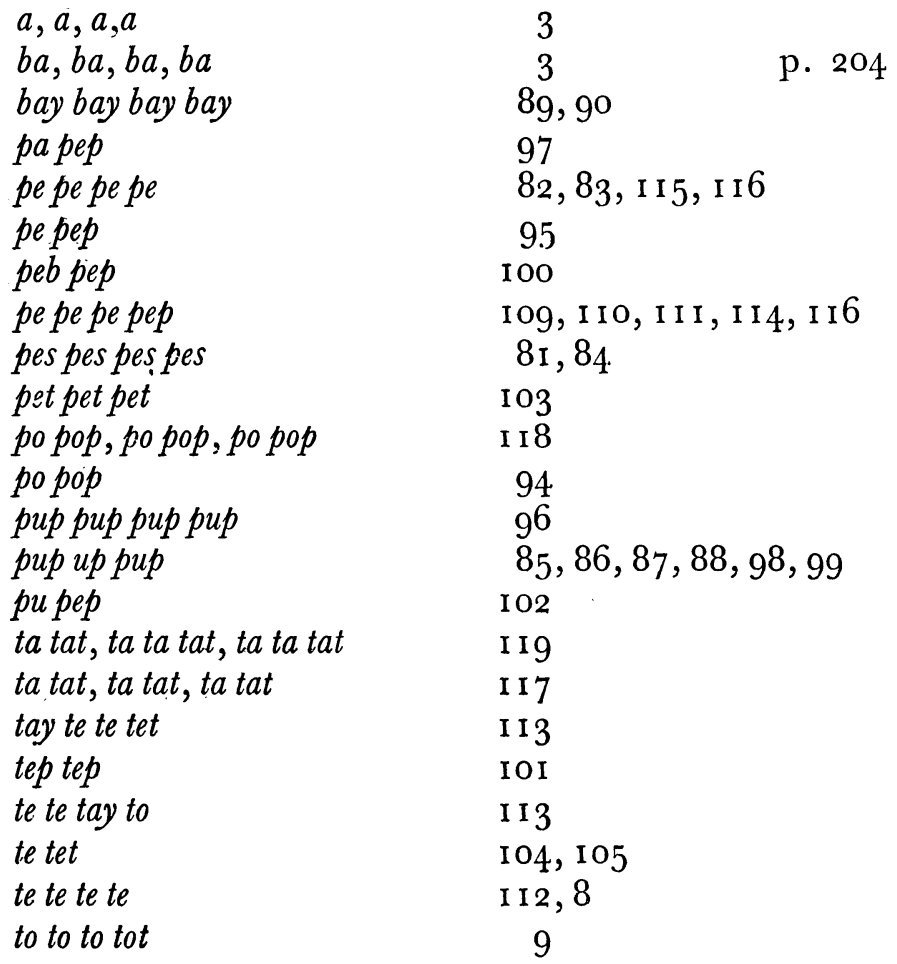




\title{
PHYSIOLOGICAL ABSTRACTS.
}

\author{
Prix net 5 sh. par mois. Abonnement par an 42 sh. franc de port.
}

Ce Journal est publié par la Physiological Society, en collaboration avec de nombreuses sociétés de physiologie en Grande Bretagne, Amérique et dans d'autres pays. Le rédacteur, le professeur J. Mellanby, est assisté d'un grand nombre de collaborateurs compétents du pays et de l'étranger.

Le Journal se propose de publier rapidement des résumés des travaux de physiologie et des sciences connexes (y-compris la physiologie végétale), ayant paru dans tous les pays du monde.

Il paraît un numéro au conmencement de chaque mois.

Le volume XII a commencé par la livraison d'avril 1927.

Les abonnements doivent être pris d'avril à mars de l'année suivante et payés d'avance.

On peut se procurer les livraisons des volumes $I$ à $X$, sauf celles qui sont épuisées, chez les éditeurs ou par l'intermédiaire d'un libraire. Les livraisons dont il ne reste plus qu'un petit nombre d'exemplaires sont en vente à un prix spécial. S'adresser aux éditeurs pour de plus amples renseignements.

Editeurs H. K. Lewis \& Co. Ltd., 28 Gower Place, Londres, W. C. 1.

\section{ARCHIVES INTERNATIONALES DE PHYSIOLOGIE,}

Ces Archives, fondées en 1904 par Léon Frederice et PaUl Heger et publiées par Léon FredericQ, paraissent par fascicules de 100 à 120 pages. Quatre fascicules forment un volume. Prix du volume: 80 francs français.

Le fascicule 4 du volume XXV (décembre 1925) contient la table des matières des volumes I à XXV.

On est prié d'adresser tout ce qui concerne la rédaction des Archives à Lúov FrfdericQ, Boulevard Frère-Orban $3^{\text {bis }}$, Liége. Les abonnements se prennent à la même adresse ou chez Gaston Dorn, éditeur à Paris, place de l'Odéon, 8.

\section{L'ANNÉE BIOLOGIQUE.}

Publiée par la „Fédération Française des Sociétés des Sciences Naturelles” est un recueil de bibliographie scientifique. Elle est dirigée par un Comité de Rédaction composé de MM. Caullery, R. Combes, Faure-Fremiet, Ch. Gravier, Hennegux, L. Mangrn, Ch. Perez, A. Prenant, M. Tipheneau, L. Chopard, C. Delezenne, P. Girard, A. Guilliermond, H. Laugier, A. Meyer, H. Pigron, E. Rabaud, J. Verne et $\mathrm{M}^{\text {me }} \mathrm{A}$. Drzewina.

L’Année Biologique dépouille et analyse plus de 300 périodiques de physiologie et biologie générale. Elle publie tous les deux mois un fascicule de 300 pages environ, scindé en deux parties: $1^{\circ}$ - Physiologie Générale, $2^{\circ}$ - Morphologie et biologie générales. Les analyses sont au nombre de 900 à 1000 par fascicule. Secretaire-Général: Madame A. Drzewina. Le prix de l'abonnement est de 75 francs par an pour la France, 125 francs par an pour l'étranger. On s'abonne aux Presses Universitaires de France, 49, Bd Saint-Michel, Paris, Ve.

\section{OUVRAGES REÇUS PAR LA RÉDACTION.}

Les Archives Néerlandaises de Physiologie de l'Homme et des Animaux ne publiant que des analyses de mémoires et d'ouvrages écrits par des Hollandais la Rédaction doit se borner à mentionner les titres des ouvrages d'auteurs étrangers qu'on lui a gracieusement envoyés. 